\title{
COOLANT MIXING IN THE LMFBR OUTLET PLENUM
}

by

Y1 Bin Chen

and

Michael W. Golay

June, 1977

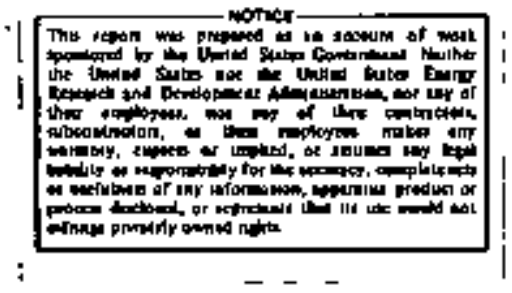

DEPARTMENT OF NUCLEAR ENGINEERING

MASSACHUSETTS INSTITUTE OF TECHNOLOGY

Cambridge, Massachusetts

02139

\author{
ERDA Research and Development \\ contract E(11-1)-2245 \\ t.S. Energy Research and Development Administration
}




\section{DISCLAIMER}

This report was prepared as an account of work sponsored by an agency of the United States Government. Neither the United States Government nor any agency Thereot, nor any of their employees, makes any warranty, express or implied, or assumes any legal liability or responsibility for the accuracy, completeness, or usefulness of any information, apparatus, product, or process disclosed, or represents that its use would not infringe privately owned rights. Reference herein to any specific commercial product, process, or service by trade name, trademark, manufacturer, or otherwise does not necessarily constitute or imply its endorsement, recommendation, or favoring by the United States Government or any agency thereof. The views and opinions of authors expressed herein do not necessarlly state or reflect those of the United States Government or any agency thereof. 


\section{DISCLAIMER}

Portions of this document may be illegible in electronic image products. Images are produced from the best available original document. 
"Th1s report was prepared as an account of Governmentsponsored work. He1ther the United States, or the Energy Research and Development Administration nor any person acting on behalf of the commission

A. Makes any warranty or representation, expressed or implied, with respect to the accuracy, completeness or usefuzness of the information contained in this report, or that the use of any information, apparatus method, or process disclosed in this report may not infringe privately owned rights; or

B. Assumes any liabilities with respect to the use of, or for damages resulting from the use of, any information, apparatus, method, or process disciosed in this report:

As used in the above, "person acting on beinalf of the Commission includes any employee or contractor of the Adrinistration. or employee of such contractor, to the extent that such employee-or contractor prepares, disseminates, or provides access to, any information pursuant to his employment or contract with the Administration or his exployment with such contractor."

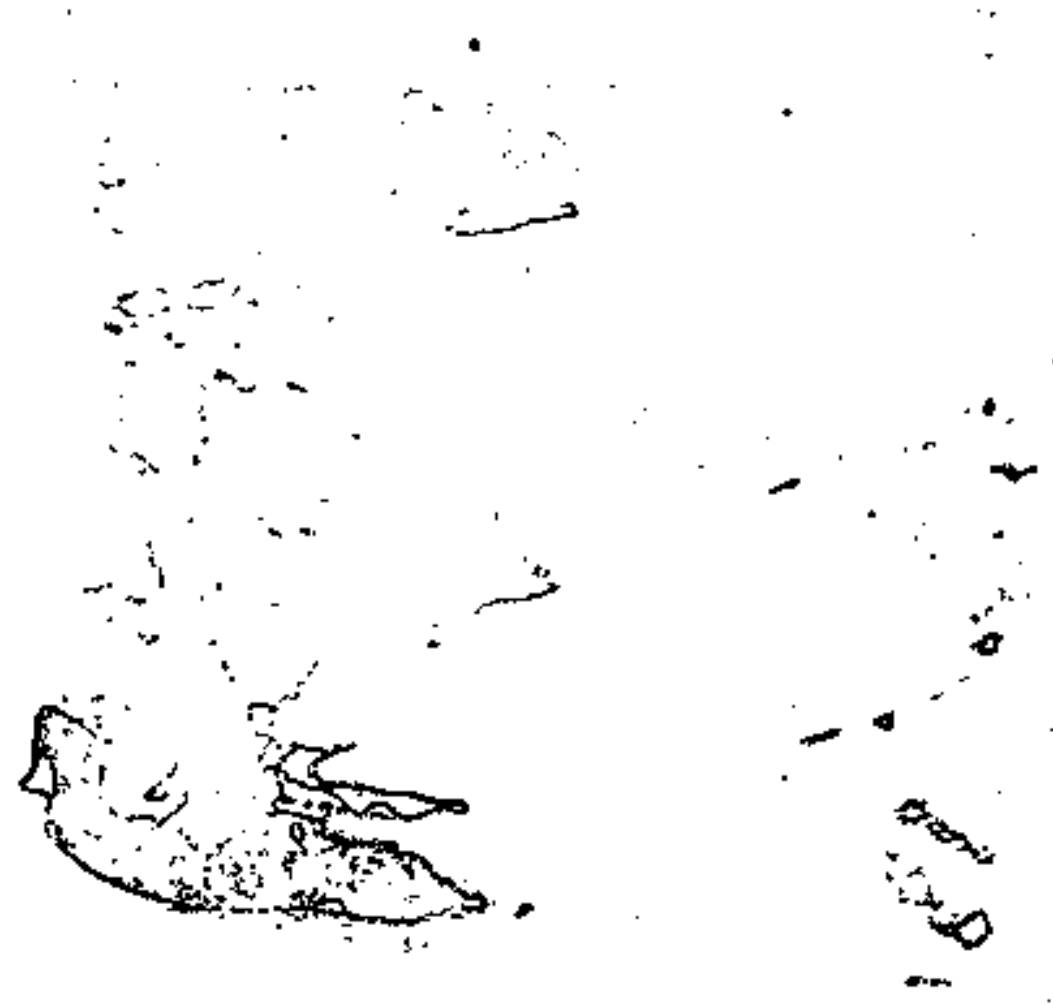


Reports and Papers Published under MIT Coolant Mixing in LMFER Rod Bundles Project

A. Quarterly Progress Reports (Available from National Technical Information Service, U.S. Department of Commerce, Springfield, VA 22151)

Co0-2245-1 Period June 1, 1972 - November 30, 1972

c00-2245-2 Perlod December 1, 1972 - February 28, 1973

Co0-2245-3 Period March 1, 1973 - May 32, 1973

Co0-2245-6 Perlod June 1, 1973 - August 31, 1973

CO0-2245-7 Per1od September 1, 1973 - November 30, 1973

c00-2245-8 Period December 1, 1973 - February 28, 1974

Co0-2245-10 Period March 1, 1974 - May 31, 1974

coo-2245-13 Period June 1, 1974 - August 31, 1974

CO0-2245-14 Period September 1, 1974 - November 31, 1974

co0-2245-15 Period December 1, 1974 - February 28, 1975

CoO-2245-23 Per1od March 1, 1975 - May 31, 1975

Coo-2245-25 Pertod June 1, 1975 - August 31, 1975

Co0-2245-26 Period September 1, 1975 - November 30, 1975

CoO-2245-28 Per1od December 1, 1975 - February 29, 1976

Co0-2245-30 Period March 1, 1976 - May 31, 1976

coo-2245-31 Period June 1, 1976 - August 31, 1976

Co0-2245-34 Period September 1, 1976 - November 30, 1976

coo-2245-38 Period December 1, 1976 - February 28, 1977 
Reports Issued Under This Contract

B. Topical Reports (Avallable from National Technical Information Service, U.S. Department of Commerce, Springfield, VA 22151)

E, Khan and N. Todreas, "A Review of Recent Analytical and Exper1mental. Studies Applicable to LMFBR Fuel and Blanket Assembly Design," COO-2245-4TR, HIT, Sept. 1973.

E. Khan, W. Rohsenow, A. Sonin and N. Todreas, "A Sirplified Approach for Predicting Temperature Distribution in Wire Wrapped Assemblies," COO-2245-5TR, MIT, Sept. 1973.

T. Eaton and N. Todreas, "Instrumentation Methods for Interchannel Coolant Mixing Studies in Whre-Wrap Spaced Nuclear Fuel Assemblies," CO0-2245-9TR, MTT, June 1974.

Y.B. Chen, K. Ip, N.E. Todreas, "Velocity Measurements in Edge Subchannels of Wire Wrapped LMFBR Fuel Assemblies," Co0-2245llTR, MIT, September 1974 .

E. Khan, N. Todreas, W. Rohsenow, A.A. Sonin, "Analysis of Mixing Data Relevant to Wire-Wrapped Fuel Assembly Therma1Hyöraul1c Design," Coo-2245-12TR, MIT, September 1974.

E. Khan, W. Rohsenow, A. Sonin, N. Todreas, "A Porous Body Model for Predicting Temperature D1stributions in W1re Wrapped Fuel and Blanket Assemblies of a LMFBR," CoO-224516TR, MIT, March 1975.

E. Khan, W.M. Rohsenow, A. Sonín, N. Todreas, "Input Parameters to the ENERGY Code (To be used with the ENERGY Code Manual) COO+2245-17TR, MIT, May 1975 .

E. Khan, W. Rohsenow, A. Sonin, N. Todreas, "Manual for ENERGY Codes I, II, III," COO-2245-18TR, MIT, May 1975.

E. Khan, W. Rohsenow, A. Sonin, N. Todreas, Manual for ENERGY Codes I, II, III Computer Programs," Co0-2245-18TR Reviston 1, HIT, July 1976 .

P. Carafilescov and N. Todreas, "Experimental and Analytical Study of Axial Turbulent Flows in an Interfor Subchannel of a Bare Rod Bundle," COO-2245-19TR, MIT,

B. Chen and N. Todreas, "Prediction of Coolant Temperature Field in a Breeder Reactor Including Interassembly Heat Transfer," CO0-2245-20TR, MIT, Hay 1975.

F. Carre and N. Todreas, "Development of Input Data to ENERGY Code for Analysis of React or Fuel Bundles," coo-224521TR, MIT, May 1975. 
Reports Issued Under This Contract

B. Toptcal Reports (Avallable from National Techntcal Information Service, U.S. Department of Commerce, Springfield, VA 22151)

E. Khan and N. Todreas, "A Review of Recent Analytical and Experimental Studies Applicable to LMFBR Fuel and Blanket Assembiy Design," COO-2245-4TR, MIT, Sept. 1973.

E. Khan, W. Rohsenow, A. Sonin and N. Todreas, "A Simplified Approach for Predicting Temperature Distribution in Wire Wrapped Assemblies," CoO-2245-5TR, MIT, Sept. 1973.

T. Eaton and N. Todreas, "Instrumentation Methods for Interchannel Coolant Mixing Studies in W1re-Wrap Spaced Nuclear Fuel Assemblies," COO-2245-9TR, MIT, June 1974.

Y.B. Chen, K. Ip, N.E. Todreas, "Veloc1ty Measurements in Edge Subchanneis of Wire Wrapped LMFBR Fuel Assemblies," CoO-2245IITR, MIT, september 1974.

E. Khan, N. Todreas, W. Rohsenow, A.A. Sonin, "Analysis of Mixing Data Relevant to Wire-Wrapped Fuel Assembly Therma1Hydraul1c Des1gn," COO-2245-12TR, MIT, September 1974.

E. Khan, W. Rohsenow, A. Son1n, N. Todreas, "A Porous Body Model for Predicting Temperature Distributions in Wire Hrapped Fuel and Blanket Assemblies of a LMFBR," COO-224516TR, MIT, March 1975.

E. Khan, W.M. Rohsenow, A. Sonin, N. Todreas, "Input Parameters to the ENERGY Code (To be used with the ENERGY Code Manual) CO0-2245-17TR, MIT, May 1975.

E. Khan, W. Rohsenow, A. Sonin, N. Todreas, "Manual for ENERGX Codes I, II, III," COO-2245-18TR, MIT, May 1975.

E. Khan, W. Rohsenow, A. Sonin, N. Todreas, "kanual for ENERGY Codes I, II, III Computer Programs," Co0-2245-18TR Revision 1, IAT, JuIy I9?6.

P. Carafilescov and $\mathrm{N}$. Todreas, "Experimental and Analytical Study of Axial Turbulent Flows in an Interior Subchannel of a Bare Rod Bundle," COO-2245-19TR, MIT,

B. Chen and N. Todreas, "Prediction of Coolant Temperature Fleld In a Breeder Reactor Including Interassembly Heat Transfer," COO-2245-20TR, MIT, May 1975.

F. Carre and N. Todreas, "Development of Input Data to ENERGY Code for Analys1s of Reactor Fuel Bundles," coo-22452JTR, MIT, May 1975. 
Reports Issued Under Th1s Contract

\section{B. Topical Reports, Continued}

H. Ninokata and N.E. Todreas, "Turbulent Momentum Exchange Coefficients for Reactor Fuei Bundle Analys1s," Coo-224522TR, MIT, June 1975.

R. Anoba and N. Todreas, "Coolant M1xing in EMFBR Rod Bundles and Outlet Plenum M1xing Transients," CoO-2245-24TR, ALgust 1975.

B. Bosy, "Fabrication Details for Wire Wrapped Fuel Assembly Components," Co0-2245-27TR, MIT, November 1975.

Ralph G. Bennett and Michael W. Golay, "Interferometric Investigation of Turbulently Fluctuating Temperature in an LMPBR Outlet Plenum Geometry," CO0-2245-29TR, MIT, June 1976.

N.E. Todreas, "Analysis Methods for LMFBR Wire Wrapped Bundles," COO-2245-32TR, NIT, November 1976.

K.L. Basehore and N.E. Todreas, "Development of Stability Criteria and an Interassembly Conduction Model for the Thermal-Hydraulics code SUPERENERGY," COO-2245-33TR, MIT December 1976 .

Robert Masterson and Netl E. Todreas, "Analysis of the Feasibility of Implementing an Implicit Temporal Differencing Scheme in the SUPERENERGY Code," C00-2245-35TR, MIT, February 1977 .

S. Glazer, C. Chiu and N. Todreas, "Collection and Evaluation of Sait Mixing Data with the Real IIme Data Acquisition System," COO-2245-36TR, MIT, April 1977.

B. Mik1c, E.U. Khan and N.E. Todreas "An Approximate Method for Predicting Temperature Distribution in Wire Wrapped Fuel Assembiles of a LMFER," COO-2245-37TR, MIT, Apr11 2977. 
Reports Issued under this Contract

\section{c. Papers and Summaries}

Y1 Bin Chen, Ka-Larn Ip, Ne11 E. Todreas, "Velocity Measurements in Edge Channels of Wire-Wrapped LMFBR Fuel Assemblies," American Nuclear Soclety Transactions vol. 19, 1974, pp. 323-324.

P. Carafilescov, N. Todreas, "Experimental and Analytical Study of Axial Turbulent Flows in an Interfor Subchannel of a Bare Rod Bundle," J. of Heat Transfer, Vol. 98, No. 2, May 1976, pp. 262-268 (Included as Appendix to Quarterly Progress Report, COO-2245-15).

E. Khan, w. Rohsenow, A. Son1n, N. Todreas, "A Porous Body Model for Predicting Temperature D1stribution in Wire-Wrapped Fuel Rod Assemblies," Nuclear Engineering and Design, $\underline{35}$ (1975) 1-12.

E. Khan, w. Rohsenow, A. Sonin, N. Todreas, "A Porous Body Model for Predicting Temperature Distribution in Wire-Wrapped Rod Assemblies Operating in Combined Forced and Free Convection," Nuclear Englneering and Design, 35 (1975) 199-211.

Ralph G. Bennett and Michael W. Golay, "Development of an Optical Method for Measurement of Temperature Fluctuation in Turbulent Flows," American Nuclear Society Transactions, Vol. 22, 1975, p. 581.

B. Chen and $N$. Todreas, "Prediction of the Coolant Temperature Field in a Breeder Reactor Including Interassembly Heat "Transfer," Nuclear Engineering and Design 35, (1975) 423-440 (Incluoed as Appendix to Quarterly Progress Report, CO0-2245-23).

R. Bennett and H.W. Golay, "Interferometric Investigation of Turbulently Fluctuating Temperature in an LMFBR outlet Plenum Geometry," Accepted for the ASME Winter Annual Meeting, Dec., 1976, (Included as Appendix in Quarterly Progress Report, co0-2245-30).

B.B. Mikic, E.U. Khan, N.E. Todreas, "An Approximate Method for Predicting Temperature Distribution in Hire Wrapped Fuel Assemblies of a Liquid Metal Fast Breeder Reactor, "Mech. Res. Comm., Vol. 3, 353-360 (1976). 


\section{Heports Issued Unoer this Contract}

\section{c. Papers and Summaries (Continued)}

L. Wolf, R. Kar1mf, I.Y. K1m, C.N. Wong, M.K, Yeung "2-D Thermoelastic Analys is of LMFBR Fuel Rod Claddings," Paper $\mathrm{c} 4 / \mathrm{d}$, 4th International Conf. Structural Mechanies in Reactor Technology, San Francisco, August I977.

M. Yeung, L. Wolf, "Effective Conduction Mixing Lengths for Subchannel Analysis of Finite Hexagonal LMPBR Bundles," ANS Meeting, New York, June 1977.

C. Chlu and N. Todreas, "Flow Split Measurements In An LMFBR Fadial Blanket Assembly," ANS Heeting, New York, June 1977. 


\section{ABSTRACT}

Small scale experiments 1nvolving water flows are used to provide mean flow and turbulence fleid data for LMFBR outlet plenum flows. Measurements are performed at Reynolds Number (Re) values of 33000 and 70000 in a $1 / 15$-scale FFTF geometry and at $\mathrm{Re}=35000$ in a $3 / 80-s c a l e$ CRBR geometry. The experimental behavior is predicted using two different turbulence model computer programs, TEACH-T and VARR-II. It is found that the qualitative nature of the flow flelo w1thin the plenum depends strongly upon the distribution of the mean inlet velocity field, upon the degree of inlet turbulence, and upon the turbulence momentum exchange model used in the calculations. It is found in the PFTF geometry that the TEACH-T predictions are better than that of VARR-II, and In the CRBR geometry neither codes provides a good prediction of the observed behavior.

From the sensitivity analysis, it is found that the production and dissipation of turbulence are the dominant terms in the transport equations for turbulent kinetic energy and turbulent energy dissipation rate, and the diffusion terms are relatively small. From the same study a new set of empirical constants for the turbulence model is evolved for the prediction of plenutn flows. 


\section{ACKNOWEEDGEMENTS}

The authors wish to express their sincere gratitude to all people who assisted them during the preparation of this report, and the researeh that supported it. In particular, to the following people:

Professor Neil E. Todreas who has given us much valuable advice and has kindly lent us the Laser Doppler Anemometer with great patience.

To Professor Lothar Wolf and Mr. John Bartzis for their helpful suggestions on our problems.

To Mr. Ralph Bennett who carefully proofread the draft of this report.

To Ms. Marsha Myles for her typing of this report.

Financlal support by the United States Energy Research and Development Administration under contract No. E(11-I)2245 is also Bincerely acknowledged. 
TABLE OF CONTENTS

TITLE PAGE

Page

REPORTS AND PAPERS ISSUED UNDER THIS CONTRACT

i

ABSTRACT

111

ACKNOWLEDGEMENTS

vili

ix

TABLE OF CONTENTS

$x$

LIST OF TABLES

xi11

LIST OF FIGURES

xiv

NOMENCLATURE

$x x i$

CHAPTER 1. INTRODUCTTON

1

CHAPTER 2. REVIEW OF LITERATURE 4

2.1 Survey of Exlsting Turbulence Models 5

2.1.1 Zero Equation Models 6

2.1.2 One Equation Models 7

2.1.3 Two Equation Models 9

2.1.4 Multi-Equation Mode1s 11

CHAPTER 3. DESCRIPTION OF THE ANALYTICAL MODEL 13 ADOPTED IN THE STUDY

3.1 TEACH-T Code 13

3.1 Basic Assumptions 13

3.1 .2 Model Equations 14

3.1 .3 Model Constants 17

3.2 VARR-II Code 18

3.2.1 Bastc Assumptions 18

3.2.2 Mode1 Equations 19

3.2.3 Model Constants 20 
CHAPTER 4. DESCRIPTION OF THE EXPERIMENTAL APPARATUS

4,1 Hydraul1c Fac1l1ties 22

4.2 Instrumentation 23

4.2 .1 Optical system. ' 23

4.2.2 ȘIgnal Processing System 24

4.2:3 S1gnal Recording System. 24

CHAPTER 5. DISCUSSION OF EXPERIMENTAL RESULTS
AND COMPUTER CODE PREDICTIONS

5.1 Degcription of Experiments 31

5.2 Computer code Calculations 31

5.3 Comparison of code Pred1ctions with 32

Experimental Data

5.3.1 FFTF Geometry . $\quad 32$

5.3.1.I FFr' Geometry, Re=33000, Normal
Inlet Veloc1ty D1stribution Case 32

5.3.1.2 FFTF Geometry, Res70000, Normal
Injet Veloc1ty D1 atribution Case 33

5.3.1.3. FFTP Geometry, Re=70000, D1storted Inlet Velocity D1stribution Case 35

5.3 .1 .4 Zero-Equation Model 37

5.3.2 CRBR Geometry. 37

5.3 .2 .1 CRBR Geometry, Re-35000, Normal
Inlet Veloc1ty Distribution Case, 38

5.4 Seng1tivity study 40

5.4.1 Case of FPTF Geometry wath Normal

Inlet Velocity Distribution

5.4.2 Case of FFTP Geometry with Distorted Inlet Veloc1ty Distribution 
5.5 Sumnary 43

5.6 Explanation of D1acrepancies 43

CHAPTER 6, CONCLUSIONS AND RECOMENDATIONS 79

6.1 Conclusions 79

6.2 Recommendations 80

6.2.1 Turbulence Mode1s 80

6.2 .2 Exper1mente 80

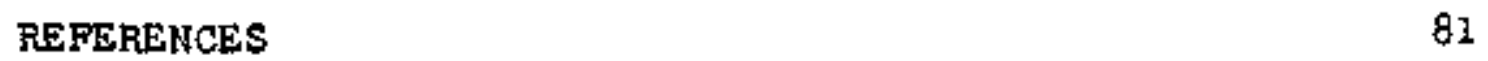

APPENDIX A. TRANSPORT EQUATIONS FOR MOMENTUM, TURBULENT KINETIC ENERGY, AND

TURBULENT ENERGY DISSIPATION RATE 84

APPENDIX B. DESCRIPTION OF THE VARR-II COTE 87

APPENDIX C. DESCRIPTION OF THE TEACH -T CODE 97

APPENDIX D. LABER DOPPLER ANEMOMETER 106

APPENDIX E. DATA REDUCTION 122

APPENDIX P. ERROR ANALYSIS 125

APPENDIX G. TABULATION OF DATA 135

APPENDIX H. CRBR GEOMETRY, Fe-35000, DISTORTED
INLET VELOCITY DISTRIBUTION CASE

APPENDIX I. DATA OF SENSITIVITY ANALYSIS 158

BIOGRAPHICAL NONE 199 


\section{LIST OF TABLES}

No.

Page

4.I Description of Equipment

5.1 List of Test Runs

5.2 L1st of Test Cases in Sensitivity Aralygis

0.1 FFTF Geometry, Re $=70,000$, Normal Inlet Mean Flow D18tribution

Q.2 FFTF Qoometry, Re* 70,000, D1storted Inlet Mean Plow D1atribution

0.3 CRBR Geometry, Re $=35,000$, Normal Inlet Mean Flow Diatribution

0.4 CRBR Geometry, Re=35,000, D1storted Inlet Mean Plow DIstribution 
No.

\section{LIST OF FIGURES}

4.1 The Hydraul1c Loop 27

4.2 Teat Section 28

4.3 Layout of Instrument 29

4.4 Experimental setup 30

5.1 Measured Mean Flow Fleld, FFTF Geometry, Re=33,000, Norma 1 Inlet Velocity Distribution

5.2 TEACH-T Pred1ct1on, FFTF Geometry, Re-33,000, Normal Inlet Velocity Distribution

5.3 VARR-II Pred1ct1on, FFTF Geometry, Re=33,000, Normal Inlet Velocity Diatribution

5.4 Compared Calculated and Measured Turbulence Kinet1c Energy F1elds, FPTF Geometry, Re*33,000, Normal Inlet Velocity Distribution

5.5 Compared Calculated and Measured Reynolds Stress Fields, FFTF Geometry, Re=33,000, Normal Inlet Veloc1ty Distribution

5.6 Measured Mean Flow Fleld, PFTF Geometry, Re=70,000, Normal Inlet Velocity Distribution 54

5.7 TEACH-T Pred1ct1on, FFTF Geometry, Re 70,000 , Normal Inlet Velocity D1stribution

5.8 VARR-II Pred1ct1on, FFTF Geometry, Re=70,000 Normal Inlet Velocity D1stribution

5.9 Compared Calculated and Measured Turbulent KInetic Energy F1eld, FFTF Geometry, Re=70,000, Normal Inlet Velocity D1strioution

5.10 Compared Calculated and Measured Reynolds

Strens Field, FFTF Geometry, Rex 70,000 ,

Normal Inlet Velocity Distribution

5.11 TEACH-T Prediction, FFTF Geometry, Re=70,000, Normal Inlet Velocity Distribution

5.12 VARR-II Pred1ct1on, FFTF Geometry, Re=70,000, Normal Inlet Veiocity D1stribution 
No.

5.13 Compared Celculated and Measured Turbulent Kinet1c Energy F1eld, FFTF Geometry, Re=70,000, Normal Inlet Velocity Distribution

5.14 Compared Calculated and Measured Reynolds

Stress Field, FFTF Geonetry, Re=70,000,

Normal Iniet Velocity Distribution

5.15 Heasured Mean Flow Fteld, FFTF Geometry, Re $=70,000$, Distorted Inlet Velocity Distribution

5.16 TEACH-T Prediction, FFTF Geometry, Re=70;000, Distorted Inlet Velocity Distribution

5.17 VAFR-II Predict1 on, FPTF Geometry, Rex70,000, Distorted Inlet Velocity Distribution

5.18 TEACH-T Prediction, PFTF Ceometry, Re=70,000, D1storted Inlet Velocity D1stribution

5.19 Compared Calculated and Measured Turbulent KInetic Energy Field, FFTF Geometry, Re=70,000, D1storted Inlet Velocity D1stribution

5.20 Compared Calculated and Heasured Reynolds

Stregs Field, FFTF Geometry, Fe=70,000,

Distorted Inlet Velocity Distribution

5.21 TEACH-T Prediction w1th Reynolds Stress $=-20\} \underline{u} l^{2}$

FFTP Geometry, Re=70,000, Normal Inlet

Velocity Distribution

5.22 TEACH-T Prediction with Reynolds Stress =-20|미?

FFT' Geometry, he=70,000, Diatrorted Inlet

Velocity D1otribution

5.23 Measured Mean Plow Fleld, CRBR Geometry, Re=35,000, Normal Inlet Volocity Distribution

5.24 TEACH-T Prediction, CRBR Geometry, Re=35,000, Normal Inlet Velocity Distribution

5.25 VARR-II Prediction, CRBR Geometry, Res 35,000 , Normal Inlet Velocity Digtribution

5.26 Compared Calculated and Measured Turbulent Kinetic Energy Fields, CRBR Geometry, Rex 35,000, Normal Inlet Velocity p1stribution 
No.

5.27 Compared Calculated and Measured Turbulent Reynolds

Stress Flelds, CRAR Geometry, Re*35,000,

Normal Inlet Velocity Diatribution

5.28 TEACH-T Prediction, CRBR Geometry, Re-35,000, Normal Inlet velocity Distribution

5.29 TEACH-T Prediction with New Set of Conatants, FFTF Geometry, Re-70,000, Normal Inlet Velocity D1stribution

5.30 Compared Calculated and Measured Turbulent KInetic Enersy F1elds, FFTF Geometry, Re=70,000, Normaz Injet Veloc1ty D1stribution

B.1 A Typical Cell Showing the Location of the Principle Variables

B.2 A Typjcal Cell Showing the Donor Cell Treatment of the Convection Terms

B.3 Detalls of VARR-II Boundary Conditions

B.4 Flow D1agram of Solution Scheme

C.l Finlte Difference Grid for TEACH-T

C.2 Boundary Conditions in TEACH-T

D.1 Frequency Sh1ft for L18ht Scattered from a Moving Particle

D.2 Modes of Operation

D.3 Fringe Pattern at Beam Crossing Point 120

D.4 Typleal Doppler S1gnal from Photomultiplier 120

D.5 a) S1gnal Omerated by Passage of S1ngle Particle in Steady, Un1 form Flow

b) S1gnal Generated by Two Part1cles Wh1ch Entered the Flow at Different Times

c) S1gnal Generated by Two Particles Having D1fferent Veloc1ties

G.1 FFTF Geometry 150

G.2 CRBR Geometry 151

H.1 Measured Mean Flow F1eld, CRBR Qeometry,
D1atorted Injet Velocity D1stribution 
No.

H.2 TEACH-T Prsdiction, CRBR Geometry, Re*35,000, D1storted Inlet Velocity D1stribution

H.3 VARR-II Pred1ct1on, CRBR Geometry, Re*35,000, D1storted Inlet Veloc1ty Distribution

H.4 Compared Calculated and Measured Turbulent

Kinet1c Energy F1elds, CRBR Geometry, Re=35,000, Distorted Inlet Velocity Distribution

H.5 Compared Calculated and Measured Reynolds

Stress Fields, CRBR Geometry, Distorted

Inlet Velocity Distribution

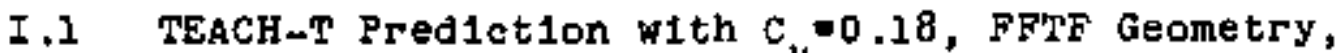
Re $=70,000$, Normal Inlet Vlliocity Distribution

I.2 TEACH-T Prediction w1th $\mathrm{C}_{\mu}=0.27$, FFTF Geometry, Re $=70,000$, Normal Inlet Vejoc1ty Distribution

I.3 TEACH-T Pred1ction w1th $\mathrm{C}_{\mu}=0.90$, FFTF Geometry, Re $=70,000$, Normal Inlet Veloc1ty Diatribution

I.4 Compared Calculated and Measured Turbulent

Kinetic Energy Flelds, FFTP Geometry, Re=70,000, Normal Inlet Velocity Diatribution

I.5. TEACH-T Predietion w1th $\sigma=0.5$, FFTF Geometry, Re-70,000, Normal Inlet velocity Distribution

I.6 TEACH-P Predietion w1th $\sigma_{x}=0.1$, FF"TF Geometry, Re=70,000, Normal Inlet Velocity Diatribution

I.7 TEACH-T Prediction w1th o -1.5 , PFTF Geometry, $R e=70,000$, Normal Inlet Velocity Distribution

I.8 Compared Calculated and Measured Turbuient Kinetic Energy Fieids, FFTF Geometry, Re=70,000, Normal Inlet Velocity Distribution

I.9 TEACH-T Pred1ction w1th $\sigma_{\varepsilon}=0.65$, FFTF Geometry, $R_{e}=70,000$, Normal Inlet Velocity Distribution

I.10 TEACH-T Prediction with $\sigma_{\varepsilon}=2.60$, FFTF Geometry, Re $=70,000$, Normal Inlet Velocity Distribution

I.11 TEACH-T Prediction w1th $\sigma_{\varepsilon}=3.90$, FFTF Geometry, Re $=70,000$, Normal Inlet Veloc1ty Distribution

I.12 Compared Calculated and Measured Turbulent

K1net1c Energy Flelds, FFTF Geometry, Re=70,000, Normal Inlet Velocity D1 atribution 
№.

I.13 TEACH-T Prediction with $\mathrm{C}_{1}=2.88$. FHT Geometry, Re=70,000, Normal Inlet Velocity Distribution

I.14 TEACH-T Prediction w1th $c_{1}=4.32$, FFPF Geometry, Re-70,000, Normal Inlet Velocity Distribution

I.15 TEACH-T Prediction with $\mathrm{c}_{1}=0.72$, FFTF Geometry, Re $=70,000$, Normal Inlet Velocity D1stribution

I.16 Compared Calculated and Measured Turbulent Kinet1e Energy Flelds, FFTF Geometry, Re*70,000, Normal Inlet Veloc1ty D1stribution

I.17 TEACH-T Prediction W1th $\mathrm{C}_{2}=0.96$, PFTF Geometry, Re $=70,000$, Normal Inlet Velocity Distribution

I.18 TEACH-T Prediction with $\mathrm{C}_{2}=0.64$, FFTF Geometry, Re $\times 70,000$, Normal Inlet Velocity D1atribution

I.19 TEACH-T Prediction W1th $\mathrm{C}_{2}=3.84$, FFTF Geometry, Re=70,000, Normal Inlet velocity D1stributuion

I.20 Compared Calculated and Measured Turbulent Kinet1c Energy Flelds, FFTF Geometry, Re=70,000, Normal Inlet Veloc1ty D1stribution

I.21 TEACH-T Prediction w1th $\mathrm{C}_{\mu}=0.25, \mathrm{C}_{2}=1.80$, FFTF Geometry, Rex70,000, Normal Inlet Veloc1ty Distribution

I.22 TEACH-T Prediction with $\mathrm{C}_{12}=0.25, \mathrm{C}_{2}=1.70$, FFTF Geometry, Re 70,000 , Normal Inlet Velocity Distribution 
No.

I.23 TEACH-T Pred1ction w1th $c_{\mu}=0.25, c_{2}=1.50$,

FFTF Ceometry, Re-70,000, 'Normal Inlet

Velocity D1stribution

I.24 Compared Calculated and Measured Turbulent

Klnet1c Energy F1elds, FFTF Geometry, Re=70,000, Normal Inlet Velocity Distribution

I.25 TEACH-T Prediction with Inlet Turbulent Energy Dissipation Rates, $0.8,1.13$, and 1.18 , FFT Geometry, Re=70,000, D18torted Inlet Velocity Distribution

I.26 TEACH-T Prediction w1th Inlet Turbilent Energy Disipation kates, $0.8,1.25$, and 1.7

EFTF Geometry, Re=70,000, Distorted Inlet

Velocity Distribution

I.27 TEACH-T Prealction w1th Inlet Turbulent Energy D1ssipation Rates, $0.3,1.0$, and 1.7 , FFTF Geometry, Re=70, 000, D1storted Inlet velocity Distribution

I.28 TEACH-T Prediction w1th Inlet Turbulent Energy Dissipation Rates, $0.2,0.2$, and 1.0 , FFTF Geometry, Re=70,000, Dietorted Inlet Velocity D1atribution

I.29 TEACH-T Prediction with Inlet Turbulent Energy D18sipation Rates,0.1, 0.1, and 0.1 , FFTF Geometry, Re=70,000, D1atorted Inlet Velocity Dtatribution

I.30 TEACH-T Prediction w1th Inlet Turbulent Energy -D1sstpation Ratea, $0.3,0.5$, and 0.7 , FFTF Geometry, Re=70,000, Distorted Inlet velocity D1etribution

I.31 TEACH-T Prediction with Inlet Turbulent Energy D1alpation Rates, $0.5,0.6$, and 0.7 ,

FFTF Geometry. Re-70,000, Diatorted Inlet Velocity Diotribution

I.32 TEACH-T Prediction w1th Inlet Túrbulent Energy D1solpation Rates, $0.5,0.5$, and 1.0 , FEFF Geometry, Re 70,000 , Distorted Inlet Velocity Distribution 
No.

I.33 TEACH-T Predictson with Inlet Turbulent Energy Disaipat 1 on Rates, $0.4,0.7$, and 1.0 , FPTS Geometry, $\mathrm{Re}=70,000$, Distorted Inlet Veloc1ty Distribution

I.34 TEACH-T Prediction with $\sigma_{1} 0.1$, FFTF Geometry. Re=70,000, Dittorted Inlet Velocity Distribution

I.35 TEACH-T Prediction w1th $\sigma_{K}=0.5$, FFTF Geometry, Re=70,000, Distorted Inlet Velocity Distribution

I.36 TEACh-T Frediction with $\sigma_{K}=2.0$, FFTF Geometry, $\operatorname{Re}=70,000$, D1storted Inlel Velocity Distribution

I.37 TEACH-T Prediction with $\sigma_{\mathrm{E}}=0.65$, FFTF Geometry, Re= 70,000 , D1storted Inlet Velocity D1strioution

I.38 TEACH-T Prediction with of $\sigma_{\mathrm{E}}=6$, FFTE Geometry, Re $=70,000$, Distorted Inlet Velocity Distribution

I.39 TEACH-T Prediction with $\sigma_{E}=3.9$, FFTF Geometry, Re=70,000, Distorted Inlet Velocity Distribution

I.40 TEACH-T Frediction with ${ }^{\circ}{ }_{E} 13.0$, FFTF Geometry, Re $=70,000$, Distarted Inlet Velocity Distribution 


\section{NOMENCLATURE}

B constant appearing in Bradshaw's turbulence model

$c_{1}, c_{2}, c_{\mu}$ constants appearing in transport equations of $\mathrm{K}-\varepsilon$ model

$\mathrm{CD}_{\mathrm{D}}, \mathrm{CS}_{\mathrm{S}}$ $\mathrm{C}_{\mathrm{B}}, \mathrm{C}_{\mathrm{K} \boldsymbol{}}$

$C Q$

$\mathrm{E}_{10}, \mathrm{E}_{20}$

$F_{D}$

$\mathrm{r}_{0}$

$$
\mathbf{B}_{\mathrm{X}}, \mathbf{B}_{\mathrm{Z}}
$$

G

I

$\mathbf{K}$

$\mathrm{K}_{1}, \mathrm{~K}_{\mathbf{z}}$

$\mathbf{t}$

N p

$y^{j}$

$\sigma$

$\sigma_{\mathrm{K}}, \sigma_{\mathrm{E}}$

$\sigma_{\text {KL }}$

p constants appearing in transport equations of $\mathrm{K}-\mathrm{K} \boldsymbol{\ell}$ mode 1

amount of heat transfer from bomdary to the gurrounding fluid

electric rleld intensity

Doppler frequency

reference frequency

gravitational forces $1 \mathrm{X}$ and $z$ direction

generation terms of turbulent kinetic energy

1nternal energy

turbulent kinet1c energy

wave numbers of 1nc1dent and scattered light respectively

length scale or Prandtl's mixing length

number of fringes in the measuring volume

coordinate 1 n cross-stream direction where $j$

1s zero for plane flows and 1s 1 for axisymmetric flows

turbulent k1nematic viscosity

effective turbulent Prandtl number for transport of $\mathrm{K}$ and $\varepsilon$

constants appearing in transport equation of $\mathrm{K}$ - Ke mode 1

density of the fluid 


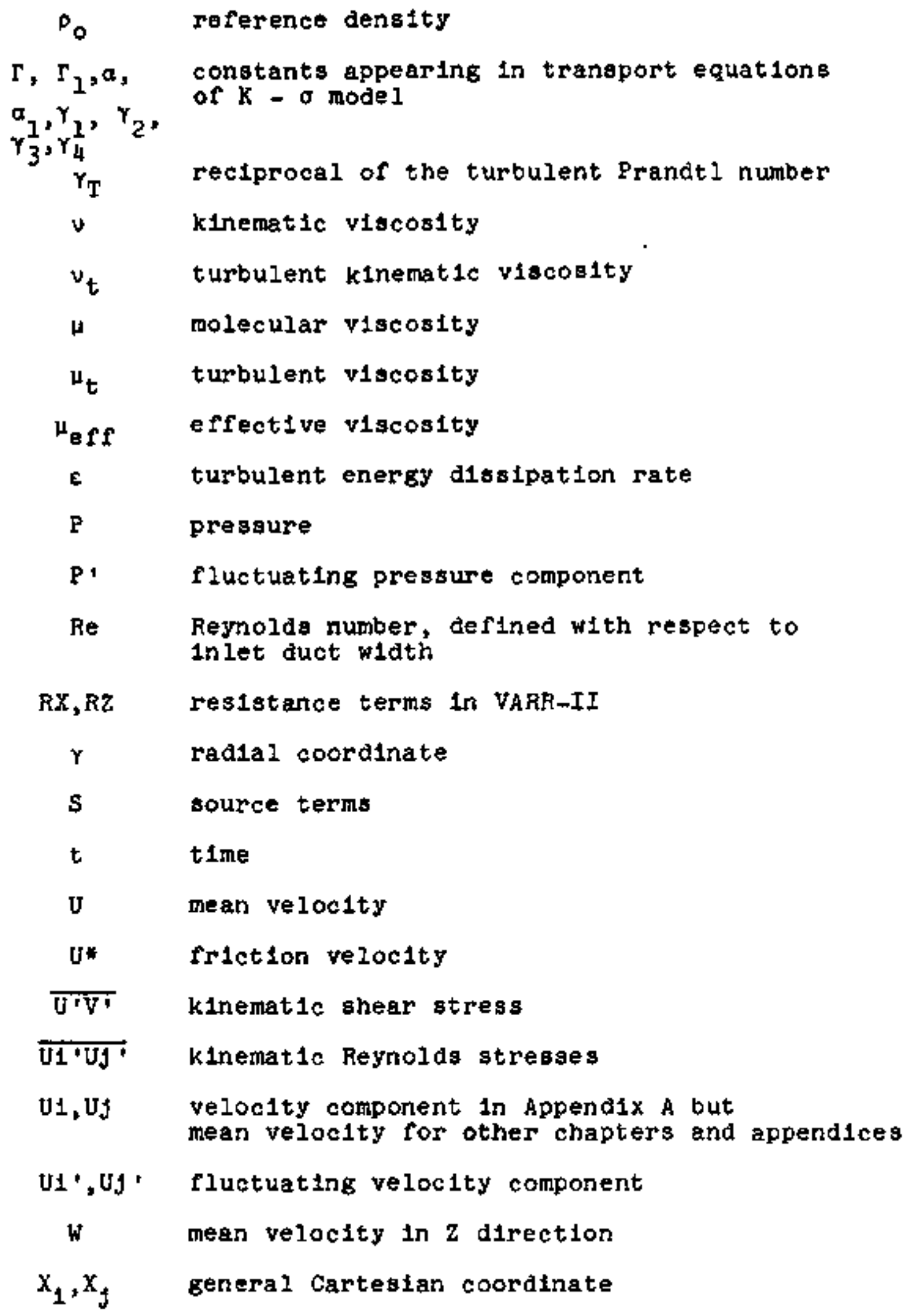




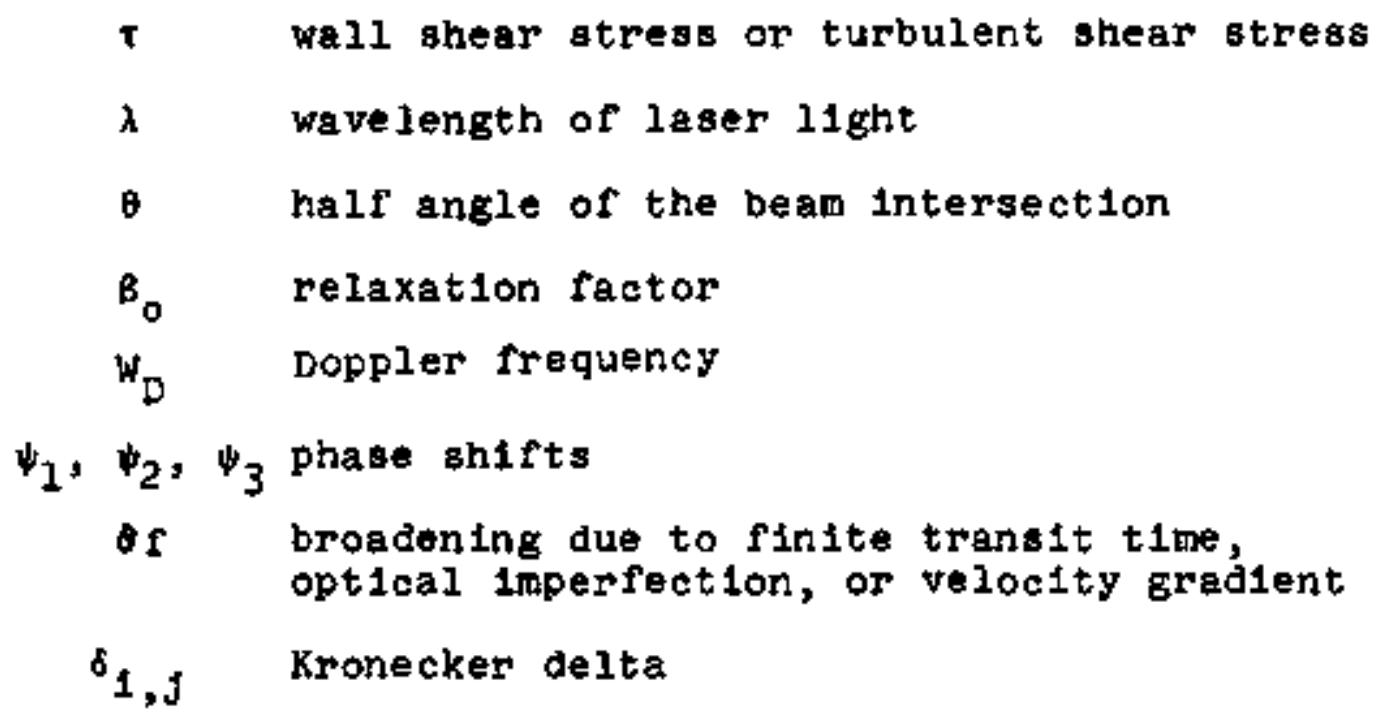


CHAPTER 1

INTRODUCTION

In the liquid metal-cooled fast breeder reactor (LMFGR), sodium is the coolant that removes heat from the reactor core. sluce sodium is a good heat transfer medium and has a low neat capactty, the temperature difference between the inlet and outlet of the core is much greater than that of the current design light water reactor (LWR). A typlcal temperature rise is approximately $300^{\circ} \mathrm{F}$. During a reactor scram, with or without flow coastiown, the cold sodium will issue from the reactor core, and w1ll mix w1th the hot sodlum that had prevlousiy filled the reactor outlet plenum. Predicting the transient thermal response of the sodium in the outlet plenum is an Important problean, Bince th1s transient will dictate the thernal fatigue environment for the outlet nozzles, instrument trees, and other mechan1cal components which will be exposed to the reactor coolant flow.

A detalieo analytical treatment of the coolant mixing In the outlet plenum is hampered by the complex nature of the resulting turbulent rlow. The Navier-stokes equation cannot be solved numerlcally oecause of the small scale of turbulence, and due to the limited storage capacity and speed of existing computers. Therefore, most problems in turbulent flow are solved by using the time-averaged Navier-Stokes equation (or Reynolds equation). Due to the nonlinearity of the NavierStokes equations, one additional term, known as the Reynolds stress, appears in the Reynolds equation. Fuch of the attention 
has been concentrated on how to model this stress in terms of known quantities. This is the so-called turbulence model approach. In general, the LAFBR outlet plenum w1ll display a recirculating flow pattern. The simplest models (e.g., Prandtl's mlxing length theory) have been found to be inadequate in providing accurate predictions of this behavior. Therefore, current design work has adopted the use of a twoequation turbulence model. Th1s decision 18 based on the need for accuracy with reasonably short computing times.

In this work, two computer codes, namely TEACH-T (1) and VARR-II (2), are used. TEACH-T is a steady-state two-dimensional code which models turbulent kinetic energy and turbulent energy dissipation rate as two additional dependent variables. VARR-II is a t1me-dependent two-d1menglonal thermal-hydraulic code. Different from TEACH-T, it solves transport equations for turbulent k1netic energy and turbulent viscosity. In addition, an energy conservation equation is incorporated Into the code for tenperature prediction, and it provides a buoyant force feedback to the momentum equation. The code TEACH-T has been modified to calculate flows in the reactor plenum geometry, and used to generate predictions for the experimental part of th1s work. The code VARR-II is currentiy in use as a design tool in the clinch River Breeder Regctor Program. Its predtctions have not been verifled experimentally in the flow geometry of Interest. It $1 \mathrm{~s}$ also being used in this work to predict the flow in an experimental test cell.

In the experimental part of thls work, a small scale 
Cartesian goometry test model of a diametrical section of the prototyplc outlet plenum geometries are used. The experiments consist of measurements of velocity, turbulent kinetic energy, and Reynolds stresses in the two perpendicular drections by a Laser Doppler Anewometer. These data are compared to predictiong of the behavior of the experiment by each of the twoequation turbulence model codes.

In order to prov1de some rational explanation of the twoequation model, a survey of existing turbulence models is included in chapter 2 . Chapter 3 describes the analytical model used in the VARR-II and TEACH-T. A detalled description of experimental apparatus is in chapter 4. The rest of the chapters discuss the results. 


\section{CHAPTER 2}

\section{REVIEW OF LITERATURE}

Most fluid problems encountered in the real world are turbulent. Turbulence is characterized by 1ts irregularity, ingh diffusivity, and dissipative nature. The design engineer demands high heat output from his heat exchanger which requires a high mass flow rate, and therefore, entalls a high Reynolds number and turbulent flow. Flows in heat exchangers, gas furnaces, turbines, etc., are all turbulent to take advantage of the highly diffusive (strongly mixed) nature of the turbulence. Therefore, a good prediction of the mean turbulent fluid behavior, such as presgure drop, velocity distribution, and heat flux 15 of great value to the designer.

Although turbulent flows exhiblt randomess, we have no doubt that they still obey the Navier-Stokes equation and continuity equation. Since the number of unknowns is exactly equal to the number of equations, and since computer methods of solving these differential equations of flutd dynamics are well advanced even for three-dimensional time-dependent flow, In princlple we should be able to solve it. Unfortunately, some of the important processes of turbulent phenomena take place in salall eddies of the order of a millimeter in size, while the whole domain of the flow field might extend to meters or k1lometers, A fine mesh to allow an accurate description of a turbulent flow would definttely exceed the existing computer storage by many orders of magnitude, to say nothing of the computer time. 
Fortunately, there is no need to predict all of the detalls of turbulent motions. Generally, we are concerned with its time-averaged effects. Th1s escapes the sequirement of an excessively fine-mesh gria, unavoldable for the NavierStokes equation approach, because the time-averaged properties of a turbulent flutd vary much more slowly than do the timedependent ones. Therefore, it is entirely possible to solve the time-averaged Navier-stokes equation for most engineering problems with today's computers.

The transport equation for momentum, known as Reynolds equation, is derived (In Append $1 x$ A) from the Navier-Stokes equation by sutable averaging procedures. Due to the nonlinear1ty of the Nav1er-stokes equation, the resulting equation contains a new unknown correlation (Reynolds stresses) which must be replaced by functions of the model variables. ThIs is the well-known closure problem. The "turbulence model" approach has been invented to solve this problem.

The following bection gives a detalled description of some existing turbulence models.

\subsection{Survey of Ex1st1ng Turbulence Models}

All of the turbulence models have a common goal, 1.e., to calculate the Reynolds stresses which appear in the momentum equation. The models are customarily classifled in order by reference to the number of differential equations that are solved beyond those governling the transport equation of mean velocities, temperature, and concentrations. 


\subsubsection{Zero Equation Models}

The models of this growp relate the turbulent shear stress (or Reynolds stress) uniquely to the mean flow properties at each location. Since they require only algebralc expressions, these simple models have enjoyed much popularity.

A11 of the zero equation models use the Boussinesq concept of eddy viscosity, 1.e.,

$$
\begin{aligned}
& \overline{\mathrm{V}^{\prime}}=-v_{t} \frac{\partial U}{\partial \mathrm{V}} \\
& \text { where } v_{t} \text { is the turbulent kinematic viscosity. }
\end{aligned}
$$

The task is thus reduced to determining the $v_{t}$. The nost popular method used by researchers is Prandtl's mixing length hypothesis! 3 )

In 1925, Frandt 1 proposed that turbulent shear stresses and veloc1ty gradients are related by formulas of the same type as for laminar flulds. The effective (or turbulent) viscosity entering the formula is proportional to the product of the local density, a local turbulence length scale, and a local velocity of a random motion; the random veloctty is proportional to the length scale multiplied by a local veloc 1 ty gradient, 1.e.,

$$
\begin{aligned}
-\overline{\rho U V} & =\mu_{t} \frac{\partial U}{\partial y} \\
\mu_{t} & =\rho \& V_{\text {randon }} \\
V_{\text {randor }} & =2\left|\frac{\partial U}{\partial y}\right| \\
\text { hence }-\rho J V & =\rho x^{2}\left|\frac{\partial U}{\partial y}\right| \frac{\partial U}{\partial y}
\end{aligned}
$$


The length scale $k$, known as Prandtl's mixing length, Is proportional to the distance of a nearby wall, or the w1dth of the region of the turbulent shear flow.

Por many boundary-layer flows, Prandth's mixing lentth theory gives remarkable results. However, the constants Involved must vary with the problem consldered. Th1s lack of universality is an 1ndication that this model falls to describe some important features of the turbulent flows.

As mentloned above, the algebra1c models are based upon the assumption that turbulent shear stresses are uniquely dependent on the local mean flelo, 1.e., the generation and dissipstion of turbulent energy are In balance everywhere, and the convection and diffusion of turbulent energy are 1gnored. Such models might be expected to be realistic only when the turbulence is influenced by the local properties of the velocity fleld or changes only slowly in the direction of the flow. In many cases (e.g., recircuiating flows (4), turbulence $1 \mathrm{~s}$ not in local equilibrium with 1ts immediate neighborhood, but depends on processes and events which happen at a considerable distance from the point in question, 1.e., the convection and diffusion of turbulence are significant for such flows. In such a situation, we must consider the transport of the turbulence by means of differential equations.

\subsubsection{One Equation Model}

\subsubsection{Transport Equation for Turbulent Kinetlc Energy}

since turbulence is characterized by its random velocity 
and length acale, Kolmogorov (5) and Prandtl $(6)$ Independentiy proposed the use of a transport equation for turbulent kinetic energy (dertved in Appendix A) to describe the random velocity scale. PrandtI retalned his assumption that the length scale could be taken as proportional to the distance frow wall. They both adopted the eddy viscosity concept, and $v_{t}$ is proposed to be

$$
v_{t}=c_{\mu} \quad x^{1 / 2} \varepsilon
$$

The quality of the prediction of this model depends, of course, on the approprlate prescription of the length scale. But whenever the diffusion and convection of turbulence play a significant role, the prediction 18 expected to be better than zero equation model.

Bradshaw et al. ( 7 ) heve proposed a different equation for eddy viscosity. They postulated that the turbulent shear stress is proportional to the turbulent kinetic energy, thus

$$
\tau=8 \rho \mathrm{K}
$$

where $B$ is supposedly a universal constant.

This model also needs to incorporate a length scale expression for the dissipation terms. They applied the rodel to a turbulent boundary level near a wall and obtalned good agreement with experimental data. For many flows this assumption is unrealiatic, Blnce the shear stress may be zero whlle $K 15$ finite as in the case of a jet.

\subsection{2,2 Iransport Equation for Eddy V1scosity}

Nee and Kovasznay $(\theta)$ have proposed a transport equation for eddy viscosity itself, based on a phenonenological theory 
of turbulence. A length scale distribution is also needed as 1nput. They were successful in making predictions in the turbulent wall boundary layer.

All the models discussed so far have necessitated the use of an algebraic length scale speciflcation, and experience has shown that this may vary with the boundary conditions. There is little hope of achleving untversality for these length scales, unless they are also solved by transport equations.

\section{1 .3 Two-Equation Models}

As a fluctuating phenomenon, turbulence is characterized by its random velocity and length scale. Hence, if we want to describe the turbulence closure in terins of two parameters, the turbulent kinetic energy and length scale are appropriate ones, Th1s leads to the two-equation turbulence model approach.

In a two-equation model, the selection of the main variables is a matter of conven1ence as long as the turbulence kinetic energy and length scale can be represented by the two chosen variables. Many pairs of varfables are sultable, the criteris being the simplicity of the governing equation and 1ts associated boundary conditions. A turbuient kinetic energy equation is incorporated in all the models. However, the second model-equation governs olther the length scale, dissipation, turbulent vort1c1ty, or the frequency.

\section{$2.1 .3 .1 \mathrm{~K}-\mathrm{E}$ Model}

A form of a $K$ - $E$ Model was first proposed by Harlow and Nakayama, $(9)$ and then pursued by researchers at the Imperial 
College ( 1 ). The turbulent energy dissipation rate, $\varepsilon$, is defined as $\overline{v\left(\partial U_{1} / \partial x_{j}\right)^{2}}$. The differential equation for $\varepsilon$ can be derlved eastly from the Navier-stokes equation (see Appendix A). Th1s model has shown great success for large variety of flows and will be discussed in detail in chapter 3 .

\section{$2.1 .3 .2 \underline{K}-\mathrm{K} 2$ Mode1}

Rodl and Spalding (10) using Rotta's ${ }^{(11)}$ equation for 2 derived the differential equation for $\mathrm{ke}$. The equations for $K$ and $K \&$ are

$$
\begin{gathered}
U \frac{\partial K}{\partial x}+v \frac{\partial K}{\partial y}=\frac{1}{y^{1}} \frac{\partial}{\partial y}\left(y^{j} \frac{v_{t}}{\sigma_{K}} \frac{\partial K}{\partial y}\right)+v_{t}\left(\frac{\partial U}{\partial y}\right)^{2}-c_{D} \frac{K^{3 / 2}}{\ell} \\
U \frac{\partial K \ell}{\partial x}+v \frac{\partial K \ell}{\partial y}=\frac{l}{y^{1}} \frac{\partial}{\partial y}\left[y^{j} \frac{v_{t}}{\sigma_{K \ell}}\left(\frac{\partial K \ell}{\partial y}+c_{K \ell} \ell \frac{\partial K}{\partial y}\right)\right] \\
+c_{B} v_{t} \ell\left(\frac{\partial U}{\partial y}\right)^{2}-C_{s}+K^{3 / 2}
\end{gathered}
$$

where $C_{D}, C_{s}, C_{B}, \sigma_{k}, a_{K l}$, and $C_{K l}$ are constants.

Th1s model has reported great success in pred1cting the behavior of free jets, mixing layers, plane jets, and radial jets. Becuase of a lack of unlversal1ty, no further progress has been made.

\section{$2.1 .3 .3 \underline{\mathrm{K}}-\sigma$ Mode1}

Stuhmiler (12) using a heuristic argument about turbulence derived the differential equations for turbulent kinetic energy, $K$ and eddy v1scostty, $\sigma$. Th1s model 1s adopted in the computer code VARR-II and 1 s discussed in Chapter 3. 
All the models discussed here use the Boussinesq formula to relate the turbulent shear stress to the local velocity gradient. There are engineering problems for which this formula is not adequate. For example, in an annulus having one rough and one smooth wall, the shear stress is often finfte when the velocity gradient is zero, and there is a signiflcant region of flow in which the shear stress and velocity gradfent have opposite s1gns. These rallures naturally lead to mult1-equation models.

\subsubsection{Mult1-Equat 1on Model (Reynolds Stress Moded)}

The most direct way to determine $\overline{U^{\prime} V}$ is, of course, to solve a transport equation for thls quantity. It is expected that the use of the Reynolds stress model will 1ncrease the universality of the prediction methods, because in contrast to the above method, $1 \mathrm{t}$ is unnecessary to 1ntroduce an approx1mate shear atress relation, whose validity is in question for certain flow conditions. However, the Reynolds stress equation (derived in Appendix A) involves new unknowns, such as triple correlations and pressure-velocity correlations. These quantities are elther difficult to measure or hard to simulate. since tnis model is still in an eariy stage, we will not go Into further detalls.

As discussed above, a good turbulence model is untversal and is not too complex to uae. Universality Implies that a single set of emplrical constants or functions inserted into the equations provides close simulations of all varleties of flows. Complex1ty 1s measured by the number of differential equations 
which the model contalns, and the number of the empirical constants and functions which are required to complete them. Now 1t should be clear that the main obstacles to model development are the difficulty of selecting the set of differential equations that are capable of providing universality, and then the diffleulty of providing, from experiments and knowledge, the required constants and functions. 
CKAPTER 3

DESCRIPTION OF THE ANALYTICAL MODEL

ADOPTED IN THE STUDY

One major task of this study is to select appropriate turoulence model codes, generate predictions, and compare them with the experimental results.

There are two codes used in this investigation. They are discussed in the following two sections.

\section{3,1 TGACH-T Code}

TEACH-T is a steady state two-dimensional two-equation turbulence model code (1). It was developed by the staff in the Mechanical Eng1neering Department at the Imperical College of Sclence and Techology In England.

\subsubsection{Basic Assumptions}

Generally, turbulence is nonlsotrople and three-dimensional, and thus turbulence parameters have directional propertios. Any description of turbulence by scalar parameters implies an 1sotropy of the mean flow properties. Therefore, in a twoequation turbulenee model, the nonisotropy of the turbulence can only be dependent upon the nonisotropy of the mean flow field, usually through an eddy viscosity, $v_{t}$. On the basis of the above discussion, the Reynolds stresses can be expressed as

$$
\overline{u_{1} v_{j}}=\frac{2}{3} K \delta_{1 j}-v_{t}\left(\frac{\partial u_{1}}{\partial z_{j}}+\frac{\partial U_{j}}{\partial x_{1}}\right)
$$

where the flrst term on the right nand side has been added in order to make the equation applicable to homogeneous and 1sotropic 
turbulence. With this formulation, the equations of motion w1ll retaln their or 1 ginal form with a varlable viscosity. From dimensional analysis, the turbulent viscosity, $v_{t}$, is related to turbulence kinet 1c energy, $K$, and a length scale, \&, by

$$
v_{\mathrm{t}} \cdot \mathrm{c}_{\mu} \mathrm{K}^{1 / 2} \&
$$

where $C_{u}$ is supposedly a constant.

\subsubsection{Model Equations}

The quantit1es $K$ and $\varepsilon$ serve as the model varlables. As stated In section 2.1.3 these are not the only possible varian bles, and in fact many other pairs of varlables are more attract1ve. The criterion of the selection is just the simplicity of the governing equations and assoclated boundary conditions.

The TEACH-T code has adopted the $K-*$ turbulence model, first proposed by Harlow and Nakayana ( 9 ). The reason for this selection lies partiy in the relative ease with which the exact equations for $K$ and $\varepsilon$ can be derived and partiy in the fact that $\varepsilon$ appears directly as an unknown in the equation for $\mathrm{K}$.

The derivation of the turbulence kinetic energy equation is included in Appendix $A$.- The resulting equation follows:

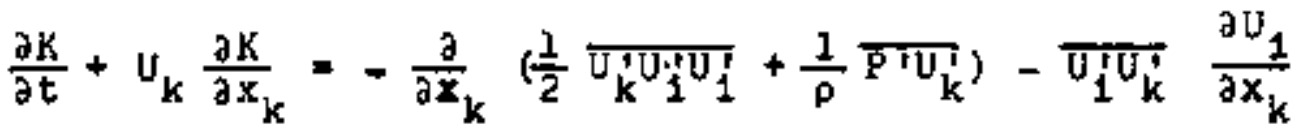

$$
\begin{aligned}
& -v\left(\frac{\partial U_{1}^{r}}{\partial x_{k}} \frac{\partial U_{1}}{\partial x_{k}}-\frac{\partial^{2}}{\partial x_{k}} k\right)
\end{aligned}
$$

The most disappointing feature it exh1bits, which 1s comnon to 
all turbulence equations is that it contains terms involving an unknown correlation of the veloctty and pressure, and therefore cannot be solved. The physical meaning of the individual terms is easily recognized as convection, diffusion, generation, and dissipation.

The generation term poses very few problems, since it contalns only the products or Reynolds stresses and velocity gradients. They can be masured experimentally or found by calculation. The physical meaning of this term is also easily understood. The mean flow performs work on the turbulent eddies, and thus energy is transferred from the wean motion into the fluctuatirig motion.

Towsend (13) has proposed an energy cascade process in turbulent flows, by which energy is transferred from the big eddies to the small eddies. At the end of the cascade, the viscous stresses perform deformation work against the fluctuating strain rate, and ali the energy is dissipated into heat. The last term describes th1s process.

The diffusion terms are the most difficult ones to tackle. The triple correlation, $\frac{1}{2} \frac{\partial}{\partial x_{k}} \overline{U^{1} U^{\prime} U_{1}}$, represents the energy transport by the turbulent eddies, and the pressure-velocity correlation represents the transport of energy by pressure fluctuations. The last process is not yet properly understood and 1 ts measurement 15 hampered by severe difficulties (4). The triple correlation can be measured, but two-equation theory is not advanced enough to model it. The escape is to recognize that both terms do not generate or absorb turbulence energy, 
and act only as agents to change the spatial distribution of the energy. This process is similar in nature to laminar diffusion, and it is suggestive to model it by a second order diffusion equation with a diffusion coeficient that is related to the turbulent viscosity, 1.e.,

$$
-\frac{\partial}{\partial x_{k}}\left(\frac{1}{2} \overline{U_{k}^{T} U_{1}^{T}}+\overline{U_{k}^{T T}}\right)=\frac{\partial}{\partial x_{k}}\left(\frac{v_{t}}{\sigma_{k}} \frac{\partial}{\partial x_{k}} K\right)
$$

Thus, the resulting equation for turbulence kinetic energy is

$$
\begin{aligned}
& \frac{D K}{D t}=\frac{\partial}{\partial x_{k}}\left(\frac{v_{t}}{\sigma_{k}} \frac{\partial}{\partial x_{k}} K\right)+G-\epsilon \\
& \text { where } G \equiv-\overline{U_{1} U_{j}} \frac{\partial U_{1}}{\partial x_{j}}=v_{t}\left(\frac{\partial U_{1}}{\partial x_{j}}+\frac{\partial U_{j}}{\partial x_{1}}\right)^{2} \\
& E \equiv v\left(\overline{\left.\frac{\partial U_{j}}{\partial x_{k}} \frac{\partial U_{1}}{\partial x_{k}}\right)}\right. \\
& \sigma_{k} \text { is a model constant. }
\end{aligned}
$$

Algebraic manipulation of the favier-Stokes equation yields a transport equation for the turbulence energy dissipation rate (see Appendix A for a derivation).

$$
\begin{aligned}
& \frac{\partial E}{\partial t}+U_{k} \frac{\partial}{\partial x_{k}}=-2 v_{\frac{\partial u_{1}}{\partial x_{k}}}\left(\frac{\partial U_{1}}{\partial x_{1}} \frac{\partial U_{k}^{r}}{\partial x_{1}}+\frac{\partial U_{1}}{\partial x_{1}} \frac{\partial U_{1}^{j}}{\partial x_{k}}\right.
\end{aligned}
$$

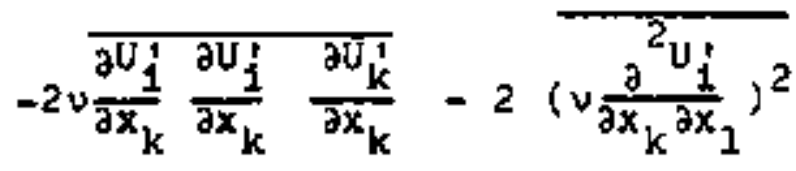

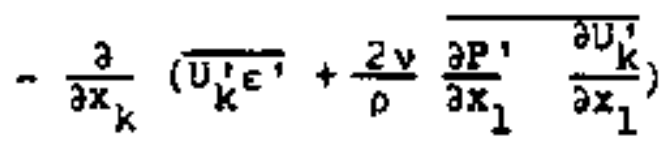




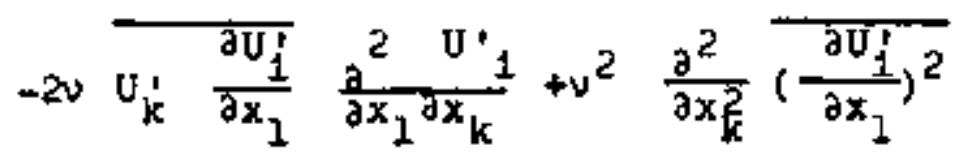

None of the terms on the right hand side of the equation are accesstble to measurement. According to Launder (4), at a high Reynolds number the equation can be simplified to

$$
\frac{D E}{D t}=\frac{1}{\partial} \frac{\partial}{\partial x_{k}}\left(\frac{\mu_{t}}{\sigma_{\epsilon}} \frac{\partial \varepsilon}{\partial x_{k}}\right)+\frac{c_{l}}{\rho} \frac{\mu_{t} \varepsilon}{K}\left(\frac{\partial U_{1}}{\partial x_{k}}+\frac{\partial U_{k}}{\partial x_{i}}\right) \frac{\partial U_{1}}{\partial x_{k}}-c_{2} \frac{\varepsilon^{2}}{K}
$$

where $\sigma_{0} c_{1}$, and $c_{2}$ are model constants.

The physical meaning of these terms is easily recognized as convection, diffusion, production, and decay.

\section{1 .3 Model Constants}

In the transport equations for $K$ and $\varepsilon$, several enpirical constants st1l1 need to be determined. Launder et al. (1) obtained the value of $\mathrm{C}_{2}$ from the decay of grid turbulence, $c_{\mu}$ and $c_{1}$ from near well turbulence, and $\sigma_{k}$ and $\sigma_{\varepsilon}$ from an optimization of theory ard data. The recommended values are

$\begin{array}{ccccc}c_{\mu} & c_{1} & c_{2} & \sigma_{k} & \sigma_{\epsilon} \\ 0.09 & 1.44 & 1.92 & 1.0 & 1.3\end{array}$

Now the only remaining problems are a solution algorithm and boundary conditions. These are quite lengthy and are described in deta1l in Appendix $C$.

The TEACH-T code has been applied to many turbulent flow problews, including reclroulating flow, free shear flow, pipe flow, and boundary layer flow. The agreement with experimental 
data $1 \mathrm{~s}$ generally very good.

\subsection{VARR - I I Code}

VARR-II 18 a time-dependent two-dimensional thermal-

hydraulic code(2). It solves turbulence klnetlc energy and turbulent viscosity equations. Hence, it is a two-equation turbulence model code. In addition, an energy conservation equation is included to account for small density variations due to temperature changes, and in thls way, it provides a buoyant force feedback Into the momentum equation. This code was developed by Sclence Applications Inc. for the Westinghouse Advanced Reactor D1vision to ald in the design of the LMFBA outlet plenum.

\section{2 .1 Bas1c Assumptions}

Stuhtilier (12) used a plauglole explanation of the turbulence transport phenomena to derlve the two turbulence model equations. H1s arguments may be summarized as follows. In a fully developed turbulent flow, fluctuations exist on every spatial scale from the largest allowed by the geometry of the boundaries to the smallest allowed by molecular viscosity. However, 1t 1a often possible to distinguish two spatial reglmes: one that is primarily responsiole for the diffusivity of the flow, and a second for the viscous dissipation of energy. based on these assumptions, the turbulence spectrum mey be simplified to one in which there are only two eddy sizes: the production scale, which interacts strongly with the mean flow by transferring energy from the mean motion to the large eddles, 
and the dissipation scale, which represents the small scale motion leading ultimately to the creation of neat. Since only large eddles have direct 1mportance to the mean flow, a single wavenumber of the turbulence frequency spectrum is considered. Physical interpretation of the interaction with other wavenumbers is made so that the equation of motion for the fluctuating guantities can be linearized. From the dynamics of the simulated fiuctuation, the equations of turbuience kinetic energy, turbulent viscosity, and Newtonian stress-strain are derived.

Different from other work, the closure of the equations for the fluctuating quantities, rather than their correlations, leads to the introduction of new parameters and reveals several interconnectlone between measurable quant1ties,

\section{2 .2 Model Equations}

The final form of the equations for mean motion, $\mathrm{U}_{1}$, turbulence kinetic energy, 8 , and turbulent viscosity, $\sigma$, is as follows:

$$
\begin{aligned}
& \frac{\partial U_{1}}{\partial t}+U_{k} \frac{\partial U_{1}}{\partial x_{k}}=-\frac{\partial P}{\partial x_{1}}+\frac{\partial}{\partial x_{k}}(\sigma+v)\left(\frac{\partial U_{1}}{\partial x_{k}}+\frac{\partial U_{k}}{\partial x_{i}}\right) \\
& \frac{\partial q}{\partial t}+U_{k} \frac{\partial q}{\partial x_{k}}=\frac{1}{2} \sigma\left(\frac{\partial U_{1}}{\partial x_{k}}+\frac{\partial U_{k}}{\partial x_{1}}\right)^{2}+\frac{\partial}{\partial x_{k}} r \sigma \frac{\partial q}{\partial x_{k}}-\alpha \frac{(20)^{2}}{\sigma} \\
& \frac{\partial \sigma}{\partial t}+U_{k} \frac{\partial \sigma}{\partial x_{k}}=\frac{\sigma^{2}}{4 q}\left(\frac{\partial U_{1}}{\partial x_{k}}+\frac{\partial U_{k}}{\partial x_{i}}\right)^{2}+\frac{\sigma}{q} \frac{\partial}{\partial x_{k}}\left[\sigma \frac{\partial q}{\partial x_{k}}\right.
\end{aligned}
$$




$$
\text { where } \begin{aligned}
-\frac{\sigma^{3}}{q^{2}} \frac{\partial}{\partial x_{k}} \Gamma q \frac{\partial}{\partial x_{k}}\left(\frac{q}{\sigma}\right)-4 \alpha_{1} g \\
\quad=3 \frac{\gamma_{1}}{\gamma_{2}}\left(2+\gamma_{2}^{2}\right) \\
a=\frac{1}{3} \frac{\gamma_{2}^{2}}{r_{2}^{2}+1} \\
r_{1}=\left(\gamma_{3} / \gamma_{1}\right) \Gamma \\
\alpha_{1}=\left(1-\frac{Y_{4}}{2 \gamma_{2}}\right) \alpha
\end{aligned}
$$

\section{2 .3 Model Constants}

The first section has described briefly the development of a two-equation turbulence model of turbulent flow, which introduces four empirical constants: either the set $\gamma_{1}, \gamma_{2}$, $\gamma_{3}$ and $\gamma_{4}$ or $r, \alpha, r_{1}, a_{1}$. They are determined from exper1ments on the decay of turbulence, a cons1deration of nearwall turbulence, of turbulent plpe flow, and of boundarylayer flow.

The recommended values are
$\Gamma$
a
$r_{1}$
$a_{1}$
1.5
0.045
0.75
0.01125

Plnally, the description of the numerical solution algorithm and boundary conditions is found in Appendix B. 
The author has applied the model to turbulent plpe flow and turbulent wake flow; the agreement $1 \mathrm{~s}$ good except near a Bol1d wall. But this code has not been tested against enough data, and the free parameters are also just tentative values. Hence, more testing is urgently needed, and the experimerits in this work are almed at oupporting this code,

The code TEACH-T has been modified to calculate flows in the reactor plenum geometry, and used to generate predictions for the experimental part of this work. The code VARR-II 18 currentiy in use as a design tool in the clinch R1ver Breeder Reactor Frogram. Its predict1ons have not been verified experimentaliy in the flow geometry of interest. It is also being used in this work to predict the flow in an experimental test cell. Thus, by 1ntercomparison of the results from these two competing turbulence model codes and the observed experimental data, one may fdentify sources of error in the predictions and make appropriate improvements in the turbulence models for the outlet plenum application. 
CHAPTER 4

DESCRIPTION OF THE EXPERIMENTAL APPARATUS

Th1s chapter describes the hydraulic facilities and instruments used in the experiments.

4.1 Hydraul1c Fac1lities

A schematic diagram of the hydraulic loop is shown in Fig. 4.1. The 50 galion aluminum tank is filled with distilled water. All the plpes, valves, and fittings are made of copper or brass to prevent corrosion. Polystyrene latex particles with sizes between $0.46 \mathrm{u}$ and $0.54 \mathrm{H}$ are added to the water to increase the intensity of the scattered 11ght. A I HP pump and a 5 HP pump are connected in parallel to delfver the flow. In order to increase the Reynolds numbers, a heat exchanger is included in the loop to increase the temperature. To measure flow rates, two different flowmeters are used in order to assure the accuracy of the flowmeter readings. Flow rates ranging from 0.7 to 37.8 GPM can be obtalned.

A variable geometry outlet plenum test section which can s1mulate two reactor cases, namely those of the Fast Plux Test Facility (PFTP) and the Clinch River Breeder Reactor (CRBR), has been fabricated. It 18 composed of one 2 "th1ck machined aluminum piece and two $I^{\prime \prime}$ thtck plexiglass faceplates which when bolted together define the rectangular internal geometry shown in F1g. 4.2. Hy moving the internal plexiglass blocks it can change From a 1/15-8cale FFTF geometry to a $3 / 80-s c a l e$ CRBR geometry, and vice versa. 
4.2 Instrumentation

A complete list of the instruments for the experiments is given in Table 4.1. The functions of the individual instruments are described in the following sections. A detalled discussion of the Laser Doppler Anemometer is found in Appendix D. 4.2.1 Optical system $(14)$

The optical arrangement for the experiments, a two channel reference beam mode, is show in P1g. 4.3. The laser beam from a Spectra-Phys1cs Model 1642 watt Argon Laser enters ax1a11y into the DISA Model 55L 83 Beam Splltter and Modular section through a small window. It then passes through a beam splitting prism which splits the beam in elther a 50/50 or 90/10 1ntensity rat10. One beam passes through a Bragg cell, where it is diffracted and $1 \mathrm{~s}$ shifted in frequency by $\pm 40 \mathrm{MHz}$ depending on the orientation of the Bragg ceIl with respect to the lncident laser beam. It then passes through a neutral density filter which 1s continuously adjustable between $0 \%$ and $100 \%$ transmission. Th1s shifted beam then passes through a DISA 55L85 Two-channel section wh1ch further splits the beam. Three beams come out of th1s two-channel sect1on. They enter the DISA Model 55L87 beam separator which focusses the beam to a point with1n the flow shannel with a $30 \mathrm{~cm}$ focal length lens. The two DISA Nodel $55 \mathrm{~L} 12$ photomultipliers are aligned with the two reference (shifted) beams to plck up the signal. Each photomultiplier $1 s$ powered from its own h1gh voltage supply. The anode currents of the photomultipliers are montored by two simpson current meters. 
The laser, optical unit, and photomultiplier are mounted on the aluminum plate shown in F1g. 4.4, The plate is supported by a table whose carriage provides three almenaional travel of the entire system. The messuring point 18 posftioned within the flow channel by moving the carriage contalning the laser, optical unit, and photomultipliers as an integral unit.

\subsubsection{Signal Frocessing System}

The signal from the photomultiplier is downshifted electronleally by elther a TSI Model 985 Frequency Shifter or DISA Hodel 55L70 Control Un1t. The amount of frequency downshift 1s adjustable and can be selected to fit the best trackins range of the slgnal processor. Then the afgnal 18 fed into e1ther the DISA Mode? 55L20 S1gnal Processor or the TSI Hodel 980 S1gnal Processor. Both trackers oontain a frequency lock loop which can track the Doppler signal continuously and provide an electric analog of the instantaneous Doppler frequency of the flow velocity.

The analog outputs of each tracker are connected to the DISA Model 52825 Turbulence Processor which makes the crosscorrelation of the two velocity components.

An HP Model $141 \mathrm{~B}$ osc1110scope monitors the output of the preamplifier, This 1s very belpful during optical alignment to optinlze the signal and to provide a constant check on the quality of the Doppler signal.

\subsubsection{Signal Recording System}

Two digltal voltmeters and two True RMS Voltmeters (with 
Integrating circuits) are connected to the output of the tracker to obtain the average voltage and rms voltage respectively. These voltages correspond to the average velocity and the rms velocity in the flow.

One more digital voltmeter is connected to the Turbulence Frocessor to get the value of the two-component voltage crasscorrelation, which in turn corresponds to the keynolds stress. The complete layout of the instrumentation is shown in Fis. 4.3 . 
Table 4.1

Description of Equipment

Unit

Argon Laser

Leser Exc1ter

Opt1cal Un1t

Photomult1plier

High Voltage

Supplier

Anode Current

Meter

IDA Control Unst

LDA Frequency

Shifter

Doppler Signal

Processor

Doppler S1gnal

Procestor

Turbulence Processor

Digltal Voltmeter

Digital Voltmeter

RMS Voltmeter

osc11loscope
Manufacturer

Spectra-Physico

Spectra-Physics

DISA

DISA

Ba1rd-Atom 1c

Simpson

DISA

TSI

DISA

TSI

DISA

FSI

Hewlett-Packard

DISA

Hewlett -Fackard
Model No.

164

265

55L88

$55 \mathrm{LI2}$

$312 \mathrm{~A}$

N/A

55170

985

$55 L 22$

980

52825

1076

$3456 \mathrm{~A}$

55D 35

1418 


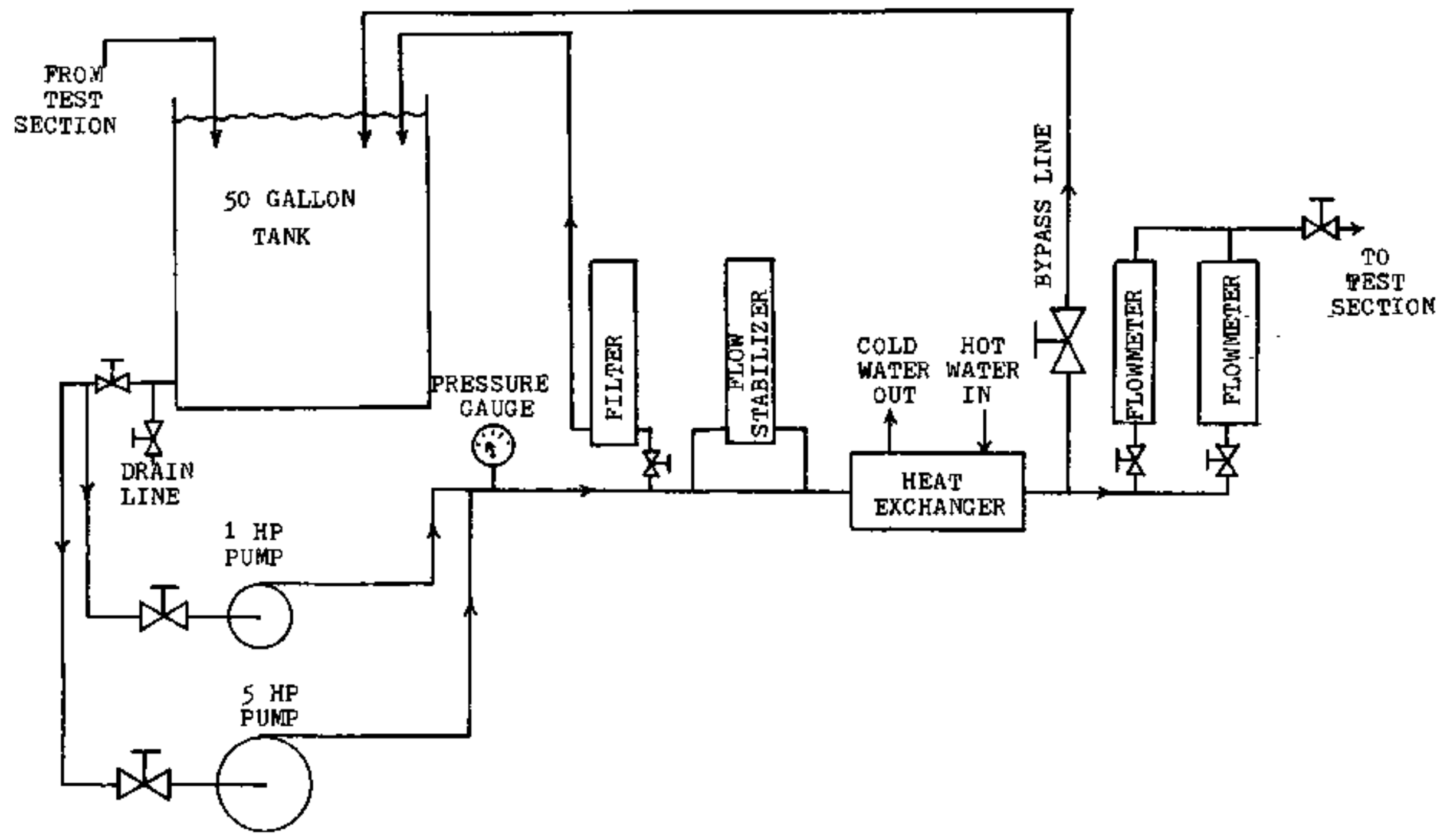

F18. 4.1 The Hydreul1e Loop 


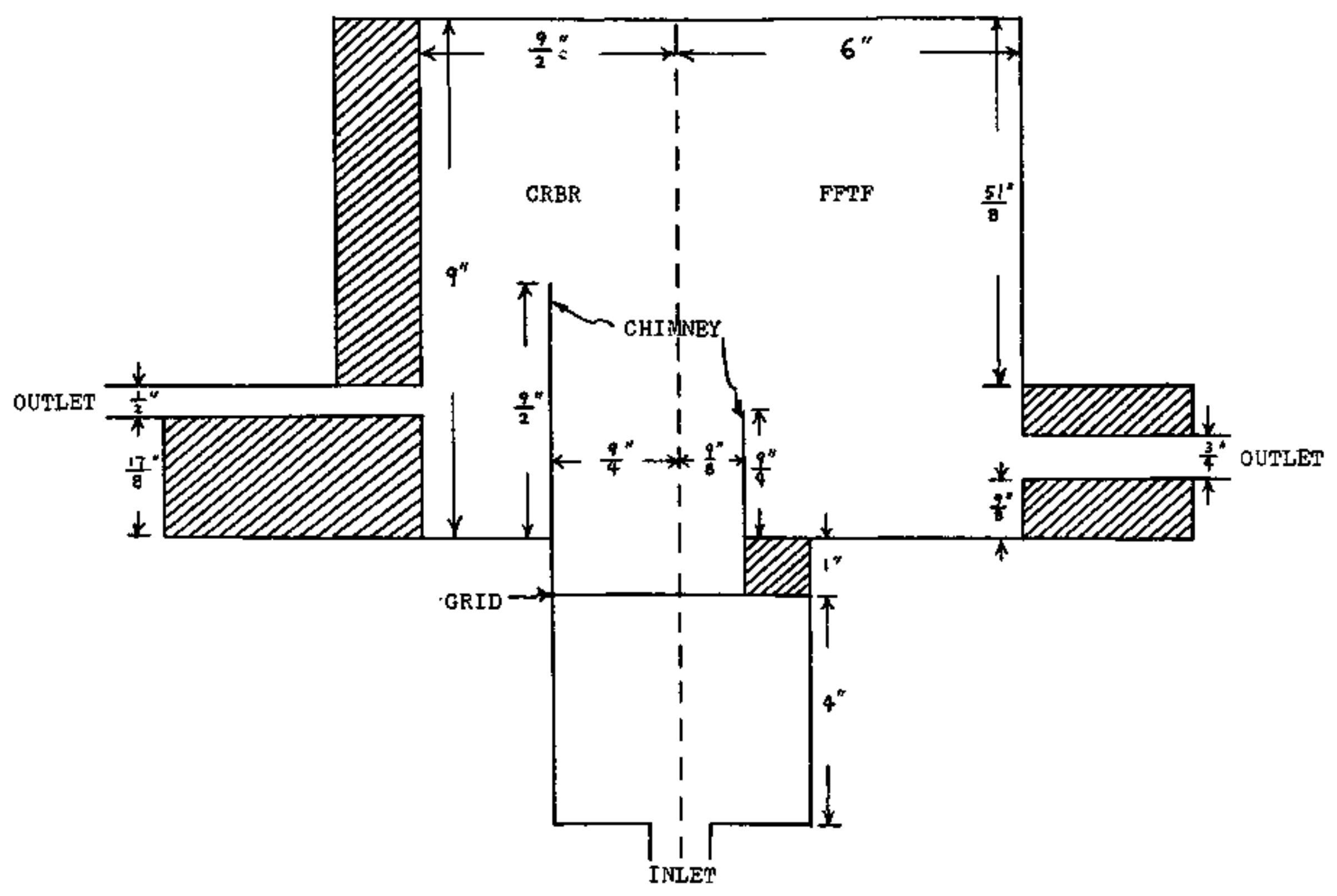

Fig. M.2 Teat Section 


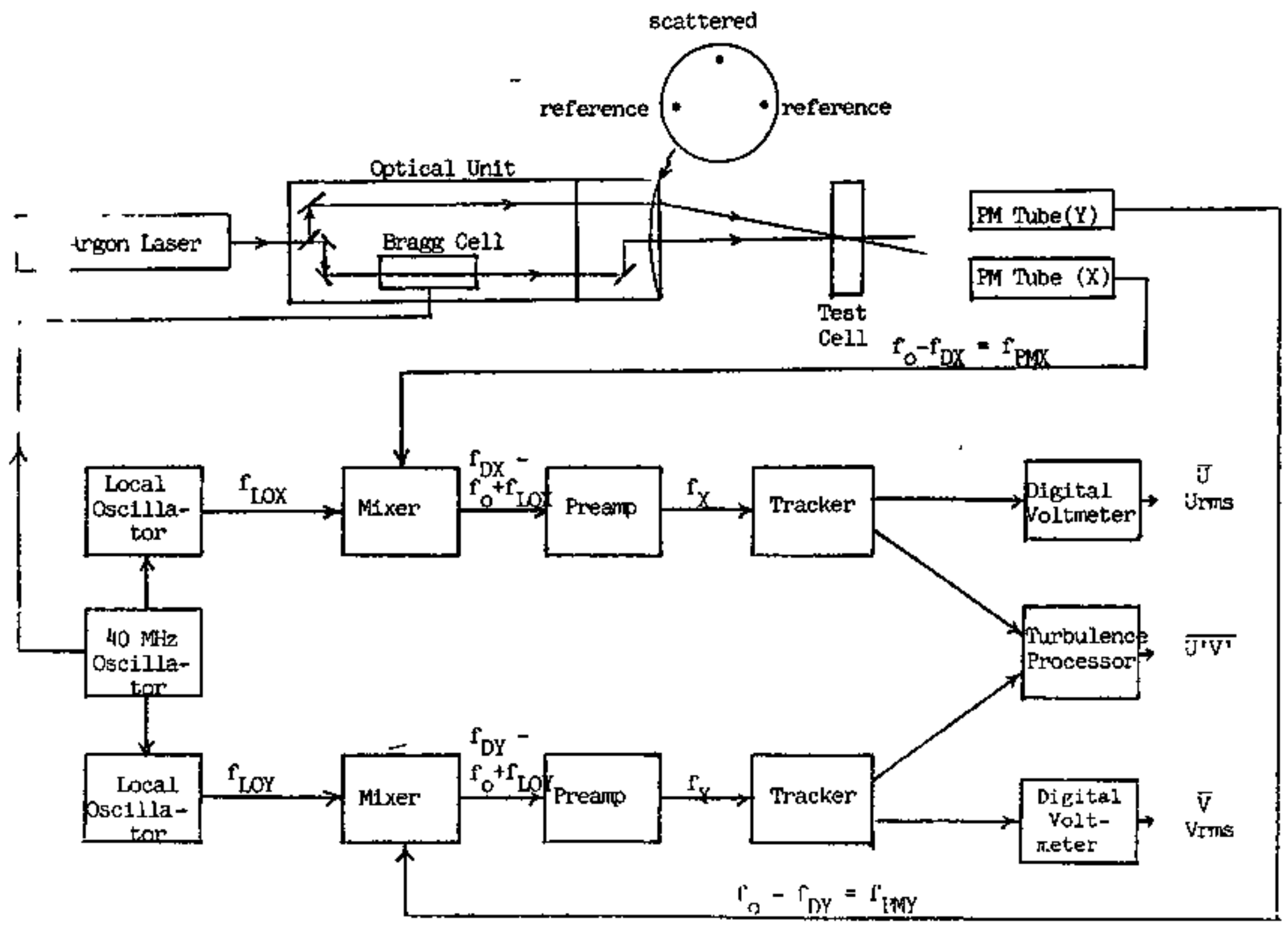


TO

SIGNAT

PROCESSING

SYSTEM

TEST

SECTION

TOM

SUPPIY

$\prod$ OPTICAL UNIT
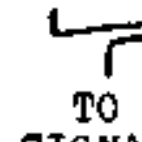

SIGNAL

PROCESSING

SYSTEM

Fig. 4.4 Experimental Setup 


\section{CHAPTER 5 \\ DISCUSSION OF EXPERIMENTAL RESULTS AND COHPUTER CODE PREDICTIONS}

\subsection{Description of Experiments}

Water flow tests were perforwed w1th Cartesian geometry 1/15-Bcale model of FFTF geometry and 3/80-bcale model of CRBR geometry as shown in F1g. 4.2. A summary of tests for which comparisons will be made is given in Table 5.1. The Reyrolds number 1s defined w1th respect to the inlet duct width and inlet flow rate. The normal inlet condition 1mplies that no Inlet blockage arise to reshape the flow distribution. In the distorted case, a partial inlet blockage is used to provide a velocity distribution which has a maximum near the outside edge of the inlet oriflce. The experimental errors are typlcally 3 percent for the mean veloc1ty, 7 percent for the turbulent k1net1c energy, and 20 percent for the Regnolds stress (see Appendix F for error analysis). The data reduction method is included in Appendix E. The reduced data are tabulated in Appendix $G$.

\subsection{Computer Code Calculations}

For the computer preciction, the inlet velocity distribution 1 s provided by the experimental data. Inlet turbulence parameters, such as turbulent k1netic energy, turbulent energy dissipation rąte, and turbulent k1nematic viscosity, efther are matched to the experimental data or are bullt-in values in.the codos. Uniform mesh in both directions is used 
to 1mprove numerical stablitity and accuracy. Due to the mean size and geometry of the test section, the minimum mesh points requ1rements are $18 \times 26$ and $14 \times 20$ for FFTF and CRBR geometry, respectively (see F1Gs,0.1 and G.2). The number of mesh points could be increased to improve the accuracy, but they are limited by computer gtorage capacity and computing time. A typical computation time for FPTF geonetry at IBM $360 / 65$ computer is 20 and 180 minutes for TEACH-T and VARR-II respectively.

\subsection{Comparison of Code Prediations with Experimental Data}

\subsubsection{FFTP Geometry}

The measured and predicted velocity fleld data are shown In F1ge.5.1 through 5.22 for the FFTF geometry. In sach of the veloelty maps the local veloc1tles are normalized to the max1m1m inlet veloc1ty. It 1 s not surprising that all the flgures show the recirculating flow pattern, which is consistent with flow visualization during the experiment in which a torroldal flow pattern 18 observed.

It is seen from the data that both the measured and predicted flow fields depend strongly on the inlet flow conditions, such as the velocity distribution and turbulence parameters.

\section{3 .1 .1 PFTF Geometry, Re=33,000, Normal Inlet Velocity Ristribution cage}

From F1gs, 5.1 to $5.3,1$ t 1 s seen that both codes predict velocity flelds with inlet jets wh1ch persist spatlally with greater momentum than are observed experimentally. 
S1milarly the predicted vortex centers are algnifleantly displaced from the observed vortex location and the precleted mean velocity values neas the wall boundary are greater than those observed experimentally. The predicted shape of the velocity contours near the top wall is also different from experiment. The agreement w1th the experiment of the TEACH-T prediction 1 a generally superior to that of VARR-II prediction. This is thought to be so becauae the fomer calculationg are performed by matching the turbulent kinet1s energy values to those obtained from the experiment. It 18 seen in Fig. 5.4 that the turbulent kinetic enercy prediction by TEACH-T agress reasonably pel1 at most poaltions with experimental values (1.e., within the same order of magnitude) and those predicted by VARR-II are generally lower than the measured values by as much as an order of magnitude, typlcally. From F1g. $5.5,1 \mathrm{t}$ is seen that the Reynolds stress agreement 19 poorer for both codes than 1s that for the turbulent kinetle eneray. Th1s 18 thought to occur because in neither calculation are the Inlet Reynolds streba value matched to the experlmental values. The generally better agreement of the TEACH-T prediction seflectg the value of specifying accurately the lnlet velocity and turbulent kinetic energy, while the VARR-II calculation employs bu1lt-in turbulent kinetic energy and turbulent kinemat1c v1scosity functions.

\subsubsection{PFTF Geometry, Re=70,000 Normal Inlet Velocity Diatribution case}

The measured and predicted velocity and turbulent fleld data are shown in Figs. 5.6 through 5.14 . It 18 seen from Figs. 5.6 through 5.8 that the velocity rield comparison between TEACH-T, VARR-II, and the experiment 1 s reasonably good reflecting the expected improvement in turbulence model predfction at high Reynolds number. As in the case of Rea 33,000 
the calculation tends to predict different shape and higher velocitles of near-wall flows and with the overall vortex shape being diatorted from that obaerved experimentally. In FigB. 5.11 and 5.12 , a ser1es of calculations is presented which is 1dent1cal to the casea of Figa, 5.7 and 5.8 except that the Inlet turbulence parameters are matched with the experimental data. It $1 \mathrm{~s}$ seen that the mean flow fleld predictions are virtually ldentical in all cases. In the TEACK-T case the overall predic-. tions of the turbulent kinetic energy and Reynolds atress flelds are 1mproved by matching the inlet turbulent energy d18sipation rate. In the VARR-II case the mean velocity, turbulent klnetic energy and Reynolds atress field are almost unaffected by matening the inlet turbulence parameters, and the quality of the predietion 1o generaliy poorer than that by TEACH-T. The Inability of both codes to predict the near-wall velocitto is thought to be due to use of an ingufficlent number of mesh point to resolve the Important deta1is of turbulence and the fallure of all the turbulence modela to describe the non-1sotrop1e turbulent flow close to the wall.

It $1 \mathrm{~s}$ seen in F1g. 5.9 that the measured turbulent kinetic energy 1a quite uniform over the ent1re flow fleld except near the inlet jet region. Hence, one expects that the diffusion of the turbulent kinet1e energy to relatively small. Code predict1ons conf1rm this argument. In the later Bensitivity analyo1s (Section 5.4), when we change the value of diffusion coefflclents, the velocity fielda are seen to remain almost unchanged. Th1s also Indicates that the diffueion termis in the transport equm tions are stall compared to other terme. The TEACH-T codo aiso Indicates that convection is 
not a small term compared to generation and dissipation, but the local equilibrium of generation and dissipation is seen to be not a bad assumption for most parts of the flow region.

From the exper1mental data it is also sugsested that the Reynolds stress 1s proportional to the local mean flow speed. Hence, a test 1s made in Section 5.3.1.4 to check the adequacy of this conclusion.

\subsubsection{FFTF Geometry, Fe $=70,000$, D1storted Inzet Velocity D1stribution Cage}

The qualitative dependence of the observed and pred1cted flow fields on the inlet mean velocity distribution is shown In F1gs. 5.15 through 5.17 . In this case the inlet flow rate 1s maintalned at $R e=70,000$; however, a partlal inlet flow blockage 1B used to provide a veloc1ty distribution which has a maximum near the outside edge of the inlet duct. This results in a mean flow map which is qualitatively different from that observed in the previous caseg. The main flow is observed to split into two parts, one of which passes through the center portion of the plenum, and another of which reaches the top wall and forms a rotating secondary flow. Th1s 1 s due to the high shear stress above the inlet oriflce which results in rapid entratnment of inlet fluid in the main plenum slow. The high near-wall velocity causes this secondary flow to move counter-clockw1se as with the main flow.

It 1 a notable that both codes are barely able to predict the qualftative featurea of this flom, and nelther code $1 \mathrm{~B}$ 
successful in describing the experimentaliy observed flow fleld In detail, particulerly in regard to the location and rate of clrculation of the secondary flow vortex. Unfortunately, in thls case, the inlet velocity and turbulent parameters measurements are not detalled enough to calculate the turbulent energy disspation rate and turbulent viscosity. Consequentiy, no exactly matched predictions can be presented here. However, comparison of experimental data and predictions suggests that a lower value for the dissipation rate should apply. Hence, the TEACH-T code is rerun for a new dissipation rate. The resulting velocity fleld is shown in FIs. 5.18 . It is aeen that the predictions of velocity fleld are of somewhat better quality in terms of magnitude but the second vortex disappears. Th1s $1 \mathrm{~s}$ due to the low inlet dissipation rate which causes the inlet jet to persist with greater momentum than in the previous case. In the later sensitivity analysis, an effort is made to adjugt the inlet turbulence parameters, and to use the best set of empirical constants, but all the predictions are unable to reproduce the experimental reaults.

As with the previous cases, the diffusion of turbulent kinetic energy is small, Reymolds atress is proportional to the local veloc1ty, and the TEACH-T prediction of the turbulence parameters is much more successful than that of VARR-II.

The 1mportance of this case $110 \mathrm{~s}$ in the fact that the qualitative nature of the mean flow fleld 1s strongly dependent not only upon the inlet mean velocity fleld but also the inlet turbulence parameters. 


\section{3 .1 .4 Zoro-Equation Model}

In a separate calculation, a simple Reynolds stress relationship $\overline{U^{\prime} V^{\prime}}=\mathrm{c}|\underline{u}|^{2}$ rather than a two-equation model 18 used In TEACH-T, where $C$ is the average value of proportional constants between Reynolds stress and square of mean flow speed in the measured flow fleld. The resuiting velocity maps are ahown In F1gs. 5.21 and 5.22 for normal and distorted inlet velocity distribution respectively. It is seen that the slmple model ylelds results which are approximately equivalent In quality to those obtained from two-equation models (see F1gs. 5.11 and 5.16) except the overest1mation of near-wall velocities. The results are weakly sensitive to the value of c. This 1ndicates that the turbulence model used to describe the turbulent momentum transfers with1n the flow may be less important than an accurate knowledge of the detafled inlet mean flow fleld.

\section{3 .2 CRBR Geometry}

Data similar to those obtalned in the 1/15-scale FrTF test cell have also been obtained ror steady state water flows In a 3/80-scale CRBR outlet plenum geometry. In th1s geometry, the inlet orifice 18 much wider and the chimney penetrates much deeper 1nto the plenum than in the FFTF case, so that relative to the lnlet duct the outlet plenum is much shorter and naprower than in the FFTF case. Because of the wider inlet orifice, the maximum attainable Reynolds number decreases to 35,000. As w1th FPTF geonetry, normal and distorted inlet s.... 
mean velocity digtributions were invegtigated. Due to uncertalntieg in the accuracy of the measured data, the diatorted mean flow diatribution case $1 \mathrm{~s}$ removed from this section and 1s Included in Appendix $\mathrm{H}$. The striking feature of the distorted inlet flow diatribution case 18 that both codes are unable to predict the mean flow anywhere qualitatively.

5.3.2.2 CRBR Geometry, Re*35,000, Normal Inlet Veloc1ty DIstrioutron case

The meatured and predfcted velocity flelds are anown In F1gls. 5.23 through 5.25. Because of the shorter distance between the inlet orifice and the top wall, the inlet jet moves perpend1cularly upward and turns only in the vicinlty of the wall, while in the FFTF case the mean flow $1 \mathrm{~s}$ able to follow atreamlines very nicely from the entrance to the exit in a fashion as would be predicted by intuition.

This greater mean flow chaos 18 seen in the comparison of the measured flow field to the TEACH-T and VARR-II predictions. It 1o seen in the lower half of the plenum that the measurements and code predictions agree reasonably well. While in the upper half of the plenum, both codes do not have good agreement with the measurement.

Due to the large discrepancy in the prediction of the mean flow fleld with the normal inlet flow distribution, TEACH-T is rerun with the mesh size reduced by half. The resulting velocity diatribution is shown in F1g. 5.28 . Comparing to F1g. 5.24 , 1 t is concluded that reducing the mesh size does not Improve the quality of the result. 
It is seen from F1g. 5.26 that the turbulent kinet is energy increases very raplaly as inlet get approaches the top wall. Th1s region 18 character1zed by conversion of mean flow kinetic energy into stagnation pressure, and turbulent kinetic energy at a rate exceeding that of disaipation. It would be expected that the pressure and velocity correlation would be large in this regton and would have a complicated spatial variation, although a measurement of this quantity is unavallable. These phenomena result in complex turbulence transport processes. In addition, because of mare tortuous flow path in the CRBF geometry, the number of significant length-scale determining the nature of the flow in any region of the plenum would be greater than in the FFTF case; the magnitude and complextity of each term in the turbulent transport equations would be increased greatly as well as the degree of departure from turbulent 1sotropy. The net result is that the closure assumptions for the turbulence models examined here are too simple to describe adequately the complicated nature of the CRBR flow fleld.

Several investigators used either a 1 umped parameter approach $(15,16)$ (1:e., the outlet plenum is divided into several characteristic resions), or zero-equation models(17) to study the trangient thermal behavior in the outlet plenutn. They all have found that the predictlons for the CRBR geonetry are of poorer quality than those of the FFTF geometry. This also confirms that flows in the CRBR geometry are too compllcated for avaliable modele to treat with reasonable sccuracy. 


\subsection{Sensitivity Study}

Due to the unatisfactory results predicted by both the TEACH-T and VARR-II models, a censitivity study of the emplrical constants was judged to be the next step to 1mprove the results of the computer code prodictions. For convenlence, the turbulence transport equations for both codes are reported here:

TEACH-T:

$$
\begin{aligned}
& \frac{\partial K}{\partial t}+U_{K} \frac{\partial K}{\partial \bar{X}_{K}}=\frac{\partial}{\partial X_{K}}\left(\frac{v_{t}}{\sigma_{K}} \frac{\partial}{\partial X_{K}} K\right)+v_{t}\left(\frac{\partial U_{1}}{\partial X_{J}}+\frac{\partial U_{1}}{\partial X_{1}}\right)^{2}+\varepsilon \\
& \frac{\partial E}{\partial t}+U_{K} \frac{\partial E}{\partial X_{K}}-\frac{\partial}{\partial X_{K}}\left(\frac{v_{t}}{\sigma_{E}} \frac{\partial}{\partial X_{K}} \varepsilon\right)+\frac{C_{1} v_{t} \varepsilon}{K}\left(\frac{\partial U_{1}}{\partial X_{K}}+\frac{\partial U_{K}}{\partial X_{1}}\right) \frac{\partial U_{1}}{\partial X_{K}} \\
&-c_{2}\left(\frac{\varepsilon^{2}}{K}\right)
\end{aligned}
$$

where $v_{t}=c_{\mu} K^{2} / \varepsilon$ and $c_{u}, c_{1}, c_{2}, \sigma_{K}, \sigma_{\varepsilon}$ are model constants ,

VARR-II:

$$
\begin{aligned}
& \frac{\partial q}{\partial t}+U_{X} \frac{\partial q}{\partial x_{K}}=\frac{g}{2}\left(\frac{\partial U_{1}}{\partial x_{K}}+\frac{\partial U_{K}}{\partial x_{1}}\right)^{2}+\frac{\partial}{\partial x_{K}} r \sigma \frac{\partial q}{\partial x_{K}}-\alpha \frac{(2 \sigma)^{2}}{\sigma} \\
& \frac{\partial \sigma}{\partial t}+v_{K} \frac{\partial \sigma}{\partial X_{K}}=\frac{\sigma^{2}}{4 q}\left(\frac{\partial \sigma_{1}}{\partial X_{K}}+\frac{\partial v_{K}}{\partial x_{1}}\right)^{2}+\frac{\sigma}{q} \frac{\partial}{\partial X_{K}} r \sigma \frac{\partial q}{\partial X_{K}} \\
& -\frac{\sigma^{3}}{q^{2}} \frac{\partial}{\partial X_{K}} r_{1} q \frac{\partial}{\partial X_{K}}\left(\frac{q}{\sigma}\right)-4 \alpha_{1} q
\end{aligned}
$$

where $\Gamma, \Gamma_{2}, \alpha$, and $a_{2}$ are model constants. 
Since the runing time for VARR-II is extremely long, sens1t1vity analyged have been concentrated on the TEACH-T model. From the comparison of two palrs of transport equations, it 1s seen that some of the parameters in the TEACH-T model apply also to VARR-II model.

The TEACH-T model has five free parameters in the transport equations for $K$ and $E$. It was decided to change each at a time in order to examine the changes in computed results espectally in the mean velocity and turbulent kinetic energy t1elds.

\subsubsection{Gape of FFTF Geometry w1th Normal Inlet Velocity D1stribution}

A FFTF test run with normal inlet velocity distribution and a Reynolds number of 70000 was selected as a starting case. A complete 11st of the range of varlables examined in the sensitivity study is shown in Table 5.2 .

As discussod before, the diffusion terms are expected to make a small contribution to the turbulence transport processes. It $1 \mathrm{~s}$ seen from Table 5.2 that the velocity fleld is indeed Insensitive to the change or diffusion parameters $\sigma_{K}$ and $\sigma_{E}$, although the turbulent kinetic energy field does change s1gniflcantly ac these parameters change. Increasing the value of $C_{\mu}$ wh1ch resulta in an 1ncrease of turbulent viscosity or momentum exchange is seen to 1mprove the predicted and measured velocity fleld agreement, but the turbulent klnet1c energy is also 1ncreased relative to the experimental results. Hence a second energy dissipation parameter, $C_{2}$, 18 decreased to 
Increase the turbulent kinetic energy disipation rate and move the turbulent kinetic energy back to the or glanl value w1thout changing too much the magnitude of the velocity fleld. From many tests, the best values of thete parameters are found to be $c_{\mu}=0.25$ and $c_{2}=0.16$, where all the other varlables are unchaged. The predicted velocity dfstribution and turbulent kinetic energy distribution are shown in Figg. 5.29 and 5. 30. As is seen from these P1gures, the quality of the pred1ctions is improved by these changes. The data of Appendix I shows the calculated velocity and turbulent kinetic energy flelds for the cases examined.

5.4 .2 Case of PFTF Geometry with-D1Btorted Inlet. Veloc1ty D1stribution

The next step 1s to apply this new set of paraneters to the case of FFTF geometry with distorted inlet velocity distribution. Because of complicated turbulent transport phenomena we are unable to reproduce the experimentally-observed double vortex velocity distribution, although the quality of the turbulent kinetic energy distribution prediction 15 improved.

Due to the resource limitations, no CRBR and VARR-II cases have been tested. But for the VARR-II model, by comparing and manipulating the transport equations, the turbulence equation parameters are found to be related to corresponding turbulence parameters in the TEACH-T model as follows: $T=$ $1 / \alpha_{K}, a=c_{\mu} / 4$, and $a_{1}=c_{\mu}\left(2-c_{2}\right) / 4$. The 1mproved values of these perameters are $r=1.0, a=0.00625$, and $\alpha_{1}=0.025$ wh1 ch are different from the values recommended by the authors of 
the model: $r=1.5, a=0.045, a_{1}=0.01125$.

\subsection{Summary}

It is round that the qualitative nature of the flow field within the plenum depends strongly upon the distribution of mean inlet velocity fleld, upon the values of the inlet turbulence parameterg, and upon the turbulence momentum exchange model used in the calculations. It is found in the FFTF geometry that the TEACH-T predictions are better than that of VARR-II, and in the CRBR geometry nelther codes provides a good prediction of the observed behavior.

From the densitivity analysis, it is found that the production and dissipation of turbulence are the dominant terms in the transport equations for turbulent kinetic energy and turbulent energy diselpation rate, and the diffusion terms are relatively small. A new set of emplrical contants is evolved from the atudy for the prediction of plenum fiows.

\subsection{Explanation of D1screpancles}

Since this is probably the first attempt to compare the turbulence model codes prediction with large scale reclrculating flow experimental data, some discrepancles are expected. Efforts are made to outline the posslble reasons why the twoequation turbulence models fall to glve good predictions in terts of elther comparison of predictions and experiments, or of other simllar types of flows. Among the 1mportant reagons for these discrepancles are the following: 
1. The present closure does not take account of the Intermittent nature of the turbulence (1.e., In some regions the rlows can alternate in time between being laminar or turbulent) whlch independent measurement (18) shows to be present in the outer edge segions of the jet. A similar jet is found in the plenum wh1ch could exhlbit the same behavior although the measurement is beyond our capability. The averaging of the equation of motion, which is an esential part of the present approach, tends to smooth out this time dependence. The validity of the concepts of turbulent kinetic energy and Reynolds stress is questionable when a flow field is alternat1ng between laminar and turbulent since the stat1stical ensemble in terms of which these parameters are defined 1o not unique. Hence, 1t is possible that th1s intermittency effect w1ll introduce some d1sagreements between predictions and measurements.

2. Due to the small velocity in the central region of the recirculating flow, it is possible that relaminar1zation could occur in th1s region. Hence, the accuracy of the turbulence transport equations to describe the momentum transport in thia region is questionable. 
3. In the present models, the closure assumption 1mplles that a single length scale will suffice to represent motion of all the edales with different sizes and shapes. From Chapter 3, the appropriate length scales are seen to be $\mathrm{K}^{3 / 2} / \varepsilon$ and $\sigma / \mathrm{K}^{1 / 2}$ for TEACH-T and VARR-II, respectively. Yet in recirculating flows the dimensions of turbulent eddies are much different in different drections and the1s ahapes w1ll alter appreclably during their ilfetime. A multi-length scale closure in turbulence modeling is necessary to describe adequately this process.

4. In the calculated prediction, two dimensional flows are assumed to ex1st. But the flows in the test section are actualiy three-dimensional. Although the transverse boundary layer is calculated to be small, the presence of the walls tends to change the flow pattern and turbulent energy transport processes. Hence, some disagreements are expected to ardge from this source.

5. In the CRBR case, the resion close to the top wal1 1s characterlzed by conversion of momentum and turbujent kinetic energy into stagnation pressure. Consequently, the veloctty and pressure correlation $\overline{\mathrm{U}^{\prime} \mathrm{P}^{\prime}}$ would be expected to be large and 
the diffusion of turbulent kinetlc energy would also be signiflcant. The experimental results Indicate the exigtence of large gradients of turbilent kinet1c energy in that region wh1ch conflrms this argument. But the parameter $\overline{\mathrm{DT}}$ is generally not avallable for measurement and hence, the modeling of this term is difflcult and inadequate. So whenever the $\overline{\mathrm{U}}$ 'P value 18 signiflcant, the accuracy of the prediction 18 expected to be questionable.

6. As flow moves cloge to the wall, the degree of departure from 1sotropy increases. The present models are Inadequate to describe turbulent transport phenomena in the near-wall region because the Ilow there is much more complicated than in the far rleld. The lasge disagreement of mean flow and turbalence parameters rield supports this rinding. Hence, the highly anlsotrople flow near a solld wall is not described adequately by a two-equation model. 
Table 5.1 L1st of Test Funs

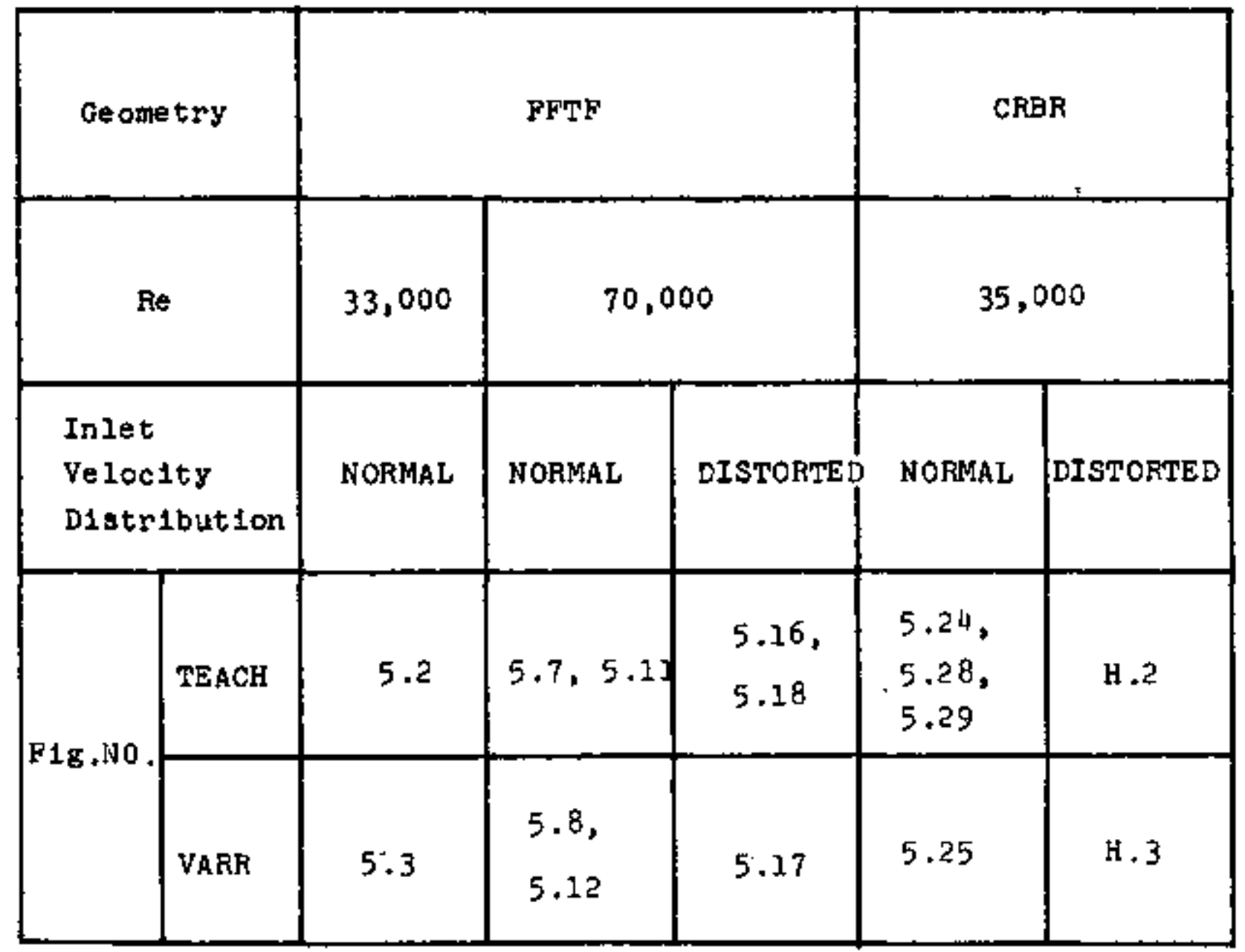


Table 5.2 List of Test Cages in Sensitivity Analysis

\begin{tabular}{|c|c|c|c|c|c|c|c|}
\hline & $\mathrm{C}_{\mu}$ & $\sigma_{\mathrm{X}}$ & $\sigma_{E}$ & $c_{1}$ & $c_{2}$ & Velocity & $\begin{array}{l}\text { Turbulent } \\
\text { Kinet1e Energ }\end{array}$ \\
\hline OFIGINAL & 0.09 & 1.0 & 1.3 & 2.44 & 1.92 & $\mathrm{~N} / \mathrm{A}$ & $\mathrm{N} / \mathrm{A}$ \\
\hline \multirow{3}{*}{$\begin{array}{l}\text { TEST } \\
\text { CASE }\end{array}$} & 0.18 & \multirow{3}{*}{1.0} & \multirow{3}{*}{1.3} & \multirow{3}{*}{1.44} & \multirow{3}{*}{1.92} & D-Moderate & I-Moderate \\
\hline & 0.27 & & & & & D-Moderate & I-Moderate \\
\hline & 0.90 & & & & & D-Moderate & I-Moderate \\
\hline \multirow{3}{*}{$\begin{array}{l}\text { TEST } \\
\text { CASE }\end{array}$} & \multirow{3}{*}{0.09} & 0.5 & \multirow{3}{*}{1.3} & \multirow{3}{*}{1.44} & \multirow{3}{*}{1.92} & No & D-sma 11 \\
\hline & & 0.1 & & & & I-Small & D-Moderate \\
\hline & & 1.5 & & & & No & $1-\operatorname{sinall}$ \\
\hline \multirow{3}{*}{$\begin{array}{l}\text { TEST } \\
\text { CASE }\end{array}$} & \multirow{3}{*}{0.09} & \multirow{3}{*}{1.0} & 0.65 & \multirow{3}{*}{1.44} & \multirow{3}{*}{1.92} & No & D-Moderate \\
\hline & & & 2.60 & & & D-small & I-Moderate \\
\hline & & & 3.90 & & & D-Small & I-Moderate \\
\hline \multirow{3}{*}{$\begin{array}{l}\text { TEST } \\
\text { CASE }\end{array}$} & \multirow{3}{*}{0.09} & \multirow{3}{*}{1.0} & \multirow{3}{*}{1.3} & 2.88 & \multirow{3}{*}{1.92} & I-Moderate & D-Large \\
\hline & & & & 4.32 & & I-Moderate & D-Large \\
\hline & & & & 0.72 & & $\begin{array}{l}\text { Difrerent } \\
\text { Dlow Pattern }\end{array}$ & I-Large \\
\hline \multirow{3}{*}{$\begin{array}{l}\text { TEST } \\
\text { CASE }\end{array}$} & \multirow{3}{*}{0.09} & \multirow{3}{*}{3.0} & \multirow{3}{*}{1.3} & \multirow{3}{*}{1.44} & 0.96 & I-Moderate & D-Large \\
\hline & & & & & 0.64 & I-Moderate & D-Large \\
\hline & & & & & 3.84 & $\begin{array}{l}\text { Difierent } \\
\text { Flow Pattem }\end{array}$ & I-Large \\
\hline $\begin{array}{l}\text { FINAL } \\
\text { RESULT }\end{array}$ & 0.25 & 1.0 & 1.3 & 1.44 & 1.60 & $\mathrm{~N} / \mathrm{A}$ & $\mathrm{N} / \mathrm{A}$ \\
\hline
\end{tabular}

Note: D or I means that prediction 1s decreased or increaged relative to prediction by oribinal set of free parameters 


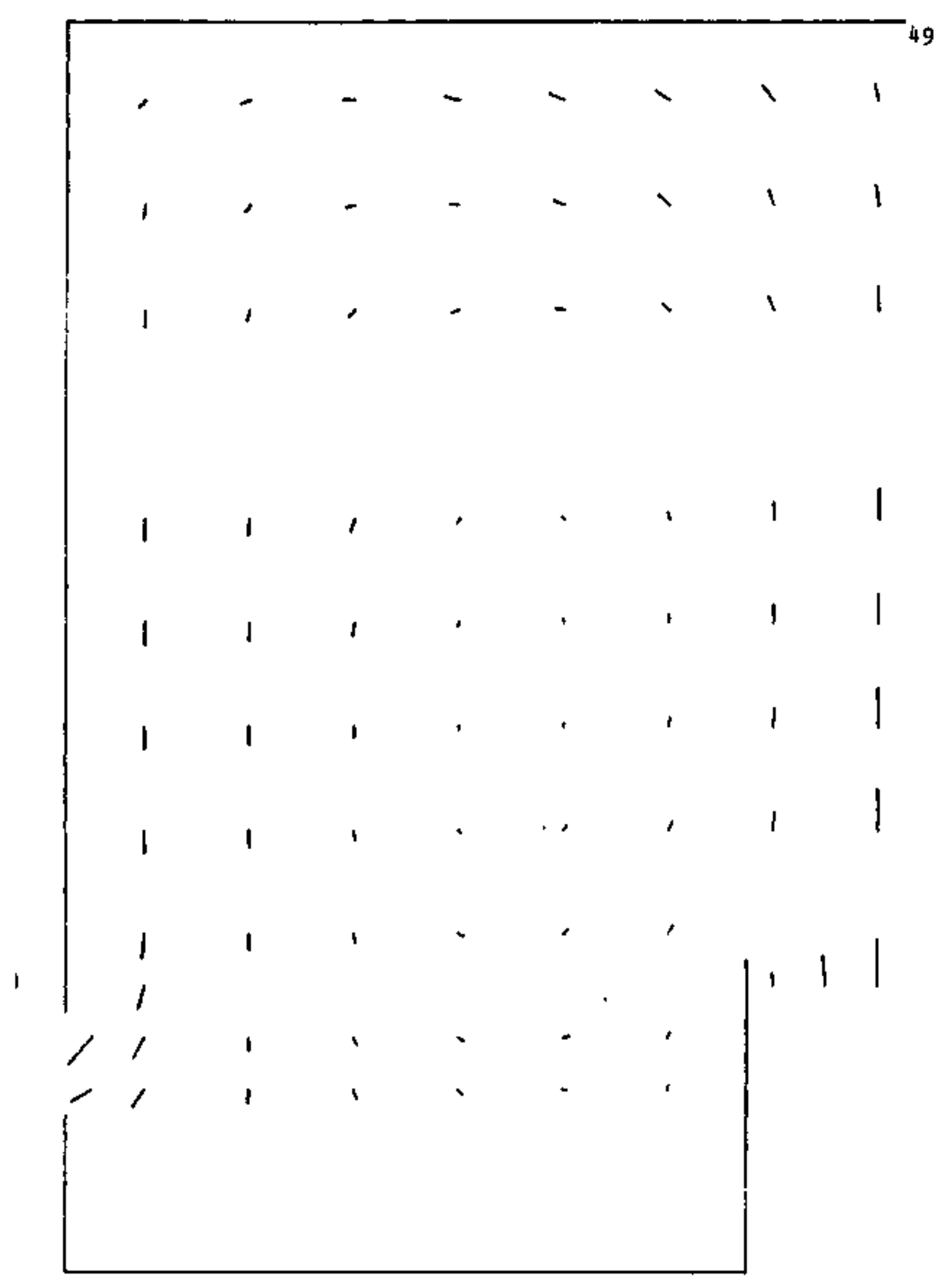

FIg. 5.1 Measured Mean Flow Field, FFTP Geometry, Re =33000, Normal Inlet Velocity Distribution 


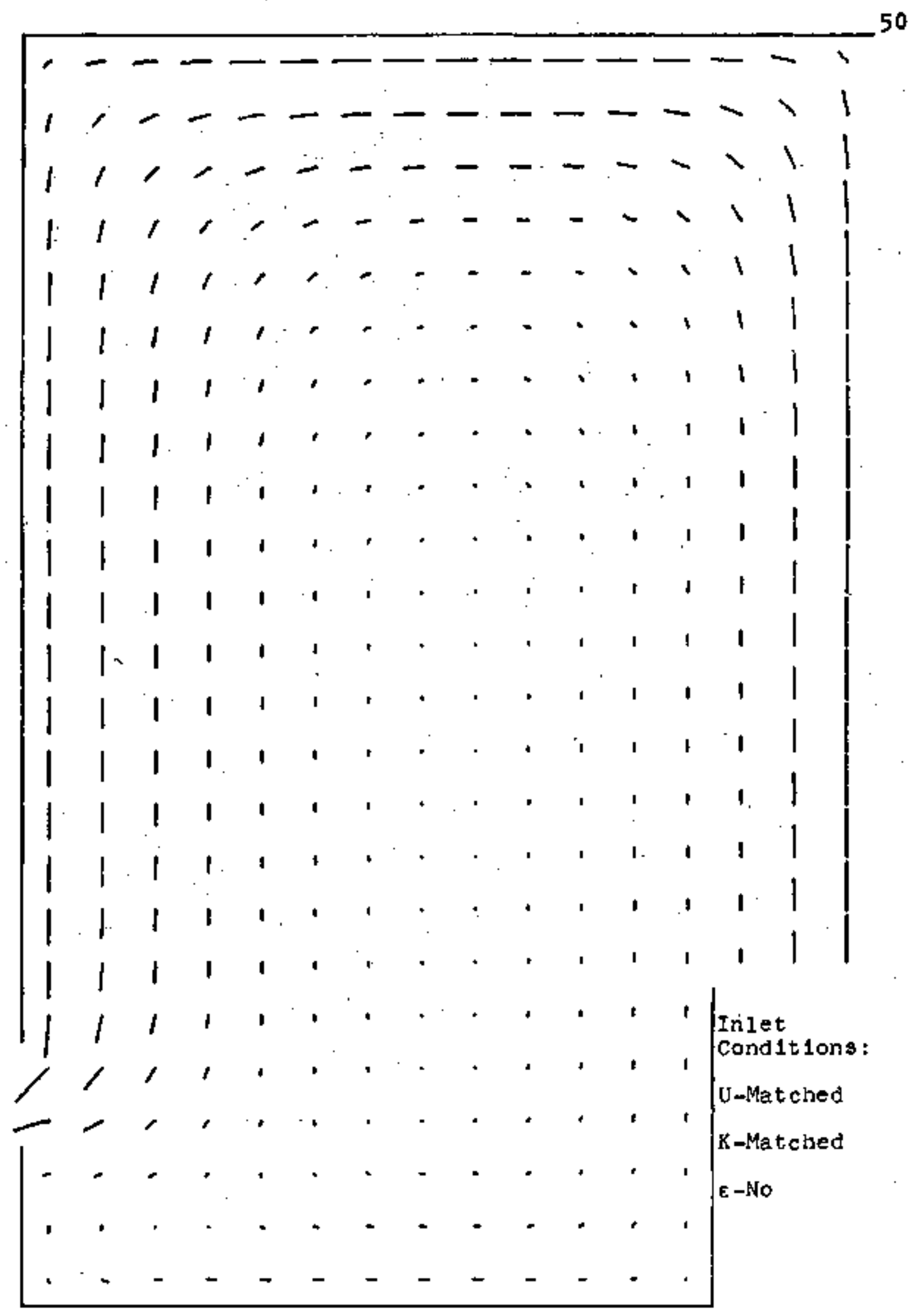
F1g. 5.2 TEACH-T Pred1ction, PFTF Geometry, Re*33000,
Normal Inlet Velocity D1stribution 


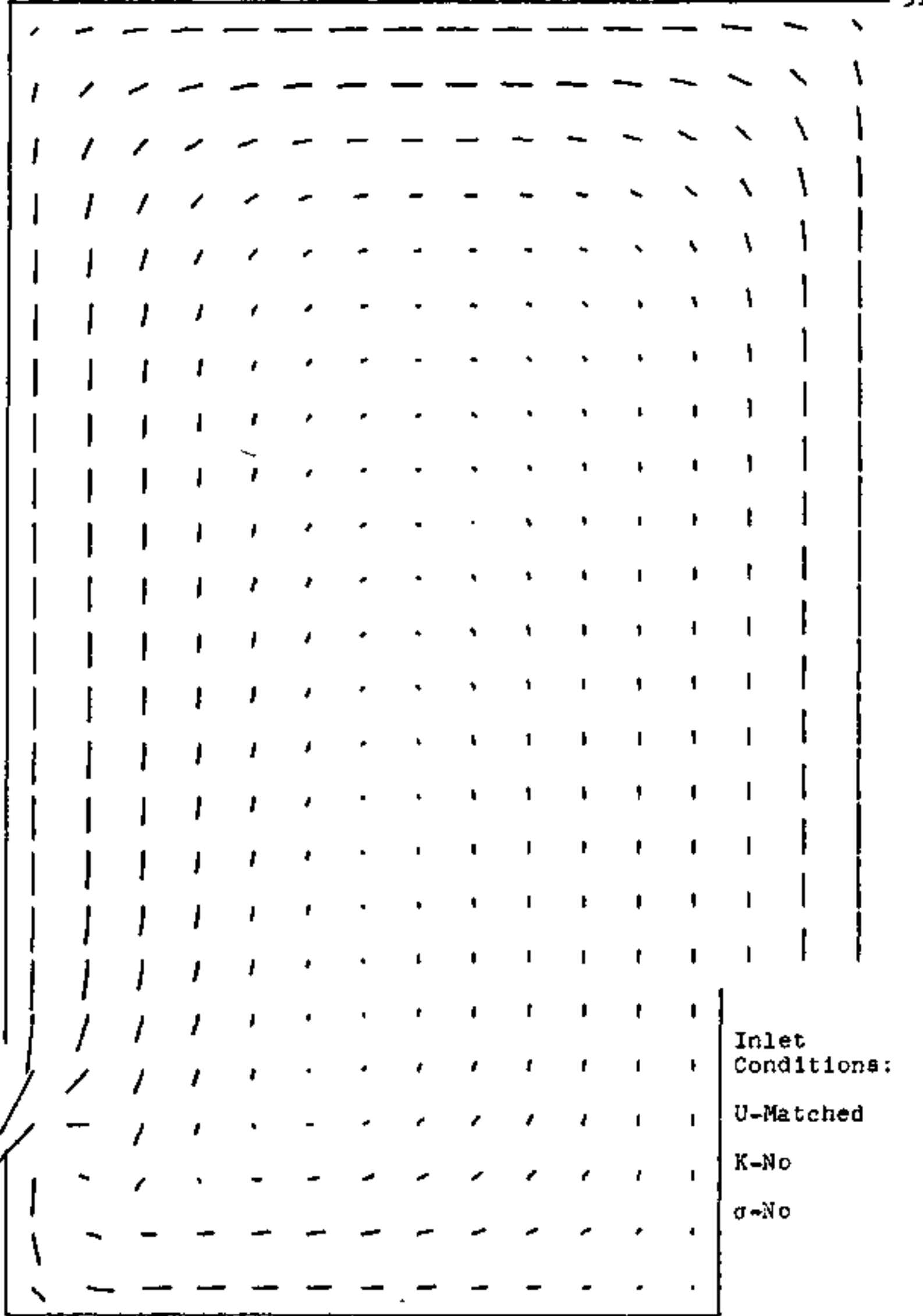

F1B. 5.3 VARR-II Prediction, FFTF Geometry, Re=33000, Normal Inlet Velocity D1stribution 


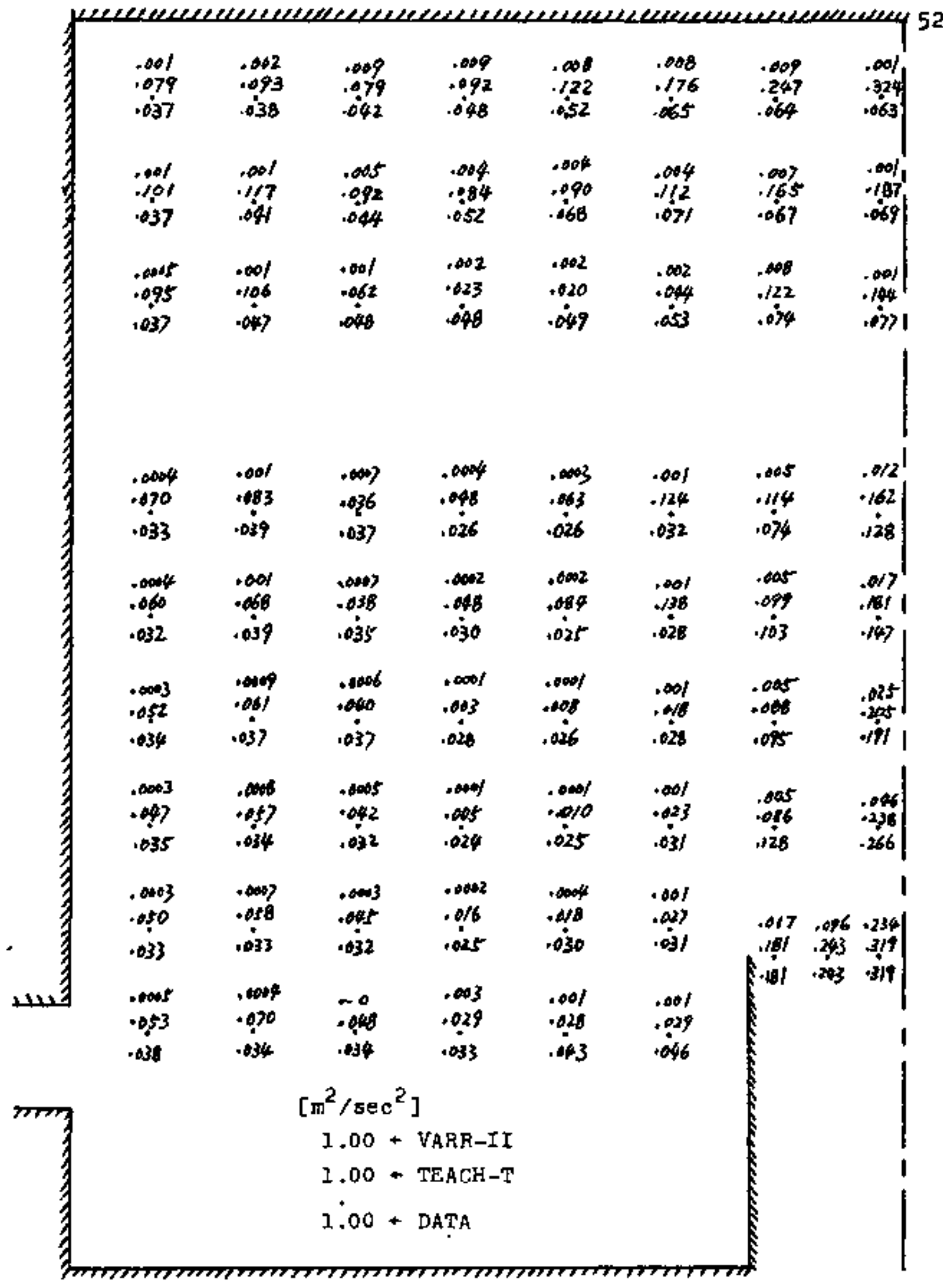

F1G. 5.4 Compared Calculated and Measured Turbulence KInet1c Energy Flelds, FFTF Geometry, Re $=33000$, kormal Inlet Velocity Distribution 


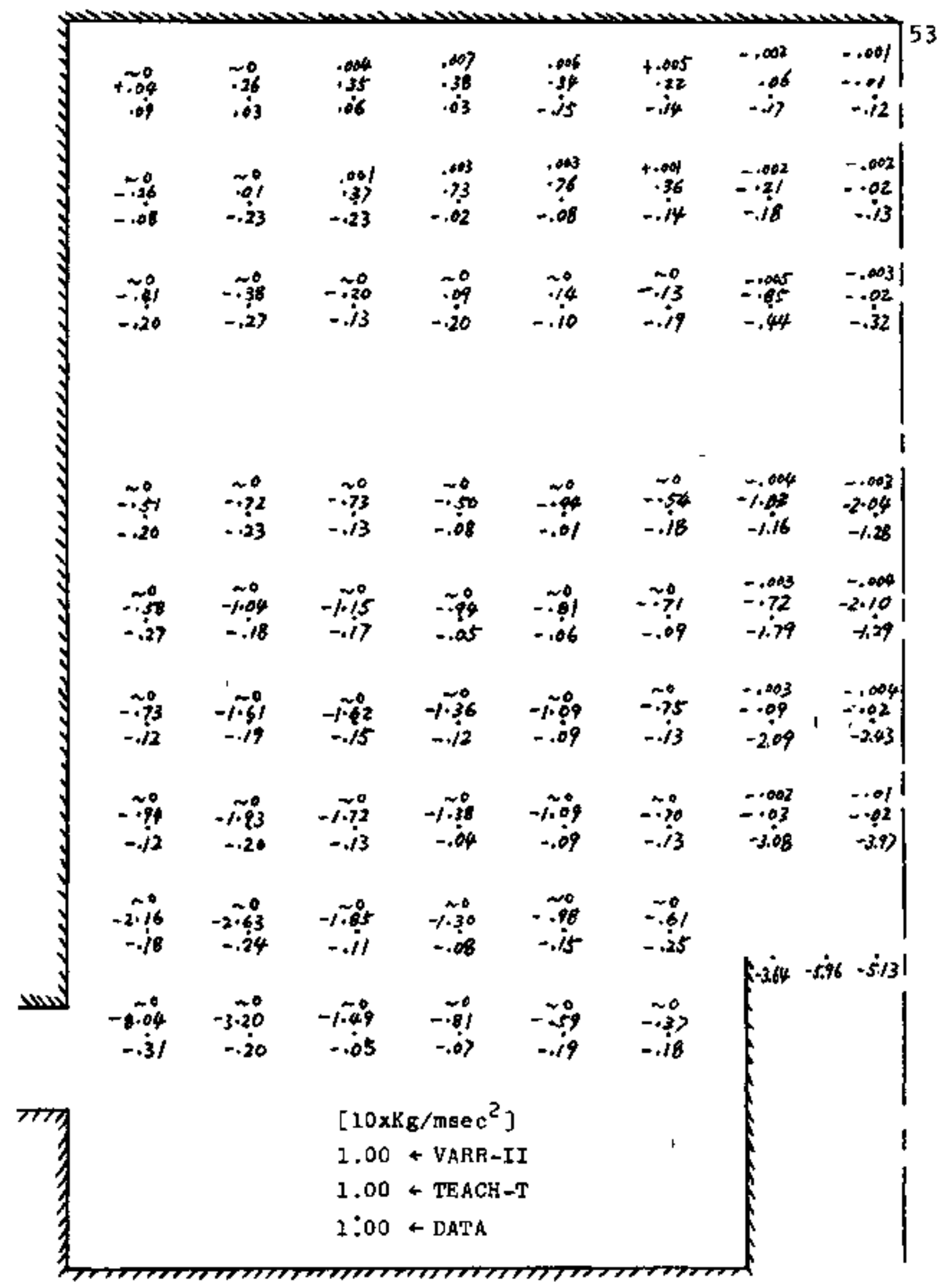

F1g. 5.5 Compared Calculated and Measured Reynolds Stress Flelds, FFTF Geometry, Re 30000 , Normal Inlet Veloc1ty Distribution 


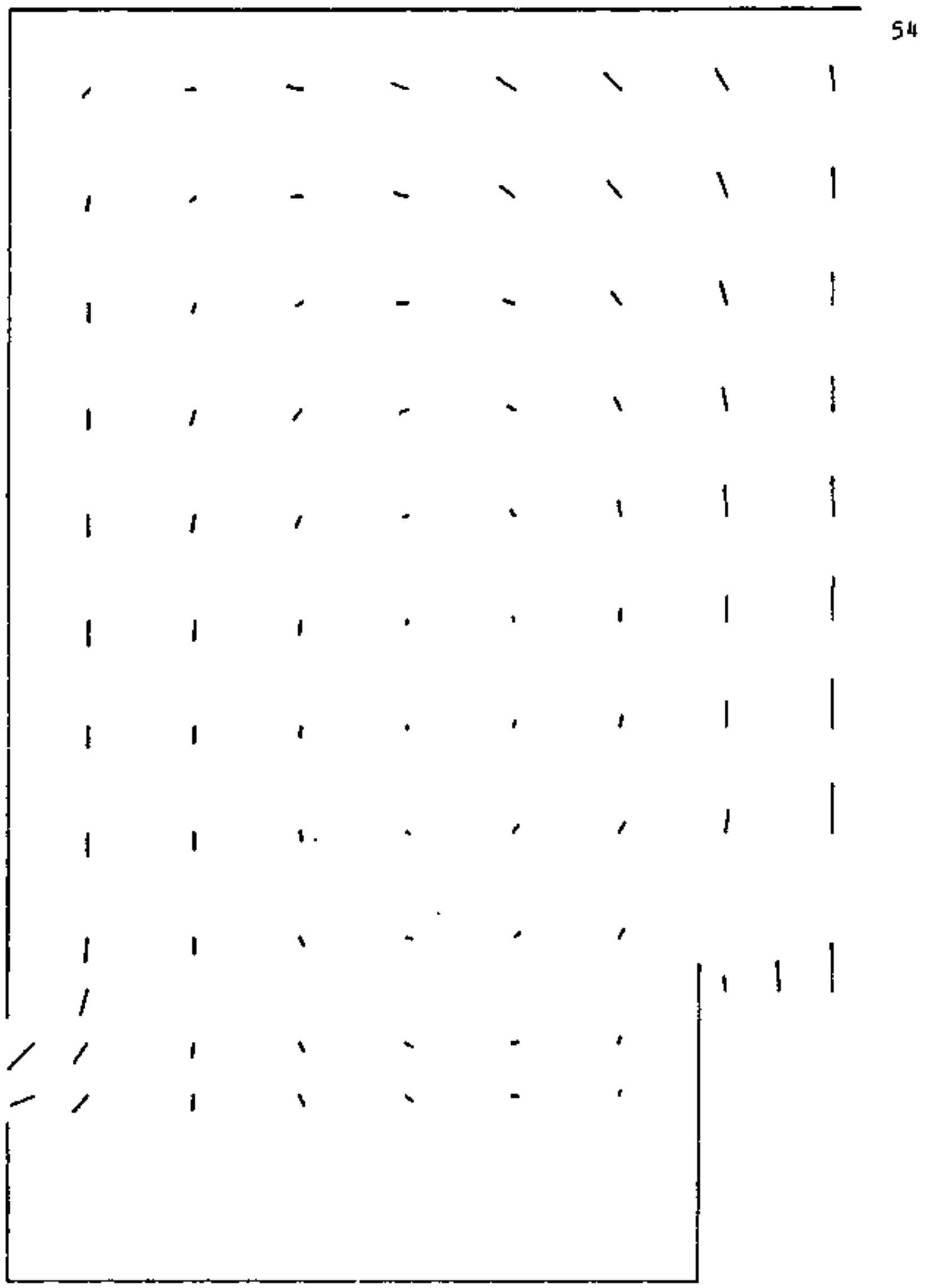

Fig. 5.6 Measured Mean Plow Fleld, FFTF Geometry, Re=70000, Nortal Inlet Velocity Distribution 


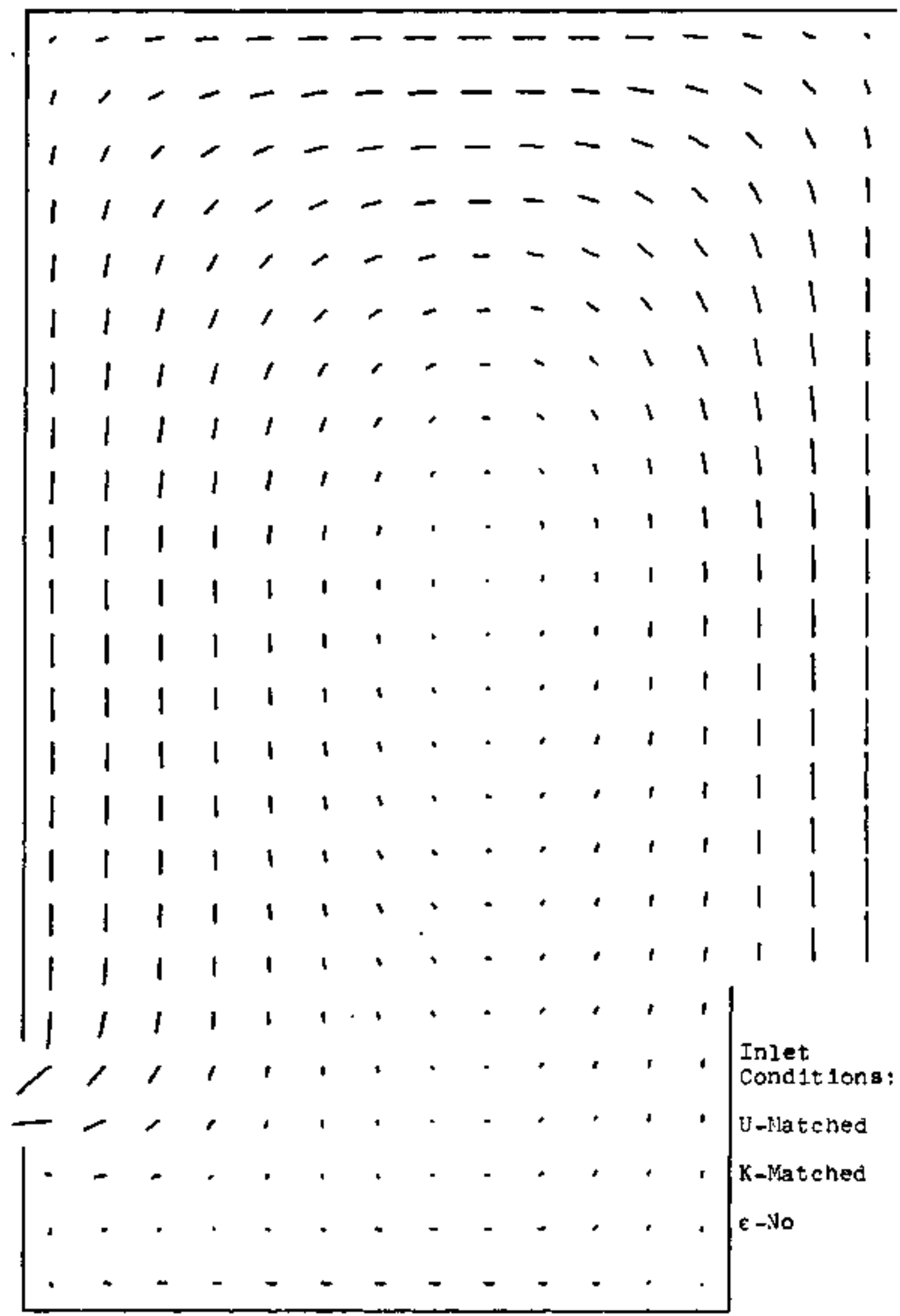

F1g. 5.7 TEACH-T Prediction, FFTF Geometry, Re=70000, Normal Inlet Velocity D1stribution 


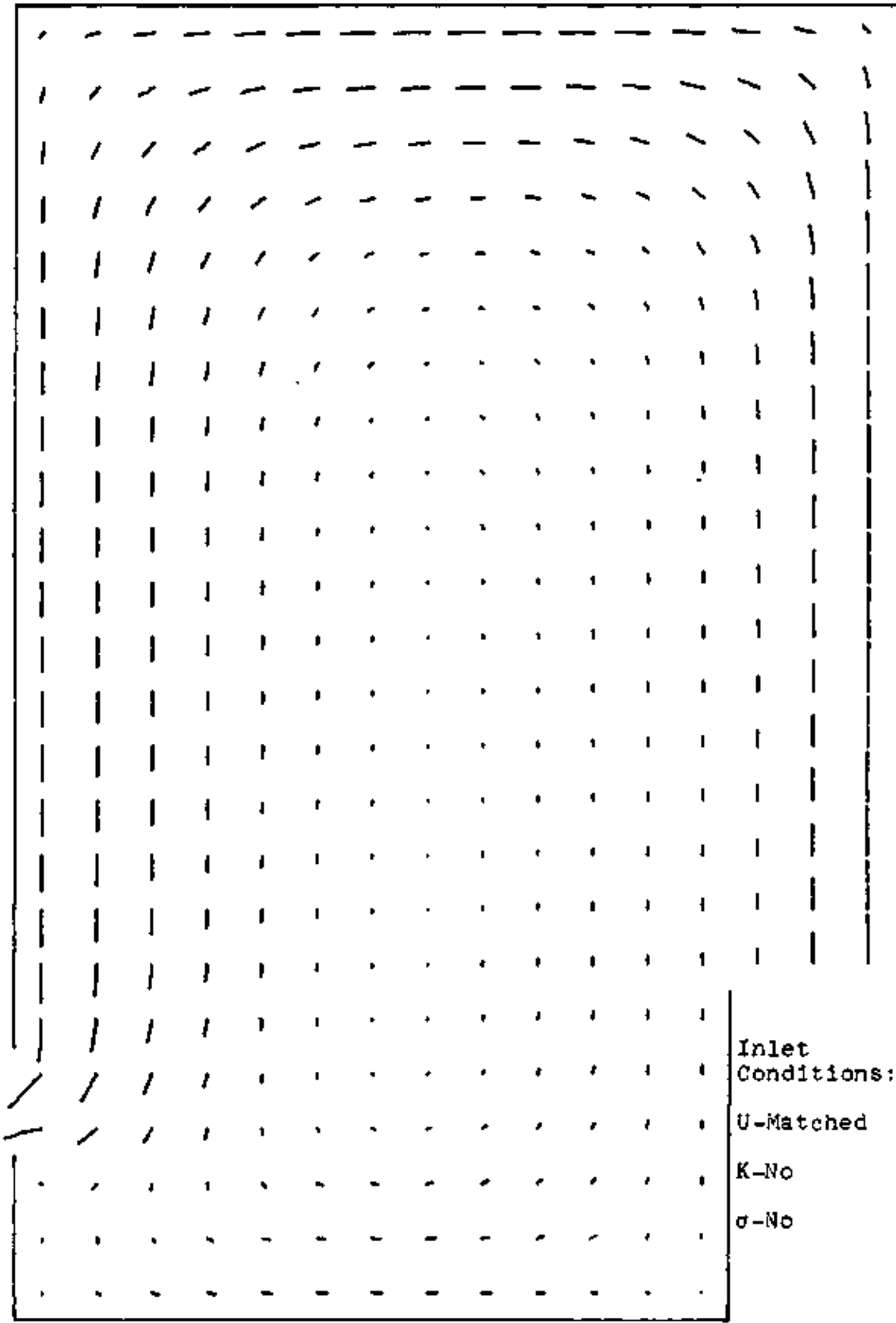

F1g. 5.8 VARR-II. Prediction, FFTF Geometry, Re-70000, Normal Inlet Velocity D1stribution 


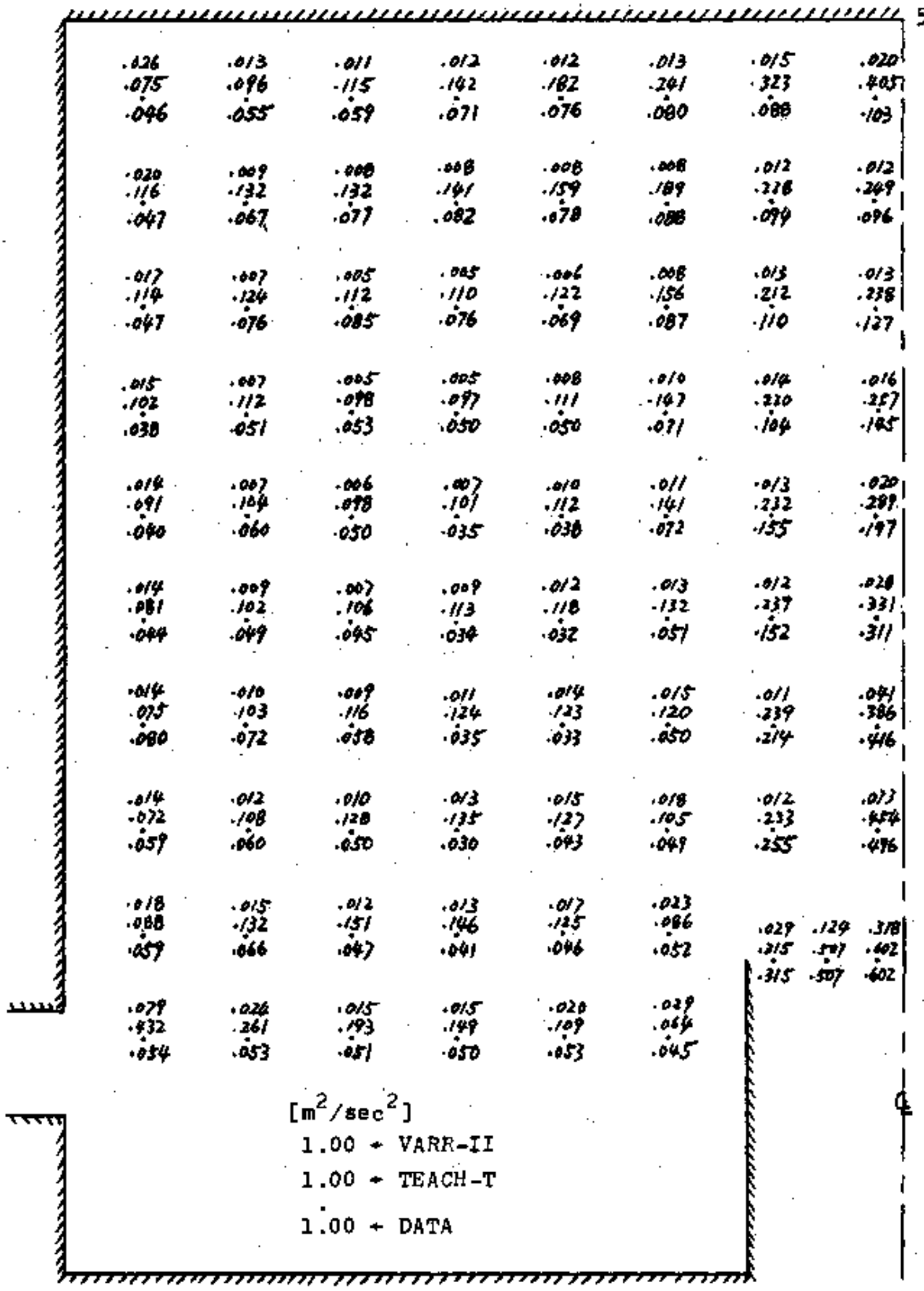

F1 5.9 Compared Calculated and Measured Turbulent Kinetic Energy Fie2ds, FFTF Geometry, Re=70000, Normal Inlet velocity Distribution 


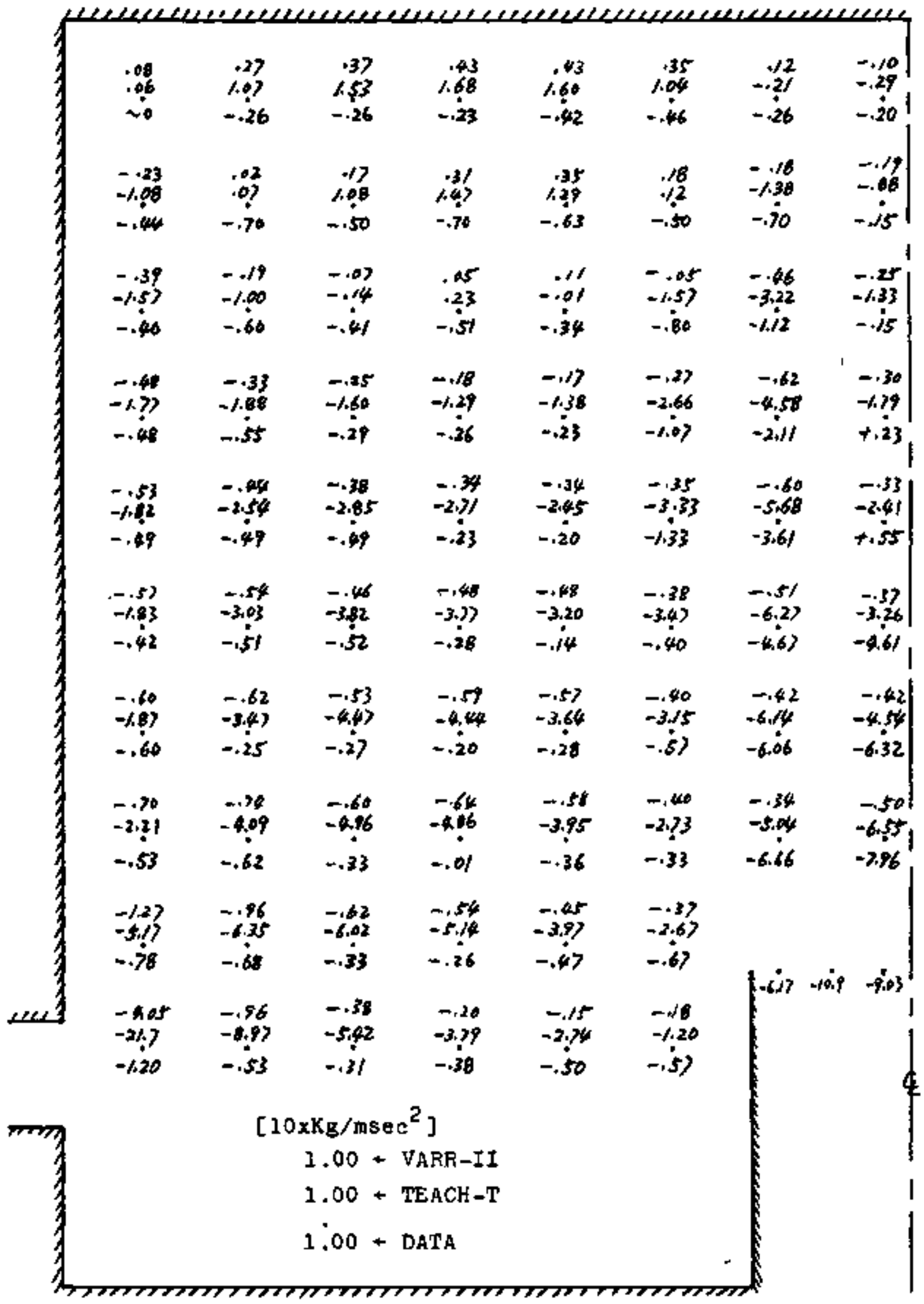

Fig. 5.10 Conpared Calculated and Measured Reynolds Stress F1elda, FFTF Geometry, Re=70000, Normal Inlet Veloc1ty Distribution 


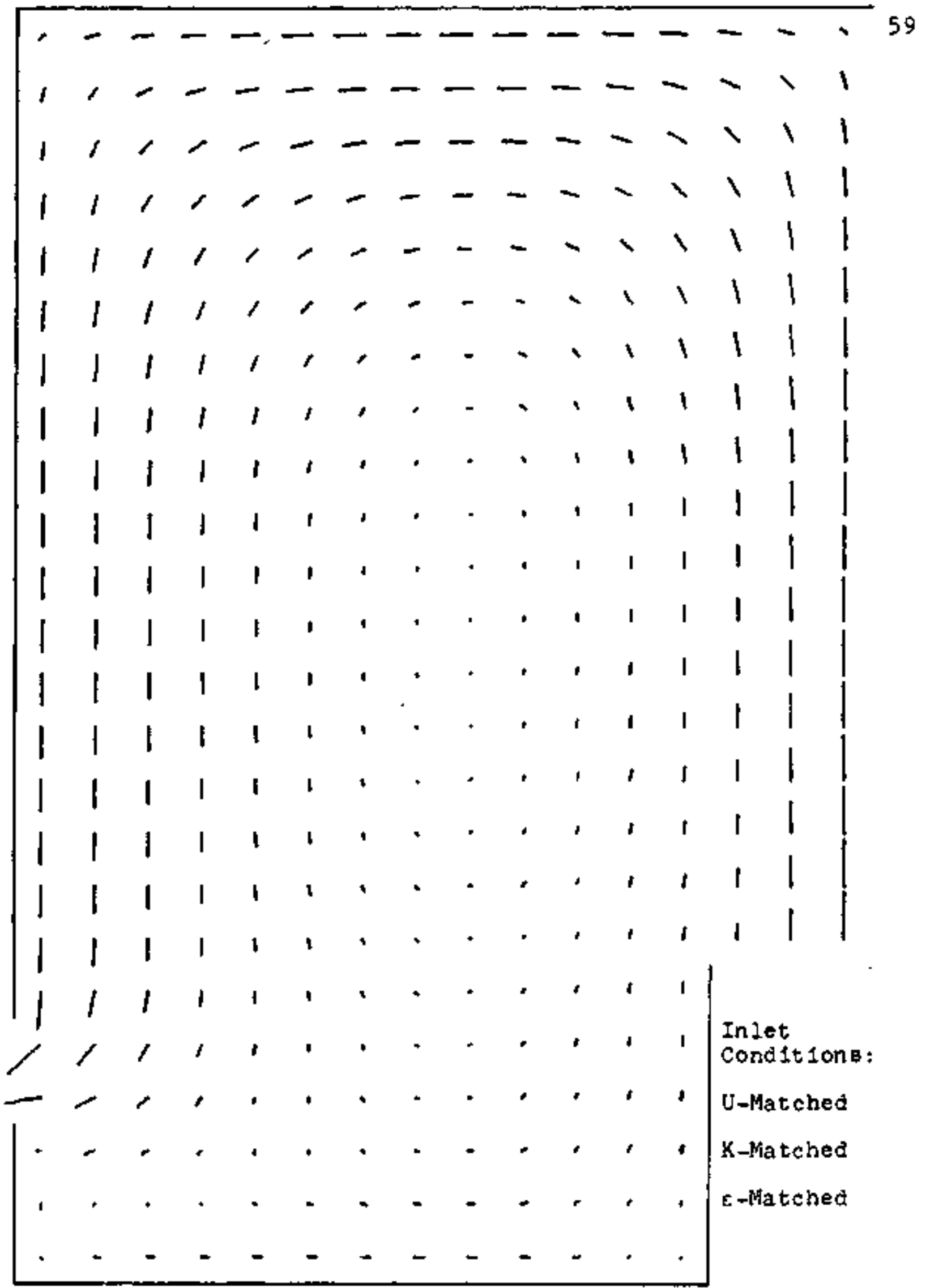

F1g. 5.11 TEACH-T Prediction, FPTP Geometry, Re=70000, Normal Inlet Velocity D1stribution 


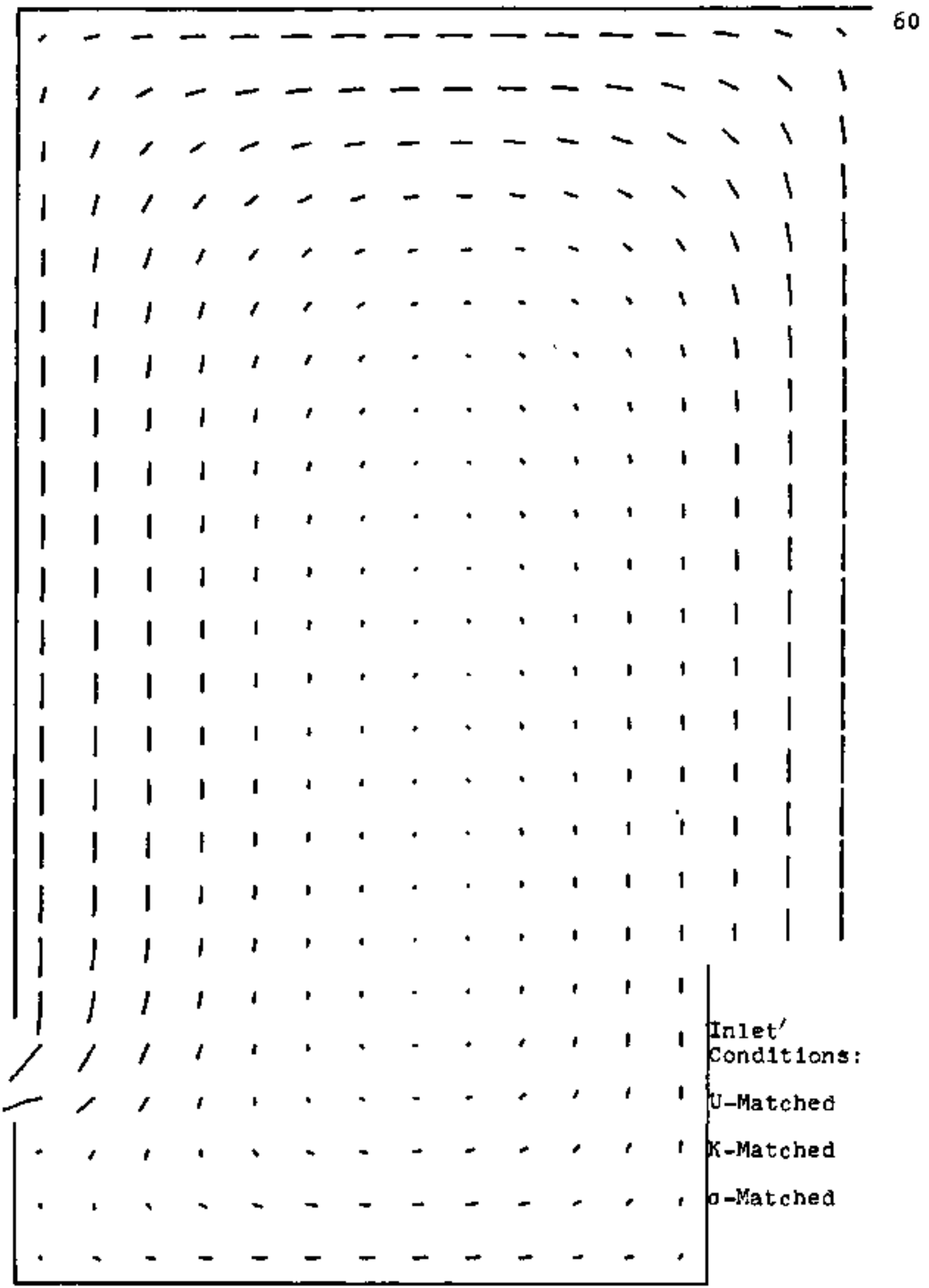

Fig, 5.12 VARR-II Prediction, FFTF Geometry, Re $=70000$, Norral Inlet Velocity Distribution 


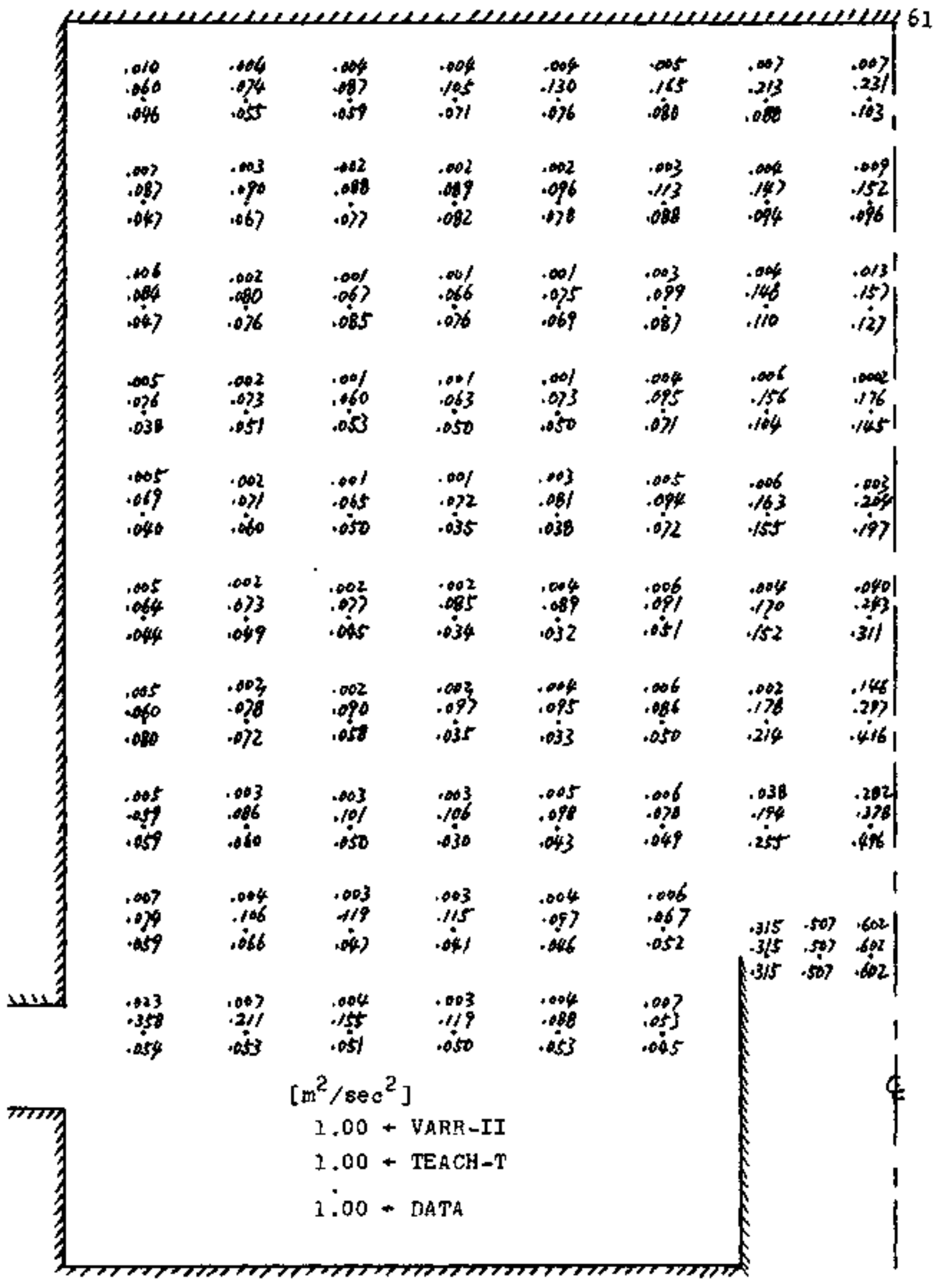

F1g. 5.13 Compared Calculated and Measured Turbulent K1netic Energy Flelds, FFTF Geometry, Re=70000, Normal Inlet Velocity Distribution 


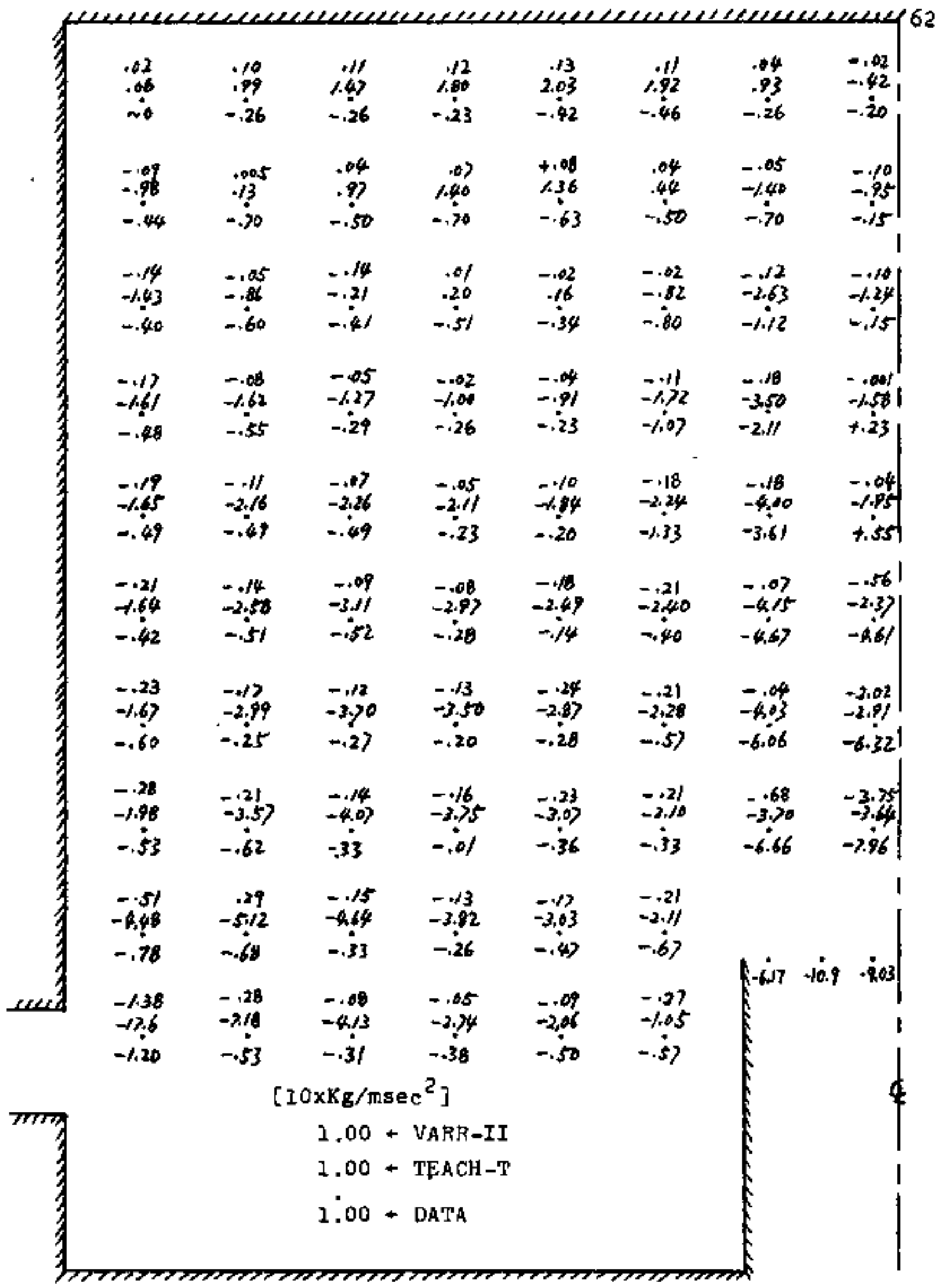

Fig. 5.14 Compared Calculated and Measured Reynolds Stress Fields, FFtr Geometry, Re*70000, Normal Inlet Velocity Distribution 


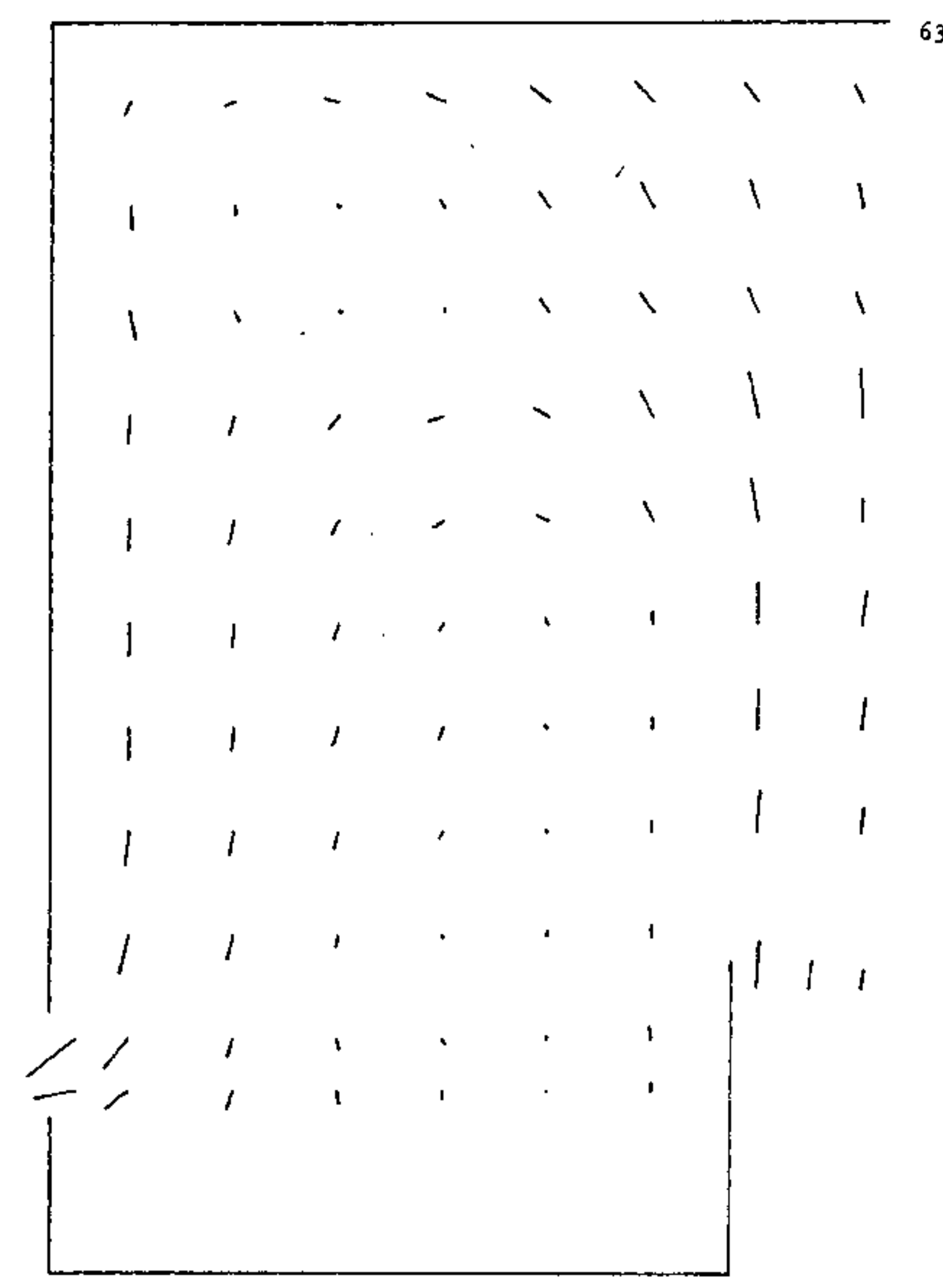

F1g. 5.15 Measured Mean F1ow F1eld, FFFF Geometry, Re $=70000$,
D1storted Inlet Velocity Distribution 


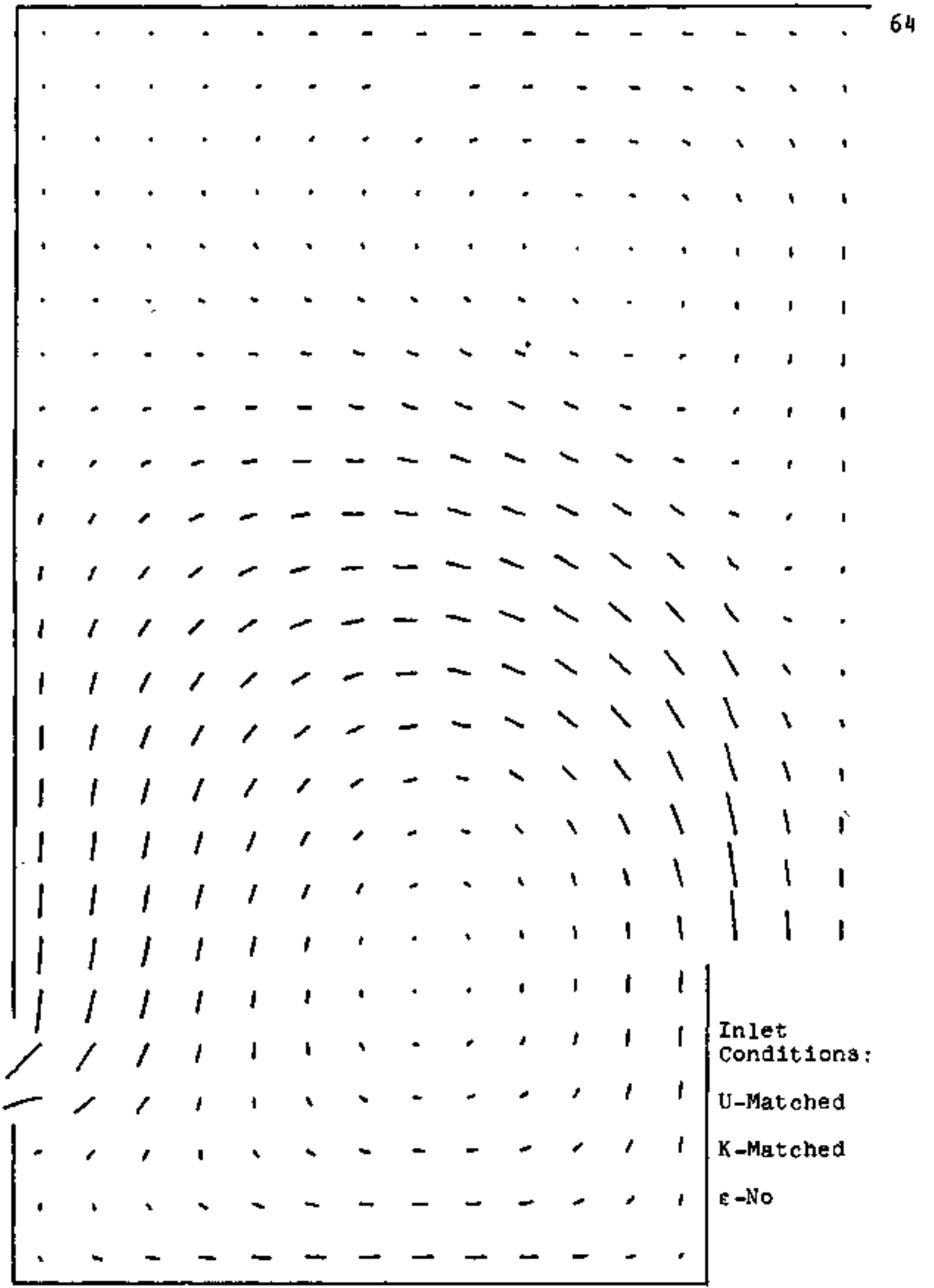

F1g. 5.16 TEACH-T Prediction, FFTF Geometry, Re=70000, Distorted Inlet Veloc1ty Distribution 


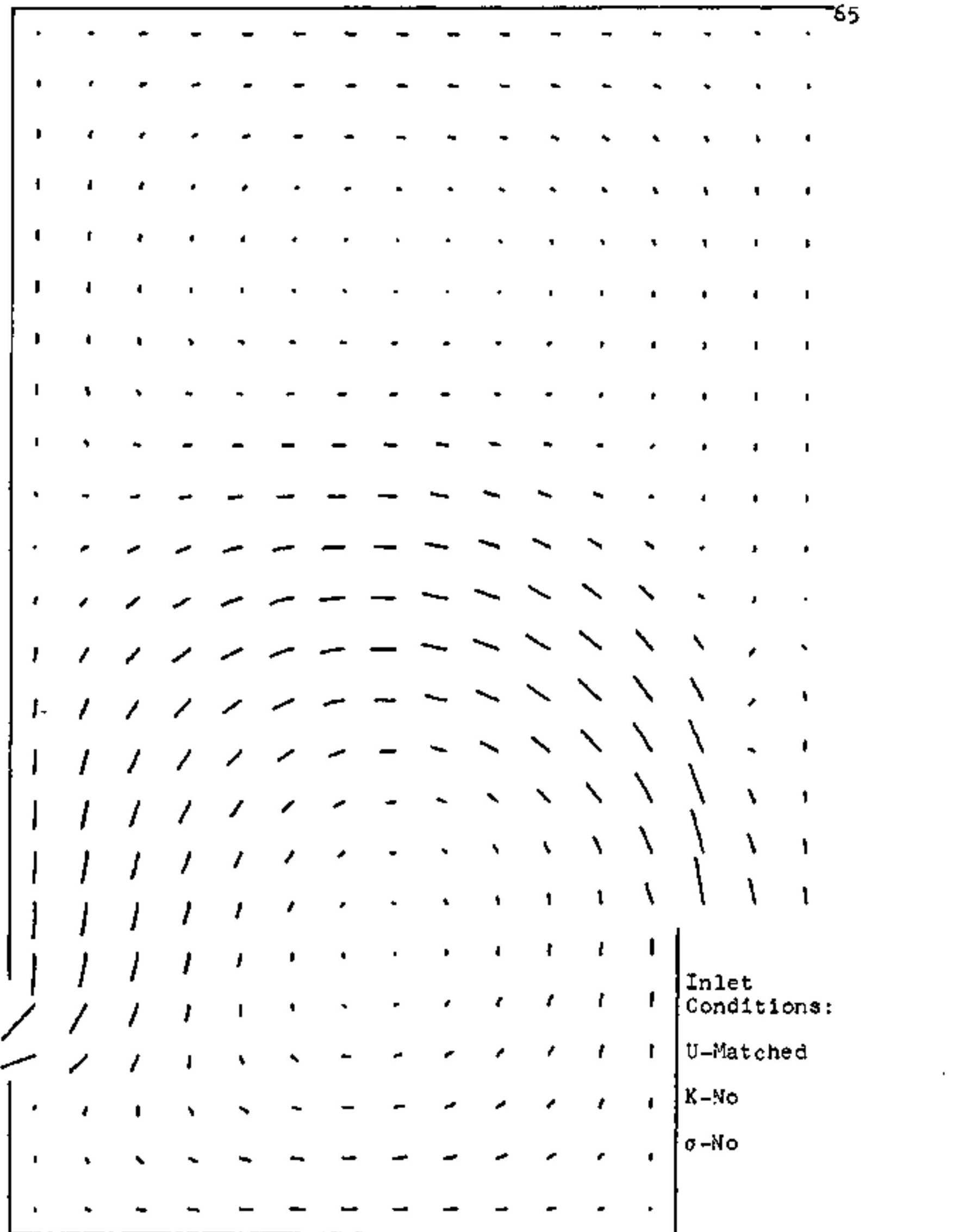




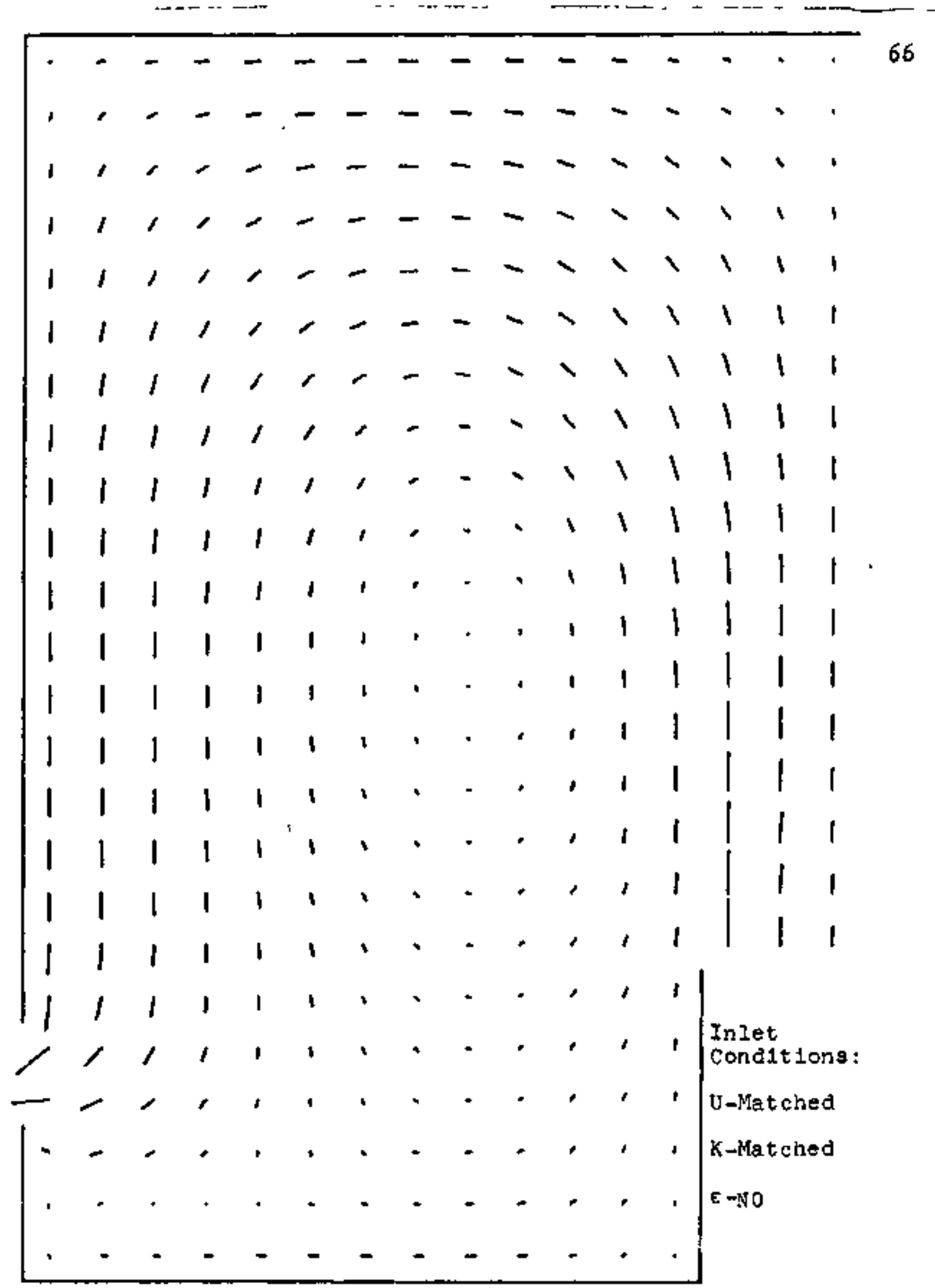

F1E. 5.18 TEACH-T Pred1ct1on, FFTF Geometry, Re=70000, Distorted Inlet Velocity D1stribution 


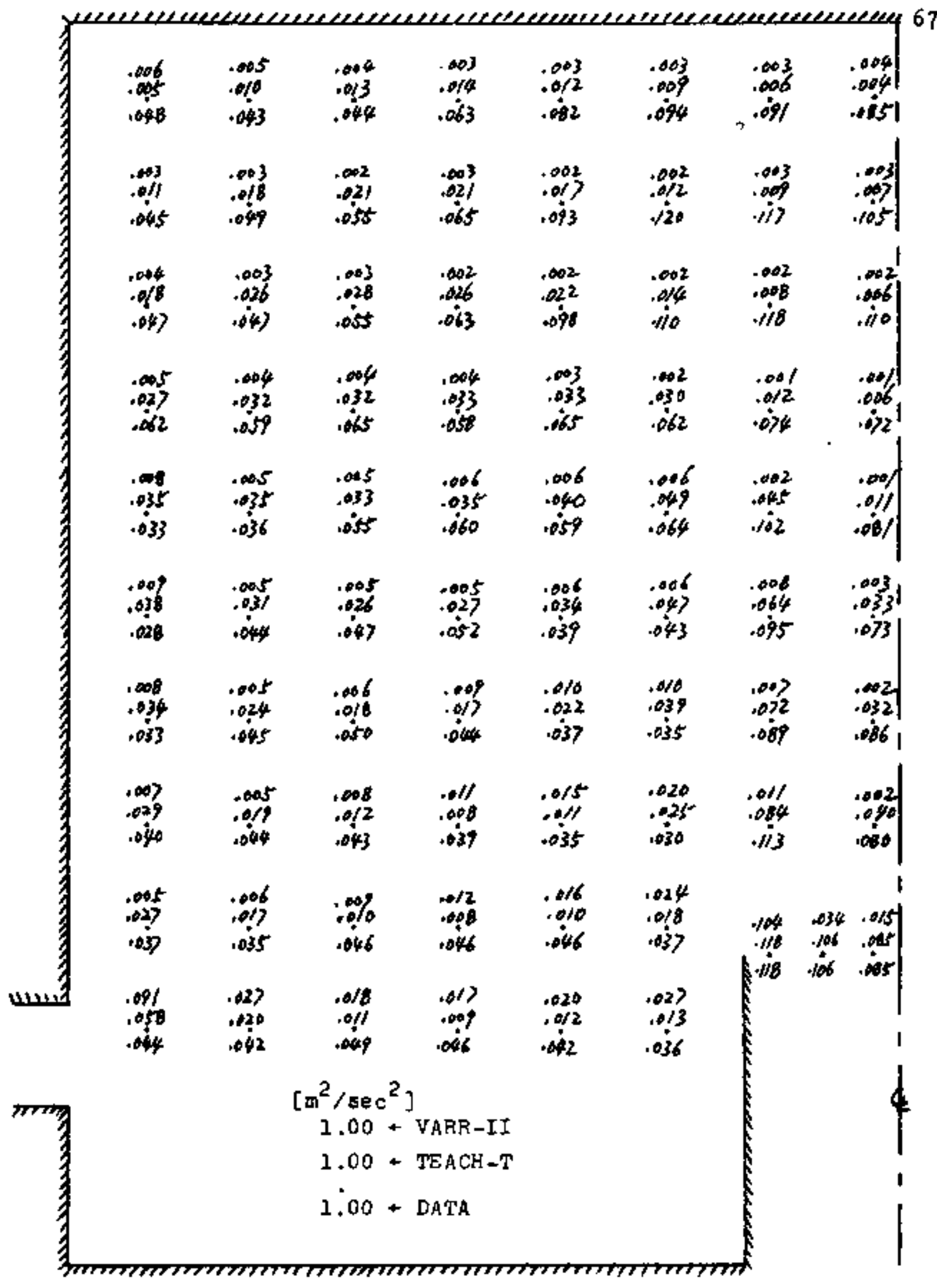

F1g. 5.19 Compared Calculated and Measured Turbulent Kinet1c Energy Fielda, FPTF Geometry, Re=70000, Diatorted Inlet Velocity Distribution 


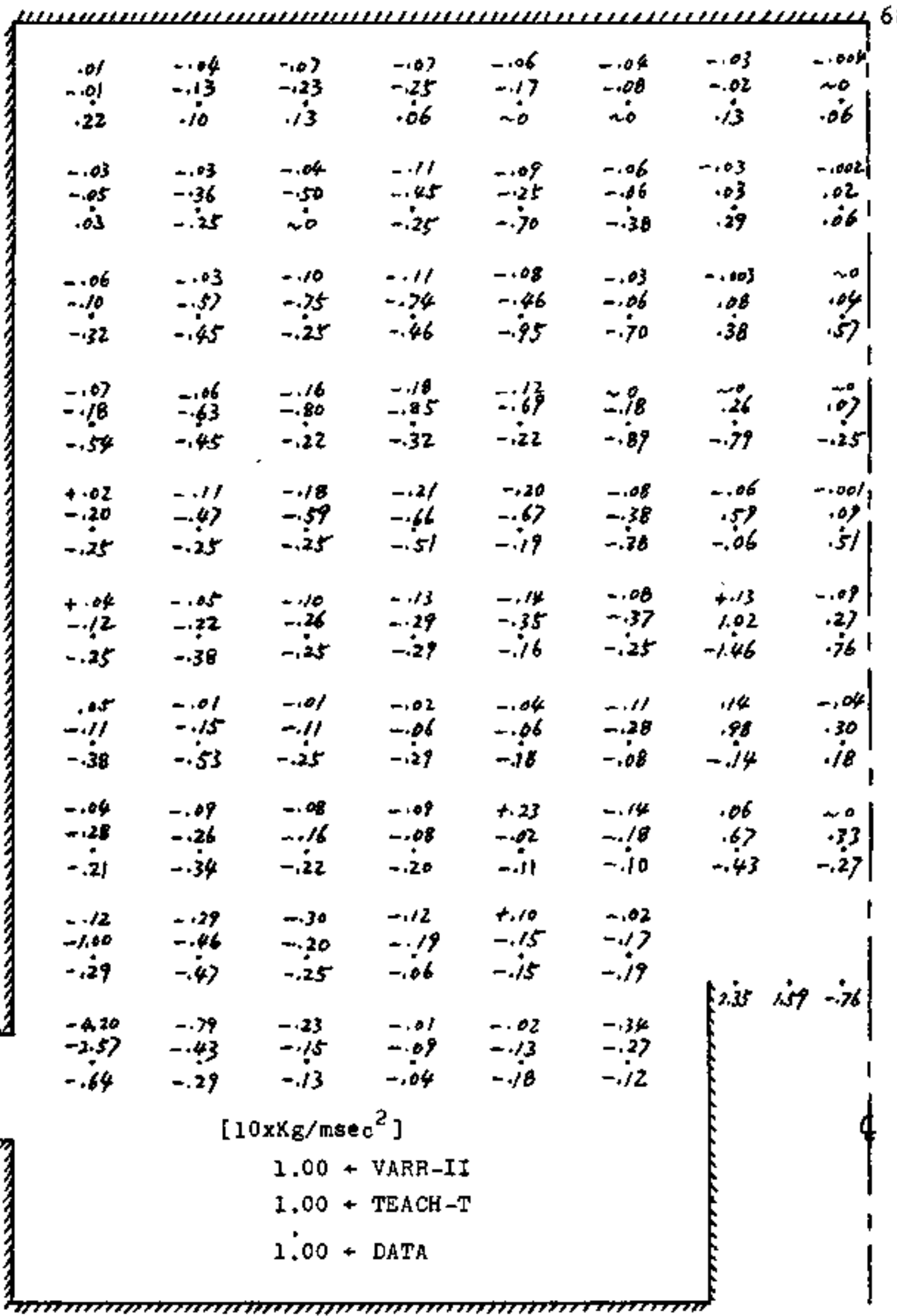

FIg. 5.20 Compared Calculated and Measured Reynolds Stress Fields, FFTF Geometry, $R=70000$, D1storted Inlet Velocity D1stribution 


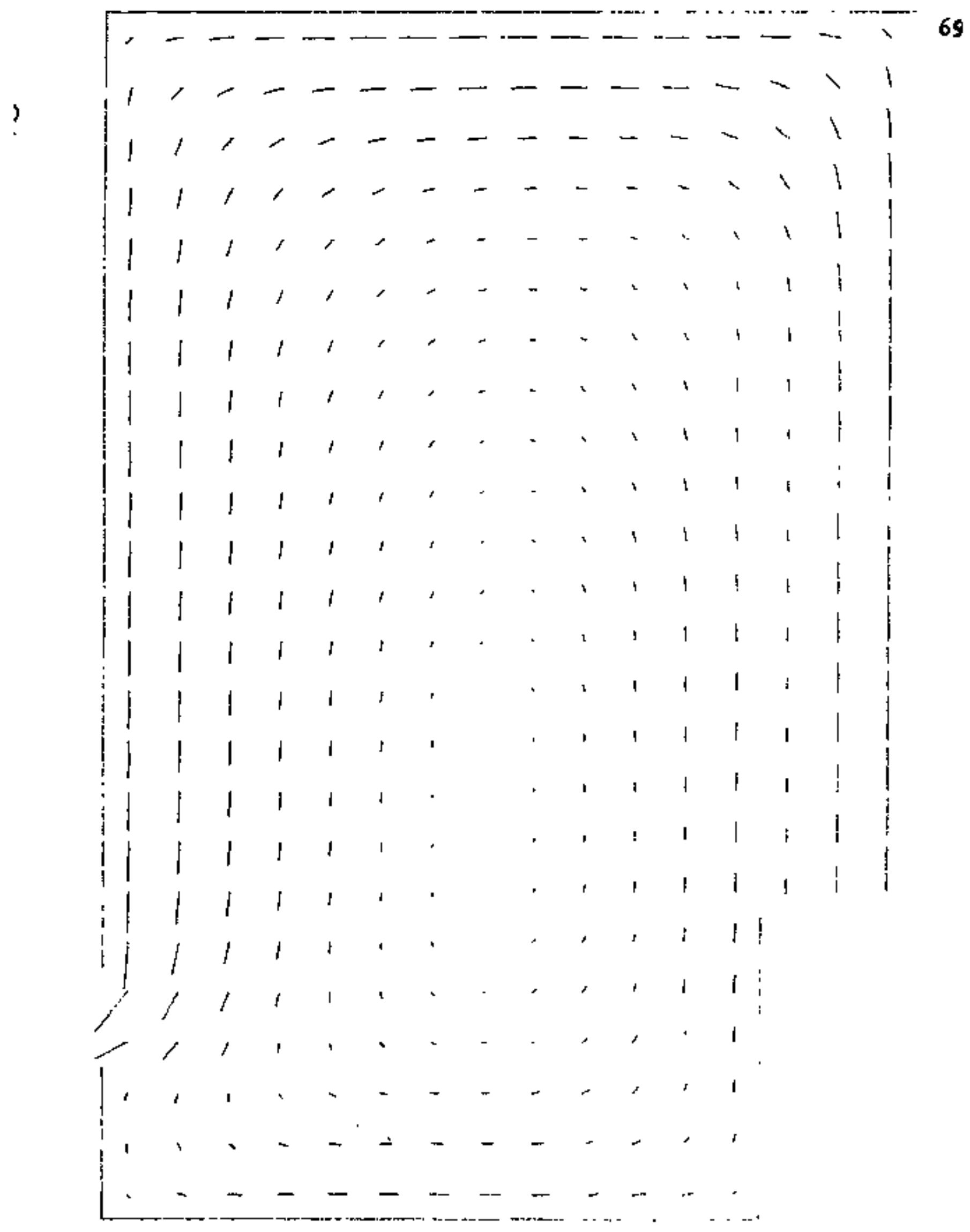

F15. 5.21 TEACH-T Prediction with Reynolde Stress $-20|\underline{U}|^{2}$, FFTF Geometry, Re=70000, Normal Inlet Veloc1ty Diatribution 


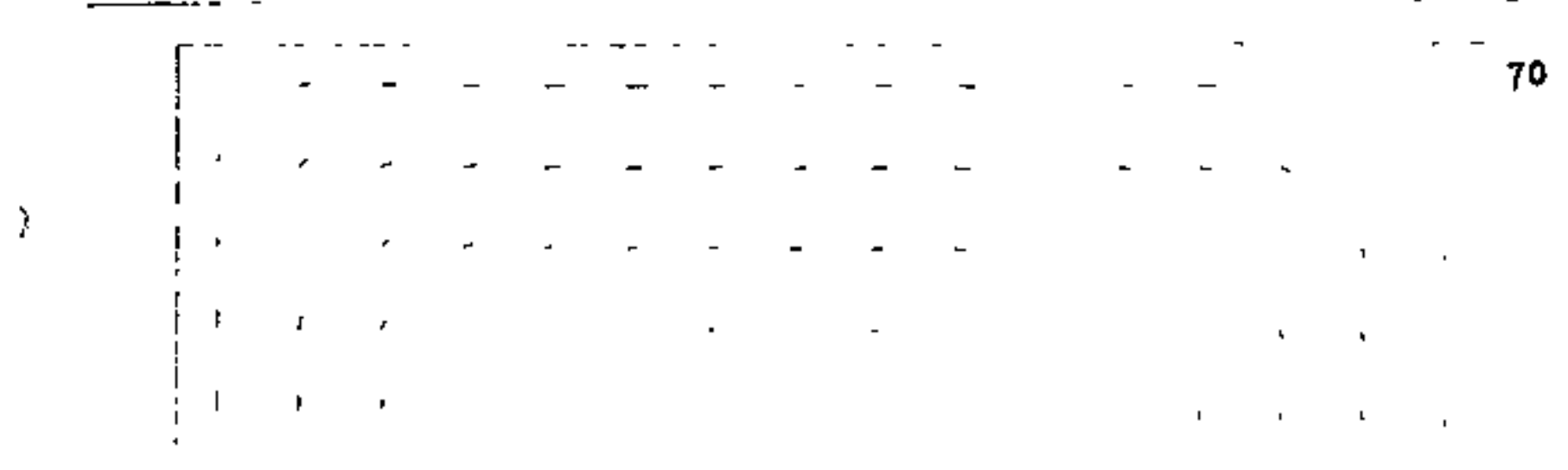

$$
\begin{aligned}
& \begin{array}{lllllll}
: & 1 & 4 & & & 1 \\
i & 1 & 1 & & - & - & 1
\end{array}
\end{aligned}
$$

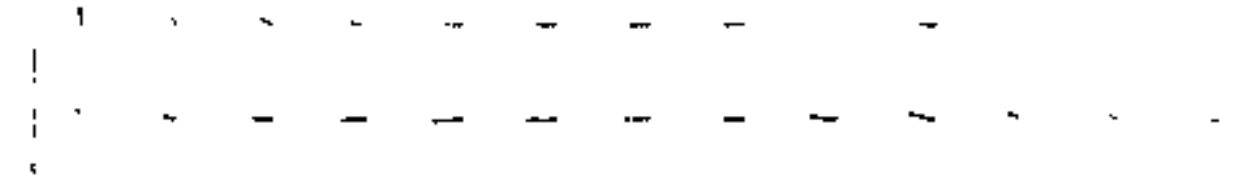

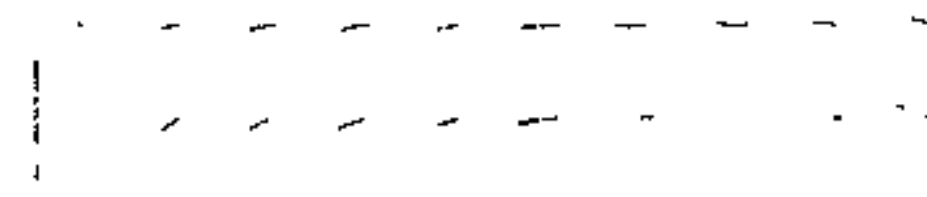

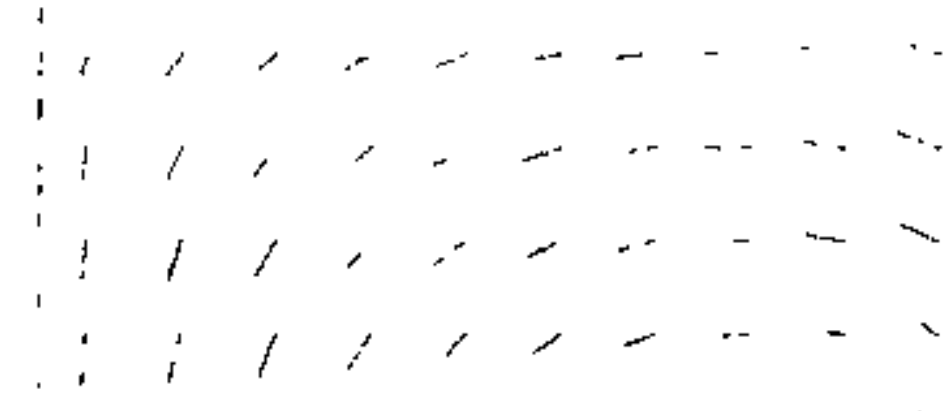

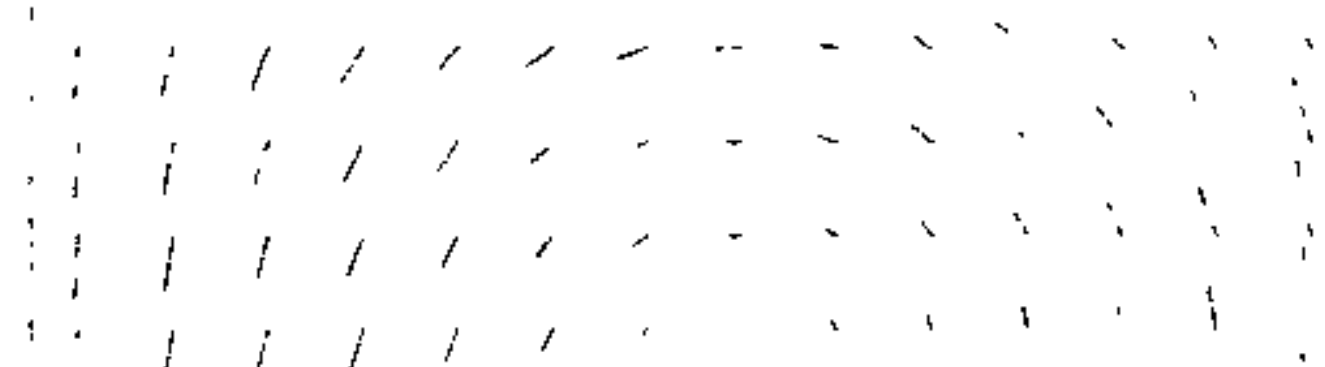

$$
\begin{aligned}
& \begin{array}{lllllllll}
i & 1 & 1 & 1 & 1 & = & - \\
i & i & 1 & 1 & v & 4 & -1 & - & -
\end{array} \\
& \text { I. } \quad \begin{array}{llllll}
- & - & - & - & - & -
\end{array}
\end{aligned}
$$




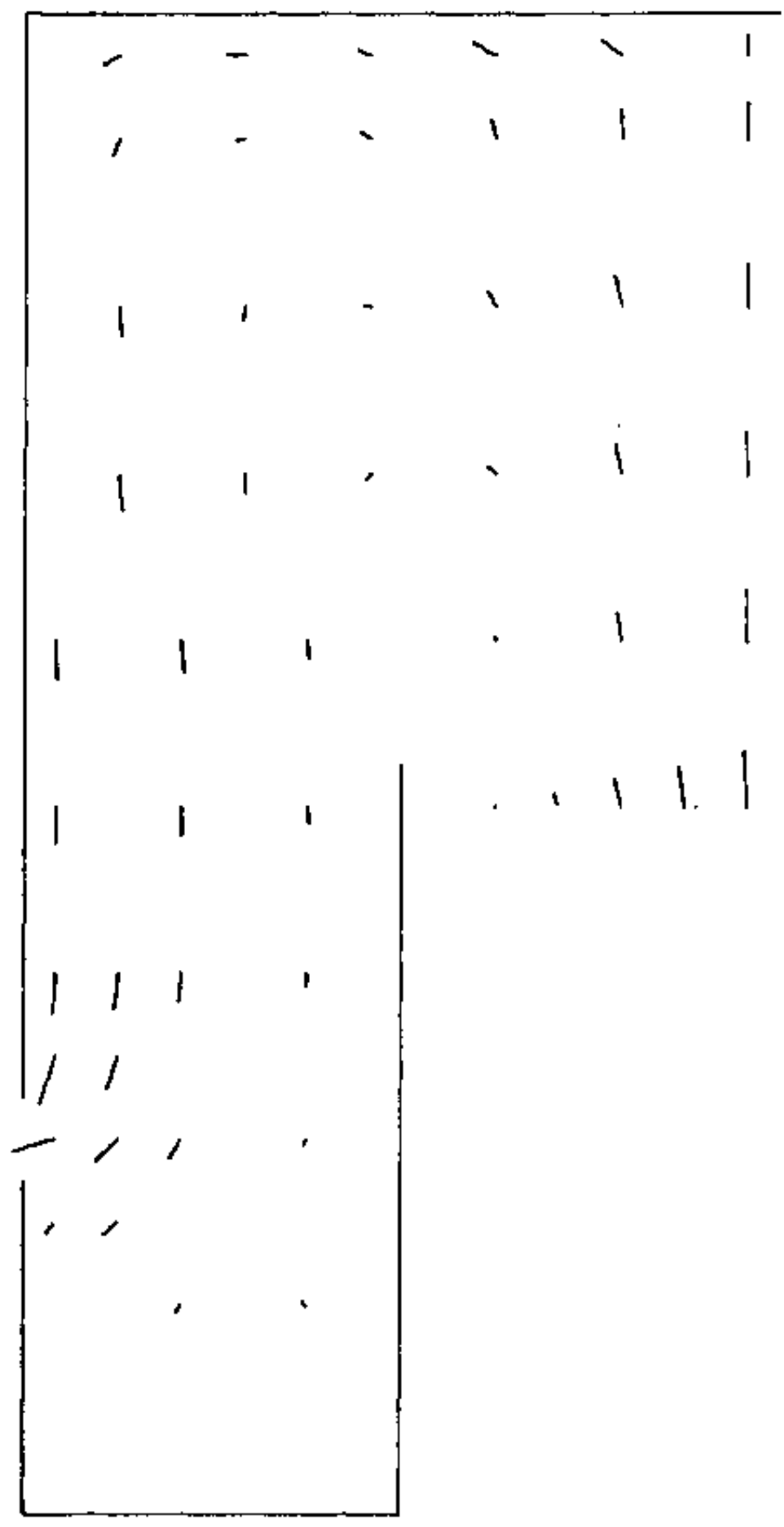

PIg, 5.23 Measured Mean Flow Fleld, CRBR Geometry, Re=35000, Nordal Inlet Velocity Distribution 


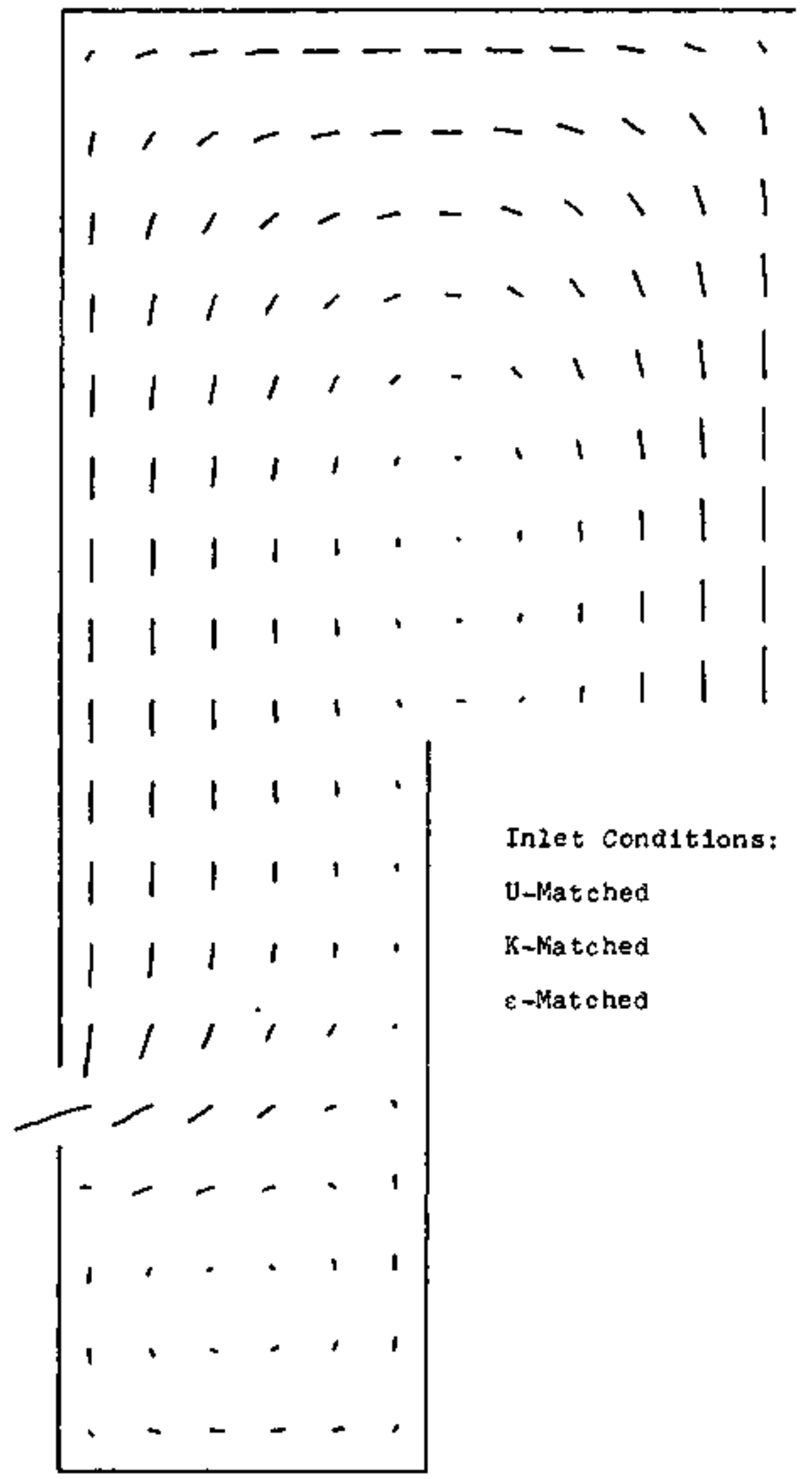

Fig. 5.24 TEACH-T Predict1on, CRBR Geometry, Re $=35000$, Normal Inlet Velocity Distribution 


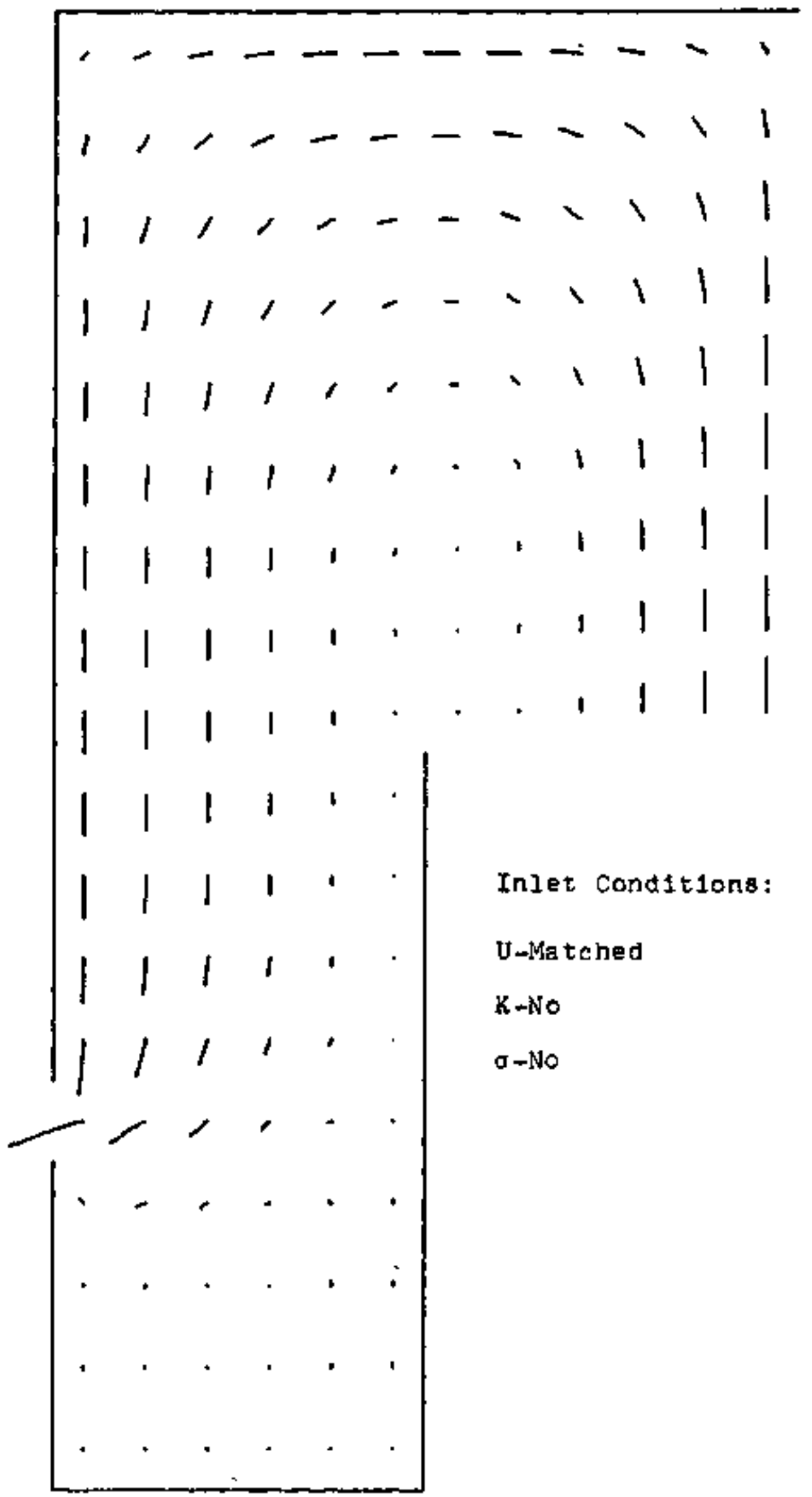

F1g. 5.25 VARR-II Prediction, CRBR Geometry, Re=35000, Normal Inlet Velocfty Distribution 


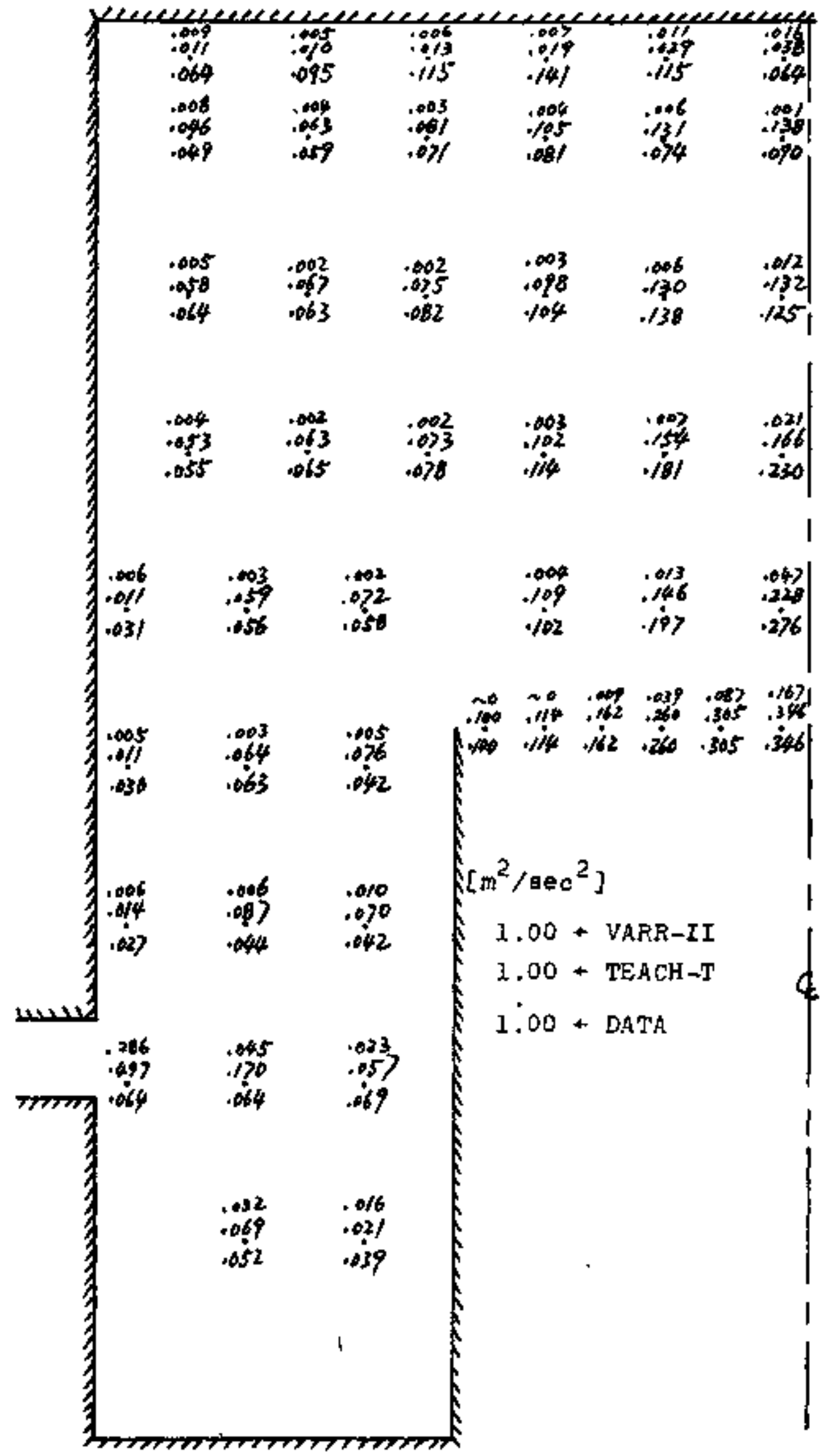




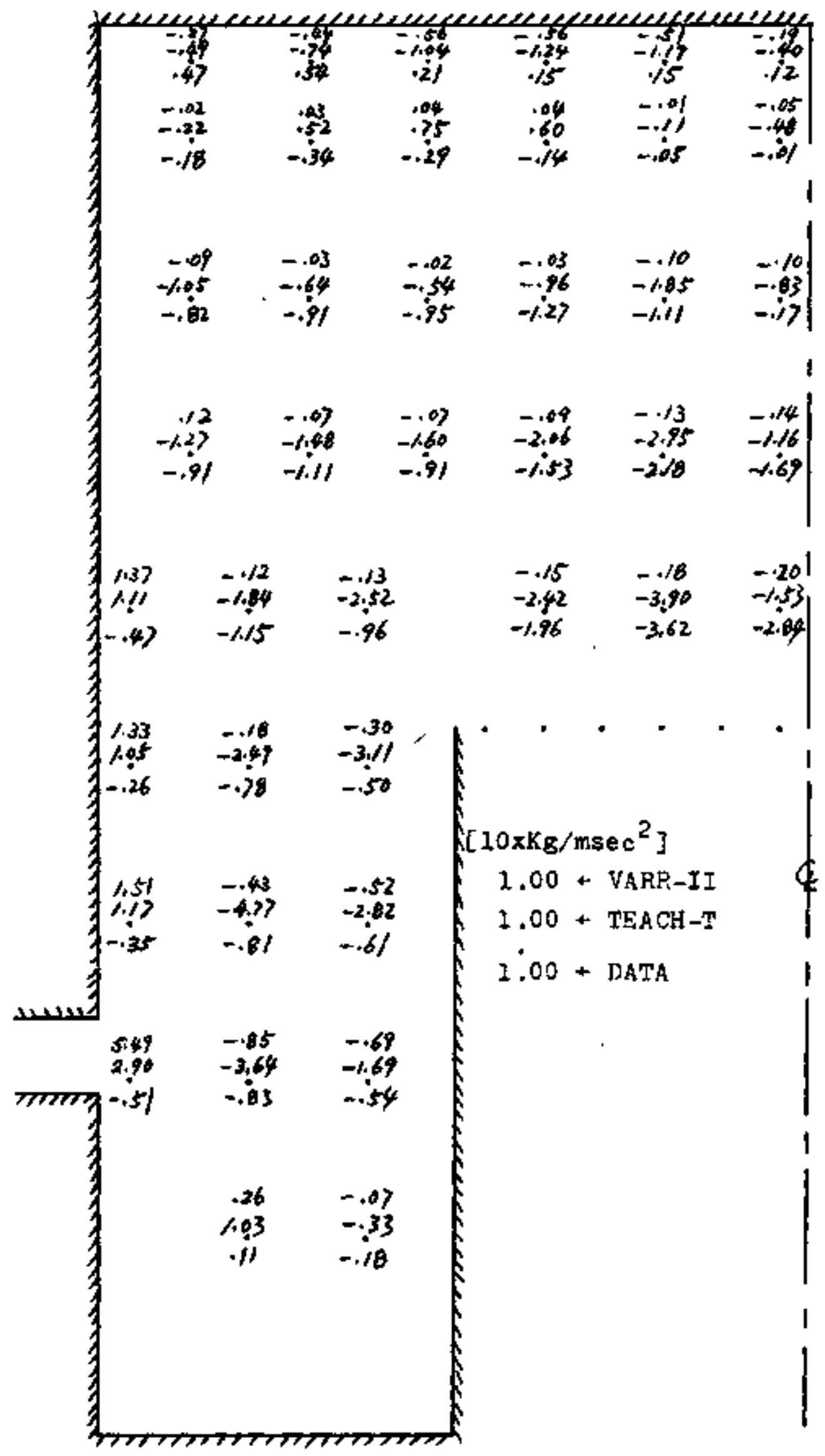




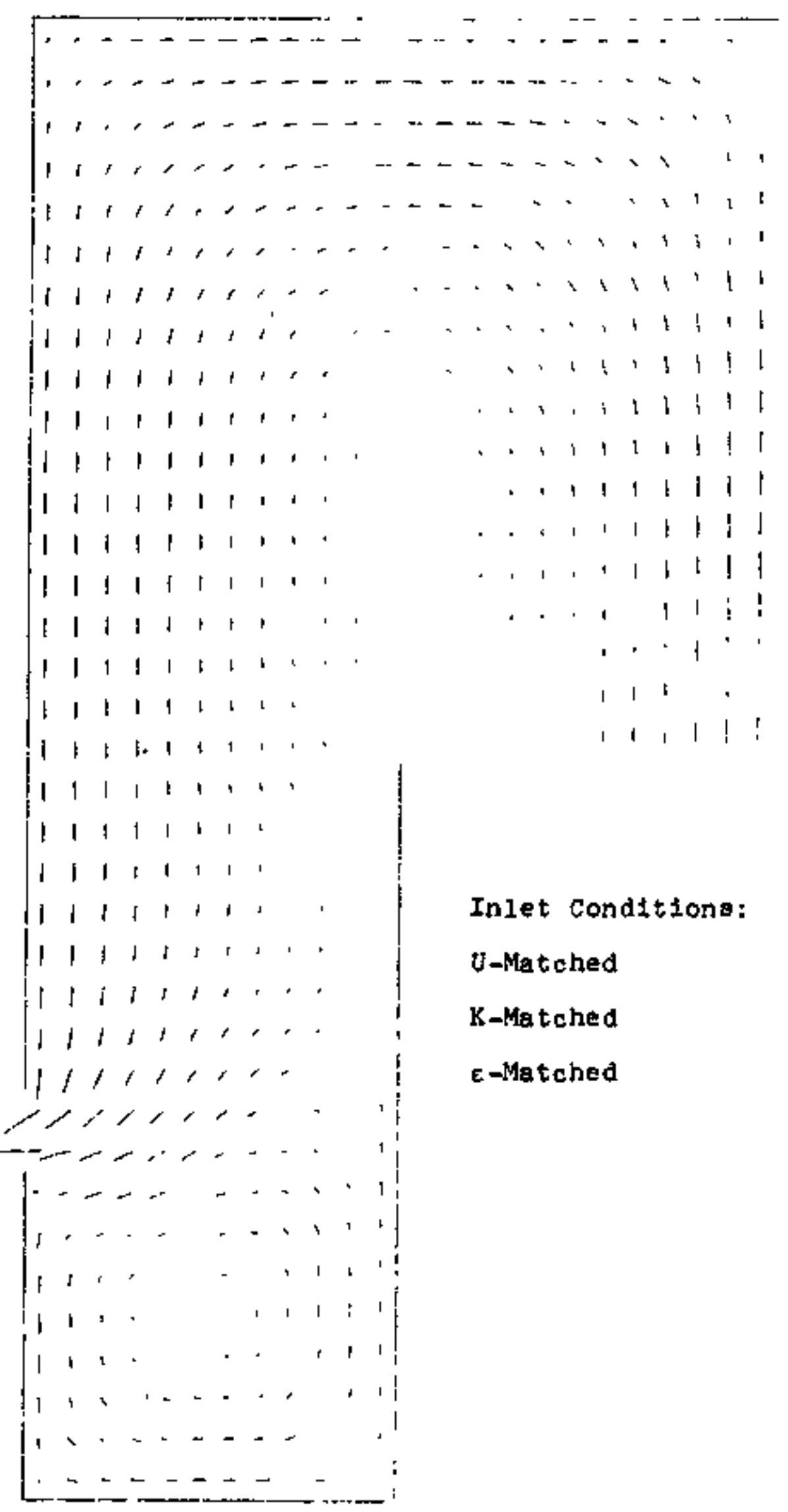

F1g. 5.28 TEACH-T Prodiction, CRBR Geometry, Re=35000, Normal Inlet Velocity D1stribution 


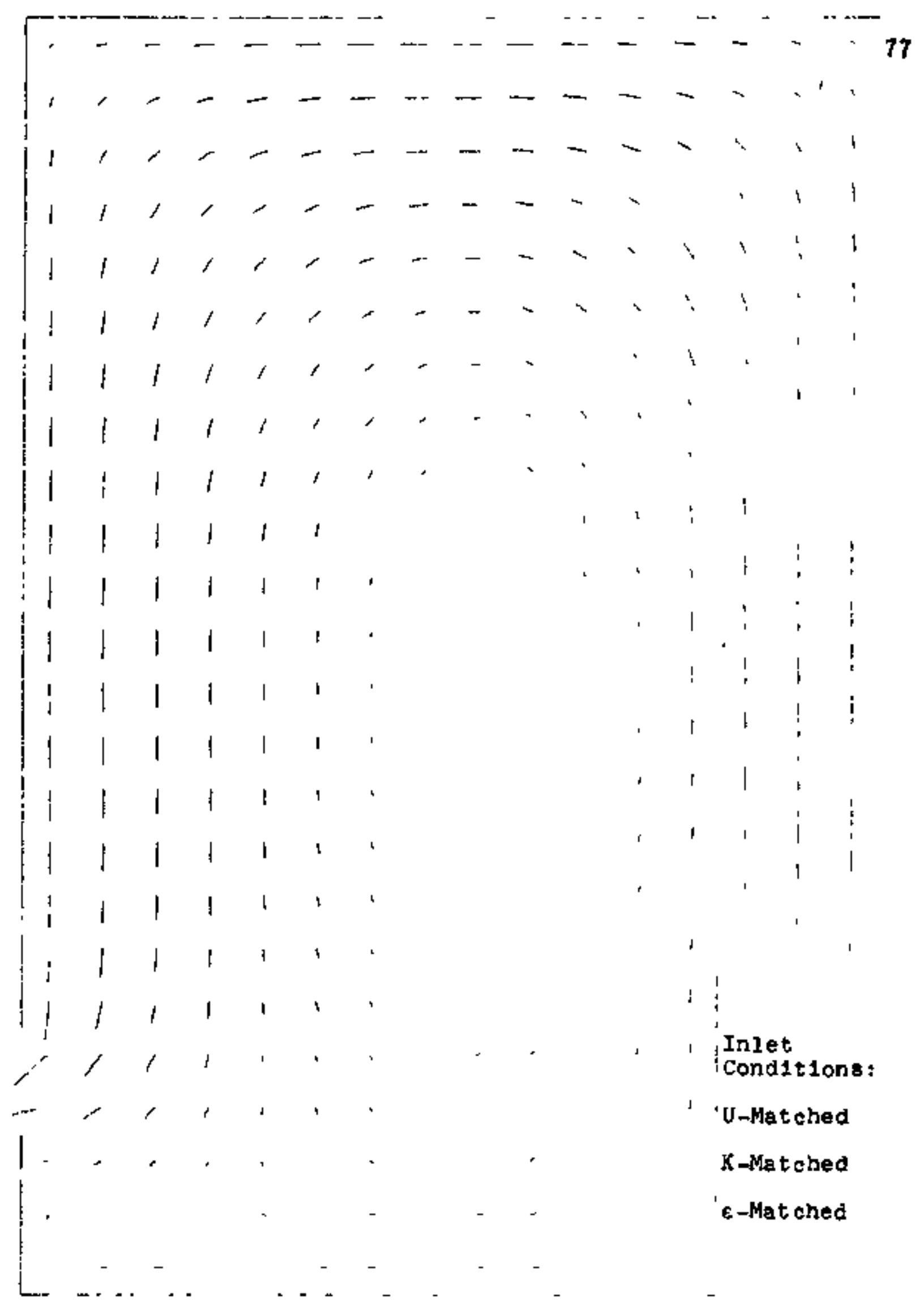

Fig. 5.29 TEACH-T Prediction wi th New Set of Constants, FFTP Geometry, Re =70000, Normal Inlet Velocity Distribution 


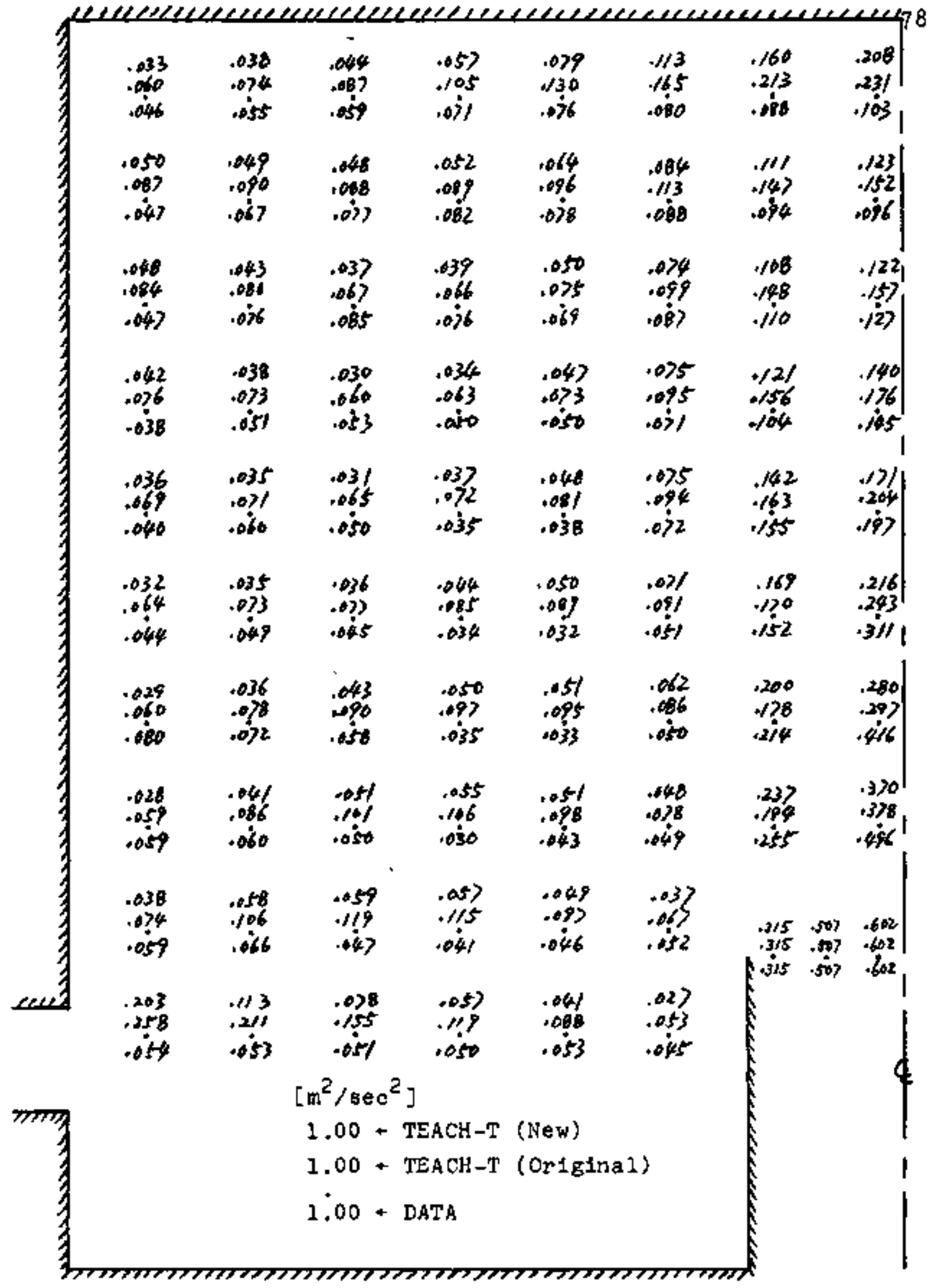

F15. 5.30 Compared CaIculated and Measured Turbulent Kınetic Energy Flelds, FFTF Geometry, Re=70000, Normal Inlet Velocity Distribution 
CHAPTER 6

CONCLUSIONS AND RECOMENDATIONS

\subsection{Conclusions}

From the PFTP case having normal inlet flow condition;

It is seen that good agrement is obtalned between the geasurements and the TEACH-T prediction. The inferior quality of the VARR-II predictions of the turbulence quantities is attributable to use of a poorly tested turbulence model, and use of bullt-in rather than experimental inlet turbulence parameters.

By contrast, in the CRBR geometry it is seen that the turbulence model calculations are much less accurate than in the PFTF case in the prealction of mean flow flelds. The predictions of turbulence quantities flelds are hopelessly poor. The cause for th1s may be due to the fact that in CRBR geometry, the tortuous flow path increases the complextty of the turbulence model equations as weil as the degree of departure from 1sotropy. The net result $1 \mathrm{~s}$ that the closure asaumptions for the turbulence models examined are too simple to describe adequately the complicated nature of the CRBR rlow fleid.

From the sens1t1pity analys1s, it is found that the production and dissipation of turbulence are the dominant terms in the transport equations for turbulent kinetic energy and turbuient energy dissipation rate over the whole slow field except near the inlet jet region, and the diffusion 
terms are relatively small. From the same study a new set of empirical constants for the turbulence model is evolved for the prediction of plenum flows.

The Inability of either program to predict the nature of the flow under distorted 1nlet conditions lndicates that the choice of a turbulence model is not as important as an accurate knowledge of inlet velocity and turoulence flelds. It also implies that models such as those used in this study should be used with great caution in situations in which abrupt changes in shape arise or in which strong mean flow gradients are imposed. Within these limitations, codes of the type used tn thia work can provide predictions which are useful for design purposes.

\subsection{Recommendat lons}

\subsubsection{Turbulence Models}

Further research work is needed to incorporate the Intermittency, relaminarization, and multi-length scale effects Into the turbulence model equations or to develop a calculation strategy to compensate for these effects.

\section{2 .2 Experiments}

For future work more measuring points in the inIet oriflce are necessary in order to calculate accurately the turbulent energy dissipation rate or turbulent viacosity ror the computer input. 


\section{REFERENCES}

1. Notes on "Turbulent Recirculating Flow - Prediction and Measurement," College of Engineering, The Pennsylvania State In1vera1ty, Ju2y 28-Auguat 1, 1975.

2. Cook, J.L., P.I. Nakayama, "VARR-II. A Computer Program for Calculating T1me Dependent Turbulent Fluid Flows with Silght Density Variation," WARD-D-0106, July 1975.

3. Prandtl, L., "Uber die ausgebildete turbulenz," ZAMM 5, 1925, P. 136.

4. Launder, B.E., "Progress in the ModeIing of Turbulence Transport, " College of Englneering, The Pennsyluanla State University, July 28 -August 1, 1975.

5. Kolmogorov, A.N., "Equations of Turbulent Motion of an Incompressible Fiuld," Itv. AK. Naluk, SSR, Seria flz1cheska VI, 1942 , pp. 56-58.

6. Prandtl, L., K, W1egkardt, "uber etn neues formelaystem fur dle ausgebildete turbulenz," Nachr. Akad. Wiss. Gottingen, Math, -Phys, K1, 1945, p. 6.

7. Bradshaw, P., D.H. Ferriss, N.P. Atwe1l, "Calculation of Boundary-layer Development using the Turbulent Energy Equation," J. Flu1d Mech., Vo1. 28, part 3, 1967, pp. $593-616$.

B. Nee, V.W., L.S.0. Kovagznay, "S1mple Phenomenolog1cal Theory of Turbulent Shear Plows,"The Phys. of Plulds, Vol. 12, No. 3, March 2969, pp. 473-484.

9. Harlow, F.H., P.I. Nakayame, "Transport of Turbulence Energy Decay Rate," Los Alamos Sc1. Lab, Rep. LA-3854, 1968 .

10. Rod1, W., D.B. Spalding, "A Two-Parameter Model of Turbulence, and 1ts Application to Free Jets," Warme und Stoffubertragung, Vol. 3, 1970, pp. 85-95.

11. Rota, J., "Statiatiche Theorle nichthomogener Turbulenz," 2e1tsch. f. Phys1k, 129, pp. 547-572, and 131, pp. 51-77, 1951 .

12. Stuhmiller, J.H., "Development and Validation of a Two-Varlabie Turbulence Model," SAI-74-509-LJ, January 1974, Sclence Application, Inc., La Jolla, Calif. 
13. Tomsend, A.A., The Structure of Turbulent Shear Flow, Cambridge Un1versity Presa, 1956.

14. The DISA Type 55L Laser Doppler Anemometer Mark II Instruction Manual, DISA Electron1cs, Franklin Lakes, N.J. 1974 .

15. Yang, J.W., A.K. Agrawal, "An Analyt1cal Model for Transient Fluid Mixing in Upper Outlet Plenum of an LMFBR, "International Meeting on Fast Reactor Safety and Related Physics, Ch1cago, Ill., Oct. 5-8, 1976.

16. Howard, P.A., "PLENUM-3: A Lumped Parameter LMFBR Outlet Plenum M1xing Code," ANL-CT-76-32, March 1976.

I7. Lorentz, J.J., "NIX - A Computer Code for Transient Thermal - Hydraulic Analysis of LMFBR Outlet Plenums," ANL-CT-75-41, Mey 1975 .

18. Hinze, J.0., Turbulence, Second Ed1tion, McOraw-H111 Book Company, 1975 .

19. Amsden, A.A,, F.H. Halow, "The SMAC Method: A inumerical Technlque for Calculating Incompressible Fluid Flows," Los Alamos Sei. Lab. Rep. LA-4370, May 1970,

20. Novendstem, E.H., "Description of VARR-II Changes," Private Communication.

27. Caretto, L.S., A.D. Cosmen, S.V. Patanker, D.B. Spalding, "Two Calculations Procedures for Steady, Three-Dimensional Flows with Rec1rculation," Imperlal College, Mechanical Engineering Department, Rep. No. HTS $/ 72 / 5$.

22. Yeh, Y., H. Cummins, "Local1zed Flu1d Flow Measurement w1th a He-Ne Laser Spectrometer," App1. Phys. Letters, $4,176,1964$.

23. Goldste1n, R.J., D.K. Kreld, "Pluld Velocity Measurement from the Doppler Shift of Scattered Laser Radiation," Un1versity of M1nnesota heat Transfer Lab. Rep. No. 85, 1968.

24. Durst, F., J.H. Wh1telaw, "Theoretical Considerations of Signiflcance to the Dealgn of Optical Anemometer," Impir1cal College, Mechanlcal Englneering Department Rep. No. ET/TN/A/25, 1972 .

25. George, W.K., Jr., "Llmitations to Measuring Accuracy Inherent in the Laser Doppler SignaI," proceedings of the LDA Syoposium Copentagen, 1975. 
26. Durst, F., J.H. Wh1telaw, "L1ght Source and Geometrical Requirements for the Optimization of Optical Anemometry S1gnala," Opto-electron1es, 5, 137, 1973.

27. Melling, A, J.H. Whitelaw, "Optleal and Flow Aspects of Particles," Proceed1ngs of the LDA Symposium, Copenhagen, 1975 .

28. W1lson, E.B.Jr., An Introduction to Sclentific ReBearch, McGraw-H1ll, New York, 1952 . 


\section{APPENDIX A}

TRANSPORT' EQUATIONS FOR MOMENTUM, TURBULENT KINETIC ENERGY, AND TURBULENT ENERGY DISSIPATION RATE

We astume that the Navier-Stokes equation is a valid description for turbulent and incompressible flulds. AccordIngly, the derfvations hare are based on the following set of equations (in tensor form):

$$
\begin{aligned}
& \frac{\partial U_{f}}{\partial t}+U_{k} \frac{\partial U_{f}}{\partial X_{k}}+g_{j}-\frac{1}{p} \frac{\partial P}{\partial X_{j}}+\frac{\partial}{\partial X_{k}}\left(\nu \frac{\partial U_{l}}{\partial x_{k}}\right) \\
& \frac{\partial U_{k}}{\partial x_{k}}=0
\end{aligned}
$$

where $u_{j}$ is the velocity component, $g_{j} 1 s$ the externally applied body acceleration, $P$ is the pressure, and $v 1 \mathrm{~s}$ the molecular kinematic viscosity.

\subsection{Transport Equations for Momentum}

In describing a turbulent flow in mathematical terms, it 1 s convenient to separate 1 into a mean motion and a rluctuating motion. Hence the rleld variables, $U_{j}$ and $P_{j}$ can be expressed as

$$
\begin{aligned}
& v_{j} \equiv \bar{U}_{j}+v_{j} \\
& P_{j} \equiv \bar{P}_{j}+P_{j}
\end{aligned}
$$

so that, by definition, the time-average of all quantities descriolng the rluctuations are equal to zero:

$$
\overline{\mathrm{U}_{j}}=0, \overline{\mathrm{P}_{j}}=0
$$

Upon Introducing relations A.3 1nto Eq. A.I and forming 
by definition, the turbulent kinetic energy, $K$, is defined as $K \equiv(1 / 2) \overline{U_{i}^{2}}$. l'ensor contraction of the 1ndices 1 and $f$ yields the transport equation for the turbulent kinetio energy:

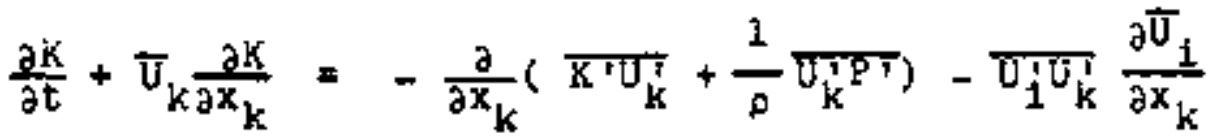

$$
\begin{aligned}
& -\left(\overline{\left.\frac{\partial \bar{U}_{1}^{\prime}}{\partial x_{k}}\right)\left(\frac{\partial \overline{U_{1}^{\prime}}}{\partial \bar{x}_{k}}\right)}+\frac{1}{2} v \overline{\frac{\partial^{2}}{\partial x_{k}^{2}} u_{i}^{2}}\right.
\end{aligned}
$$

\subsection{Transport iquat 10h for the Turbulence Energy Dissipat 1on Rate}

Taking the derlvative of Eq. A.7 for $U_{1}$ with respect to $x_{1}$, miltiplying throughout by $2 v \partial u_{1} / \partial x_{1}$ and forming averages, we get the transport equation for the turbulence energy dissipation rate:

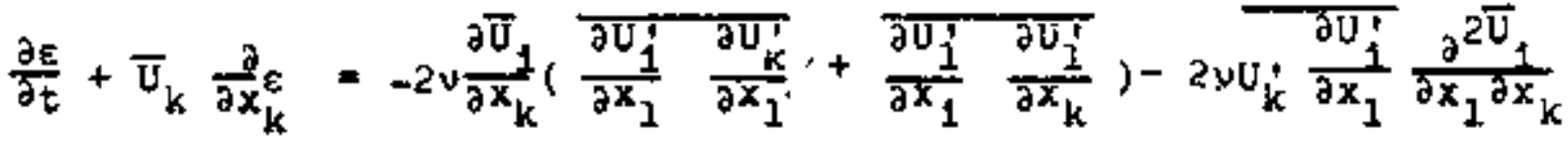

$$
\begin{aligned}
& -2 v \frac{\partial U_{1}^{\prime}}{\partial x_{k}} \frac{\partial U_{1}^{\prime}}{\partial x_{1}} \frac{\partial U_{k}^{\prime}}{\partial x_{1}}-2 \overline{\left(v \frac{\partial^{2 U_{1}}}{\left.\partial x_{k} \frac{\partial x_{1}}{{ }^{2}}\right)^{2}}+v^{2} \frac{\partial^{2}}{\partial x_{k}^{2}}\left(\frac{\partial_{1}}{\partial x_{1}}\right)^{2}\right.} \\
& -\frac{\partial}{\partial x_{k}}\left(\overline{U_{k}^{\prime} c^{\prime}}+\frac{2 v}{\frac{\partial P^{\prime}}{\partial x_{1}} \frac{\partial_{k}^{\prime}}{\partial x_{l}}}\right)
\end{aligned}
$$

Where the turbulence energy dissipation rate, $\varepsilon$, is defined as

$$
\varepsilon \equiv v\left(\overline{\left.\frac{\partial U_{i}}{\partial x_{j}}\right)\left(\frac{\partial U_{1}}{\partial x_{j}}\right)} .\right.
$$


A PPENDIX B

DESCRIPTION OF TIE VARR-II CODE

The detalled structure of the code is described in the VARR-II user's manual (2). Here we state briefly the solution algorithm in VARR-II, and changes which have been made in order to run VARR-II on an IBM computer.

I. Equations of Motion

In Varr-II, the $q-O(1$ entical to $K-\sigma)$ two equation model 18 adopted (12). Six differential equations are solved by this code in cyclindrical coordinates:

$$
\begin{aligned}
& \frac{\partial U}{\partial t}+\frac{1}{r} \frac{\partial}{\partial r} r U^{2}+\frac{\partial}{\partial z} U W--\frac{\partial P}{\partial r}+\frac{\left(\rho-\rho_{0}\right)}{\rho} z_{X}-R X(U) \\
& +\frac{\partial}{\partial r}\left[\left(\frac{\sigma}{r}\right) \frac{\partial}{\partial r}(r u)\right]+\frac{\partial}{\partial z}\left[(\sigma) \frac{\partial U}{\partial z}\right] \\
& \frac{\partial W}{\partial t}+\frac{1}{r} \frac{\partial}{\partial r} r W W+\frac{\partial}{\partial z} W^{2}=-\frac{\partial P}{\partial z}+\frac{\left(\rho-\rho_{0}\right)}{\rho} g_{z}-R Z(W) \\
& +\frac{1}{r} \frac{\partial}{\partial r}\left[(r \sigma) \frac{\partial W}{\partial r}\right]+\frac{\partial}{\partial z}\left[(\sigma) \frac{\partial W}{\partial z}\right] \\
& \frac{\partial q}{\partial t}+\frac{1}{r} \frac{\partial}{\partial r}(r U q)+\frac{\partial}{\partial z}(W q)=+2 \sigma(S I J) \\
& +\Gamma\left[\frac{1}{r} \frac{\partial}{\partial r}\left[(r \sigma) \frac{\partial q}{\partial r}\right]+\frac{\partial}{\partial z}\left[(\sigma) \frac{\partial q}{\partial z}\right]\right\}-4 \alpha q^{2} / \sigma \\
& \frac{\partial \sigma}{\partial t}+\frac{1}{r} \frac{\partial}{\partial r}(r U \sigma)+\frac{\partial}{\partial z}(w \sigma)=+\frac{\sigma^{2}}{q}(S I J)+\Gamma(\sigma / q) l \frac{1}{r} \\
& \left.\frac{\partial}{\partial r}\left[(r \sigma) \frac{\partial q}{\partial r}\right]+\frac{\partial}{\partial z}\left[(\sigma) \frac{\partial q}{\partial z}\right]\right\}-\Gamma_{1}\left(\frac{\sigma^{3}}{q^{2}}\right)\left(\frac{1}{r} \frac{\partial}{\partial r}(r \sigma)\right. \\
& \left.\left.\frac{\partial}{\partial x}(q / \sigma)\right]+\frac{\partial}{\partial z}\left[(q) \frac{\partial}{\partial z}(q / \sigma)\right]\right)-\alpha(q / \sigma) \sigma
\end{aligned}
$$




$$
\begin{aligned}
& \begin{aligned}
\frac{\partial I}{\partial t}+\frac{1}{r} & \frac{\partial}{\partial r}(r U I)+\frac{\partial}{\partial z}(W I)=-C Q+\frac{1}{r} \quad \frac{\partial}{\partial r}\left[\left(r Y_{\mathrm{t}} \sigma\right) \frac{\partial I}{\partial r}\right] \\
& +\frac{\partial}{\partial z}\left[\left(Y_{T} \sigma\right) \frac{\partial I}{\partial z}\right]
\end{aligned} \\
& \frac{1}{r} \quad \frac{\partial}{\partial r}(r U)+\frac{\partial W}{\partial z}=0 \\
& \text { where } S I J=\left(\frac{\partial U}{\partial r}\right)^{2}+\left(\frac{\partial W}{\partial z}\right)^{2}+(1 / 2)\left(\frac{\partial U}{\partial z}+\frac{\partial W}{\partial r}\right)^{2}+\frac{U^{2}}{r^{2}}
\end{aligned}
$$

In the above equations, $U$ and $W$ are mean velocitfes, $P$ Is the pressure normalized by the reference denstty, $p$ is the density of the fluld, $\rho_{0} 1 s$ the reference density, $S_{x}$ and $s_{y}$ are components of gravitational acceleration, $R X$ and $\mathrm{RZ}$ are the model resistance terms, $\mathrm{q}$ is the turbulence kinetic energy, $\sigma$ is the turbulence k1nemat1c viscosity, and $I$ is the specific internal energy. $\gamma_{T} 1$ the reciprocal of the turbuient Prandt number, and $-C Q$ is the amount of heat transfer. from an obstacle subregion to the surrounding fluid. The congtants $a, r$, and $r_{1}$ are parameters whose values were chosen by considerIng the decay of lsotropic turbulence, turbulent plpe flow, and turbulent wakes.

\section{Analyg1s}

\subsection{Finite D1fference Formualtion}

The finlte difference mesh for numerloally solving the above equations consists of a rectangular cell with edges $\delta_{x}$ and $\delta Y$. Fiuld propertles are located at the cell posttions show in F1g. B.1. The velocitles are defined at the middle of the cell faces to facilitate the finfte difference fortalation.

The complete finite difference equations can be found in the VARR-II user's manual. Except for the treatment of the convection terms, the equations can be easily derived. Due 
to a stab111ty problem, the authors adopt the donor cell approach to treat the convection teras. For instrance, consider the following one dfmensional equation,

$$
\frac{\partial Q}{\partial t}+\frac{\partial}{\partial x}(U Q)=0 \text {. }
$$

Using central differencing in space and forward dfferencing in time, the finite difference equation is (see Fig. B.2)

$$
\begin{aligned}
\left(Q_{1}^{\mathrm{n}+1}-\theta_{1}^{\mathrm{n}}\right) / \delta \mathrm{t} & =-\left[U_{R}\left(Q_{1}+Q_{1+1}\right) / 2-U_{L}\left(Q_{1}+Q_{1-1}\right) / 2\right] / \delta \mathrm{x} \\
& =-\frac{1}{2 \delta \mathrm{x}}\left[\mathrm{U}_{\mathrm{R}}\left(Q_{1}+Q_{1+1}\right)-U_{L}\left(Q_{1}+Q_{1-1}\right)\right]
\end{aligned}
$$

We now assume that $U_{R}$ and $U_{L}$ are greater than zero, and that fluld with a velocity $U_{R}$ or $U_{L}$ carries the property $Q_{1}$ or $Q_{1-1}$ respectively. The new formulation under the donor cell approach is

$$
\frac{Q_{1}^{n+1}-Q_{1}^{n}}{\delta t}=-\frac{U_{R} Q_{1}-U_{L} Q_{1-1}}{\delta x} \quad U_{R}, U_{L}>0
$$

Similariy, for $U_{R}, U_{L}<0$ we have

$$
\frac{Q_{1}^{n+1}-Q_{1}^{n}}{\delta t} \cdot \frac{U_{R} Q_{1+1}-U_{L} Q_{1}}{\delta x}
$$

$$
\mathrm{U}_{\mathrm{R}}, \mathrm{U}_{\mathrm{L}}<0
$$

These can be put Into a general form that encompasses both cases,

$$
\begin{gathered}
\frac{Q_{1}^{n+1}-Q_{1}^{n}}{\delta t}=-(1 / 2 \delta x)\left[U_{R}\left(Q_{1}+Q_{1+1}\right)+\left.\alpha_{x}\right|_{R} U_{R}\left(Q_{1}-Q_{1+1}\right)-\right. \\
\left.U_{L}\left(Q_{1-1}+Q_{1}\right)-a_{x}\left|U_{L}\right|\left(Q_{1-1}-Q_{1}\right)\right]
\end{gathered}
$$

If $\alpha_{x}$ equals 0 or 1 , the above form reduces to the central difference or donor cell methods respectively. In general, the donor cell treatment 1mproves the numerical stability and convergence rate. 


\subsection{Solution Procedures}

The velocities computed from $\mathrm{Eq} . ' \mathrm{~s}$ B.l and B.2 will not, In general, satisfy the continuity equation (Eq, B.6). VARR-II adopts the simplified Marker-and-Cell (SiAC) method ${ }^{(19)}$. The cont1nu1ty constra1nt 1s 1mposed by adjusting the cell pressure. For example, if the divergence of a cell, $\nabla \cdot D \equiv \frac{\partial U}{\partial r}+\frac{\partial V}{\partial z}+\frac{U}{r}$, is negative corresponding to a net rlow of mass into the cell, the cell pressure is Increased to counteract the inflow. Likewise, when there is a net flow out of the cell, the cell pressure 1s decreased to draw the flow back. Because there is one pressure varlable for each cell, the divergence for each cell can be driven to zero in thls way. However, the pressure adjustment must be done iteratively, since the adjustment in one cell will affect 1 ts nelghbors.

The new cell pressure 1s $P_{1 j}+\delta P$, and the new veloc1 ties are

$$
\begin{aligned}
& \mathrm{u}_{1 \mathrm{k}} \rightarrow \mathrm{u}_{1 \mathrm{k}}+(1 / \delta \mathrm{x}) \delta \mathrm{P} \delta \mathrm{t} \\
& \mathrm{u}_{1-1, k} \rightarrow \mathrm{U}_{1-1, \mathrm{k}}=(1 / \delta \mathrm{x}) \delta \mathrm{P} \delta \mathrm{t} \\
& w_{1, k} \rightarrow w_{1, k}+(1 / \delta 2) \delta P \delta t
\end{aligned}
$$

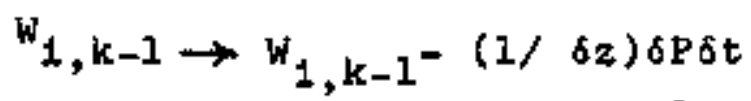

$$
\begin{aligned}
& \delta P=-\beta D / \delta t \text {, where } \beta=\frac{1}{2} \beta_{0}\left[\frac{1}{(1 / \delta x)^{2}+(1 / \delta z)^{2}}\right]
\end{aligned}
$$

Eq. 9.8 1s derived by substituting the right side of Eq. B.7 Into the divergence condition, Eq. B.6, and solving for 6 P. The term $\beta_{0}$ is a relaxation factor.

The convergence rate will be improved by using this relaxation factor. Bo 1 s usually bounded between 1.2 and 2.0 . 


\subsection{Boundary Conditions}

Four types of boundary conditions can be simulated in VARR-II .

\subsubsection{Rigid Boundary Cond1tions}

Following the example in Fig. B.3(a), if the left boundary is to be a rigid free-slip wall, then the normal velocity there must be zero and the tangential velocity should have no normal gradient, $1 . e ., U_{1, k}=0$, and $W_{1, k}=W_{2, k}$. If the left boundary is a no-slip rigid wall, then the tangentlal velocity component at the wall should also be zero, $1, e_{.}, U_{1, k}=0$, and $w_{1, k}=-w_{2, k}$.

\subsubsection{Continuative Boundary Conditions}

Th1s boundary condition allows for an outflow of flutd. For a top wall w1th a free-slip wall boundary condition, as shown in F1g. B.3(b), the outsfde tangentlal velocities are $\mathrm{U}_{1, k+2}=\mathrm{U}_{1, k+1}$ and $\mathrm{U}_{1-1, k+2}=\mathrm{U}_{1-1, k+1}$. For the no-s11p wall boundary condition, the opposite signs are used. The normal veloctty is determinet by satisfying the divergence free condition in the unit cell.

\section{3 .3 Period1c Boundary Cond1tions}

The periodic boundary condition allows the setting up of a mesh boundary configuration that approximates an infinitly long mesh in which perlodic flows exist one after another. It is shown in F18. B.3(c). Th1s boundary condition 18 very useful for calculating fully developed flows. 


\subsubsection{Derived Boundary Conditions}

This boundary condition 1nsures the correct turbulent shear stress at the wall when the mesh size is too large to properly resolve the velocity distribution near the wall. Th1s 1s done by analytically prescribing a logarithmic velocity proflle between the computational cell next to the wall and the wall 1tself. This proftle is: $W^{\prime}=U^{*}\left(A \operatorname{In} \frac{W^{*} x}{\psi}+B\right.$ ), where $U^{*}=\sqrt{\frac{T}{D}}$, and $A$ and $B$ are universal constants. The above equation can be put into the following form:

$$
U^{*}=\frac{W}{A \ln \left(U^{*} x / v\right)+B}
$$

An Iteration scheme determines $v^{*}, W, q$ and $\sigma$. The complete solution scheme in VARR-II is shown in Fig. B.4. One calculational cycle is composed of four steps:

(1) Compute guesses for the new velocities for the entire wesh from Eq.'s B.1 and B.2 which involve only the valueg at previous times.

(2) Match the boundary conditions and adjust the new velocities to satisfy the continulty equation (Eq.B.6) by making appropriate changes in the cell pressures. In the iteration, each cell is considered successively and is given a pressure change that drives its velocity divergence to zero.

(3) When convergence has been achleved, the velocity and pressure flelds are used to compute the turbulent kinetic energy, kinematic viscosity, and internal energy.

(4) Fina2ly, all of the field properties are at the advanced time level and are used as the starting values for the 
next cycle.

3. Changes made in VARR-II

The ortginal version of VARR-II was developed to run on a CDC 7600 computer. The Westinghouse Advanced Reactor Division has made several small modifications ${ }^{(20)}$. The changes discussed below are from the Westinghouse version of the code. Due to the different assembly language and plotting subroutines used by different computer faclittles, the following changes were made in order to run VARR-II on an IBM computer:

(1) An overlay structure was removed, due to the large active memory of the IBif machine,

(2) All the plotting subroutines were removed, and a new rout1ne was inserted.

(3) An assembly language subroutine, EITPIC, for b1t manipulation was removed, and appropriate actions were taken to ensure the correctiness of the remalning statements .

(4) All of the seven-character names were reduced to s1x by removing either the first or the last character.

(5) Programing errors in the der1ved boundary condition were corrected.

The correctness of the new verston was tested by running a sample problem. 


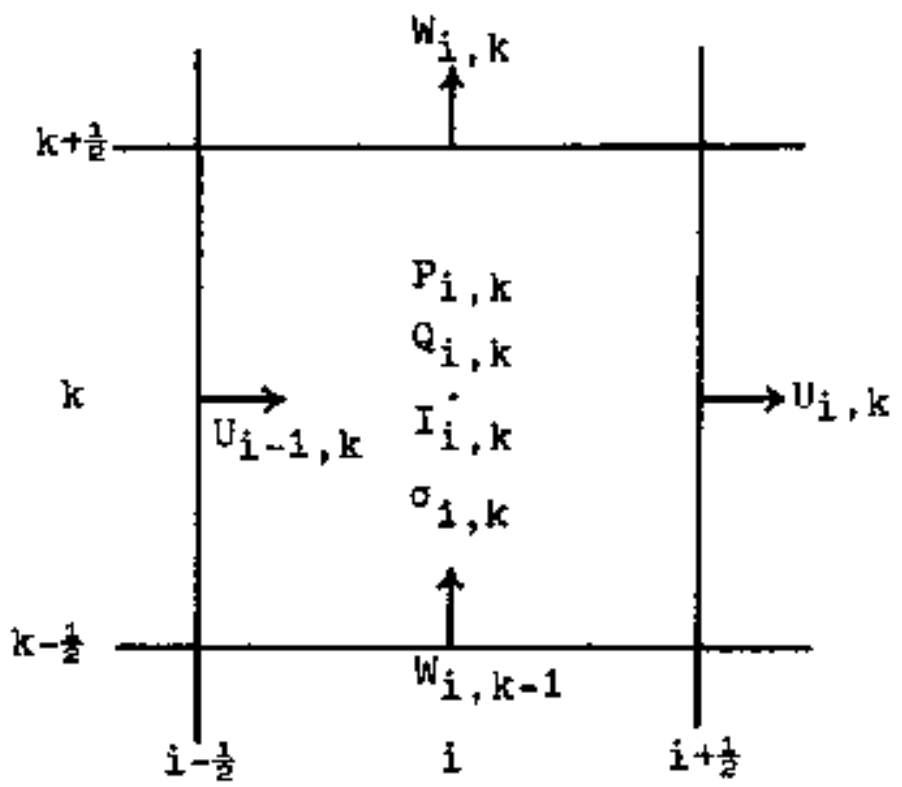

Fig. B.l A typical cell showing the locations of the principle vartables

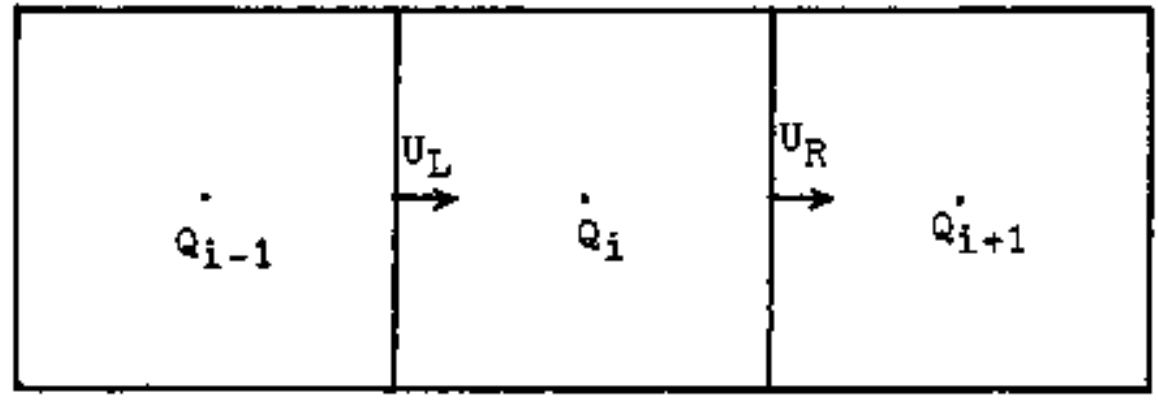

F1g. B.2 A typlcal cell showing the donor cell treatment of the convection terms 


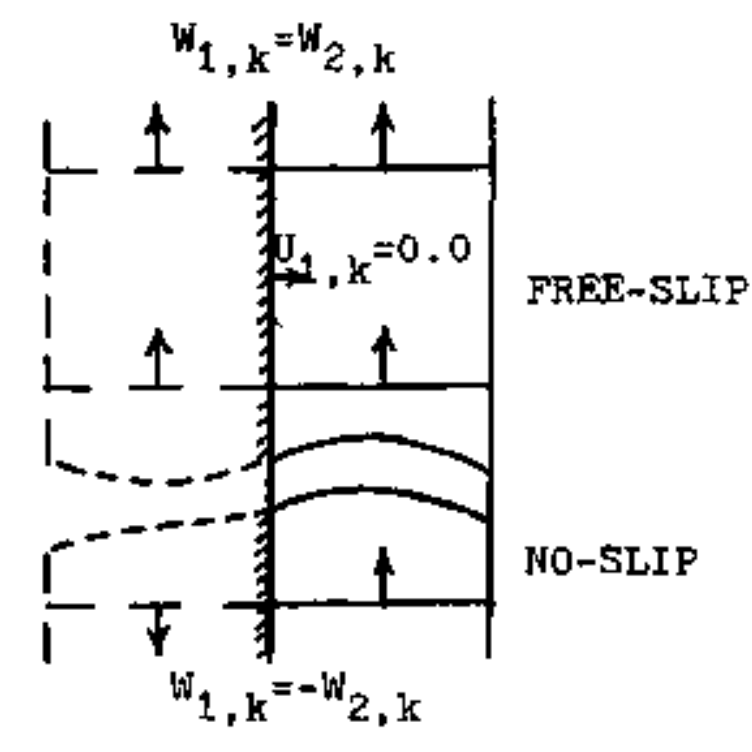

(a) RIGID BOUNDARY-IEFT WALL

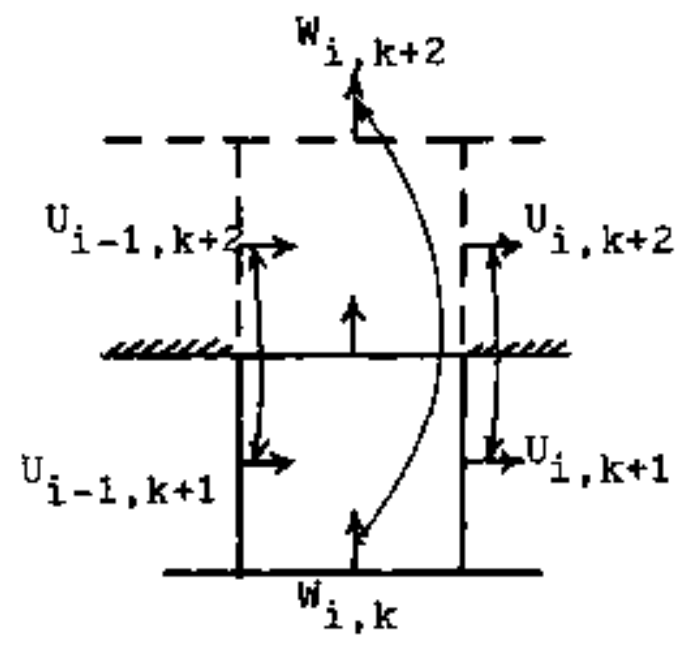

(b) CONTINUATIVE BOUNDARY - TOP WALL

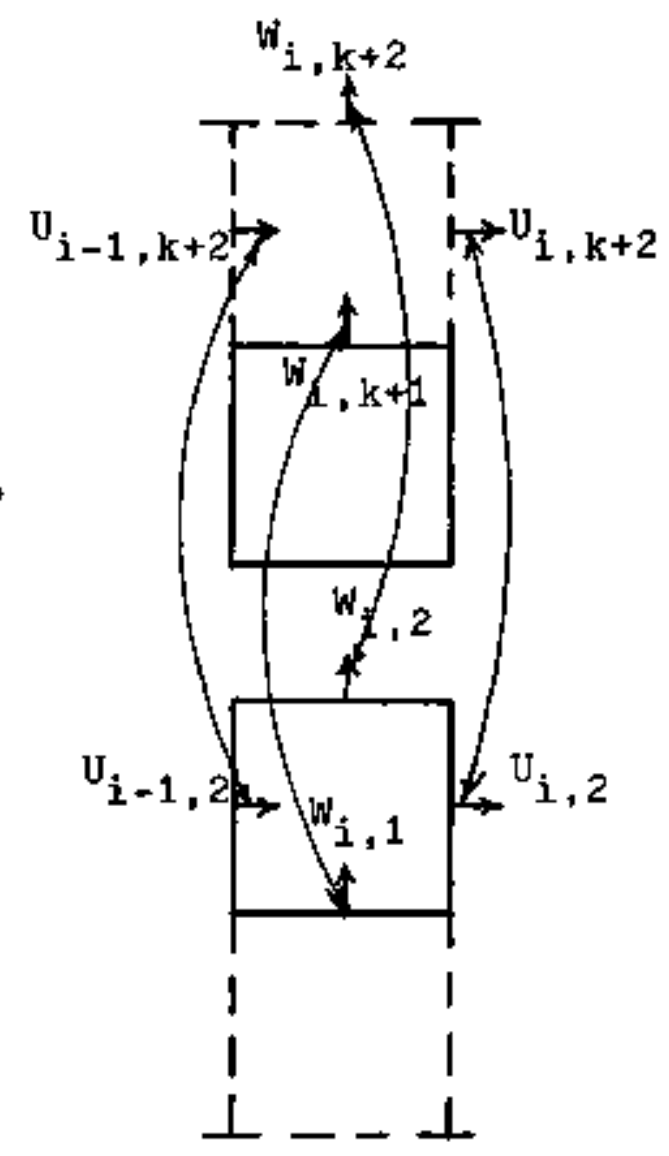

(c) PERIODIC BOUNDARY-TOP AND BOTTOM

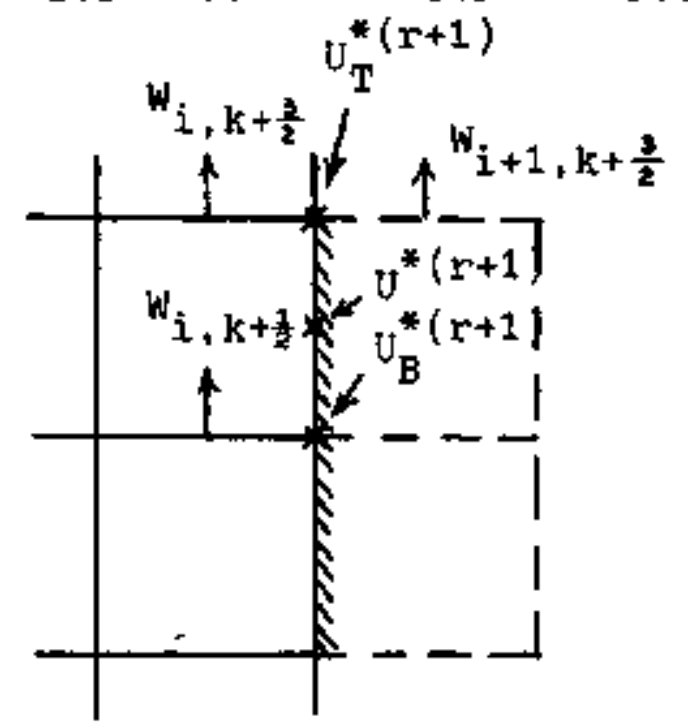

(d) DERIVED BOUNDARY CONDITION - RIGHT WALL

F1z. B.3 Deta1is of VARR-II Boundary Cond1tions 


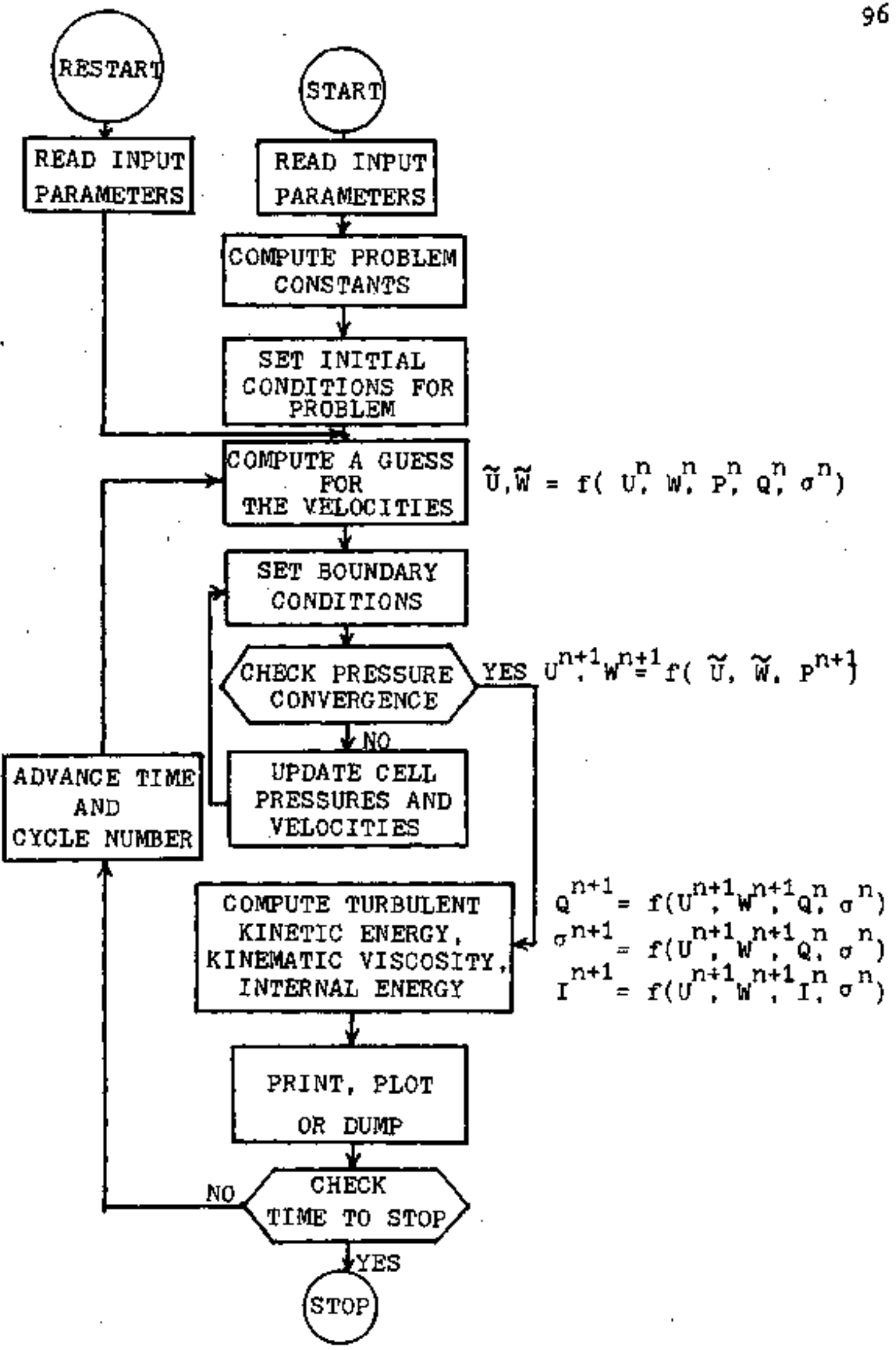

Fig. B.4. Flow Diagram of Solution Scheme 


\section{APPENDIX C \\ DESCRIFTION OF THE TEACH-T CODE}

The TEACH-T code (1) was develaped in the Mechanical Engineer1ng Department at the Imperial College of Sclence and Technology in England.

\section{Equation of Motion}

This code adopts a K-E two-equation turbulence model. Four differential equations are solved by the code:

$$
\begin{aligned}
& \frac{\partial}{\partial x_{j}}\left(D U_{j} U_{1}\right)-\frac{\partial}{\partial x_{j}}\left(\omega \frac{\partial U_{1}}{\partial x_{j}}-\partial \overline{V_{1}} U_{j}\right)-\frac{\partial P}{\partial x_{1}}=0 \\
& \frac{\partial}{\partial x_{1}}\left(\rho U_{i}\right)=0 \\
& U_{j} \frac{\partial}{\partial x_{j}} \rho K-\frac{\partial}{\partial x_{j}}\left(\frac{\mu_{t}}{\sigma_{K}} \frac{\partial K}{\partial x_{j}}\right)-\mu_{t} G+\partial E=0 \\
& J_{j} \frac{\partial}{\partial x_{j}} \rho \varepsilon_{-} \frac{\partial}{\partial x_{j}}\left(\frac{\mu_{t}}{\sigma_{\varepsilon}} \frac{\partial \varepsilon}{\partial x_{j}}\right)-\frac{C_{1} E}{K} \mu_{t} G+c_{2} \rho \frac{\varepsilon^{2}}{K}=0 \\
& \text { where }=o \nabla_{1}=H_{t}\left(\frac{\partial U_{j}}{\partial x_{j}}+\frac{\partial U_{1}}{\partial x_{1}}\right) \\
& \mu_{t}=c_{\mu} \rho \kappa^{2} / \varepsilon \\
& G \equiv\left(\frac{\partial U_{1}}{\partial x_{j}}+\frac{\partial U_{j}}{\partial x_{1}}\right) \frac{\partial U_{1}}{\partial x_{j}}
\end{aligned}
$$

In the above equations, $U_{1}$ is the mean velocity, $P$ is the mean pressure, $o$ 1s the density of the fluid, $k$ is the turbulent kinetic energy, $\varepsilon$ is the turbulent energy disspation rate, 4 is the $v$ iscosity, $\mu_{t}$ is the turbulence $v 1 \operatorname{scosity}$, and $\sigma_{K}, \sigma_{E}, C_{1}$, $c_{2}$, and $c_{\mu}$ are constants determined by experiments. 
2. Analysis

\subsection{Finlte D1frerence Formulation}

In the previous section, all of the differential equations except the continuity equation can be expressed in terms of the foilcwing general transport equation in cyclindrical coordinates:

$$
\begin{gathered}
\frac{1}{t}\left[\frac{\partial}{\partial x}(p r v \theta)+\frac{\partial}{\partial \Gamma}(\operatorname{prv} \theta)-\frac{\partial}{\partial x}\left(\operatorname{rr} \frac{\partial \theta}{\partial x}\right)-\frac{\partial}{\partial \Gamma}\left(r \Gamma \frac{\partial \emptyset}{\partial \Gamma}\right)\right] \\
-s_{\emptyset}=0
\end{gathered}
$$

The finlte difference grid is shown in Fig. C.1. Scalar quantities are defined at the Intersections of grid lines, and the velocities are defined at control volume boundarles (dashed 11nes).

A finite difference equation for the scalar $\|_{p}$ is obtained by integrating Eq. C.5 over the control volume, and then by using Gauss's theorem to replace volume integrals by surface integrals. The resulting equation is

$$
\begin{aligned}
& \int_{S}^{n}\left[\left(\rho r \cup \emptyset-r \Gamma \frac{\partial \emptyset}{\partial x}\right)_{E}-\left(\rho r U \emptyset-r \Gamma \frac{\partial \emptyset}{\partial x}\right)_{W}\right] d r+ \\
& \int_{W}^{E}\left[\left(\rho r V \emptyset-r \Gamma \frac{\partial \emptyset}{\partial r}\right)_{N}-\left(\rho r V \emptyset-r \Gamma \frac{\partial \emptyset}{\partial r}\right)_{S}\right] d x-\int_{V} S_{\partial} d V+0,(C, 6)
\end{aligned}
$$

Assume that the net $x$-direction convection and diffusion of through the control volume are given by

$$
a_{E}\left(\theta_{E}-\phi_{p}\right)+a_{w}\left(\phi_{w}-\phi_{p}\right) \text {, }
$$

where 


$$
\begin{gathered}
a_{E}= \begin{cases}0 & \text { when } F_{E}>D_{E} \\
-2 F_{E} & \text { when } F_{E}<-D_{E} \\
D_{E}-F_{E} & \text { when }-D_{E} \leqslant F_{E} \leqslant D_{E}\end{cases} \\
F_{E}=\dot{m}_{E}^{\prime \prime} A_{E} / 2, D_{E}=r_{E} A_{E} / \delta x_{E}
\end{gathered}
$$

The terms $\dot{m}_{E}^{\prime \prime}, A_{E}$, and $r_{E}$ stand for the mass flux, crosssectional area, and average exchange coeffictent at the boundary respectively.

The above scheme is a hybrid of central and upwind (donor ceil) difference schemes. As $|F / D|$ is less than or greater than unity, 1t reduces to central or upwind difference schemes respectively. Th1s hybrid scheme has the advantage of being more accurate and stable over a wide range of $F / D$.

The resultant difference equation from $\mathrm{Eq} . \mathrm{s} \mathrm{C} .6$ and $\mathrm{C.7}$ 1s $a_{p} \eta_{p}=\sum_{n}^{\Sigma} a_{n} p_{n}+\$_{\emptyset}$,

where $\sum_{n}$ is a summation over all neighbors, and

$$
a_{p}=\sum_{n} a_{n} \text {. }
$$

The treatment of the monentum equation is essentlaliy the same as the above. The control volume for the veloclties are, of course, displaced from those of 9 . Interpolation 15 sometimes necessary to obtain velocities, densities, viscosities, etc. The difference equations are,

$$
\begin{aligned}
& a_{p} U_{p}={ }_{n}^{2} a_{n} U_{n}+A_{W}\left(P_{W}-{ }_{p}\right)+s_{W} \\
& a_{p} V_{p}={ }_{n} a_{n} V_{n}+A_{s}\left(P_{s}-P_{p}\right)+s_{v}
\end{aligned}
$$

there $s_{u}$ and $s_{v}$ are integral source terms, that are discussed in Sec. $2,2,1$ below. 
Finaliy, the finite difference equation for the continulty equation is

$$
(\rho \cup A)_{E}-(\rho \cup A)_{W}+\left(\rho V_{A}\right)_{i N}-(\rho V A)_{S}=0
$$

\subsection{Treatment of Source Terms}

\section{2 .1 Momentum}

In the momentum equation, the source terms are

$s_{u}=\frac{\partial}{\partial x}\left(\mu_{\text {efr }} \frac{\partial U}{\partial x}\right)+\frac{l}{r} \frac{\partial}{\partial r}\left(r \mu\right.$ eff $\left.\frac{\partial U}{\partial r}\right)$, and

$s_{v}=\frac{\partial}{\partial x}\left(\mu_{\text {eff }} \frac{\partial V}{\partial x}\right)+\frac{l}{r} \frac{\partial}{\partial r}\left(r \mu\right.$ eff $\left.\frac{\partial V}{\partial r}\right)-\mu_{\text {eff }} \frac{V}{r^{2}}$.

The integral source terns in Eq. C.6 can be simply derived by integrating the above equation over the control volume.

\section{$2,2.2$ Turbulence K1net 1c Energy}

The source term in the $K$ equation $1 \mathrm{~s}$,

$$
\begin{aligned}
S_{K} & =\mu_{t} G+C_{D} p \varepsilon \\
& =-2 \mu_{t}\left[\left(\frac{\partial U}{\partial x}\right)^{2}+\left(\frac{\partial V}{\partial r}\right)^{2}+\left(\frac{V}{r}\right)^{2}\right]+\left(\frac{\partial U}{\partial r}+\frac{\partial V}{\partial x}\right)^{2}+C_{D} \rho \varepsilon .
\end{aligned}
$$

The integral source can be calculated by assuming that the source term is unffort over the control volume, $1 . e .$,

$$
\begin{aligned}
\int_{V} s_{K} d V & =-\int_{V}\left(\mu_{t} G-C_{D} \rho \varepsilon\right) d V=\int\left[C_{D} \rho\left(\frac{C_{\mu \rho K^{2}}}{\mu_{t}}\right)-\mu_{t} G\right] d V \\
& \approx b K_{D}+c
\end{aligned}
$$

where $\quad b \equiv-c_{\mu} C_{D} \rho_{p}^{2} K_{p}^{*} \delta V / \mu_{t}, c \equiv \mu_{t} G \delta V$, and

$K_{p}^{*}$ is the previous value of $K_{p}$.

\subsubsection{Turbulence KInet1c Energy D1ssipation Rate}

The source terms in the equation are,

$$
s_{\varepsilon}=c_{1} \varepsilon \frac{\mu_{t}{ }^{G}}{K}+\frac{c_{2} \rho \varepsilon^{2}}{K}
$$


Assuming $S_{\varepsilon}$ is uniform over the control volume, the integral source term is.

$$
\begin{aligned}
\int_{V E} S_{\varepsilon} d V & =\int\left(c_{1} \frac{\mu_{t}^{G E}}{K}-\frac{c_{2} \rho \varepsilon^{2}}{K}\right) d V \\
& \approx b \varepsilon_{p}+c \\
\text { Where } b \approx-c_{2} \frac{c_{p}^{* \delta V}}{K_{p}} & \\
& c \approx c_{1} \frac{u_{t}^{G E *}}{K_{p}^{*}}
\end{aligned}
$$

\subsection{Boundary Conditions}

F1g. C.2 12lustrates the boundary conditions discussed below.

\section{3 .1 veloctty}

In order to assure the correct shear stress on the wall, the shear stress 18 calculated as

$$
\tau_{s}=-\frac{\left.\rho_{p}\left(c_{p} c_{D}\right) \frac{1}{4 K_{p} \frac{1}{2}\left(U_{p}-U_{s}\right.}\right)}{U^{+}}
$$

where $\quad K_{p w} \equiv\left(K_{p}+K_{w}\right) / 2$

$$
\begin{aligned}
& U^{+}=\frac{1}{K} \ln \left(E^{+}\right) \\
& K=0.4, E=9.793, y^{+} \equiv\left(C_{\mu C_{D}}\right)^{\frac{1}{3}} \mathrm{~K}^{\frac{1}{2}} \mathrm{y}_{\mathrm{p}} / \mu
\end{aligned}
$$

For laminar flow $\left(y^{+}<11.63\right)$, a laminar law is employed:

$$
\tau_{\mathrm{s}}=-\frac{\left.\mu_{\mathrm{p}}-\mathrm{u}_{\mathrm{s}}\right)}{\mathrm{y}_{\mathrm{p}}}
$$

The usual shear force expression is suppressed by setting $a_{\text {out alde }}=0$. 
2.3.2 Turbulent Kinetic Energy

Calculation of $G$ is altered by

$\int_{V} \mu_{t}\left(\frac{\partial U}{\partial x}+\frac{\partial V}{\partial x}\right)^{2} d V \approx t_{s}\left(U_{p}-U_{s}\right) \delta V / y_{p}$

where $\tau_{s}, U_{s}$ and $U_{p}$ are nearby average values,

Contributions fron the outside are suppressed by setting $a_{\text {outside }}=0$.

\subsubsection{Turbulent Energy D1ssipation Fate}

The fintte difference equation at the near wall node is replaced by a log-law based relation:

$$
\varepsilon_{p}-\frac{\left(c_{\nu} c_{D}\right)^{3 / 4}}{\bar{c}_{D} \frac{k_{p}^{3 / 2}}{y_{p}}}
$$

In order to ut1l1ze the above formulation, the source coeff1clents are replaced by,

$$
b=-10^{30}, c=30^{30} \varepsilon_{p}
$$

\subsection{The Solution Procedures}

The solution technique is a series of guess and correct operations. F1rst, the guessed pressures $P^{k}$ and velocities $U^{*}$ and $V^{*}$ (which may be 1nitial guesses, or values from the previous cycle) are substituted into the momentum equations. Th1s ylelds an intermediate $U^{*}$ and $V^{*}$. In general, these velocities w1ll not satisfy the continulty equation.

The pressures are then adfusted to satisfy continuity. The relations between velocities and pressures are

$$
U_{w}=U_{w}^{*}+\frac{\partial U_{w}}{\partial\left(P_{w}-P_{p}\right)}\left(P^{\prime}{ }_{w}-P_{p}^{\prime}\right)
$$


where $P^{\prime}$ is the pressure correction.

The veloc1ty and pressure relations can be deduced from the momentum equation as

$$
D_{w}=\frac{\partial U_{w}}{\partial\left(P_{w}-P_{p}\right)}=\frac{A_{w}}{a_{p}-b} .
$$

Substituting this into the momentum equation, we obtain

$$
\begin{aligned}
\left(a_{p}-b\right) P_{p}^{\prime} & =\sum a_{n} F_{n}+M_{P}+c, \\
\text { where } M_{p} & =\left(\rho U^{*} A\right)_{W}-\left(\rho U^{*} A\right)_{E}+\left(\rho V^{*} A\right)_{S}-\left(\rho V^{*} A\right)_{N} \\
s_{U} & =b U_{p}+c \\
a_{W} & =p_{W} D_{W} A_{W} \\
a_{p} & \equiv \sum_{n} a_{n} .
\end{aligned}
$$

Once the $F^{\prime}$ field has been obtained, it is a stralghtforward matter to update the pressures and velocit1es. In general, 1t is not necessary to satisfy the continuity equation for each cycle, since the subsequent calculation for 0 (e.g., K, \&) will affect the velocities. The procedures adopted by TEACH-T are, for each cycle, $U, V, K$ and $\varepsilon$, 1terated three times, and $P$ flve times. The convergence criterion Is that residual sources for mass and velocities are below certaln values.

This solution aigorithm obviates the need to approach the steady state via the time evolution of the flow, as is required by the conventional method (such as the SMAC method in VARR-II). In the plenum considered in tinls work, the computation time for TEACH-I is approximately one order of magnitude less than that of VARR-II. 


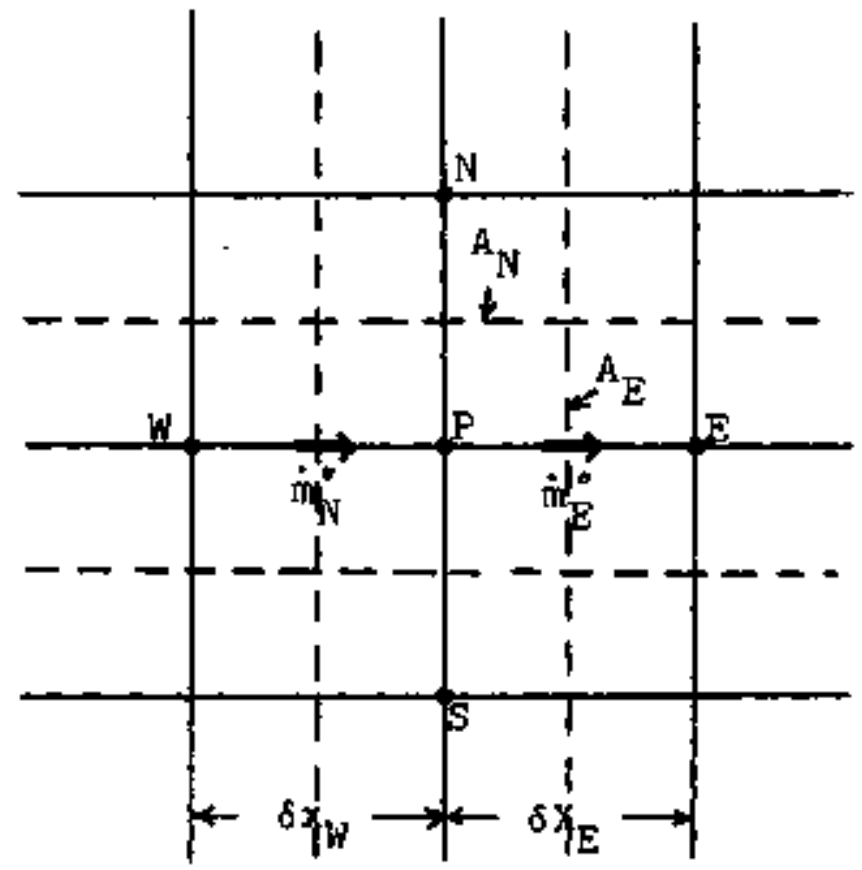

F1g. C.I Finite D1fference Grid for TEACH-T 


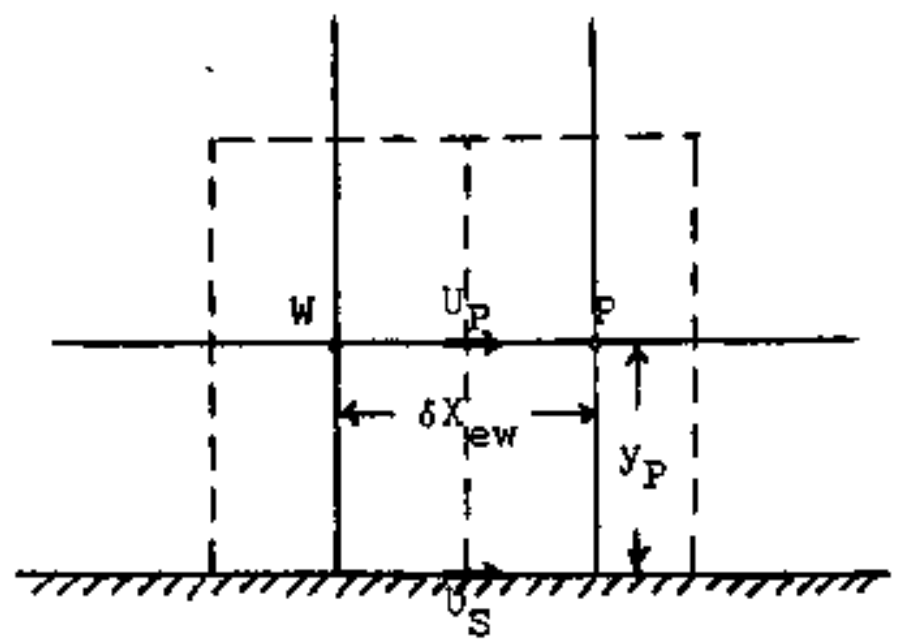

(a) Velocity Boundary Cond1tions

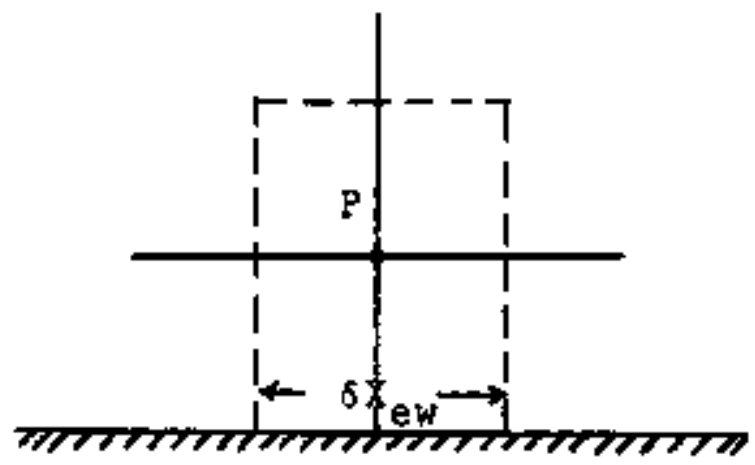

(b) Turbulent Kinetic Energy and Dissipation Rate Boundary Condition

F18. C.2 Boundary Cond1tions in TEACH-T 


\section{APPENDIX D \\ LASER DOPPLER ANEWOMETER}

\section{Introduction}

The Lager Doppler Anemometer (LLA) was developed in 1964 by Yeh and cumins (22) who first demonetrated that the Doppler shift of light scattered by moving particles could be detected by heterodyning the scattered 21ght with a laser source on a photocell. Since then, a tremendous effort has been made by many researchers around the world toward making the LDA a reliable fluid velocity measuring instrument.

The major advantages of the LDA over conventsonal hot wire or pitot tube probes are:

1. The measurement 1s performed $w 1$ th laser beams; no probes disturb the flow.

2. The measuring (or scattering) volume is very small, which allowa a high spatial resolution.

3. No callbration of the equipment 1 s required.

4. The flu1d velocity is Inearly proportional to the Doppler shift.

5. The directional sensitivity is ideal for two or three-dimensional measurements.

\section{Princ1ple of the Laser Doppler Anemometer}

If a source of sound or electromagnetic waves of constant frequency is put into motion, a fixed observer will recelve a different frequency. Th1s is the well-known Doppler effect. 
A similar phenomenon is also observed when the source is fixed but the wave is scattered by a moving body before reachIng a fixed obgerver. The Doppler shift of an electromagnetic wave 1 s usually very small compared to the source frequency and very difficult to detect. Conventional light sources have a bandw1dth larger than the Doppler shift and this change in frequency could not be detected in the broad s1gnal. It is the introduction of the laser that permits the measurement of a Doppler shift at optical frequencles. The laser is a source monochromatic light with a very smell bandwidth. For example, a single axial mode of the He-Ne laser operating at $6328 \AA$ $\left(t^{2} 10^{14} \mathrm{~Hz}\right.$ ) has a bandwidth of $10 \mathrm{kz}$. The Doppler shict is usually Iarger than one Kilohertz. Although this is still smal l compared to the source frequency, it is large compared to the source bardw1dth and thus is detectable with a heterodyne tochnique.

As 1liustrated in Fig. D.1, light incident on a scattering particle is scattered at a different wave number. If $\underline{k}_{1}$ and $\underline{k}_{\mathrm{s}}$ are the wave numbers of the lncident and acattered light respectively, the difference in wave number is given by $\underline{K}=\underline{k}_{1}-\underline{k}_{8}$.

If $U$ is the velocity vector of the scattering particle, the frequency shift between 1ncldent and scattered 11ght as seen by a flxed observer is (23)

$$
W_{D}=2 \pi f_{D}=\underline{K}+\underline{U} \text {, or } S_{D}=\frac{l}{\lambda_{1}} \underline{U} \cdot\left(\hat{K}_{1}-\hat{k}_{s}\right)
$$

where $\lambda_{1}$ 1s the wavelength of the 1ncident beam, and $\hat{k}_{1}$ and 
$\hat{K}_{s}$ are unit vectors.

Note that the Doppler shift is Inearly proportional to the component of velocity in the direction of $U \cdot\left(\hat{K}_{1}-\hat{K}_{s}\right)$. This result permits us to measure components of velocity in any direction by properly orlenting the difference vector, $\left(\hat{K}_{1}-\hat{K}_{5}\right)$. Secondly, the LDA has an amblgulty of the flow alrection, 1.e., the LDA system is unable to distinguish whether the velocity is postlive or negative. Unless a frequency shift device 1s used, the LDA will give erroneous results for small and possibly reverse flows.

The Doppler shift can be detected by a square law detector, such as photomultiplier or photodiode. Considering the reference beam systen shown in P1g. D.2, the two light beams may be represented by

$$
\begin{aligned}
& E_{1}=E_{10} \sin 2 \pi r_{0} t \\
& E_{2}=E_{20} \sin 2 \pi\left(r_{0}+r_{D}\right) t
\end{aligned}
$$

The output current, 1 , is proportional to the square of the total electric field incldent on 1 :

$$
\text { 1a } \begin{aligned}
&\left(E_{1}+E_{2}\right)^{2} \\
&=E_{10}{ }^{2} \sin ^{2} 2 \pi f_{0} t+E_{20}{ }^{2} \sin ^{2} 2 \pi\left(f_{O}+f_{D}\right) t \\
&+E_{10} E_{20}\left[\cos 2 \pi f_{D} t-\cos 2 \pi\left(2 f_{O}+f_{D}\right)\right]
\end{aligned}
$$

Since the detector cannot follow frequencies greater than several hundred megahertz, terms in the expansion Involving $f_{O}, f_{O}+f_{D}$, and $2 f_{0}+f_{D}$ will give rise only to a D.C. current proportional to the time average of those terms. If 
$f_{D}$ is below the frequency cutoff of the detector, there will be a signal

$$
10 \frac{E_{10}{ }^{2}+E_{20}{ }^{2}}{2}+E_{10} E_{20} \cos 2 \pi f_{D} t
$$

The first terw is the D.C. current and the second term 1s the A.C. or Doppler current. In order to know the velocity, a proper frequency analysis 1nstrument (such as spectrum analyzer, frequency tracker, or frequency counter) may be used to determine the Doppler frequency.

\section{Modes of Operation}

There are several dffferent opt1cal arrangements for the experimenter. The two most popular schemes are discussed here.

\subsection{Reference Beam Mode}

As shown in F1g. D.2, the incident light is first split into two beans. After passing tinrough the focusing lens, they intersect within the fluid to form the measuring volume. A photodetector is aligned with the reference beam to pick up the signal. In order to reduce the intensity of the reference bear and optimize the s1gnal, a neutral density filter must be used.

This mode is preferred for measkrement in flows with high particie concentrations.

\subsection{Dual Scatter (or Fringe) Mode}

In the dual scatter mode, two beams intersect to form the fringes lllustrated in Fig. D.3. The Doppler frequency 
is shown to be proportional to the rate at which fringes are crossed by the scatterlig particles. Note that this result is identical to Eq. D.1. Consequently, the Doppler shift is Independent of the direction of detection. The Inmediate advantage of this result is that scattered light can be collected over a wide solid angle with relatively low intensity scattered light. In general, this mode regulres a low particle concentration for a good signal to noise ratio.

\section{Limitations on Accuracy}

The Laser Doppler Anemometer provides an absolute measurement of velocity and does not require any calibration. Its frequency and spatial resolution are excelient. Also, this technique allows the scattering voluse to be easily posttioned In the flow channel by traversing the optjcal components. In spite of these advantages over other types of anemoneters, the LDA still has many IImitations.

\subsection{Frequency Broaden1ng}

The term "frequency broadening" refers to the finite w1dth of the frequency probalilty density distribution of the optical signals resulting from effects other than the varlation of local velocity with time. There are several contributions to the frequency broaden1ng, and these are subdivided into three different classes for discussion. 


\subsubsection{Finite Transit Time Broagening}

A typical signal generated by a particle passing through the measuring volume is shown in F18, D.4. The small size of the measuring volume and the finite velocity of the scattering particles result in a $f$ inite signal burst. Since the coherent information only exists for a time interval $\Delta t$, it limits the resolution of the magnitude of the local velocity variations with time. If an electronic data processing system is used, It gives not only the signal frequency but also the envelope of the signal burst. From detafled frequency analysis(24), 1t can be deduced that the finite spectral width, $\delta f$, is Inverseley proportional to the duration, $\Delta t, 1, e .$,

$$
\begin{aligned}
& \text { of } i \frac{1}{\Delta \tau} \\
& \text { since } \Delta \tau=\frac{d_{\text {fl }}}{U}=\frac{N_{p f}}{f} \\
& \frac{\delta f}{f} \sim \frac{1}{i_{p r}}
\end{aligned}
$$

where $d_{m}$ is the fringe spacing, and $N_{p f}$ is the number of fringes in the measuring volume. From the above equation, it is concluded that in order to ensure this broadening is less than 1\%, Wuf must be greater than 100 .

\subsubsection{Broadening due to Optical Imperfections}

From Eq. D.1, the Doppler frequency is

$$
f=\frac{1}{\lambda} \underline{u} \cdot\left(\hat{K}_{1}-\hat{K}_{s}\right)
$$

Due to the finte s1ze of the laser beam, imperfections of the optical components, and possible optical alignment errors, the 
$\underline{U} \cdot\left(\hat{K}_{1}-\hat{K}_{3}\right)$ term will not be unlform over the transtt time of particles.

\section{1 .3 Broadening Due to Spatial Variations in Veloc1ty}

If a velocity gradient exists over the finite size of the meaturing volume, particles crossing the control volume at different positions will have different velocitles. These velocity differences cannot be distingulshed from velocity varlations with time, and have to be constdered as a broaden1ng. Th1s can be represented by

$$
\frac{\delta f}{\mathrm{f}} \frac{1}{2 U}\left[\frac{\partial U}{\partial \mathrm{x}}\right] \delta \mathrm{x}
$$

where $\delta x$ is the dimension of the scattering volume perpendiclilar to the direction of the velocity gradient measurement.

\subsection{Veloc1ty Btas1ng}

The number of particles which arrive having a particular veloc1ty 18, in general, dependent on the veloc1ty. If the particie distribution 1s uniform in space, the rate of particles arriving in the acattering volume will be higher for fast particles (cf, a high volume flow rate for fast particles). Consequently, the average value of the measurts velocity conponent will tend to be higher than the statistical mean value. The degree of blasing depends not only on the signal processors used, but also on the averaging mode employed. For example, consider two different averaging modes for the frequency tracker: 
Mode 1 - the analog voltage is 1ntegrated over all time, no matter whether the Doppler s1gnal is present or not.

Mode 2 - the analog voltage is integrated only over the t1me that the Doppler signal is present.

It is no surprise that these two modes give different average values, and mode 2 tenas to give better results. Unfortunately; most of the comercial trackers adopt the first scheme. The ideal signal processor for decreasing the velocity blasing is the random sampling clrcuit, 1.e., it observes the scattering volume at random lastants of time, so that there is an equal probability to detect elther fast or slow particles.

\subsection{Random Fhase Fluctuation due to Many Scattering Particles}

So far only the signal produced by olngle particle has been discussed. While more than one particle is in the volume, not only the signal amplitude changes, but also the phase changes abruptiy. 25) For example, in F1g. D.5(a) there is only one particle in the volume, and the Doppler current is given by

$$
1_{D} \alpha \begin{cases}A \cos \left(\omega_{D} t+\theta\right) & \text { particle in volume } \\ 0 & \text { particle not in volume }\end{cases}
$$

Considering F1g. D.S(b), there are two particles in the volume which entered at different times. The Doppler current is given by 


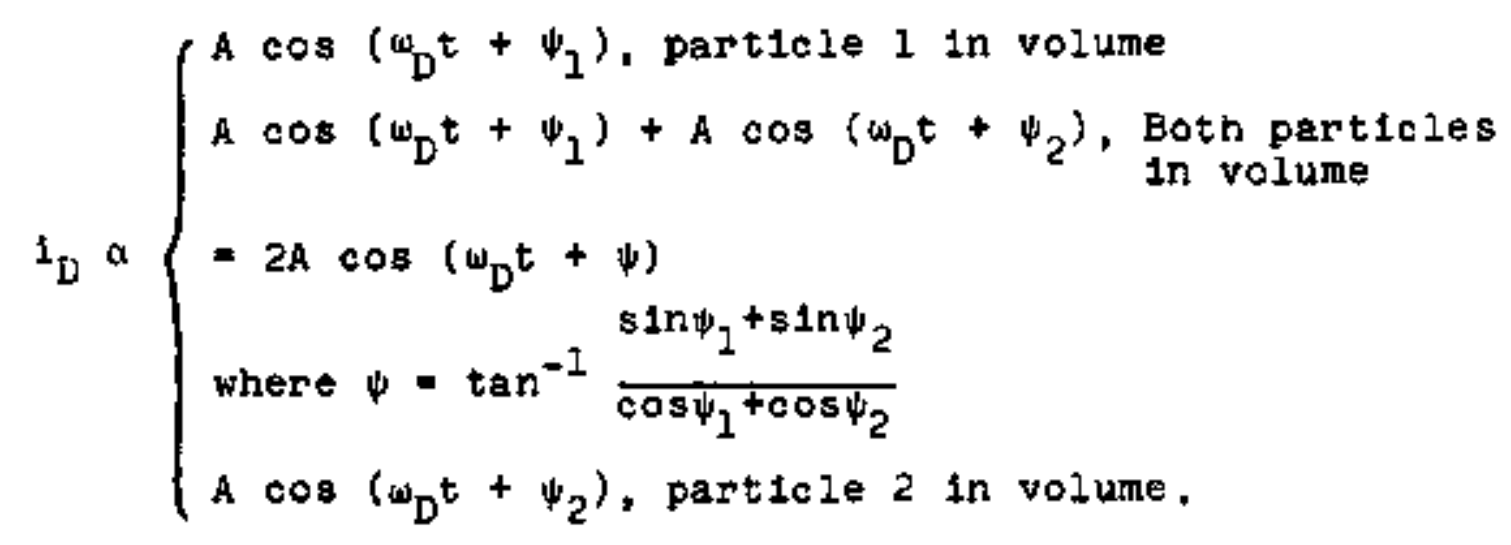

As show in the figure, each of the abrupt changes of phase amounts to an anomelous zero crossing. A tracker cannot distingulin these crosings from velocity fluctuations.

The second example of a phase fluctuation 18 shown in F15. D.5(c). There are two particles with different velocities which entered at the same time. The output 18 given by

$$
\begin{aligned}
& { }_{D} a A \cos \left(\omega_{D_{1}} t\right)+A \cos \left(\omega_{D_{2}} t\right) \\
& =2 A \cos \left(\frac{{ }^{\omega} D_{1}+{ }^{\omega} D_{2}}{2}\right) t \cos \left(\frac{{ }_{D_{1}}+{ }^{\omega} D_{2}}{2} t\right)
\end{aligned}
$$

The first term gives a frequency proportional to the mean velocity. The second term $1 \mathrm{~s}$ an entelope of the signal. As shown in the figure, extra zero crossings w1Il be detected as velocity fluctuations.

In summary, a phase fluctuation will result from

(a) a veloctty difference across the control volume,

(b) a particle population change in the control volume, and

(c) a Doppley envelope crossing a zero, even when particles are present. 
5. Optimization of the Doppler Signal

Some optimization procedures are rollowed to improve the $81 \mathrm{gnal}$ to noise rat1o, and to 1ncrease the accuracy of the mea surement.

\subsection{Laser Power Requirements}

When light strikes a particle, it scatters in every direction. The resulting distribution depends on several factors such as the propertles of the l1ght (e.g., wavelength), and the propertles of the scattering partioles (e.g., size, shape, refractive index). The intensity of 11ght scattered baskward is about three orders of magnitude less than the intensity of light scattered forward. Since only part of the total laser power scattered by a partlcle 1s collected by the photomultiplier and several photons per unit time are required to insure a good signal, the laser power requirement varles with the scattering direction. For forward scattering, the suggested laser power ${ }^{(26)} 19.05 \mathrm{mw} /$ (w/sec). For backward scattering, the requirement is a thousand times greater. In this experiment, a 2 watt laser is used, and is well above this limit for flows of water.

\subsection{Optical Path Lenxth D1fference}

The requirement here is that the optical path length difference of the two beans should be zero or differ by integral mult1ple of $2 L$, where $L 1 s$ the laser resonator cavity length. In practice, the comnerclally avallable integrated optical unit is designed so that the difference will cause only a small 
decrease in the amplitude of the signal. For the DISA Optic Unit with a two-channel section, the path length difference Is about $5.7 \mathrm{~cm}$, and $1 \mathrm{~s}$ small compared to the $1 \mathrm{~m}$. laser cav1ty length.

\subsection{Measuring Volume}

As discussed in section 4.1 , a small scattering volume is desirable for high spatial resolution and to ininimize broadening due to velocity gradients. But a small scattering volume can cause a large transit time broadening. Hence, there exists an optimum size for minsinum broadentng. The measuring volume can be adjusted by changing the focal lengti of the lens or the beam seperation distance. In practice, as long as one percent spatial resolution and 100 fringe lines are assured, no optimization is necessary.

\subsection{Scatter1ng Particles}

Since the scattered 11ght comes from the 1nteraction of the laser beam with the particles suspended on the fluld, it 1s very important to choose the perticle properly for accurate results. In this experiment, polystyrene latex particles are uged.

\subsubsection{Relative Density of the Particles and the Flutd}

The LDA system measures the particle velocity in the fiuld instead of fluld velocity 1tseif. It is very 1mportant to know whether the particles suspended in the fluld will follow the fluld. It has been shown ${ }^{(27)}$ that particles with a density close to that of the rlutd will follow the fluld 
within a broad velocity range. In this experiment, polystyrene latex particles with density of 1.05 are used, which $1 \mathrm{~s}$ very close to the density of water.

\section{4 .2 Particle Concentration}

As discussed in section 4.3, if several particles are slmultaneously passing through the measuring volume, the mixed signal will lead to less accurate results in the fringe mode. Thus the best concentration is that which results in only one particle being within the measuring volume at any t1me. This condition can be obtained by properly seeding the fluid and adjusting the size of measuring volume. In contrast, the reference beam mode usually requires a high particle concentration in order to get a better signal to no1se ratio.

\section{4 .3 Particle state}

In the fringe mode, if the size of the particles is larger than the fringe spacing, then no slgnal can be detected. In practice, the size of the partlcles snould be smaller than one quarter of a fringe spacing. But the size should not be too small, because the scatterins intensity decreases with the area of the particles. In this experiment, polystyrene latex farticles with size ranging from 0.46 to 0.54 micron are used. 


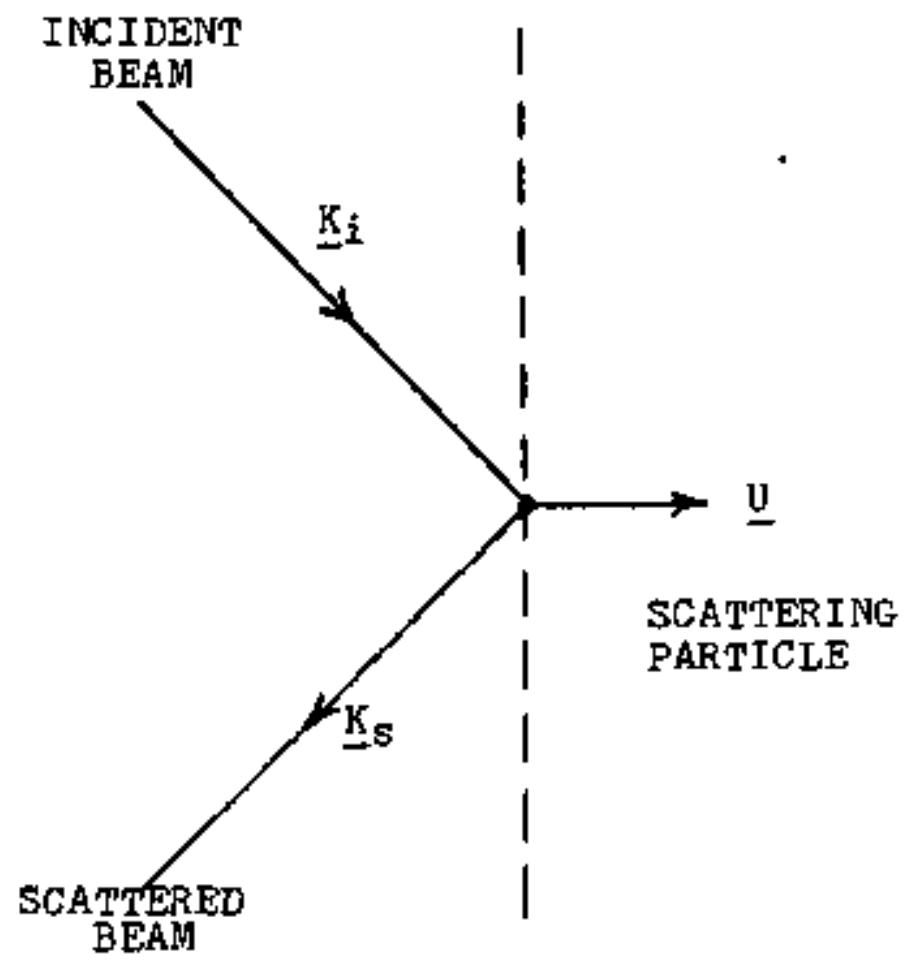

F1B. D.I Prequency Shtft for L1ght Scattered from a Moving Part1cle 


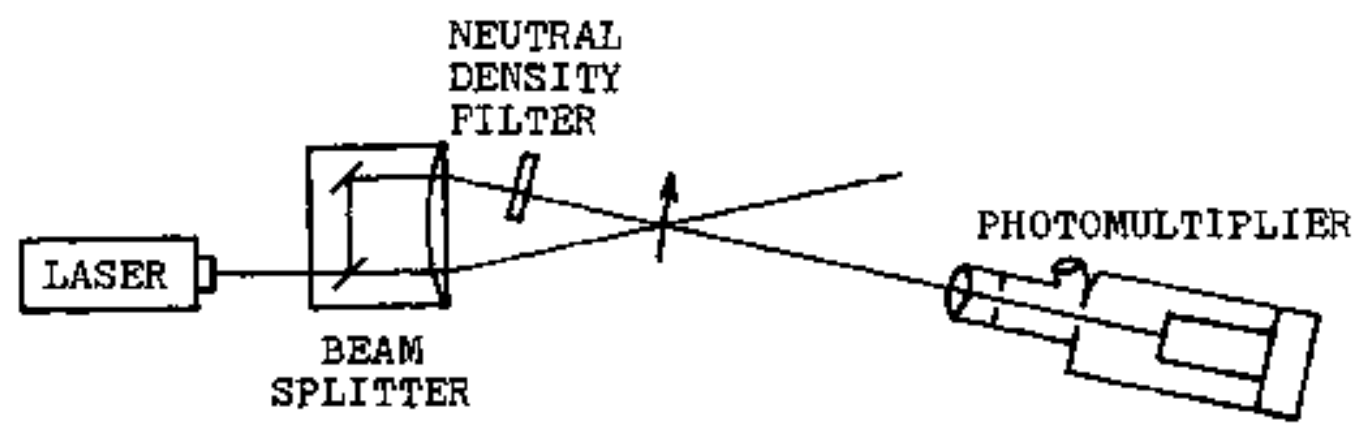

REFERENCE BEAM MODE

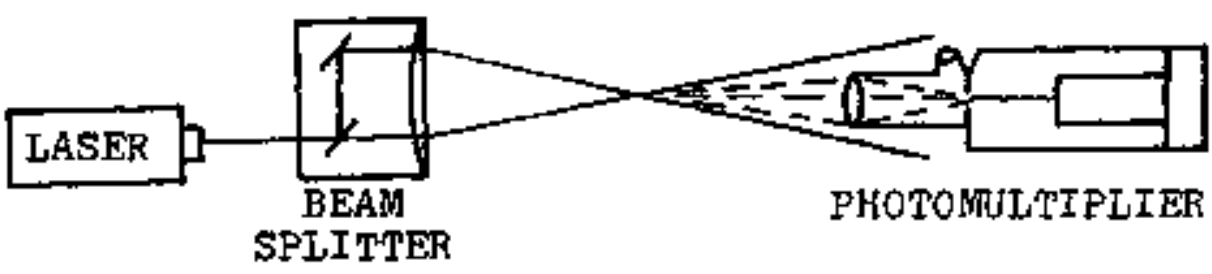

DUAL SCATTEF (FRINGE) MODE

F1g. D,2 Modes of Operation 
120

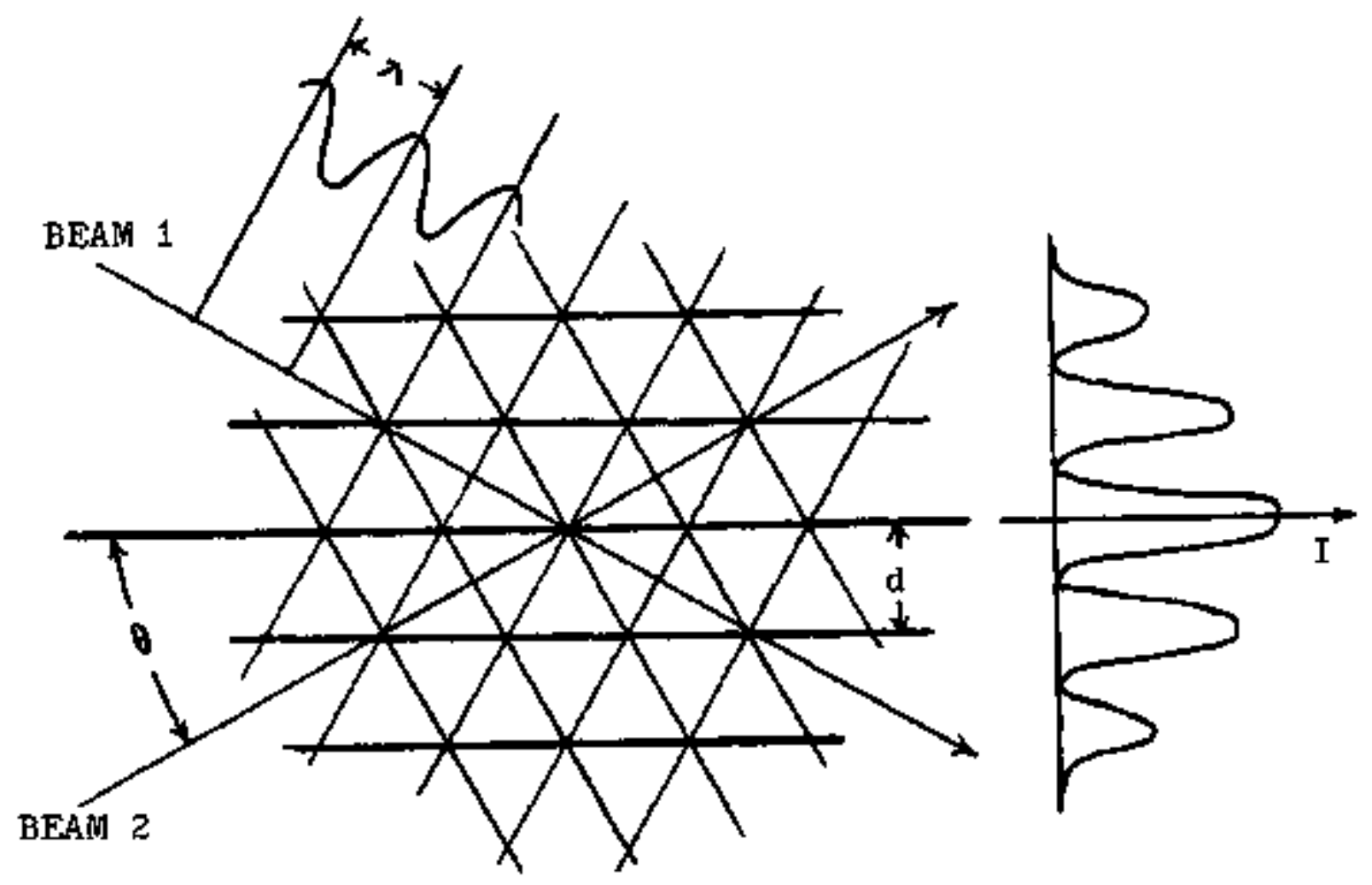

Fig. D.3 Fringe Patter at Beam crossing Point

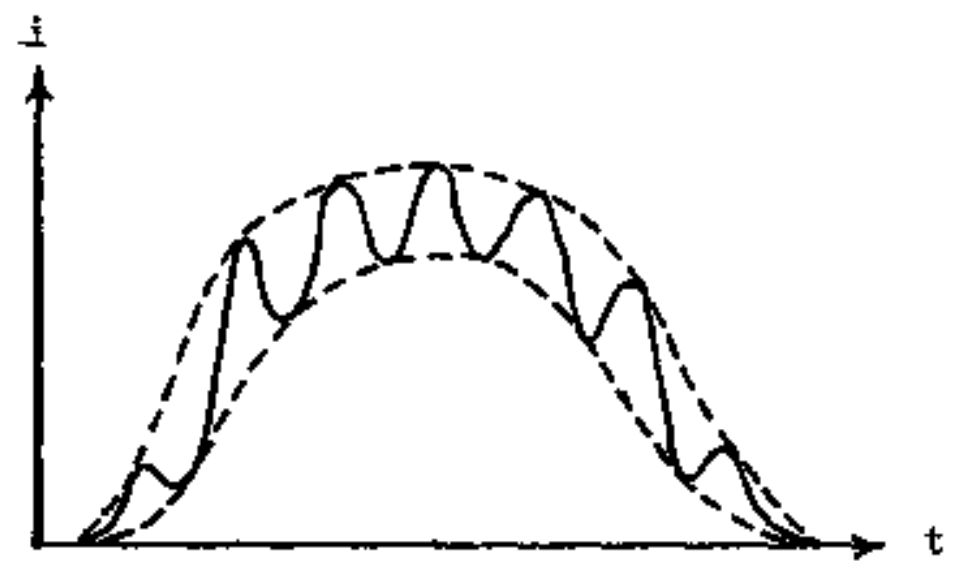

Fig. D.4 Typical Doppler S1 gal from Photomultiplier 

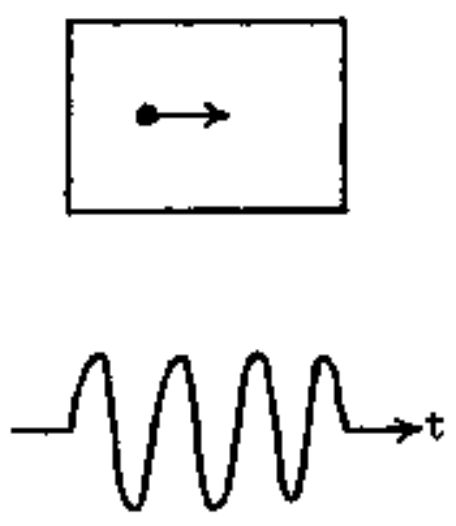

(a)
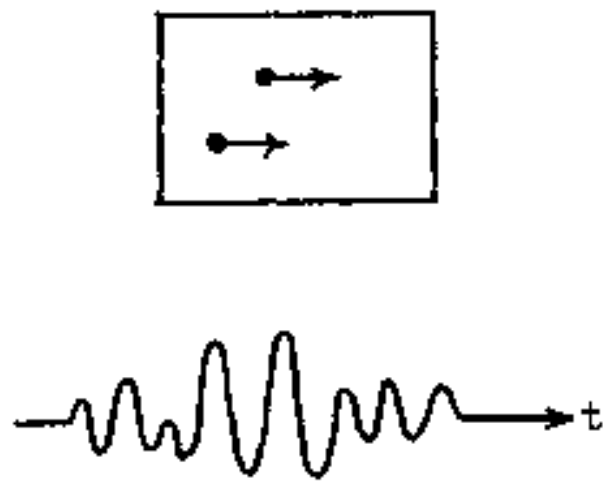

(b)
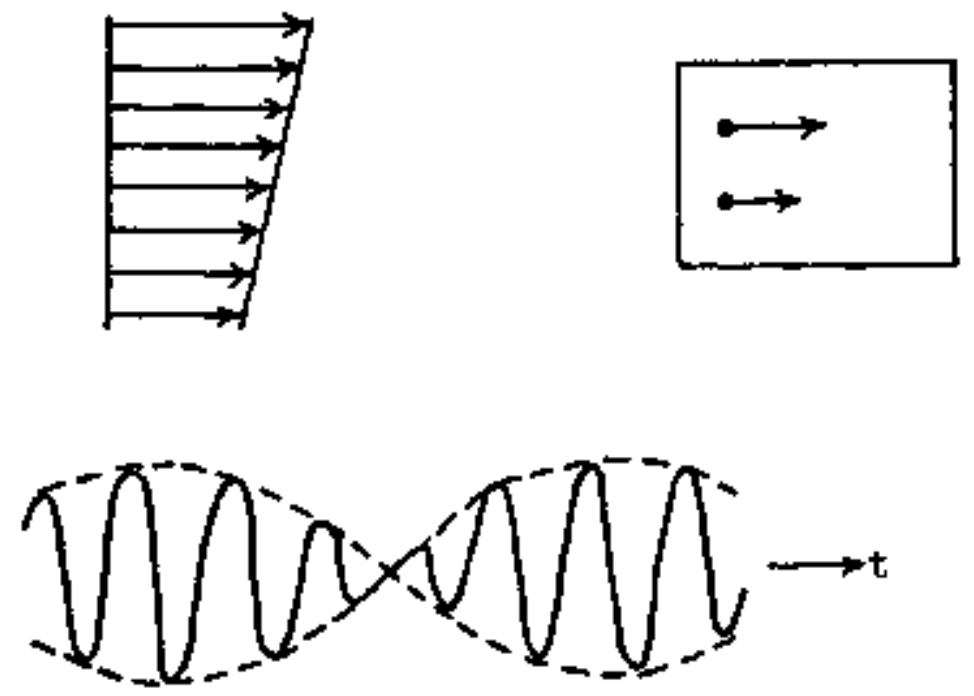

(c)

F1g. D.5 a) S1gnal Eenerated by passage of single particle in eteady, uniform flow

b) Slgnal generated by two particles which entered the flow at different times

c) Signal generated by two particles having different velocities 


\section{APPENDIX E \\ DATA REDUCTION}

1. Average Veloo1ties, Root Hean Square Veloc1ties, and

\section{Bennolds_stresses}

From Eq. D.l in Append $1 x$ D, the Doppler (or frequency) shift 18

$$
f_{D}=\frac{1}{\lambda} \underline{U} \cdot\left(\hat{K}_{1}-\hat{K}_{s}\right)
$$

It can be shown that when two intersecting beams are used, this vector equation can be rewritten as

$$
\mathrm{v}=\frac{\mathrm{f}_{\mathrm{D}}^{\lambda}}{2 \sin \theta}
$$

where $U$ the component-of local fiow veloc 1 ty which is normel to the b1sector or the beam intersection angle,

$\theta$ - the half angle of the beam intersection,

$\lambda$ - the wavelength of laser light.

In tois experiment, $\lambda=5145 \times 20^{-10} \mathrm{~m}$, and $\theta=4.047^{\circ}$, hence, $U(\mathrm{~m} / \mathrm{sec})=3.645 \times 10^{-3} \mathrm{f}_{\mathrm{D}}(\mathrm{KHz})$.

\subsection{Average Velocity}

Since analog output of the tracker is inearly proportional to the Doppler frequency in the range selected, and since 10 Volts corresponds to the maximam frequency, $f_{\text {MAX }}$, 1n that range, the average veloctty can be expressed as 
$U(\mathrm{~m} / \mathrm{sec})=3.645 \times 10^{-3} \times\left[\frac{V_{x}-v_{\text {shift }}}{10}\right] \times f_{\text {MAX }}(\mathrm{KHz})$

$=3.645 \times 10^{-4} \times\left(v_{x}-v_{\text {sh1ft }}\right) \times F_{\text {MAX (KHz) (E.2) }}$

where $v_{x}=$ the average analog voltage reading in the digltal voltmeter,

$v_{\text {shift }}$ * the voltage corresponding to the shifted frequency.

\subsection{Root Mean Square Velocity}

From Eq. 2, the rms velocity is simply

$\sqrt{\sqrt{v^{2}}}(\mathrm{~m} / \mathrm{sec}) \equiv \sqrt{\frac{1}{\mathrm{~T}} \int_{0}^{\mathrm{T}} \mathrm{v}^{2} \mathrm{dt}}=3.645 \times 20^{-4} \times f_{\mathrm{Y}_{1} \mathrm{AX}}(\mathrm{KHz}) \times \sqrt{\overline{\mathrm{Vt}^{2}}}$

\subsection{Reynolds Stress}

The velocity cross-correlation can be expressed as

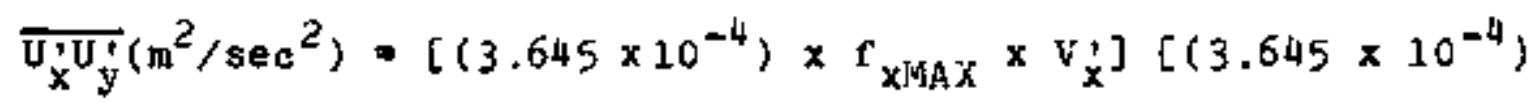

$$
\begin{aligned}
& \left.x f_{y \operatorname{MAX}} \times V^{\prime}{ }_{y}\right]=1.329 \times 10^{-7} \times r_{x[M A X} \times f_{y M A X} \times \bar{v}_{x}
\end{aligned}
$$

where subscripts $x$ and $y$ stand for velocity components in the $x$ and $y$ directions respectively.

The Reynolds stress is given simply as - o $\bar{x} \frac{V_{y}}{y}$.

2. Revnolds litumbers

The Reynolds number of the test cell 15 based on the inlet geometry and average inlet velocity. 


\section{2,1 FFTF Geometry}

Flow Rate $(G P M)=$ area $\left(\mathrm{m}^{2}\right) \times \mathrm{U}_{\text {INLET }}(\mathrm{m} / \mathrm{sec}) x$

$$
\begin{aligned}
& \left..01585 \times 10^{6} \text { (GPM/a }{ }^{3} \mathrm{sec}\right) \\
= & 46.02 \times \mathrm{U}_{\text {INLET }}(\mathrm{m} / \mathrm{sec})
\end{aligned}
$$

or $\mathrm{J}_{\text {INLET }}(\mathrm{m} / \mathrm{sec})=.02173 \times$ Flow Rate (GRH)

The Reynolas number is defined as

$R e \equiv \frac{a U_{\text {INLET }}{ }^{D}}{H}$

where $\mathrm{D}_{e}$, hydraulic diameter, is defined with respect to inlet duct width.

At $110^{\circ} \mathrm{F}, \quad$ Re $=1909 \times$ Flow Rate (GPM)

\subsection{CRBR Geometry}

Similarly, UINLET and Re in the CRBR geometry are

$U_{\text {INLET }}(\mathrm{m} / \mathrm{sec})=0.01087 \times$ Flow Rate (GPM)

At $110^{\circ} \mathrm{F}$, he $=1248 \times$ Flow Rate (GPM) 


\section{APPENDIX $F$ \\ ERROR ANALYSIS}

The purpose of this appendix 1s to estimate the errors in the velocities, root mean square velocities, turbulent kinetic energles, and double velocity correlations from the uncertainties in the LDA measurement technique and the accuracy of the instrument.

\section{Genoral Principle}

S1nce the errors come from many sources, the method of compounding errors suggested by Wilson ${ }^{(28)}$ was used here.

Suppose that the final result, $y$, is related to the components, $x_{1}$, by the relation

$$
Y=F\left(x_{1}, x_{2}, \ldots x_{n}\right)
$$

where $F$ is a known functional form. The small variation in $x_{i}$ will alter $y$ by the amount

$$
\begin{aligned}
\mathrm{dy} & =\frac{\partial F}{\partial x_{1}} d x_{1}+\frac{\partial F}{\partial x_{2}} d x_{2}+\ldots+\frac{\partial F}{\partial x_{n}} d x_{n} \\
& =\sum_{1=1}^{n} \frac{\partial F}{\partial x_{1}} d x_{1}
\end{aligned}
$$

The square of the error w11 be

$$
(d y)^{2}=\sum_{1, j}^{\Sigma} \frac{\partial F}{\partial X_{j}} \frac{\partial F}{\partial X_{j}} d x_{1} d x_{j}
$$

If the components $d x_{1}, d x_{2}, \ldots, d x_{n}$ are independently distributed and symmetrical with respect to positive and negative values, then the products, $\mathrm{dx}_{1} d \mathrm{dx}_{\mathrm{J}}(1 \neq \mathrm{J})$, will vanish on the average so that 


$$
(d y)^{2}=\sum_{t=1}^{n}\left(\frac{\partial y}{\partial x_{1}}\right)^{2}\left(d_{1}\right)^{2}
$$

Th1s may also be written in terms of the varlance, o, as

$$
\sigma^{2}=\sum_{1=1}^{n}\left\langle\frac{\partial X_{1}}{\partial X_{1}}\right)^{2} \sigma_{1}^{2} \quad \text { (F.1) }
$$

2. Calculation of the Error in Velocity

The velocity is calculated by the expression

$$
V=\frac{f \lambda}{2 \sin \theta}
$$

$$
\begin{aligned}
& \text { where } f \text { the Doppler shift } \\
& \lambda=\text { the wavelength of laser light } \\
& \theta=\text { the half angle of the beam intersection }
\end{aligned}
$$

Hence, there are three quant1ties, $r, \lambda$, and $\theta$ which will make a contribution to the errors. The error in $\lambda$ is negligibly smal2. The errors assoclated with $f$ and $\theta$ are discussed below.

\section{I Errox due to the Uncerta inty in $\theta$}

The uncertainty in $\theta$ comes from the following sources:

1. the beam separation distance

2. the focal length of the optical lens

Factor one, the accuracy of the beam separation distance was Judged to be 17 which results in a $1 \%$ error in $\theta$. Factor two, the error in the focal length of the optlcal lens was judged to be very small. 
In Eq. F.a, differentiate $V$ with respect to $\theta$ :

$$
\frac{\partial V}{\partial \theta}=-r \lambda \cos \theta / 2 \sin ^{2} \theta
$$

From Eq. F.I, the error (normalized by the velocity) is

$$
\begin{aligned}
\frac{I}{v^{2}}\left(\frac{\partial \mathrm{V}}{\partial \theta}\right)^{2}(\Delta \theta)^{2} & =\left(\frac{\Delta \theta}{\tan \theta}\right)^{2} \\
& \simeq\left(\frac{\Delta \theta}{\theta}\right)^{2}
\end{aligned}
$$

where $\tan \theta \simeq \theta\left(\theta=4.047^{\circ}\right.$ in this experiment $)$

\subsection{Error Due to the Uncertainty in $r$}

The uncertalnty in the frequency comes from the following sources :

1. the accuracy of the frequency tracker

2. the accuracy of the digital voltmeter

3. the accuracy of the frequency shifter

4. signal broadening

5. pnase fluctuations

6. velosity biasing

Factor one, the overall accuracy of the tracker as spectified by the manufacturer is $1 \%$ of the full scale deflection. For this experiment, the measured frequency was close to $40 \%$ of the full scale reading, hence the accuracy is $2.5 \%$. Pactor two, the accuracy of the digital voltaeter is $0.1 \%$. It is smazl compared to other errors, and thus will be neglected in the calculation. 
For factor three, the manufacturers do not specify the accuracy of their frequency sinfter. It involves both frequency upshifting and downshifting, and errors might occur during these processes. A 1 to error is assigied for this factor.

Factor four, signal broadening, is discussed in Appendix D. Since the average frequency (or voltage) was obtained by taking the time average of the Doppler signal, the values should be very accurate and not be affected by broadening. Factors five and six, phase fluetuations and velocity blasing, are also discussed in Appendix D. These errors depend on the particular setup of the experiment, e.g., the concentration of the scattering particles; only very delicate experiments can determine the magnitude of this error. But these two factors were judged to have srall contribution, and a 1 total error $1 \mathrm{~s}$ assigned to these factors.

In Eq. F.2, differentiate $V$ with respect to $f$ :

$$
\frac{\partial V}{\partial f}=\frac{\lambda}{2 \sin \theta}
$$

Hence the error is

$$
\sum_{1} \frac{2}{V^{2}}\left(\frac{\partial V}{\partial f_{1}}\right)^{2}\left(\Delta f_{1}\right)^{2}=\sum_{1}^{\Sigma}\left(\frac{\Delta f_{j}}{f}\right)^{2}
$$

where 1 - all six factors discussed above.

\section{3 other Brrors}

In the above sections, only errors assoclated with Eq. F. $z^{2}$ were discussed. The other posslble errors are 11sted here: 
1. Position errors, 1.e,, the measuring points are not exactiy the desired positions. In this experiment the test section is relatively large compared to the measuring volume, hence this error is judged to be neglibly small.

2. Erros in the measurement angle, i.e., the laser beam 1s not perpendicular to the test section, so that the measured velocity component is not the correct one. A 1 error in velocity 1 s assigned to th:s factor.

\subsection{Sample Calculation for the Error in the Velocity}

The total error for the velocity measurement can be calculated by combinsng Eq*. F.1, F.4, F.5 and other errors from the previous sections :

$$
\begin{aligned}
\left(\frac{\Delta V}{V}\right)^{2} & =\left(\frac{\Delta \theta}{\theta}\right)^{2}+\frac{\sum}{\left(\frac{\Delta f 1}{f}\right)^{2}+\left(\frac{\Delta V O}{V}\right)^{2}} \\
& =(.01)^{2}+(.025)^{2}+(.01)^{2}+(.01)^{2}+(.01)^{2} \\
& =0.001025 \\
\frac{\Delta V}{V} & =3.2 \%
\end{aligned}
$$

Hence, the error in the velocity measurement $1 \mathrm{~s} 3.2 \%$.

3. Calculation of the Error in the froot Mean square Velocity The root mean square velocity 19 calculated by an express1on similar to that for the velcc1ty:

$$
v_{\text {rms }}=\frac{f_{\text {rms } \lambda}}{2 \sin \theta}
$$


where $f_{\text {rms }}$ is the fluctuating component of the Doppler rrequency. The errors in $v_{\text {rmg }}$ are also from $r_{\text {rms }}$ and $\theta$.

\subsection{Error due to the Uncerta inty in $\theta$}

Since the source of the error is the same as that for the velocity, we can use Eq. F.4 for $\mathrm{V}_{\mathrm{rms}}$;

$$
\frac{1}{\mathrm{~V}_{\mathrm{m}} \mathrm{s}^{2}}\left(\frac{\partial \mathrm{Vrms}}{\partial \theta}\right)(\Delta \theta)^{2}=\left(\frac{\Delta \theta}{\theta}\right)^{2}
$$

\subsection{Error due to the Uncertianty in rms}

The uncertalnty comes from the following sources:

1. The accuracy of the frequency tracker

2. The Accuracy of the RMS voltmeter

3. Signal broadening

4. Phase fluctuations

Factor one 1 discussed in section 2.2 . The accuracy $1 \mathrm{~s} 2.5 \%$.

Factor two, the accuracy of the RMS voltmeter, 1s apecifled by the manufacturer to be $2 \%$, for frequencies below $10 \mathrm{kHz}$ wh1ch is the upper bound for water flows. Factor three, 81 gnal broadening 1s, no longer small. Since It is difflcult to geparate 1t from the much larger broadenIng due to the turbulent fluctuationg, an error of 1,15 assigned to this factor, Factor four, phase fluctuations, is also very difficult to determine. An error of $1 \%$ is assigned to this factor. 
Hence, the total error is

$\sum \frac{l}{v_{\text {rms }}{ }^{2}}\left(\frac{\partial v_{\text {rms }}}{\partial f_{r m s, 1}}\right)^{2}\left(\Delta f_{r m s, 1}\right)=\sum_{1}\left(\frac{\Delta f_{r m s, 1}}{f_{r m s}}\right)^{2} \quad$ (F.9)

\subsection{Sample Calculation for the Error in the Root Mean}

square velocity

The total error is calculated by combining Egs. F.8 and F.9:

$$
\begin{aligned}
\left(\frac{\Delta \mathrm{v}_{\mathrm{rms}}}{\mathrm{V}_{\mathrm{rms}}}\right)^{2} & =\left(\frac{\Delta \theta}{\theta}\right)^{2}+\frac{t}{1}\left(\frac{\Delta \mathrm{rms}, 1}{\mathrm{rms}}\right)^{2} \\
& =(.01)^{2}+(.025)^{2}+(.02)^{2}+(.01)^{2}+(.01)^{2} \\
& =0.001325 \\
\frac{\Delta \mathrm{v}_{\mathrm{rms}}}{V_{\mathrm{rms}}} & =3.67
\end{aligned}
$$

Hence, the error in the root mean square veloc1ty measurement is 3.67 .

4. Calculation of the Error in the Turbulent Kinet1c Energy

The turbulent kinetic energy, $k$, is calculated with

the expression

$$
\mathrm{K}=\frac{1}{2}\left(\mathrm{U}_{\mathrm{rms}}{ }^{2}+\mathrm{v}_{\mathrm{rms}}{ }^{2}\right)
$$

where $U_{\text {rms }}$ and $V_{\text {rms }}$ are the root mean square values of the velocity components $U$ and $V$ respectively.

The error comes from the following two sources:

1. Eq. F.10 should 1nclude all three velocity fluctuation components, $1, e ., \mathrm{K} \equiv \frac{1}{2}\left(\mathrm{U}_{\mathrm{rms}}{ }^{2}+\mathrm{v}_{\mathrm{rms}}{ }^{2}+\mathrm{w}_{\mathrm{rms}}{ }^{2}\right)$. 
Since no measurement was made of $W_{\text {rms }}$, and since Wms was not in the ma1n flow direction, the neglect of this term was judged to have approximately 5\% error.

2. Accuracy of $\mathrm{U}_{\mathrm{rms}}$ and $\mathrm{v}_{\mathrm{rms}}$. From section 3.3, these were determined to be $3.6 \%$. In Eq. F.10, differentiate $K$ with respect to $U_{r m s}$ and $v_{\text {rms }}$,

$$
\frac{\partial K}{\partial U_{r m s}}=u_{r m s}, \frac{\partial K}{\partial V_{r m s}}=v_{r m s}
$$

Hence, the error (normalized by the tirbulent kinetic energy) is

$$
\begin{aligned}
& \frac{1}{\mathrm{~K}^{2}}\left[\left(\frac{\partial \mathrm{K}}{\partial U_{\mathrm{rms}}}\right)^{2}\left(\Delta \mathrm{U}_{\mathrm{rms}}\right)^{2}+\left(\frac{\partial \mathrm{K}}{\partial V_{\mathrm{rms}}}\right)^{2}\left(\Delta \mathrm{V}_{\mathrm{rms}}\right)^{2}\right] \\
& =\frac{1}{K^{2}}\left[\left(U_{r m s}\right)^{2}\left(\Delta U_{r m s}\right)^{2}+\left(V_{r m s}\right)^{2}\left(\Delta V_{r m s}\right)^{2}\right] \\
& =4\left[\frac{\left(U_{r m s}\right)^{2}\left(\Delta U_{r m s}\right)^{2}+\left(v_{r m s}\right)\left(\Delta v_{r m s}\right)^{2}}{\left(U_{r m s}{ }^{2}+v_{r m s}\right)}\right] \\
& =\left(\frac{\Delta U_{r m s}}{D_{r m s}}\right)^{2}+\left(\frac{\Delta V_{r m s}}{V_{r m s}}\right)^{2} \text { 1f } U_{r m s}=v_{r m s}
\end{aligned}
$$

In this measurement, $U_{\text {rms }}$ was very close to $v_{\text {rms }}$, so $\mathrm{j}_{\text {rms }}$ is assumed to be approximately equal to $V_{\text {riss }}$ to simplify the analysis.

The total error in turbulent kinetic energy is the sum of parts one and two above:

$$
\left(\frac{\Delta K}{K}\right)^{2}=(.036)^{2}+(.036)^{2}+(.05)^{2}
$$




$$
\begin{aligned}
& =0.005092 \\
\frac{\Delta K}{K} & =7.1 \%
\end{aligned}
$$

Hence, the error in the turbulent kinetic energy $187.1 \%$.

5. CaIculation of the Error in the Veloc1ty Correlation

The velocity correlation is represented by UV'. The error comes from the following four sources:

1. Errors in $U^{*}$ and $V^{*}$

2. The accuracy of the turbulence processor

3. The accuracy of the digital voltmeter

4. Errors in visual reading

In the first factor, since the errors associated with U' and $V '$ are not expected to be correlated, they will not make a contribution to the error in the velocity correlation measurement. Factor two, the accuracy of the turbulence processor which does the multiplication, is specified by the manufacturer as $2 \% \pm 10 \mathrm{~m}$. Since a constant calibration was used, the possible \pm 10 tN electronlc drift error was eliminated. Factor three, the accuracy of the digltal voltmeter, is negliglbly small.

Factor four, the vistal reading error, is common to v1sually recorded data if the reading is not a constant. Although an Integrating c1rcult with a 30 second time constant was used, the reading of the digital voltmeter was st1ll not a constant. For the experiments, a visual averaging method was used. Since 
the fluctuation was typleally 20\%, this value is assumed to. be the error.

Hence, the total error in the velocity correlation measurement $1 \mathrm{~s} 20 \%$. 


\section{APPENDIX G \\ TABULATION OF DATA}

The reduced data from the experiments is presented in Tables G.1. through G.4. The measurement locat1ons are shown in Figs. G.I and G.2 for the FFTF and CRBR geometries, respectively . 
Table G.I

FFTP Geometry, Re*70,000, Normal

Inlet Mean liow Distribution

\begin{tabular}{|c|c|c|c|c|c|c|}
\hline $\begin{array}{l}\text { Location } \\
(\mathrm{I}, \mathrm{J})\end{array}$ & $\begin{array}{c}u \\
(m / \sec ) \\
\end{array}$ & $\begin{array}{c}V \\
(m / \text { sec })\end{array}$ & $\begin{array}{c}\text { Urms } \\
(m / s e c)\end{array}$ & $\begin{array}{l}\text { Vras } \\
(\mathrm{m} / \mathrm{sec}) \\
\end{array}$ & $\begin{array}{c}\overline{\mathrm{U}}\left(10^{-3} \mathrm{~m}^{2} / \mathrm{sec}^{2}\right) \\
(\end{array}$ & $\mathrm{s}^{\left.\mathrm{K} / \mathrm{sec}^{2}\right)}$ \\
\hline 24,2 & .867 & .121 & .372 & .260 & 1.97 & .103 \\
\hline 24,4 & .778 & .441 & .336 & .250 & 2.62 & 0.878 \\
\hline 24,6 & .619 & .608 & .311 & .250 & 4.59 & .0798 \\
\hline 24,8 & .442 & .675 & .297 & .250 & 4.26 & .0755 \\
\hline 24,10 & .265 & .645 & .283 & .250 & 2.29 & .0714 \\
\hline 24,12 & .149 & .543 & .255 & .232 & 2.62 & 0.593 \\
\hline 24,24 & -.0177 & .380 & .255 & .213 & 2.62 & .0552 \\
\hline 24,16 & -.276 & .256 & .234 & .195 & 20 & .0462 \\
\hline 22,2 & 1.079 & .0519 & .347 & .269 & 1.50 & .0962 \\
\hline 22,4 & .920 & .321 & .340 & .269 & 7.015 & .0938 \\
\hline 22,6 & .584 & .497 & .329 & .260 & 5.05 & .0878 \\
\hline 22,8 & .407 & .571 & .297 & .260 & 6.36 & .0778 \\
\hline 22,10 & .177 & .552 & .276 & .297 & 7.015 & .0821 \\
\hline 22,32 & 0 & .404 & .265 & .287 & 5.05 & .0765 \\
\hline 22,14 & -.195 & 219 & .265 & .250 & 7.015 & .0665 \\
\hline 22,16 & -.499 & .0797 & .237 & 195 & 4.39 & .0470 \\
\hline 20,2 & 1.250 & .0575 & .407 & .297 & 1.50 & .127 \\
\hline 20,4 & .849 & .256 & .371 & .287 & 11.305 & .110 \\
\hline 20,6 & .478 & .358 & .318 & .269 & 8.065 & .0868 \\
\hline 20,8 & .159 & .441 & .276 & .250 & 3.47 & .0694 \\
\hline 20,10 & 0 & .423 & .255 & .297 & 5.12 & .0764 \\
\hline 20,12 & -.092 & .219 & .276 & .306 & 4.13 & .0849 \\
\hline 20,14 & -.294 & .108 & .297 & .250 & 6.10 & .0755 \\
\hline
\end{tabular}




\begin{tabular}{|c|c|c|c|c|c|c|}
\hline $\begin{array}{c}\text { Location } \\
(\mathrm{I}, \mathrm{J}) \\
\end{array}$ & $\begin{array}{c}U \\
(\mathrm{~m} / \mathrm{sec})\end{array}$ & $\begin{array}{c}V \\
(\mathrm{~m} / \mathrm{sec}) \\
\end{array}$ & $\begin{array}{c}\text { Urms } \\
\text { (m/sec) } \\
\end{array}$ & $\begin{array}{l}\text { Vrms } \\
(\mathrm{m} / \mathrm{sec})\end{array}$ & $\begin{array}{c}\overline{U V V} \\
\left(10^{-3} \mathrm{~m}^{2} / \mathrm{sec}^{2}\right) \\
\end{array}$ & $\begin{array}{c}K \\
\left(\mathrm{~m}^{2} / \mathrm{sec}^{2}\right) \\
\end{array}$ \\
\hline 20,16 & -.672 & .0056 & .230 & .204 & 4.07 & .0472 \\
\hline 18,2 & 1.274 & .0519 & .407 & .352 & -2.29 & .145 \\
\hline 28,4 & .849 & .263 & .347 & .297 & 21.30 & .104 \\
\hline 18,6 & .478 & .219 & .290 & .241 & 10.80 & .0711 \\
\hline 18,8 & .159 & .284 & .255 & .185 & 2.29 & .0496 \\
\hline 18,10 & -.127 & .311 & .248 & .195 & 2.62 & .0496 \\
\hline 18,12 & -.389 & .284 & .230 & .232 & 2.95 & .0533 \\
\hline 18,24 & -.548 & .163 & .219 & .232 & 5.57 & .0509 \\
\hline 18,16 & -.718 & .0148 & .205 & .185 & 4.855 & .0382 \\
\hline 16,2 & 1.486 & .063 & .478 & .408 & -5.57 & .197 \\
\hline 16,4 & 1.150 & .108 & .425 & .362 & 36.44 & .155 \\
\hline 16,6 & .563 & .0871 & .301 & .232 & 13.42 & .0721 \\
\hline 76,8 & .251 & .117 & .234 & .148 & 1.97 & .0383 \\
\hline 16,10 & -.088 & .163 & .216 & .352 & 2.29 & .0348 \\
\hline 16,12 & -.421 & .191 & .234 & .213 & 4.916 & .050 \\
\hline 16,14 & -.619 & .108 & .248 & .241 & 4.916 & .0597 \\
\hline 16,16 & -.814 & .020 & .198 & .204 & 4.916 & .0404 \\
\hline 14,2 & 1.698 & -.022 & .601 & .510 & 46.53 & .311 \\
\hline 24,4 & .938 & -.0315 & .425 & .352 & 47.14 & .152 \\
\hline 24,6 & .478 & -.022 & .255 & .195 & 4.068 & .0514 \\
\hline 14,8 & .156 & .033 & .212 & .137 & 1.44 & .0319 \\
\hline 14,10 & -.177 & .0612 & .212 & .148 & 2.816 & .0335 \\
\hline 14,22 & -.538 & .0630 & .226 & .195 & 5.25 & .0446 \\
\hline 14,24 & -.796 & .0389 & .212 & .232 & 5.12 & .0494 \\
\hline 14,10 & -.945 & -.0185 & .205 & .213 & 4.20 & .0438 \\
\hline
\end{tabular}


$\overline{\mathrm{UV}^{\top}} \quad \mathrm{K}$

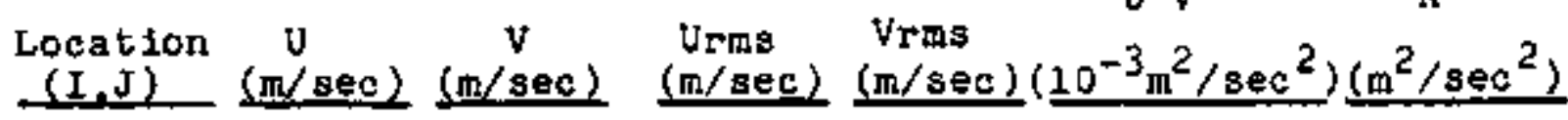

$\begin{array}{lllllll}12,2 & 1.840 & .0148 & .708 & .575 & 63.79 & .416 \\ 12,4 & .938 & -.0408 & .495 & .426 & 61.27 & .214 \\ 12,6 & .442 & -.106 & .248 & .195 & 5.77 & .0496 \\ 12,8 & .230 & -.050 & .216 & .139 & 2.816 & .0330 \\ 12,10 & -.106 & .0056 & .219 & .248 & 2.03 & .0351 \\ 12,12 & -. .393 & .0148 & .290 & .176 & 2.685 & .0576 \\ 12,14 & -.637 & .0241 & .318 & .204 & 2.49 & .0715 \\ 12,16 & -.828 & .0148 & .354 & .185 & 6.097 & .0798 \\ 10,2 & 1.886 & -.022 & .814 & .575 & 80.35 & .496 \\ 10,4 & .870 & -.124 & .566 & .436 & 67.225 & .255 \\ 10,6 & .386 & -.208 & .251 & .185 & 3.28 & .0487 \\ 10,8 & .287 & -.191 & .248 & .158 & 3.60 & .0431 \\ 10,10 & -.0354 & -.128 & .202 & .239 & .979 & .030 \\ 10,12 & -.333 & -.0723 & .269 & .163 & 3.28 & .0495 \\ 10,14 & -.686 & -.020 & .297 & .176 & 6.23 & .0597 \\ 10,16 & -.899 & -.0185 & .304 & .158 & 5.31 & .0587 \\ 8,6 & .357 & -.208 & .241 & .213 & 6.75 & .0517 \\ 8,8 & .198 & -.282 & .234 & .195 & 4.78 & .0462 \\ 8,10 & -.0318 & -.226 & .241 & .152 & 2.624 & .0405 \\ 8,12 & -. .315 & -. .152 & .262 & .158 & 3.28 & .0467 \\ 8,14 & -.616 & -.0093 & .333 & .148 & 6.88 & .0663 \\ 8,16 & -.934 & .089 & .283 & .195 & 7.87 & .0590 \\ 7,16 & -.899 & .256 & .283 & .185 & 9.51 & .0572 \\ 7.5,2 & 1.843 & .024 & .885 & .649 & 91.15 & .602 \\ 7.5,3 & 1.153 & .0742 & .814 & .593 & 120.225 & .507\end{array}$




\begin{tabular}{|c|c|c|c|c|c|c|}
\hline $\begin{array}{c}\text { Location } \\
(I, J)\end{array}$ & $\begin{array}{c}\mathrm{U} \\
(\mathrm{m} / \mathrm{sec})\end{array}$ & $\begin{array}{c}V \\
(m / \text { sec })\end{array}$ & $\begin{array}{c}\text { Urms } \\
\text { (m/sec) }\end{array}$ & $\begin{array}{c}\text { Vrms } \\
\text { (m/sec })\end{array}$ & $\begin{array}{c}\overline{U V '} \\
\left(10^{-3} \mathrm{~m}^{2} / \sec ^{2}\right)\end{array}$ & $\left.m^{2} / \sec ^{2}\right)$ \\
\hline $7.5,4$ & .552 & .0519 & .637 & .473 & 62.28 & .325 \\
\hline 6,6 & .265 & -.059 & .230 & .195 & 5.70 & .0454 \\
\hline 6,8 & .0637 &.,- 208 & .230 & .232 & 5.05 & .0533 \\
\hline 6,10 & -.120 & -.245 & .248 & .195 & 3.866 & .0496 \\
\hline 6,12 & -.287 & -.152 & .265 & .176 & 3.08 & .0507 \\
\hline 6,14 & -.492 & .0742 & .283 & .158 & 5.38 & .0525 \\
\hline 6,16 & -.757 & .515 & .290 & .152 & 12.07 & .0536 \\
\hline 6,17 & -1.005 & 1.029 & .290 & .222 & 13.24 & .0668 \\
\hline 5,6 & .237 & -.0686 & .244 & 195 & 4.916 & .0487 \\
\hline 5,8 & .0242 & -.226 & .241 & .222 & 4.72 & .0537 \\
\hline 5,10 & -.191 & -.245 & .244 & .213 & 3.866 & .0525 \\
\hline 5,12 & -.350 & -.182 & .248 & .276 & 2.89 & .0462 \\
\hline 5,14 & -.531 & .0538 & .276 & .204 & 4.72 & .0589 \\
\hline 5,16 & -.563 & .515 & .297 & .167 & 5.097 & .0581 \\
\hline 5,17 & -.350 & .921 & .311 & .156 & 4.72 & .0609 \\
\hline
\end{tabular}


Table $\mathbf{G} .2$

FFTF Geometry, Re-70,000, D1storted

Inlet Mean Flow Distribution

\begin{tabular}{|c|c|c|c|c|c|c|}
\hline $\begin{array}{c}\text { Location } \\
(I, J)\end{array}$ & $\begin{array}{c}U \\
(\mathrm{~m} / \mathrm{sec})\end{array}$ & $\begin{array}{c}V \\
(m / s e c)\end{array}$ & $\begin{array}{l}\text { Urms } \\
\text { (m/sac) }\end{array}$ & $\begin{array}{c}\text { Vrms } \\
\text { (m/sec) }\end{array}$ & $\begin{array}{c}\overline{U^{\prime} V} \\
\left(10^{-3} m^{2} / \sec ^{2}\right)\end{array}$ & $\begin{array}{c}K \\
\left(m^{2} / \mathrm{sec}^{2}\right)\end{array}$ \\
\hline 24,2 & .338 & .166 & .338 & .234 & -.642 & .0847 \\
\hline 24,4 & .374 & .285 & .338 & .261 & -1.28 & .0934 \\
\hline 24.6 & .417 & .388 & .338 & .270 & $\sim_{0}$ & .0938 \\
\hline 24.8 & .313 & .406 & .303 & .270 & 20 & .0824 \\
\hline 24,10 & .182 & .388 & .249 & .252 & -.642 & .0629 \\
\hline 24,12 & .0784 & .325 & .214 & .207 & -1.284 & .0443 \\
\hline 24,24 & -.0712 & .216 & .214 & .198 & -.963 & .0425 \\
\hline 24,16 & -.267 & .142 & .232 & .207 & -2.25 & .0483 \\
\hline 22,2 & .474 & .099 & .356 & $.2-8$ & -.642 & .105 \\
\hline 22,4 & .552 & .189 & .374 & .306 & -2.89 & .117 \\
\hline 22,6 & .509 & .279 & .374 & .315 & 3.85 & .220 \\
\hline 22,8 & .313 & .207 & .321 & .288 & 7.06 & .0930 \\
\hline 22,10 & .153 & .0991 & .267 & .243 & 2.57 & .0653 \\
\hline 22,12 & .0534 & .0632 & .249 & .216 & 20 & .0545 \\
\hline 22,14 & -.157 & .009 & .249 & .289 & 2.57 & .0490 \\
\hline 22,16 & -.470 & -.0451 & .232 & .189 & -.321 & .0447 \\
\hline 20,2 & .417 & .153 & .356 & .306 & -5.78 & .110 \\
\hline 20,4 & .509 & .225 & .392 & .288 & -3.85 & .118 \\
\hline 20,6 & .410 & .279 & .356 & .306 & 7.06 & .110 \\
\hline 20.8 & .267 & .180 & .321 & .306 & 9.63 & .0983 \\
\hline 20,10 & .0997 & .00901 & .267 & .234 & 4.62 & .0631 \\
\hline 20,12 & -.00356 & -.0487 & .249 & .216 & 2.57 & .0545 \\
\hline 20,14 & -.178 & -.0901 & .249 & .180 & 4.49 & .0473 \\
\hline
\end{tabular}




\begin{tabular}{|c|c|c|c|c|c|c|}
\hline $\begin{array}{c}\text { Location } \\
(I, J)\end{array}$ & $\begin{array}{c}U \\
(\mathrm{~m} / \mathrm{sec}) \\
\end{array}$ & $\begin{array}{c}V \\
(m / \sec ) \\
\end{array}$ & $\begin{array}{c}\text { Urms } \\
(\pi / s \notin c)\end{array}$ & $\begin{array}{c}\text { Vrms } \\
(\mathrm{m} / \mathrm{sec})\end{array}$ & $\begin{array}{c}\overline{\mathrm{u} \cdot \mathrm{V}} \\
\left(10^{-3} \mathrm{~m}^{2} / \sec ^{2}\right) \\
\end{array}$ & $\begin{array}{c}\mathrm{k} \\
\left(\mathrm{m}^{2} / \mathrm{sec}^{2}\right) \\
\end{array}$ \\
\hline 20,16 & -.552 & -.114 & $.24 \%$ & .180 & 3.21 & .0473 \\
\hline 18,2 & .994 & .0519 & .313 & .216 & 2.56 & .0723 \\
\hline 18,4 & $.920^{\circ}$ & .200 & .313 & .225 & 7.96 & .0743 \\
\hline 18,6 & .520 & .274 & .285 & .207 & 8.99 & .0620 \\
\hline 18,8 & .180 & .312 & .274 & .234 & 2.25 & .0649 \\
\hline 18,10 & -.0991 & .330 & .256 & .225 & 3.31 & .0581 \\
\hline 16,12 & -.230 & .219 & .256 & .252 & 2.25 & .0645 \\
\hline 16,14 & -.357 & .108 & .253 & .234 & 4.49 & .0594 \\
\hline 18,16 & -.559 & .0426 & .278 & .216 & 5.46 & .0620 \\
\hline 16,2 & .463 & .00901 & .338 & .216 & -5.136 & .0806 \\
\hline 16,4 & .883 & .157 & .374 & .252 & .642 & .102 \\
\hline 16,6 & .399 & .189 & .285 & .216 & 3.85 & .0640 \\
\hline 26,8 & .207 & .256 & .285 & .189 & 1.926 & .0585 \\
\hline 16,10 & -.142 & .225 & .285 & .198 & +5.136 & .0603 \\
\hline 16,12 & -.274 & .115 & .249 & .216 & 2.57 & .0545 \\
\hline 16,14 & $=.484$ & .117 & .214 & .162 & 2.57 & .0360 \\
\hline 16,16 & -.627 & .027 & .214 & .144 & 2.57 & .0332 \\
\hline 14,2 & .695 & -.112 & .303 & .234 & -7.70 & .0733 \\
\hline 14,4 & .873 & .00901 & .356 & .252 & 14.765 & .0953 \\
\hline 14,6 & .274 & .0252 & .232 & .180 & 2.57 & .0430 \\
\hline 14,8 & .142 & .0632 & .249 & .126 & 2.60 & .0390 \\
\hline 14,10 & -.125 & .0991 & .267 &.$I B O$ & 2.89 & .0519 \\
\hline 24,12 & -.317 & .110 & .249 & .180 & 2.57 & .0473 \\
\hline 24.14 & -.463 & .0451 & .249 & .162 & 3.85 & .0442 \\
\hline 14,16 & -.673 & .00901 & .196 & .135 & 2.57 & .0283 \\
\hline
\end{tabular}




\begin{tabular}{|c|c|c|c|c|c|c|}
\hline $\begin{array}{c}\text { Location } \\
(I, J)\end{array}$ & $\begin{array}{c}\mathrm{U} \\
(\mathrm{m} / \mathrm{sec}) \\
\end{array}$ & $\begin{array}{c}V \\
(\mathrm{~m} / \mathrm{sec}) \\
\end{array}$ & $\begin{array}{c}\text { Urms } \\
(\mathrm{m} / \mathrm{sec})\end{array}$ & $\begin{array}{l}\text { Vrms } \\
\text { (m/ sec })\end{array}$ & $\begin{array}{c}\overline{U V I} \\
\left(10^{\left.-3 \mathrm{~m}^{2} / \mathrm{sec}^{2}\right)}\right. \\
\end{array}$ & $\begin{array}{c}K \\
\left(m^{2} / \sec ^{2}\right) \\
\end{array}$ \\
\hline 12,2 & .623 & -.0775 & .321 & .261 & -1.80 & .0855 \\
\hline 12,4 & .816 & -.0379 & .338 & .252 & 1.41 & .0891 \\
\hline 12,6 & .232 & .00901 & .214 & .153 & .770 & .0346 \\
\hline 12,8 & .0677 & .0649 & .232 & .144 & 1.80 & .0372 \\
\hline 12,10 & -.232 & .0991 & .249 & .162 & 2.89 & .0442 \\
\hline 12,12 & -.346 & .223 & .232 & .216 & 2.50 & .0502 \\
\hline 12,14 & -.452 & .0469 & .232 & .189 & 5.39 & .0447 \\
\hline 12,16 & $=.655$ & .0180 & .214 & .144 & 3.852 & .0332 \\
\hline 10,2 & .516 & -.0631 & .303 & .261 & 2.696 & .0800 \\
\hline 10,4 & .873 & -.0811 & .392 & .270 & 4.30 & .113 \\
\hline 10,6 & .256 & .0108 & .214 & .117 & 2.03 & .0297 \\
\hline 10,8 & .0606 & .0306 & .232 & .126 & 1.156 & .0348 \\
\hline 10,10 & -.128 & .0811 & .232 & .153 & 2.05 & .0385 \\
\hline 10,12 & -.331 & .0901 & .249 & .153 & 2.25 & .0428 \\
\hline 10,14 & -.484 & .0847 & .249 & .162 & 3.40 & .0442 \\
\hline 10,26 & -.695 & .0775 & .249 & .135 & 2.12 & .0402 \\
\hline 8,6 & .235 & .00901 & .232 & .144 & 1.93 & .0372 \\
\hline 8,8 & .125 & $=.0270$ & .249 & .271 & 1.54 & .0457 \\
\hline 8,10 & -.0499 & -.00361 & .249 & .171 & .578 & .0457 \\
\hline 8,12 & -.232 & .0451 & .249 & .172 & 2.50 & .0457 \\
\hline 8,14 & -.484 & .226 & .232 & .126 & 4.75 & .0348 \\
\hline 8,16 & -.787 & .286 & .232 & .144 & 2.89 & .0372 \\
\hline $7.5,2$ & .374 & -.0559 & .338 & .234 & 7.70 & .0847 \\
\hline $7.5,3$ & .563 & -.0811 & .374 & .270 & -16.05 & .106 \\
\hline $7.5,4$ & .976 & -.0631 & .410 & .261 & -23.75 & .118 \\
\hline
\end{tabular}




\begin{tabular}{|c|c|c|c|c|c|c|}
\hline $\begin{array}{c}\text { Location } \\
(I, J)\end{array}$ & $\begin{array}{c}U \\
(\mathrm{~m} / \mathrm{Bec})\end{array}$ & $\begin{array}{c}\mathrm{V} \\
(\mathrm{m} / \mathrm{sec})\end{array}$ & $\begin{array}{c}\text { Urms } \\
(\mathrm{m} / \mathrm{sec})\end{array}$ & $\begin{array}{r}\text { Vrms } \\
(\mathrm{m} / \mathrm{sec})\end{array}$ & $\begin{array}{c}\overline{\mathrm{UVi}} \\
\left(10^{-3} \mathrm{~m}^{2} / \mathrm{sec}^{2}\right)\end{array}$ & $\begin{array}{c}\mathrm{K} \\
\left(\mathrm{m}^{2} / \sec ^{2}\right) \\
\end{array}$ \\
\hline 6,6 & .271 & .0451 & .232 & .135 & 1.22 & .0359 \\
\hline 6.8 & .0784 & 0 & .232 & .171 & 1.86 & .0425 \\
\hline 6,10 & -.0891 & -.0631 & .249 & .171 & .3852 & .0457 \\
\hline 6,12 & -.296 & -.0451 & .267 & .162 & 2.28 & .0488 \\
\hline 6,14 & -.346 & .108 & .249 & .244 & 2.89 & .0415 \\
\hline 6,16 & -.591 & .496 & .249 & .262 & 6.42 & .0442 \\
\hline 6,37 & -.784 & 1.009 & .232 & .180 & 4.17 & .0430 \\
\hline 5,6 & .178 & .0108 & .214 & .180 & .706 & .0391 \\
\hline 5,8 & .0178 & .00902 & .214 & .189 & .770 & .0407 \\
\hline 5,10 & -.142 & -.00901 & .232 & .180 & 1.48 & .0430 \\
\hline 5,12 & -.249 & -.0451 & .249 & .189 & 1.80 & .0490 \\
\hline 5.14 & -.356 & .115 & .249 & .198 & 2.44 & .0507 \\
\hline 5,16 & -.367 & .487 & .338 & .216 & 2.82 & .0806 \\
\hline 5,27 & -.153 & .856 & .338 & .279 & .770 & .0963 \\
\hline
\end{tabular}


CRBR Geometry, Re-35,000, Normal Inlet Mean Flow

D1stribution

\begin{tabular}{|c|c|c|c|c|c|c|}
\hline $\begin{array}{l}\text { pcation } \\
(I, J)\end{array}$ & $\begin{array}{c}\mathrm{U} \\
\text { (m/sec }) \\
\end{array}$ & $\begin{array}{c}V \\
(m / \sec ) \\
\end{array}$ & $\begin{array}{c}\text { Urms } \\
(\mathrm{m} / \mathrm{sec}) \\
\end{array}$ & $\begin{array}{c}V_{r m s} \\
(m / s e c)\end{array}$ & $\begin{array}{c}\overline{U V^{1}} \\
\left(10^{-3_{m^{2}}} / \sec ^{2}\right) \\
\end{array}$ & $m^{\left.2 / s e c^{2}\right)}$ \\
\hline 19,2 & .478 & .0315 & .336 & .121 & -1.18 & .0637 \\
\hline 29.4 & .363 & .528 & .292 & .380 & -1.51 & .125 \\
\hline 19,6 & .292 & .575 & .274 & .454 & -2.51 & .241 \\
\hline 19,8 & .250 & .324 & .221 & .426 & -2.165 & .115 \\
\hline 19,10 & .0265 & .445 & .195 & .389 & -5.45 & .0947 \\
\hline 19,22 & -.221 & .389 & .168 & .315 & -4.79 & .0638 \\
\hline 18,2 & .858 & .0093 & .425 & .015 & +.131 & .090 \\
\hline 18,4 & .699 & .0519 & .354 & .148 & +.459 & .0736 \\
\hline 38,6 & .433 & .139 & .292 & .278 & +1.44 & .0813 \\
\hline 18,8 & .195 & .260 & .221 & .306 & +2.92 & .0712 \\
\hline 18,20 & -.044 & .241 & .186 & .287 & +3.42 & .0585 \\
\hline 28,12 & -.380 & .158 & .177 & .260 & +1.77 & .0493 \\
\hline 16.2 & 2.053 & .046 & .442 & .232 & +1.676 & .125 \\
\hline 16,4 & .752 & .204 & .389 & .352 & +11.18 & .138 \\
\hline 16,6 & .380 & .204 & .301 & .343 & +12.83 & .204 \\
\hline 16,8 & .265 & .167 & .230 & .334 & +9.55 & .0821 \\
\hline 16,10 & -.310 & .074 & .295 & .297 & +9.216 & .0629 \\
\hline 16,12 & -.681 & -.074 & .186 & .306 & +8.24 & .0640 \\
\hline 14,2 & .999 & .0556 & .495 & .464 & +17.06 & .230 \\
\hline 24,4 & .716 & .167 & .425 & .426 & +22.00 & .181 \\
\hline 14,6 & .186 & .185 & .301 & .371 & +15.44 & .124 \\
\hline 14,8 & -.0973 & .112 & .212 & .334 & +9.165 & .0782 \\
\hline 14,10 & -.433 & -.0093 & .203 & .297 & +11.15 & .0647 \\
\hline 14,12 & -.840 & -.093 & .195 & .269 & +9.185 & .0551 \\
\hline 12,2 & 1.229 & .0371 & .531 & .519 & +28.68 & .276 \\
\hline
\end{tabular}




\begin{tabular}{|c|c|c|c|c|c|c|}
\hline $\begin{array}{c}\text { Location } \\
(I, J)\end{array}$ & $\begin{array}{c}u \\
(\mathrm{~m} / \mathrm{sec})\end{array}$ & $\begin{array}{c}V \\
\langle\mathrm{~s} / \mathrm{sec}\rangle \\
\end{array}$ & $\begin{array}{c}\text { Urms } \\
\text { (m/sec) }\end{array}$ & $\begin{array}{c}\text { Vrmo } \\
(\mathrm{m} / \text { sec })\end{array}$ & $\begin{array}{c}\overline{U V '} \\
\left(10^{-3} \mathrm{~m}^{2} / \sec ^{2}\right)\end{array}$ & $\left(m^{2} / s e c^{2}\right)$ \\
\hline 12,4 & .663 & .111 & .433 & .454 & $+36,55$ & .197 \\
\hline 12,6 & .0973 & .0185 & .283 & .352 & +19.81 & .102 \\
\hline 12,9 & -.416 & -.037 & .195 & .278 & +9.65 & .0576 \\
\hline 12,11 & -.734 & -.074 & .212 & .260 & +11.62 & .0562 \\
\hline 12,13 & -.911 & -.037 & .195 & .156 & +4.72 & .0311 \\
\hline $10.5,2$ & 1.336 & .0927 & .619 & .556 & +30.79 & .346 \\
\hline $10.5,3$ & .964 & .130 & .584 & .519 & +42.90 & .305 \\
\hline $10.5,4$ & .646 & .346 & .460 & .556 & +45.22 & .260 \\
\hline $10.5,5$ & .310 & .0927 & .354 & .445 & +40.97 & .162 \\
\hline $10.5,6$ & .0265 & 0 & .248 & .408 & +27.15 & .114 \\
\hline 10,9 & -.363 & -.0372 & .186 & .222 & +5.06 & .0420 \\
\hline 20,11 & -.681 & -.00927 & .195 & .297 & +7.84 & .0629 \\
\hline 10,13 & -.858 & 0 & .177 & .167 & +2.59 & .0296 \\
\hline 8,9 & -.301 & .0185 & .186 & .222 & +6.20 & .0420 \\
\hline 8,11 & -.681 & .0556 & .195 & .222 & +8.166 & .0437 \\
\hline 0,12 & -.840 & .0927 & .173 & .222 & +5.976 & .0398 \\
\hline 8,13 & -.946 & .0556 & .159 & .167 & +3.48 & .0266 \\
\hline 7,12 & -.770 & .260 & .212 & .250 & +10.80 & .0539 \\
\hline 7,13 & -1.123 & .371 & .248 & .241 & +5.22 & $.059 ?$ \\
\hline 6,9 & -.133 & .0556 & .195 & .315 & +5.45 & .0686 \\
\hline 6,12 & -.433 & .260 & .248 & .260 & +8.40 & .0644 \\
\hline 6,12 & -.504 & .501 & .248 & .260 & +7.74 & .0644 \\
\hline 6,13 & -.310 & 1.010 & .265 & .241 & +5.12 & .0643 \\
\hline 5,12 & -.292 & .334 & .265 & .315 & -1.78 & .0849 \\
\hline 5,13 & -.239 & .185 & .230 & .297 & -4.72 & .0704 \\
\hline
\end{tabular}




\begin{tabular}{|c|c|c|c|c|c|c|}
\hline $\begin{array}{c}\text { Location } \\
(\mathrm{I}, \mathrm{J}) \\
\end{array}$ & $\begin{array}{c}v \\
(\mathrm{~m} / \mathrm{sec}\rangle\end{array}$ & $\begin{array}{c}V \\
(m / \mathrm{sec}) \\
\end{array}$ & $\begin{array}{c}\text { Urms } \\
\text { (ng/sec }\end{array}$ & $\begin{array}{c}\text { Vrms } \\
(\mathrm{m} / \mathrm{sec}) \\
\end{array}$ & $\begin{array}{c}\overline{\mathrm{U}^{\prime} \mathrm{V}} \\
\left(10^{-3} \mathrm{~m}^{2} / \mathrm{sec}^{2}\right) \\
\end{array}$ & $\left.\mathrm{m}^{2} / \sec ^{2}\right)$ \\
\hline 4,9 & .115 & .0742 & .142 & .241 & +1.84 & .0391 \\
\hline 4,11 & -.150 & .111 & .212 & .241 & -1.12 & .0516 \\
\hline
\end{tabular}


Table 0.4

CRBR Geometry, Re 35,000 , Distorted

Inlet Mean Flow D1stribution

\begin{tabular}{|c|c|c|c|c|c|c|}
\hline $\begin{array}{c}\text { Location } \\
(I, J)\end{array}$ & $\begin{array}{c}U \\
(\mathrm{~m} / \mathrm{sec})\end{array}$ & $\begin{array}{c}V \\
(m / \sec )\end{array}$ & $\begin{array}{c}\text { Urms } \\
(\mathrm{m} / \mathrm{sec})\end{array}$ & $\begin{array}{c}\text { Vrms } \\
(\mathrm{m} / \mathrm{sec})\end{array}$ & $\begin{array}{c}\overline{v^{\prime} V^{\prime}} \\
\left(10-3 m^{2} / \sec ^{2}\right)\end{array}$ & $\begin{array}{c}K \\
\left(m^{2} / \sec ^{2}\right)\end{array}$ \\
\hline 19,2 & .255 & -.046 & .265 & .241 & .919 & .0643 \\
\hline 19.4 & .251 & .161 & .248 & .250 & +1.24 & .0620 \\
\hline 19,6 & .234 & .297 & .248 & .297 & -.722 & .0747 \\
\hline 19,8 & .263 & .399 & .212 & .297 & -2.03 & .0665 \\
\hline 19,10 & .0743 & .399 & .195 & .315 & -2.03 & .0686 \\
\hline 19,12 & -.256 & .269 & .177 & .241 & -3.67 & .0445 \\
\hline 18,12 & .340 & .0093 & .336 & .352 & +2.23 & .119 \\
\hline 18,4 & .357 & .083 & .318 & .325 & +.262 & .100 \\
\hline 18,6 & .340 & .195 & .283 & .315 & +1.24 & .0897 \\
\hline 18,8 & .225 & .139 & .248 & .241 & +2.23 & .0597 \\
\hline 18,20 & .0566 & .139 & .195 & .204 & +4.855 & .0397 \\
\hline 18,12 & -.333 & .0278 & .186 & .185 & +6.82 & .0344 \\
\hline 16,2 & .375 & -.0278 & .318 & .352 & +5.64 & .113 \\
\hline 16,4 & .340 & -.0278 & .318 & .352 & +1.37 & .113 \\
\hline 16,6 & .340 & -.0278 & .318 & .334 & -.262 & 106 \\
\hline 16,8 & .216 & .0093 & .301 & .324 & +5.64 & .0979 \\
\hline 16,20 & -.0495 & -.0278 & .230 & .315 & 9.246 & .0762 \\
\hline 16,12 & -.280 & -.0742 & .230 & .204 & 5.15 & .0472 \\
\hline 14,2 & .251 & -.0278 & .265 & .121 & .656 & .0414 \\
\hline 14,4 & .198 & -.121 & .283 & .334 & -.328 & .0957 \\
\hline 14.6 & .287 & -.0927 & .318 & .371 & -4.59 & .119 \\
\hline 14,8 & .198 & -.0093 & .283 & .278 & 10.50 & .0787 \\
\hline 14.10 & -.191 & -.0649 & .248 & .278 & 10.50 & .0693 \\
\hline
\end{tabular}


$\overline{U+V}$

\begin{tabular}{|c|c|c|c|c|c|c|}
\hline $\begin{array}{l}\text { Location } \\
(I, J)\end{array}$ & $\begin{array}{c}U \\
(\mathrm{~m} / \mathrm{sec})\end{array}$ & $\begin{array}{c}V \\
(\mathrm{~m} / \mathrm{sec}) \\
\end{array}$ & $\begin{array}{c}\text { Urms } \\
(\mathrm{m} / \mathrm{sec})\end{array}$ & $\begin{array}{l}\text { Vrms } \\
(\mathrm{m} / \mathrm{sec})\end{array}$ & $\left(10^{-3} m^{2} / 5 e c^{2}\right)$ & $\left(\mathrm{m}^{2} / \mathrm{sec} \mathrm{c}^{2}\right.$ \\
\hline 14,12 & -.563 & -.121 & .230 & .222 & 10.19 & .0512 \\
\hline 22,2 & .340 & 0 & .354 & .352 & 1.94 & .125 \\
\hline 22,4 & .322 & -.0649 & .336 & .315 & 2.59 & .106 \\
\hline 12,6 & .340 & -.102 & .301 & .297 & -2.00 & .0892 \\
\hline 12,9 & -.209 & -.083 & .212 & .222 & 8.50 & .0473 \\
\hline 12,11 & -.545 & -.139 & .230 & .204 & 12.415 & .0472 \\
\hline 12,13 & -.846 & -.083 & .212 & .285 & 4.39 & .0397 \\
\hline $10.5,2$ & .163 & 0 & .371 & .334 & 3.94 & .125 \\
\hline $20.5,3$ & .172 & 0 & .354 & .352 & 3.12 & .125 \\
\hline $10.5,4$ & .163 & -.0278 & .336 & .352 & 1.635 & .119 \\
\hline $10.5,5$ & .198 & -.0556 & .354 & .371 & -4.26 & .131 \\
\hline $10.5,6$ & .340 & -.0278 & .336 & .352 & -8.20 & .119 \\
\hline $10.2,7$ & .534 & -.0278 & .336 & .241 & -6.56 & .0855 \\
\hline 10,9 & -.315 & -.321 & .195 & .185 & 6.56 & .0361 \\
\hline 10,11 & -.580 & -.083 & .230 & .241 & 9.185 & .0555 \\
\hline 10,13 & -.775 & -.0556 & .212 & .148 & 3.94 & .0335 \\
\hline 8,9 & -.315 & -.0742 & .195 & .167 & 4.59 & .0329 \\
\hline 8,11 & -.580 & -.020 & .195 & .185 & 7.87 & .0361 \\
\hline 8,12 & -.722 & .00927 & .195 & .185 & 9.185 & .0361 \\
\hline 8,13 & -.846 & 0 & .212 & .185 & 5.25 & .0397 \\
\hline 7.12 & $=.704$ & .232 & .212 & .185 & 11.51 & .0397 \\
\hline 7,13 & -1.04 & .334 & .212 & .167 & 7.87 & .0365 \\
\hline 7,9 & -.315 & -.0185 & .195 & .185 & 5.57 & .0361 \\
\hline 7,11 & -.527 & .0927 & .212 & .222 & 9.51 & .0473 \\
\hline 0,9 & -.191 & .0464 & .195 & .204 & 3.15 & .0397 \\
\hline
\end{tabular}




\begin{tabular}{|c|c|c|c|c|c|c|}
\hline $\begin{array}{l}\text { 10ation } \\
(I, j)\end{array}$ & $\begin{array}{c}U \\
(\pi / \mathrm{sec})\end{array}$ & $\begin{array}{c}V \\
(\mathrm{~m} / \mathrm{sec}) \\
\end{array}$ & $\begin{array}{c}\text { Urms } \\
\text { (m/sec) }\end{array}$ & $\begin{array}{c}\text { Vrms } \\
(\mathrm{m} / \mathrm{sec})\end{array}$ & $\begin{array}{c}\overline{\mathrm{U}^{1}} \\
\left(10^{-3} \mathrm{~m}^{2} / \sec ^{2}\right)\end{array}$ & $\left(\mathrm{m}^{2} / \sec ^{2}\right)$ \\
\hline 6,12 & -.386 & .213 & $.21<$ & .222 & 7.25 & .0473 \\
\hline 6,12 & .421 & .399 & .248 & .222 & 7.90 & .0554 \\
\hline 6,13 & -.191 & .881 & .301 & .260 & 5.935 & .0789 \\
\hline 2,12 & -.192 & .250 & .212 & .204 & -2.26 & .0433 \\
\hline 5,13 & -.156 & .145 & .230 & .222 & -.391 & .0512 \\
\hline 4,9 & .0566 & .0093 & .133 & .111 & .525 & .0150 \\
\hline 4,21 & $=.129$ & .0834 & .277 & .241 & .360 & $.0447^{\circ}$ \\
\hline
\end{tabular}




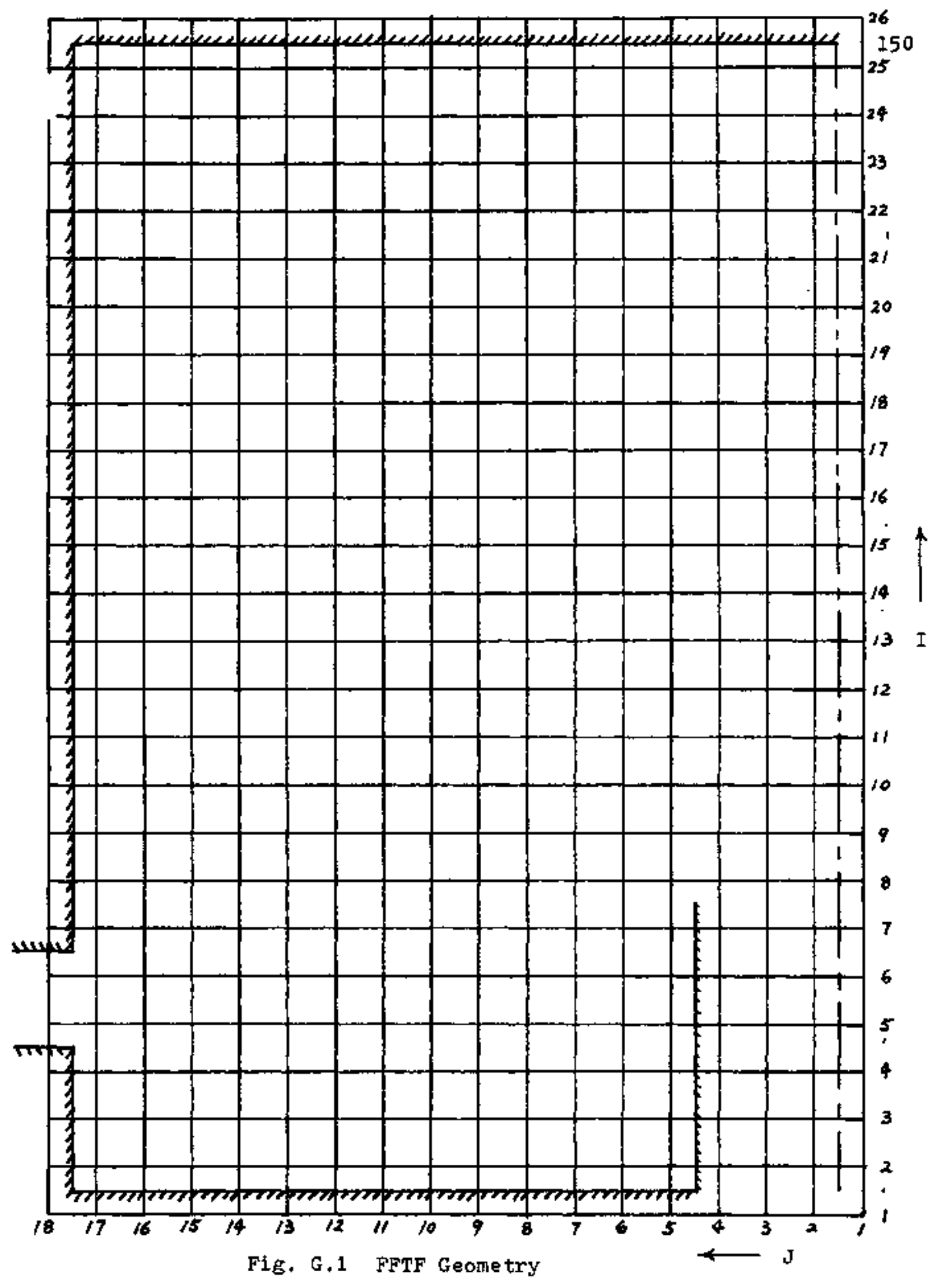




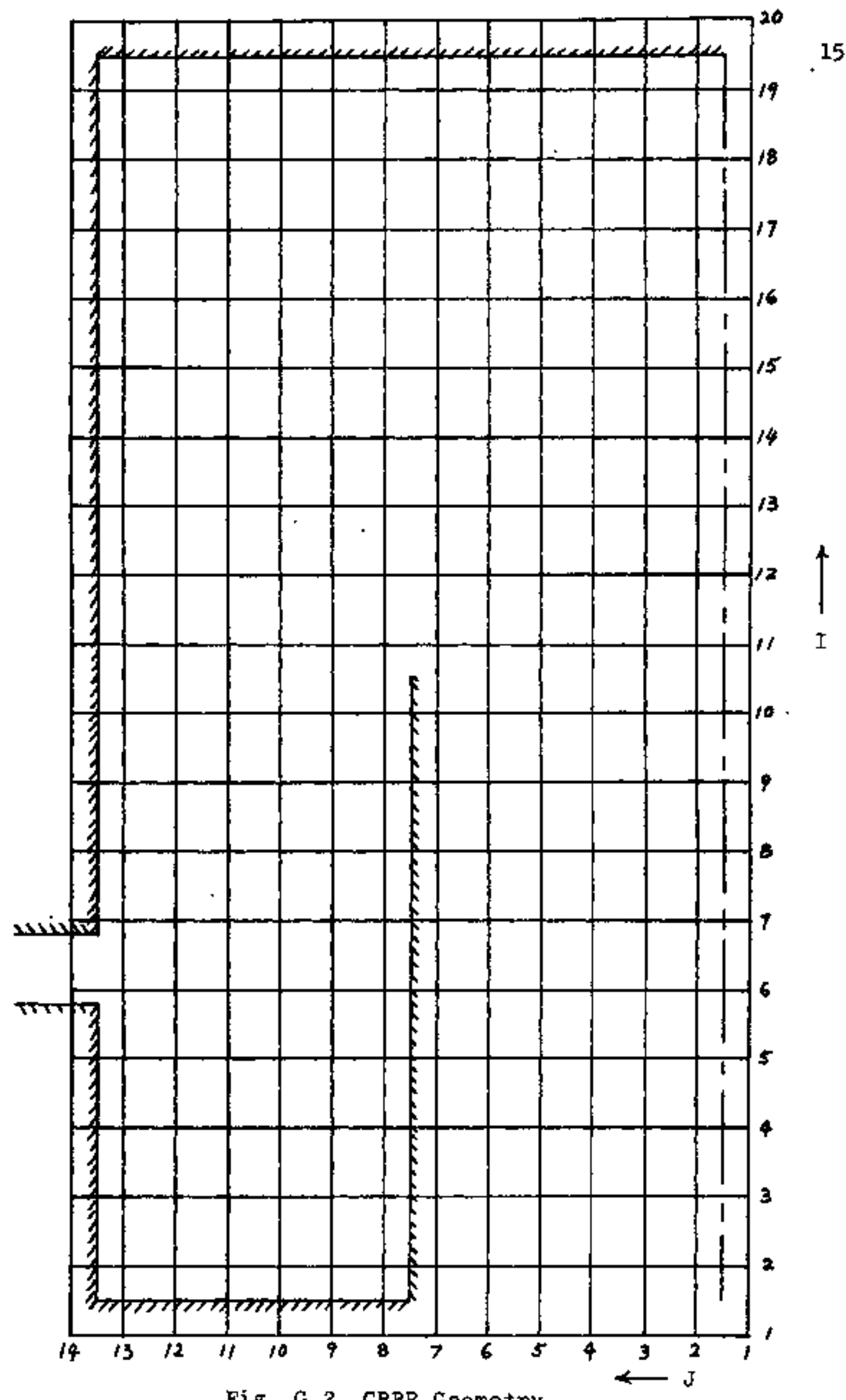

Fig. G.2 CRBR Geometry 
AP PENDIX H

CABR GEOMETRY, Re $=35,000$, DISTORTED

INLET VELOCITY DISTRIBUTION CASE

In F1gs. H.l through H.5 CRBR flow data are shown for the case with a partial inlet flow blockage which results in a distorted inlet velocity distribution. The gtriking feature is that neither code is able to predict the mean flow anywhere qualitatively except in the vicinity of the oulet orifice. Both codes predict that there is a stagnant flow region in the upper part of the plenum and that the inlet fet 13 unable to reach the top wall. It contradicts the measured mean flow fleld. As stated in section 5.3 .2 , the higbly complex turbulent transport processes in the CRBR geometry which results in great difficulties to predict the mean flow fleld even in the normal inlet velocity distribution case. Hence, in a highly chaot 1c mean flow fleld in CRBR geometry, the computer codes fa11 completely. 


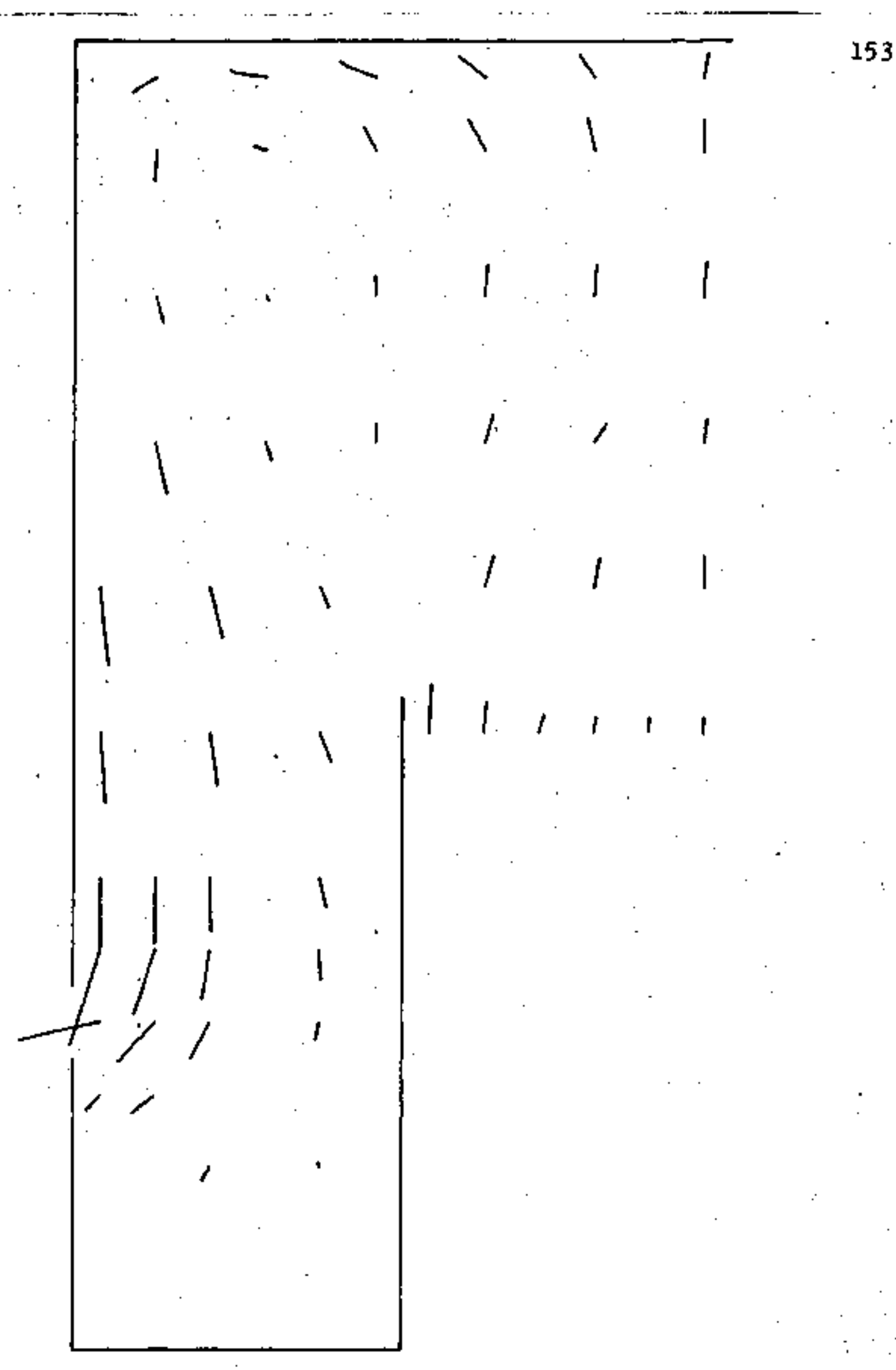

Fis. H.1 Measured Mean Flow Fleld, CRBR Geometry, D1storted Inlet Velocity 01stribution 


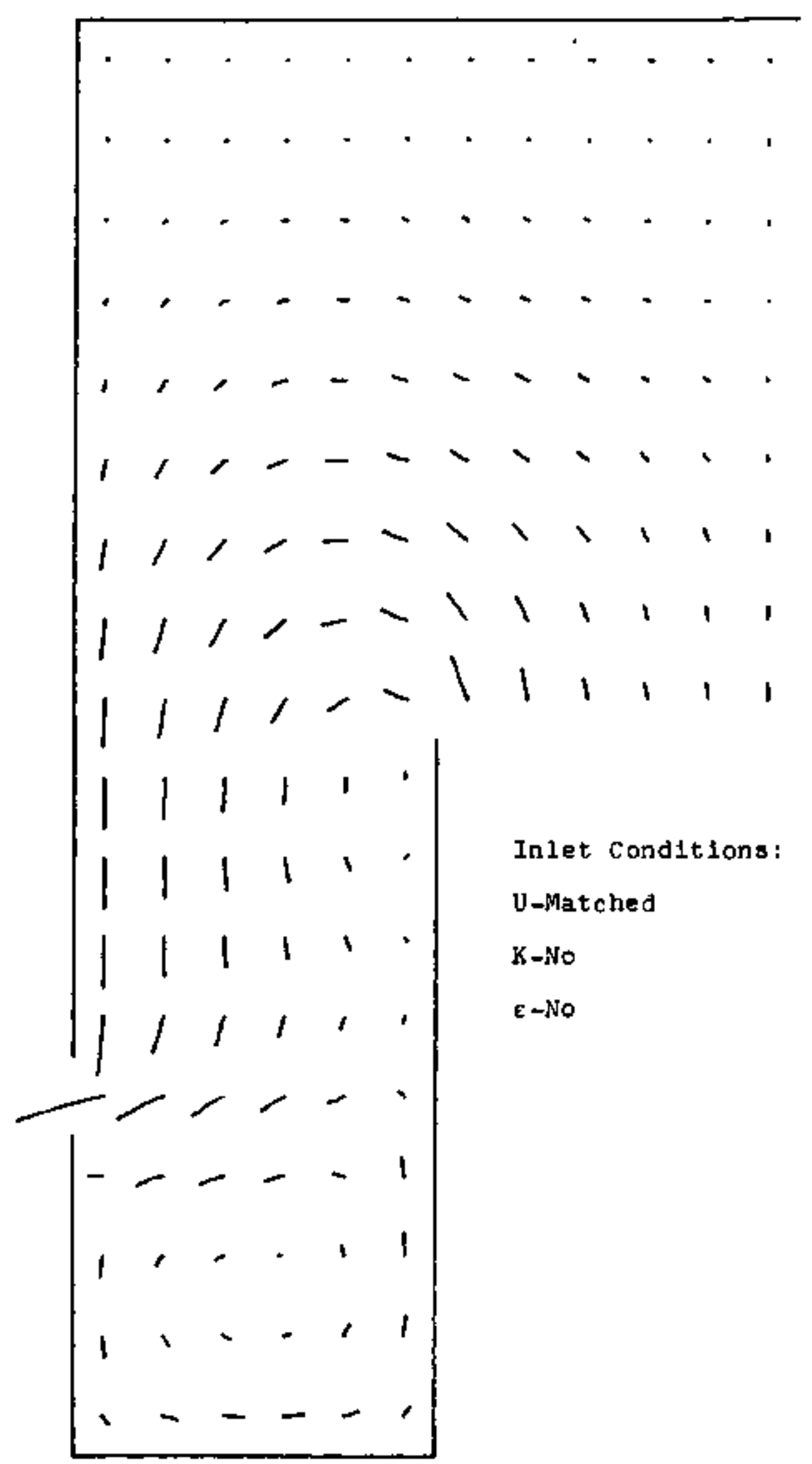

F18. H.2 TEACH-T Prediction, CRBR Geometry, Re $=35000$ Distorted Inlet Velocity D1stribution 


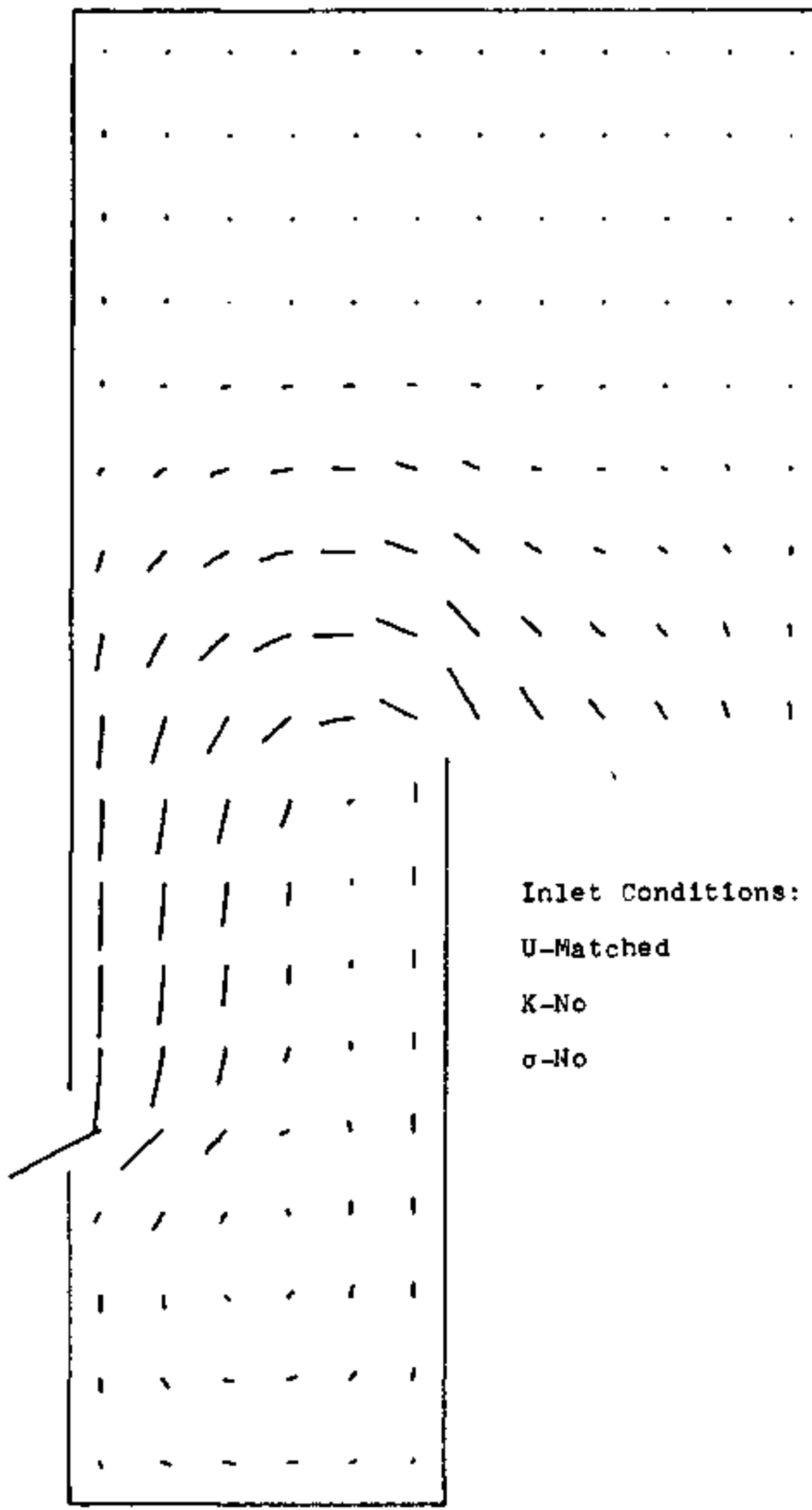

F1g. H, 3 VARR-II Prediction, CRBR Geometry, Re $=35000$ Distorted Inlet velocity D1stribution 


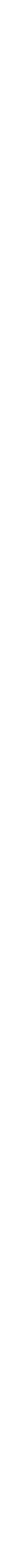

FIg. H.4 Compared Calculated and Measured Turbulent Xinetic Energy Fields, CRBR Geometry, D1storted Inlet Velocity D1stribution" 


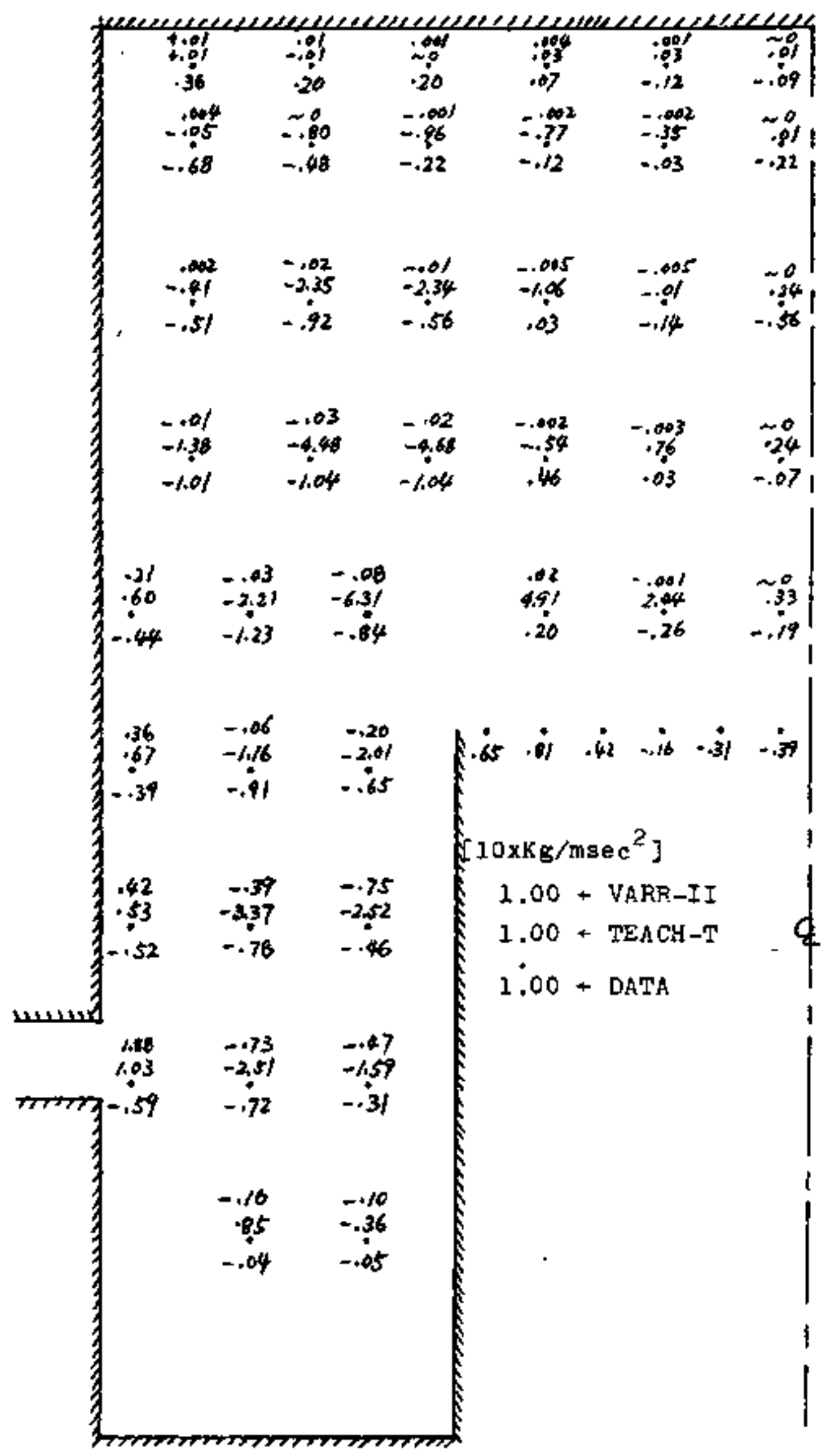




\section{APPENDIX I \\ DATA OF SENSITIVITY ANALYSIS}

The results of sensitivity analysis of flve free parameters 1n TEACH-T model for case of FFTF geometry with normal inlet velocity distribution are shown in figo. I.I through I.24. The reaulting best set of parameters is applied to distorted inlet velocity distribution case with different combination of inlet turbulent kinetic energy disbipation rates. They are shown in Figs. I.25 through I.33. Finally, the results of sensitivity analysis of two parameters, $\sigma_{K}$ and $\sigma_{E}$, for the distorted inlet velocity distribution case are shown in Fige. I.34 through I. 40 . 


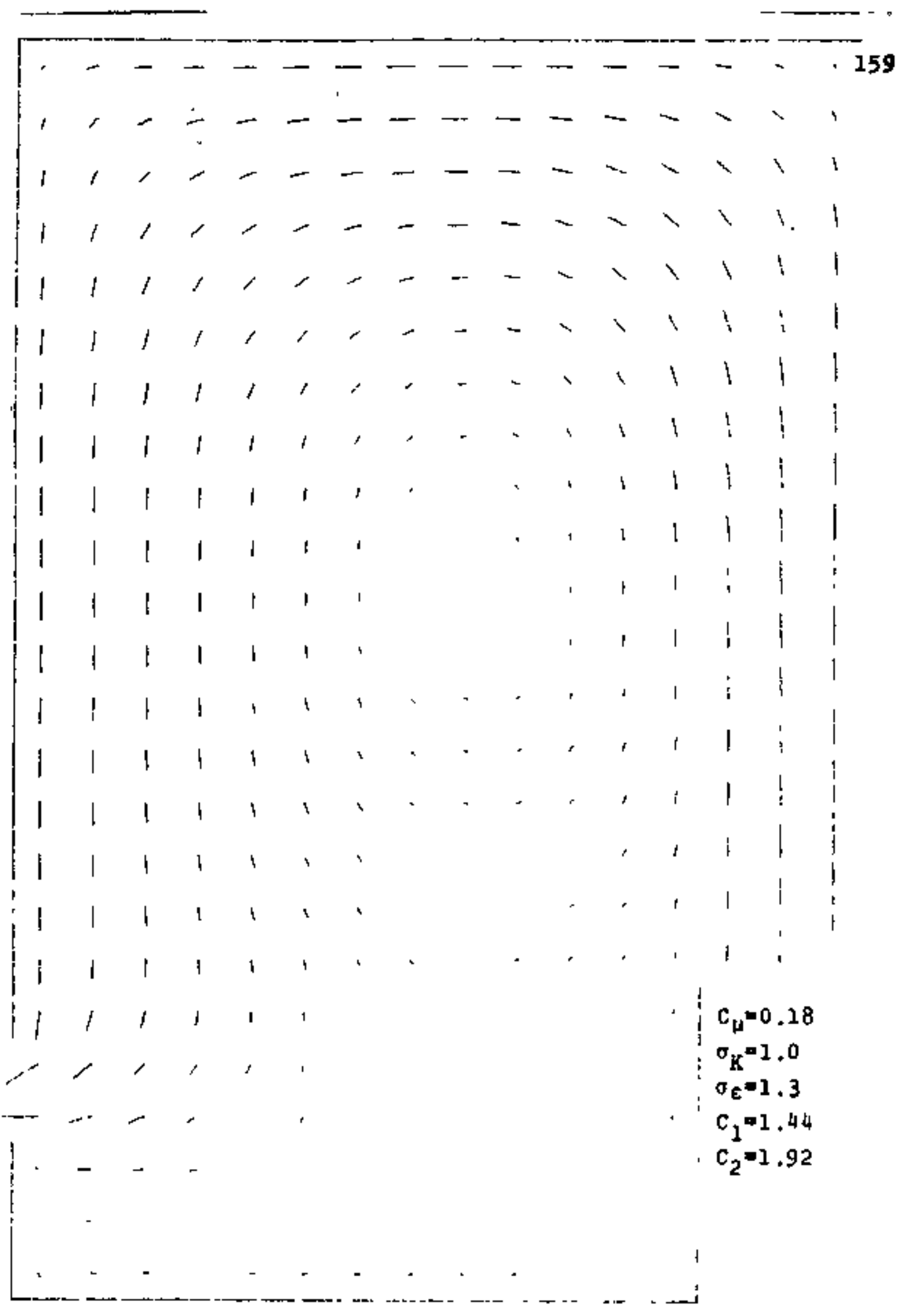

F1g. I.I TEACH-T rediction with $C_{y}=0.18$, FFT? Geometry, Re-70000, Normal Inlet Velocity Distribution 


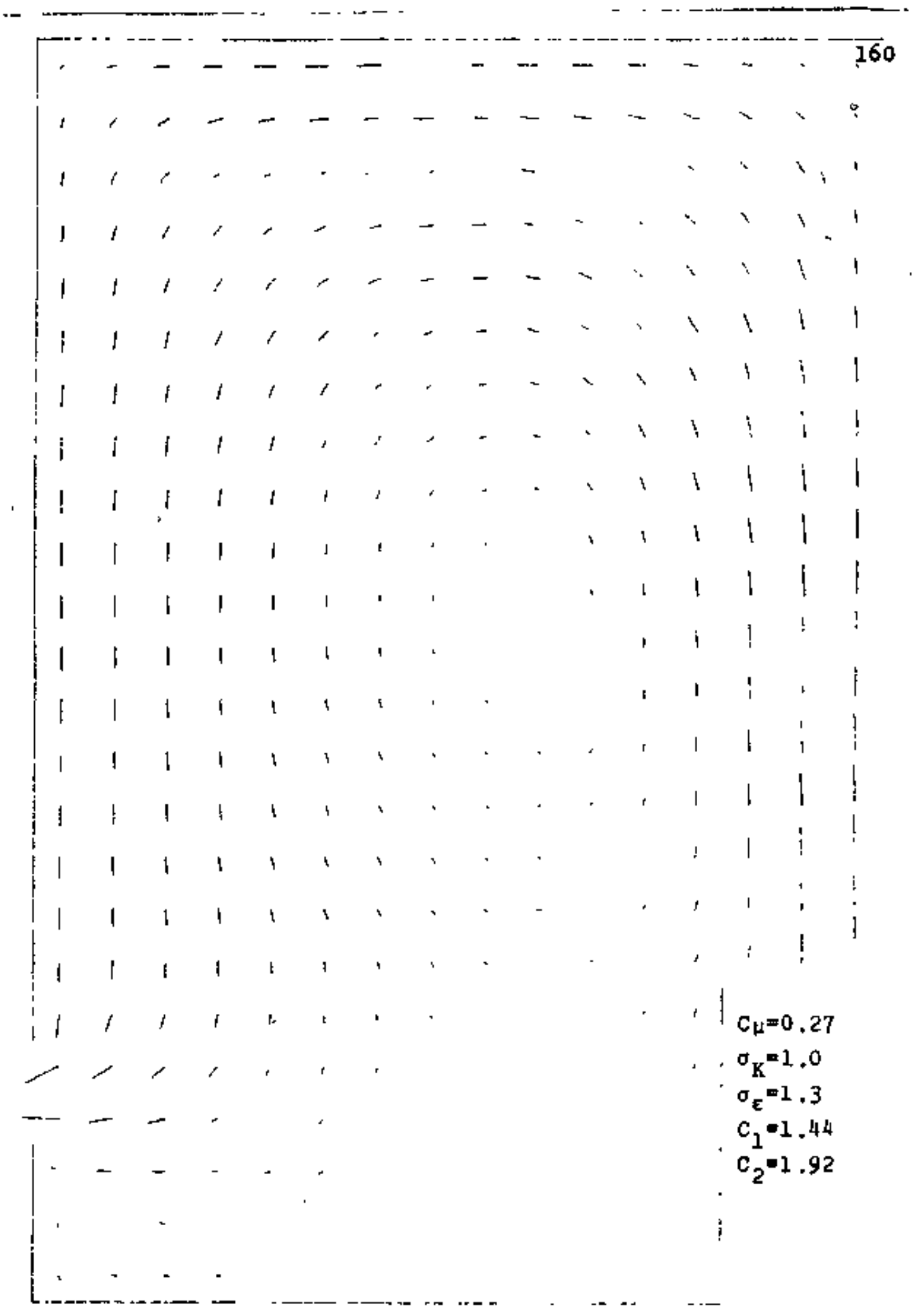

F1g. I.2 TEACH-T Prediction w1th $C_{y}=0.27$, FFTP Geometry, Re $=70000$, Normal Inlet Velocity distribution 


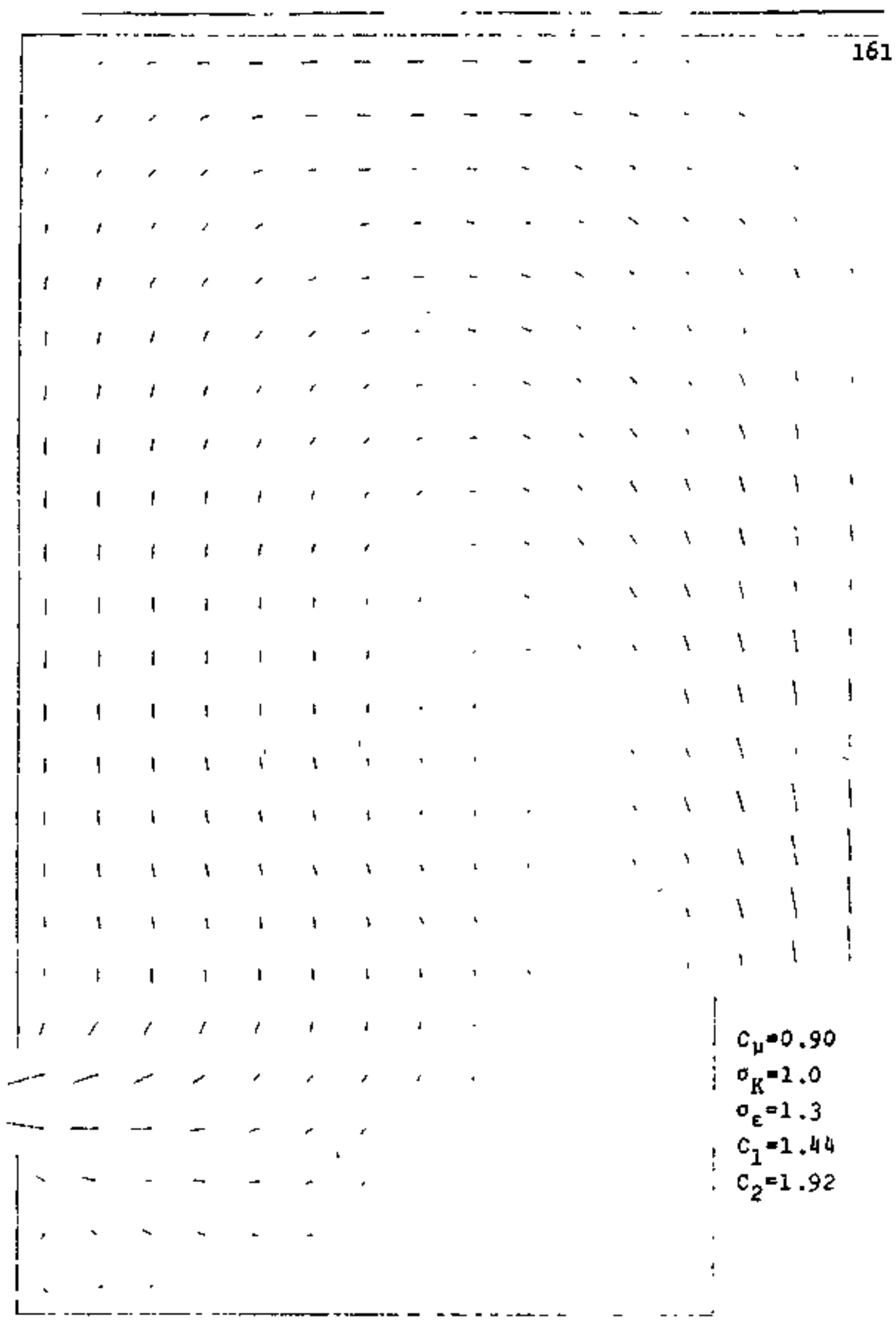

P1g. I.3 TEACH-T Prediction W1th $C_{\mu}=0.90$, FFTF Geometry, Re-70000, Norwal Inlet Voloctty Distribution 


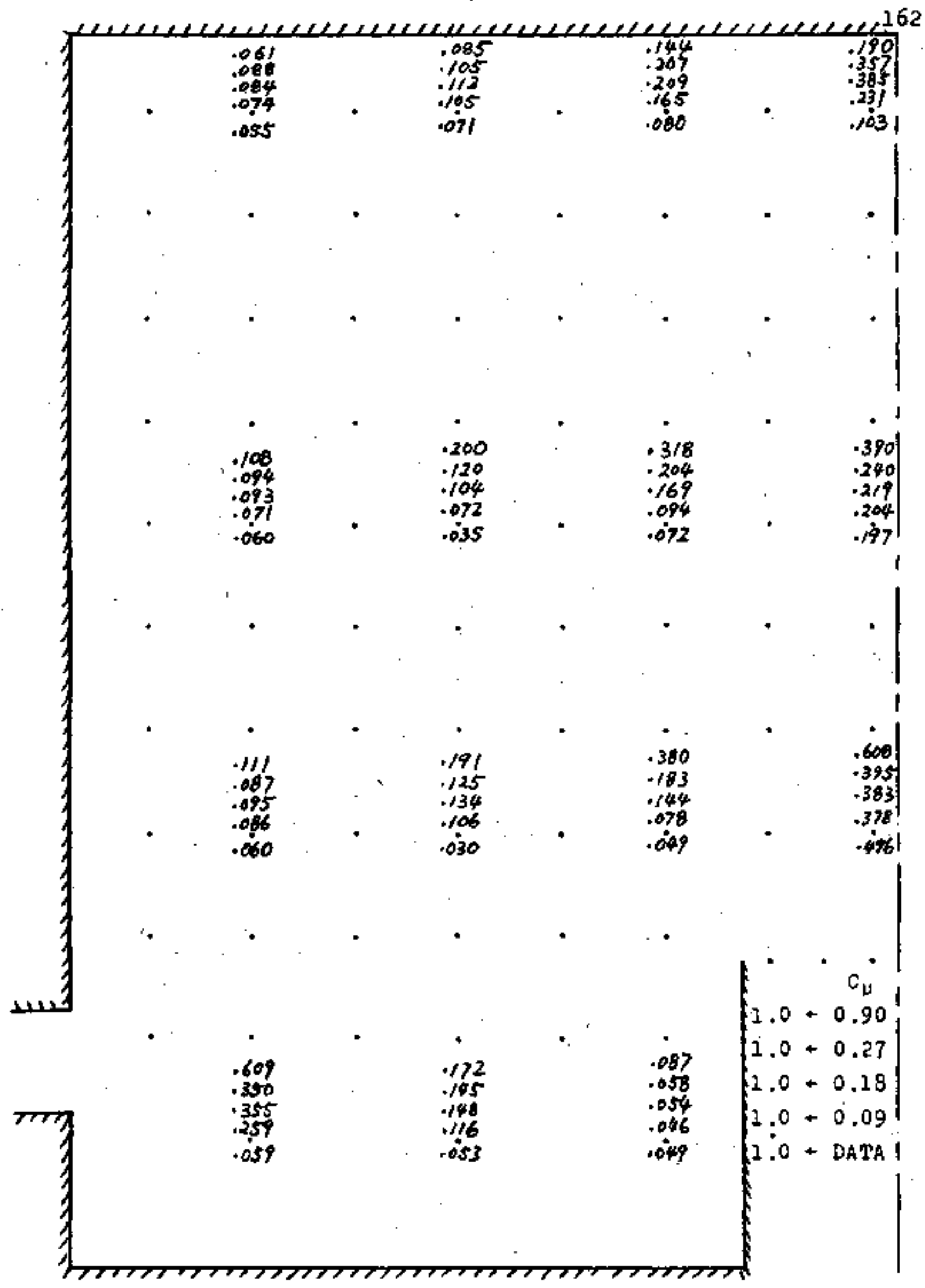

F1g. I.4 Compared Calcualted and Meagured Turbulent K1net10 Energy Fields, PFTF teometry, Re=70000, Nornal Inlet Veloc1ty D1otribution 
, - - - - - - - - - - -163

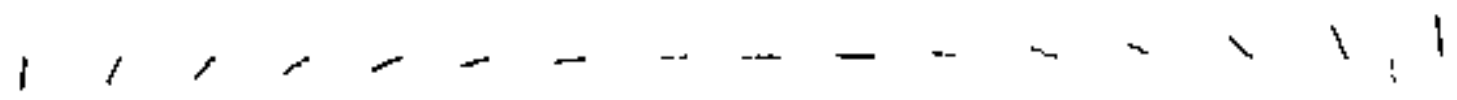

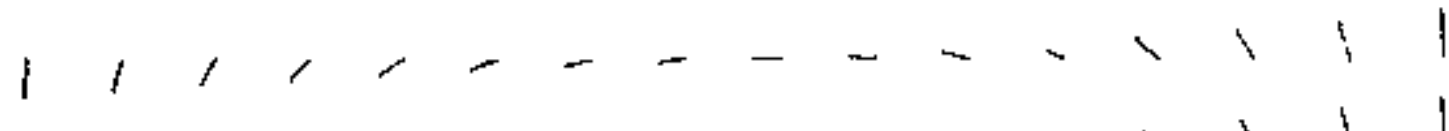

1. $1,1+-2,-\infty, 1)$

$111,1, \ldots, \ldots 1,11$

$1,1+\ldots, \ldots+1,1,1$

$111,1, \cdots, 1$

$1+1,1,1,1,11$

$\begin{array}{lllll}1 & 1 & 1 & 1\end{array}$

$1+1,1,1,1,111$

$\left|\begin{array}{lllllllll}1 & 1 & 1 & 1 & 1 & 1 & 1 & 1 & 1\end{array}\right|$

\begin{tabular}{|lllllllllll}
1 & 1 & 1 & 1 & 1 & 1 & 1 & 1 & 1 & 1
\end{tabular}

$\begin{array}{lllllllllll}1 & 1 & 1 & 1 & 1 & 1 & 1 & & & & 1\end{array} \mid$

$\left|\begin{array}{lllllllll}1 & 1 & 1 & 1 & 1 & 1 & 1 & 1\end{array}\right|$

$\begin{array}{llllllllll}1 & 1 & 1 & 1 & 1 & 1 & 1 & 1 & 1 & 1\end{array} \mid$

$\begin{array}{llllllllll}1 & 1 & 1 & 1 & 1 & 1 & 1 & 1 & 1 & 1\end{array}$

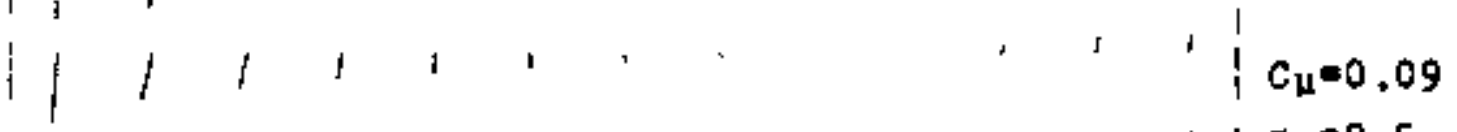

r 1,1,

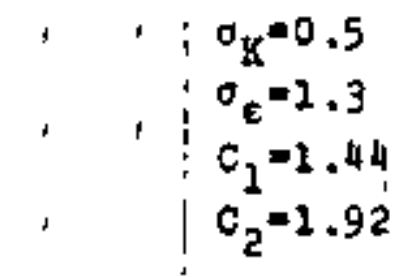

P1g. I.5 TEACH-T Prea1ction with $\sigma_{K}=0.5$, FFTF Geometry, Re=70000, Normal Inlet Velocity pistribution 


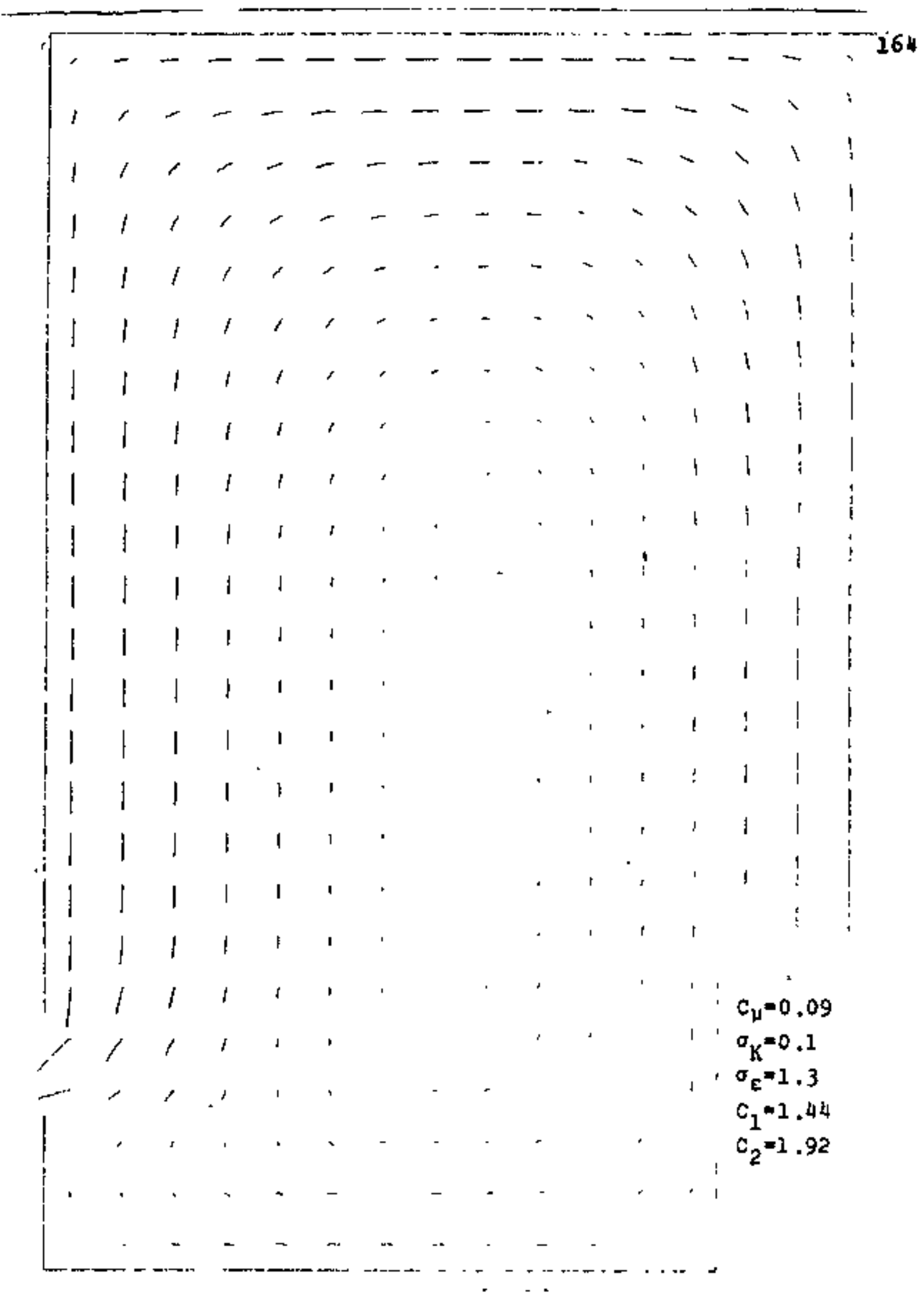

F1g. I.6 TEACH-T prediction w1th $\sigma_{K}=0.1$, FFTF Geometry, Re $=70000$, Normal Inlet Vefocity Distribution 


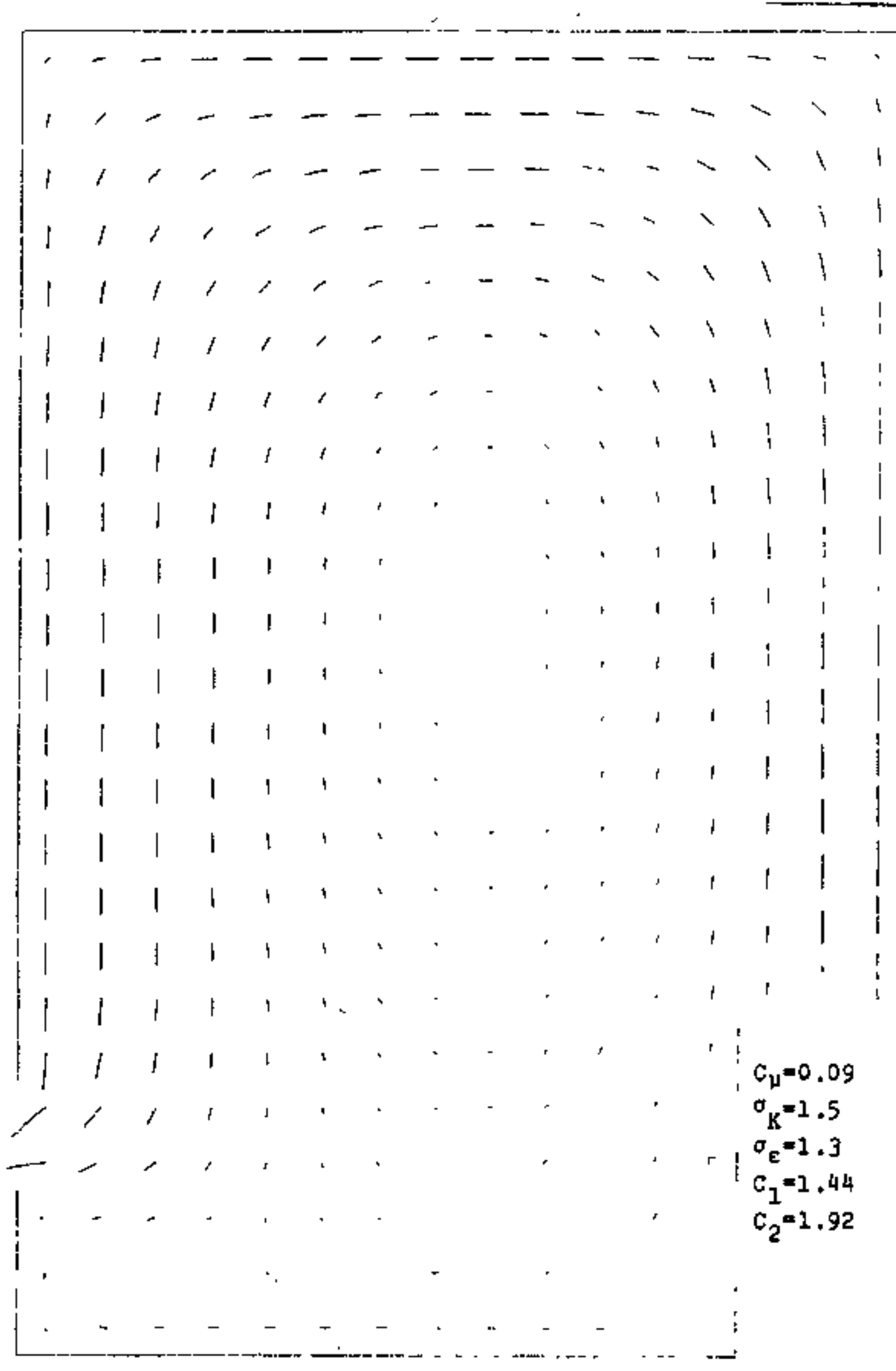

F18. I.7 TEACH-T Pred1et1on w1th $\sigma_{K}=1.5$, PFTP Geometry, Re $=70000$, Normal Indet Vefoclty D1stribution 


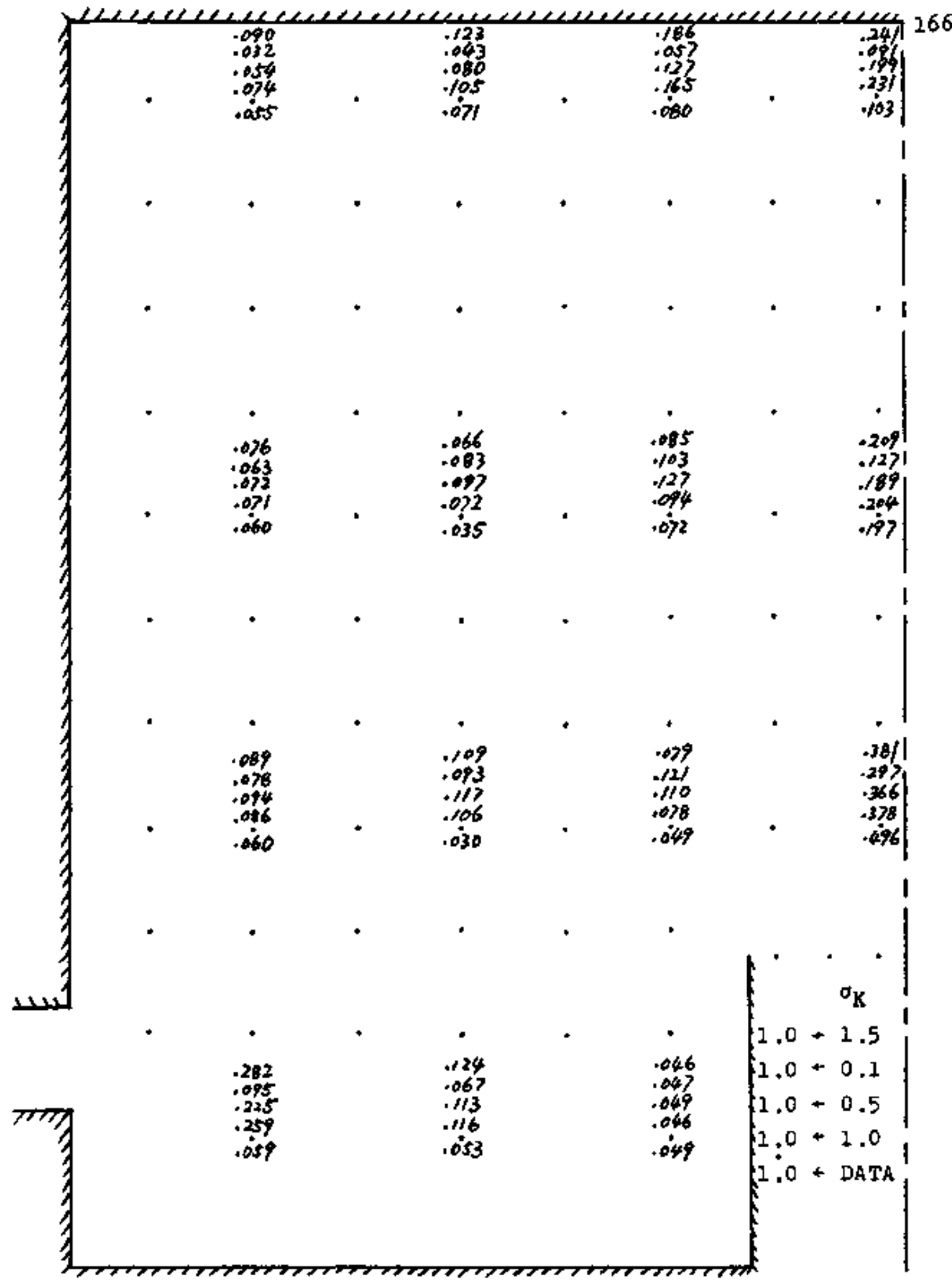

Fig. I.8 Compared Calculated and Measured Turbulent Kinetic Energy Flelds, FFTF deonetry, Re $=70000$, Normal Inlet velocity Distribution 


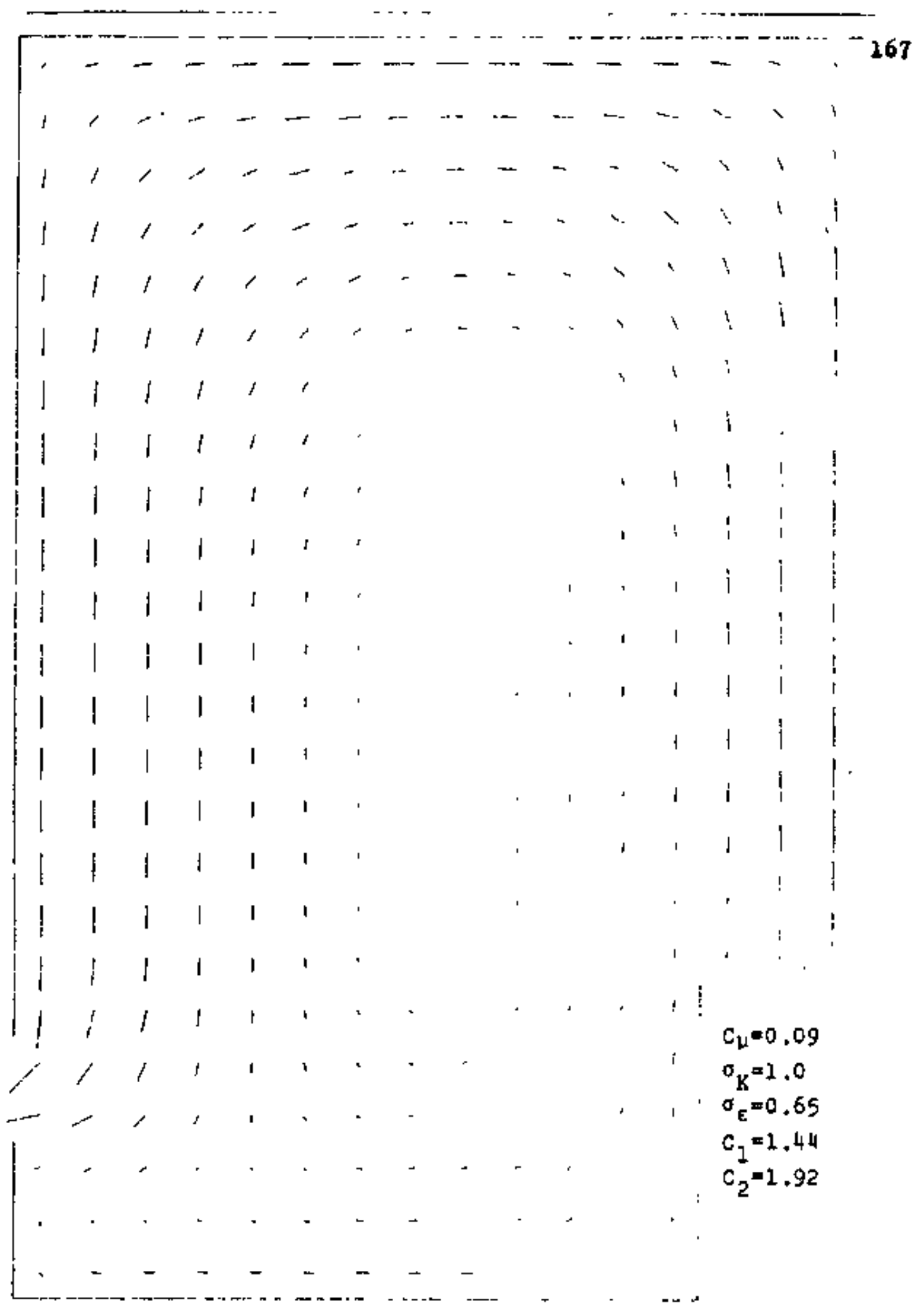

P1g. I.9 TEACH-T Prediction w1 th $\sigma=0.65$, FFTF Geometry, Re $=70000$, Normal Inlet vefocity Distribution 


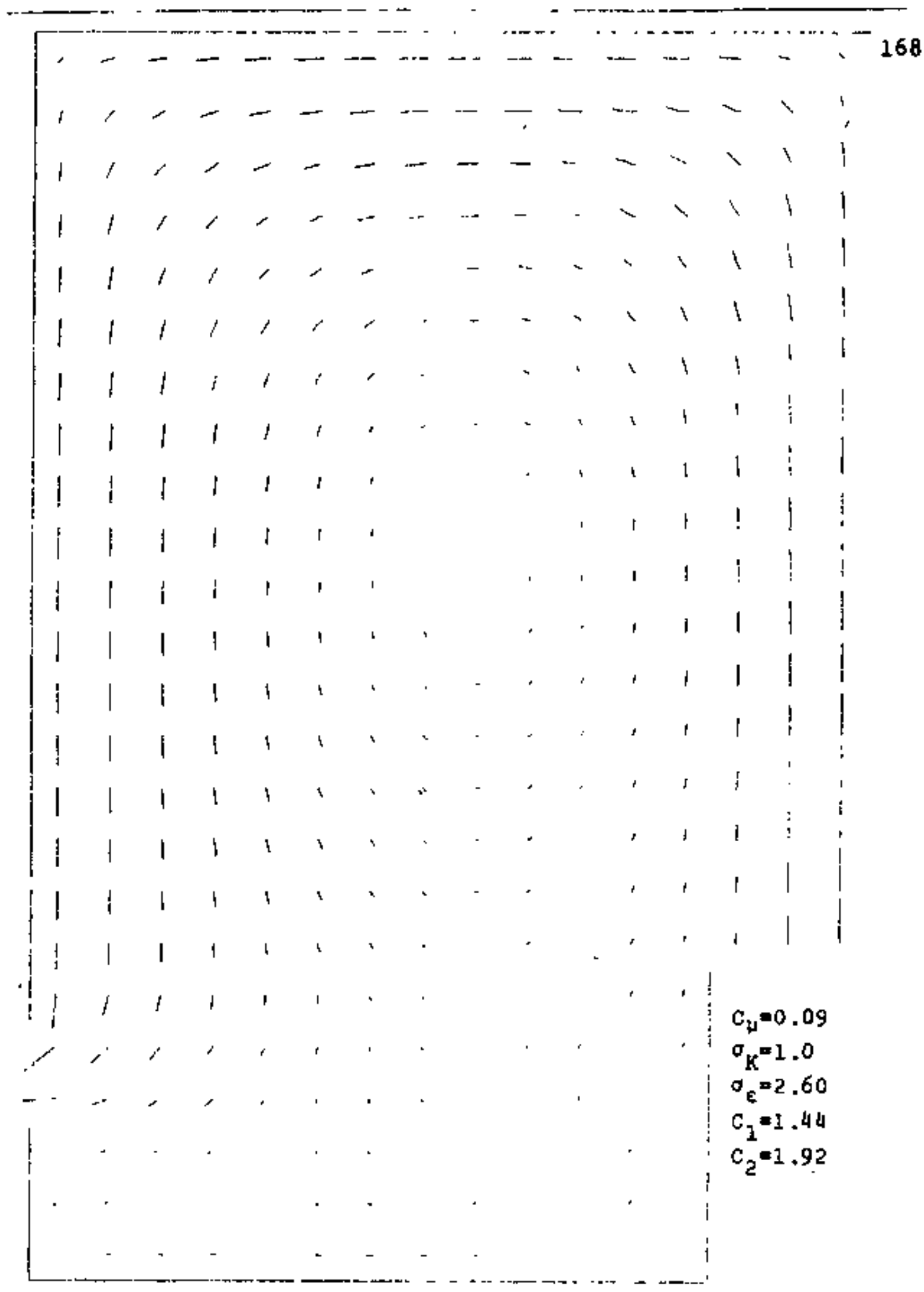

Fig . I.10 TEACH -T Prediction with $\sigma_{\varepsilon}=2.60$, FFTF Geometry, Re $=70000$, Normal Inlet velocity Distribution 


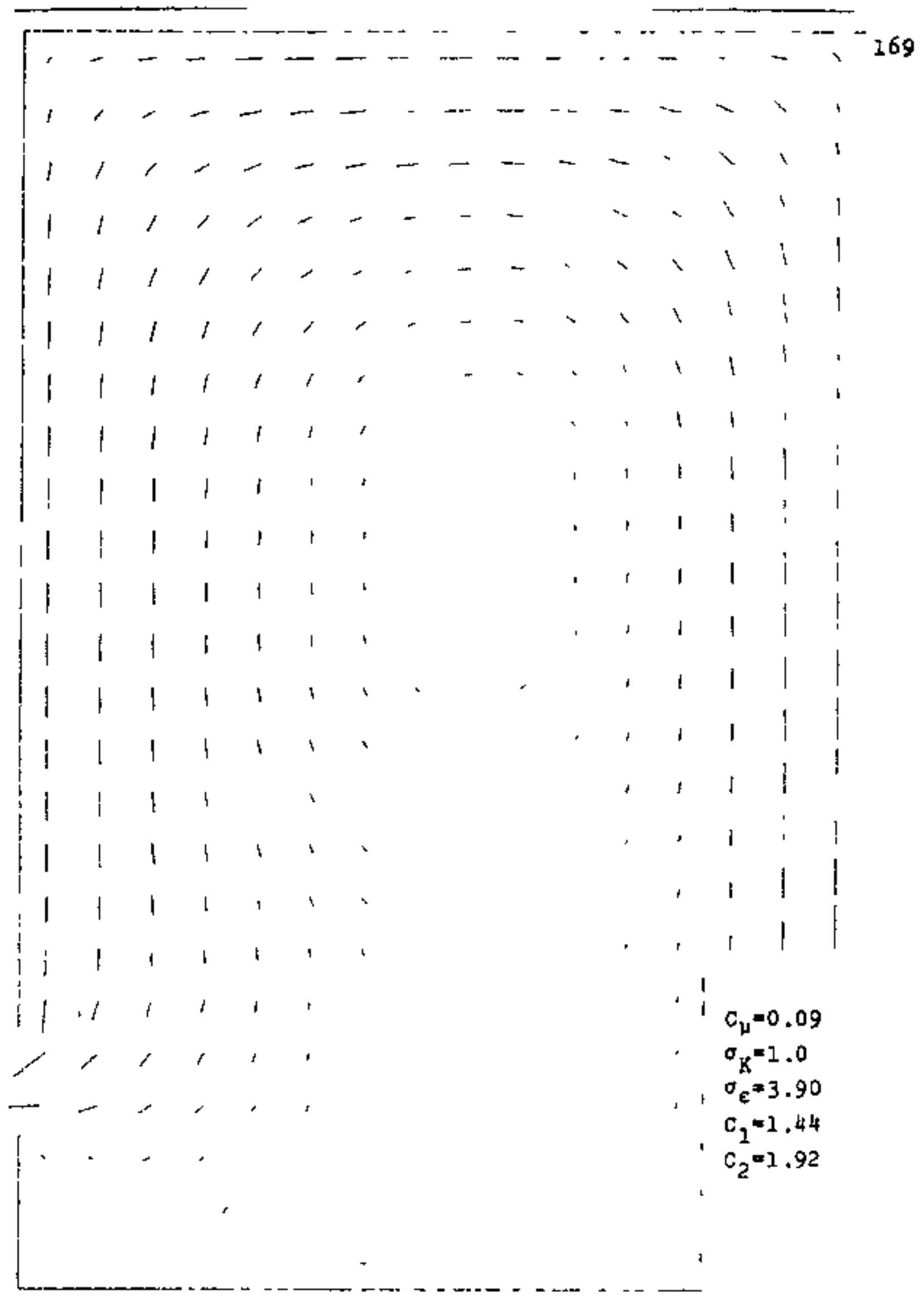

F18. I.1I TEACH-T Prediction w1th $\sigma_{E}=3.90$, FFrF Geometry $\mathrm{Re}=7000$, Normal Inlet Velocity Distribution 


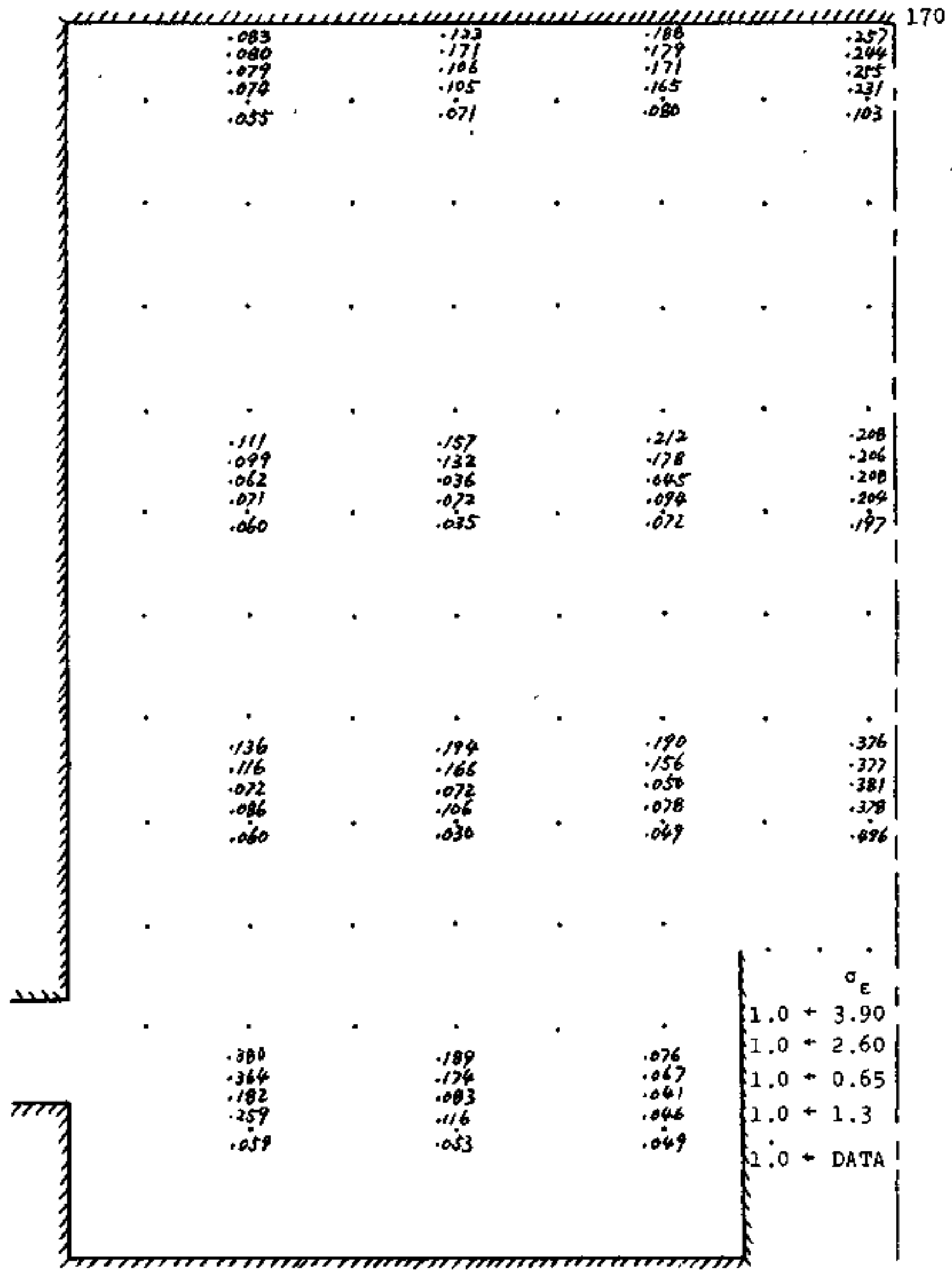

F1g. I.12 Compared Calculated and Messured Turbulent

Kinetic Enersy F1elds, FFTF Goometry, Re=70000, Normal Inlet Velocity D1stribution 


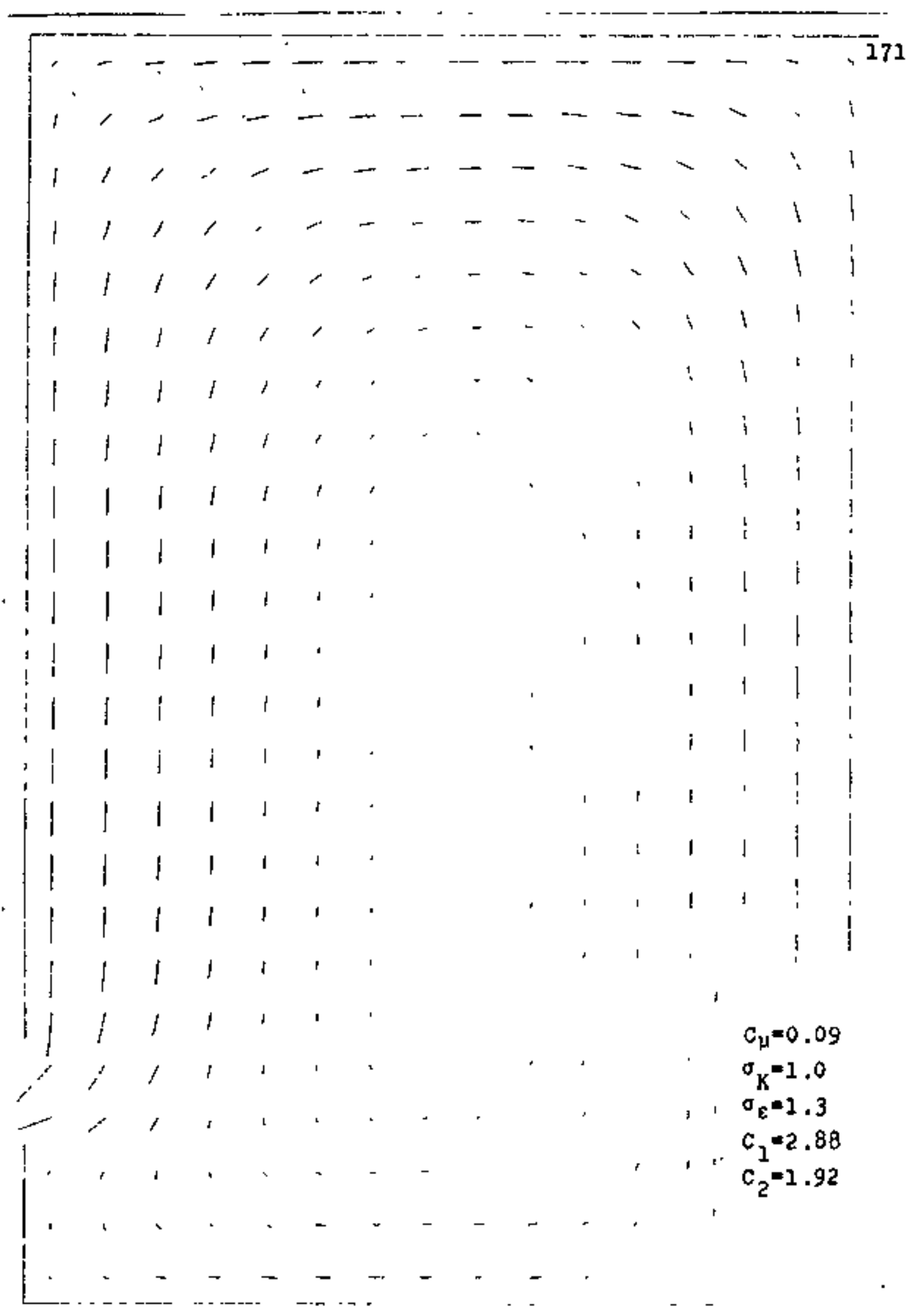

F18. I.13 TEACh-T prediction w1th $c_{1}=2.88$, FFTP Geometry, $R e=70000$, Normal Inlet velocity Distribution 


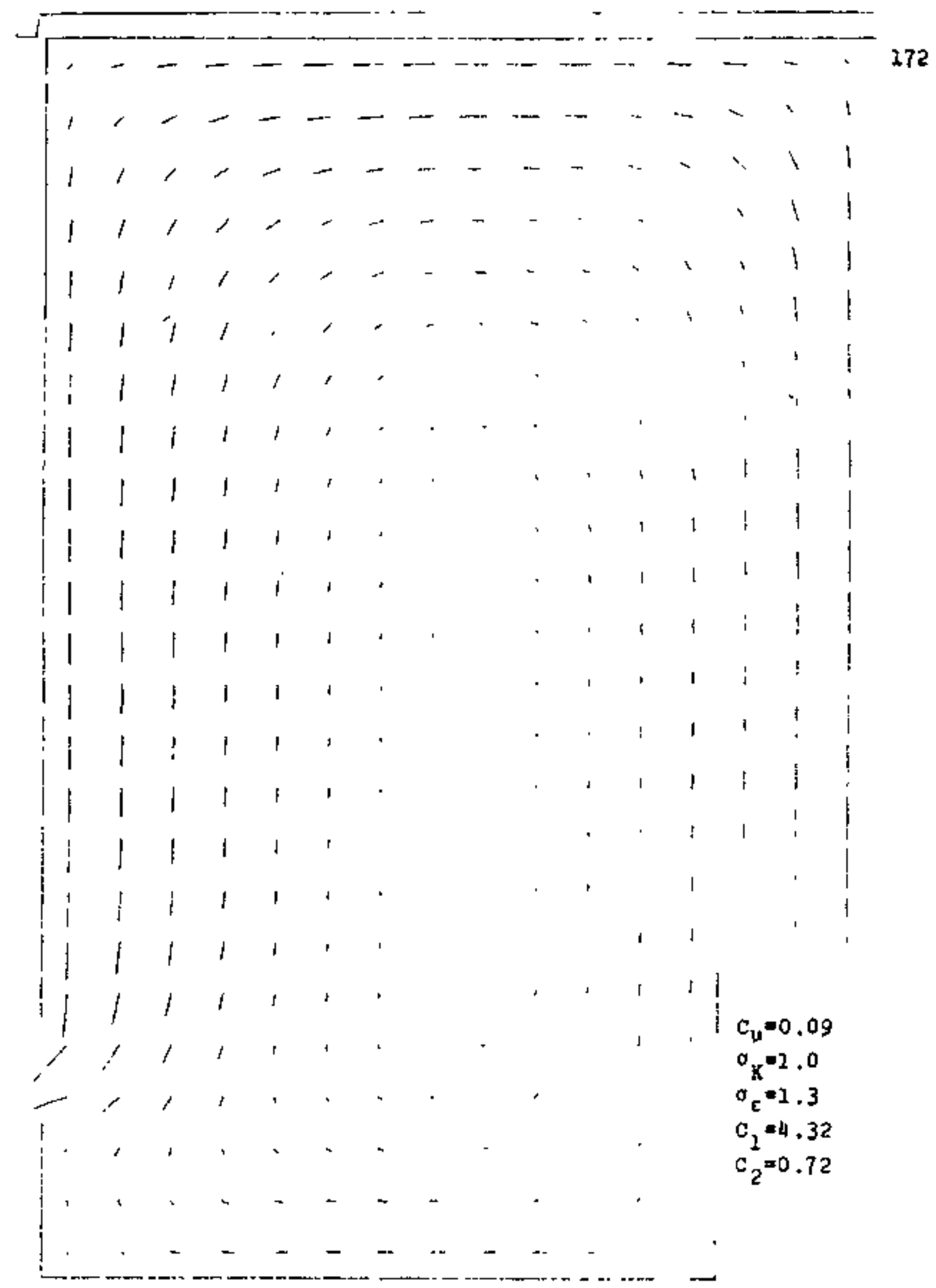

Fig. I.14 TEACH-T prediction w1th $c=4.32$, FFTP Geometry, Re=70000, Normal Inlet Velocity Distribution 


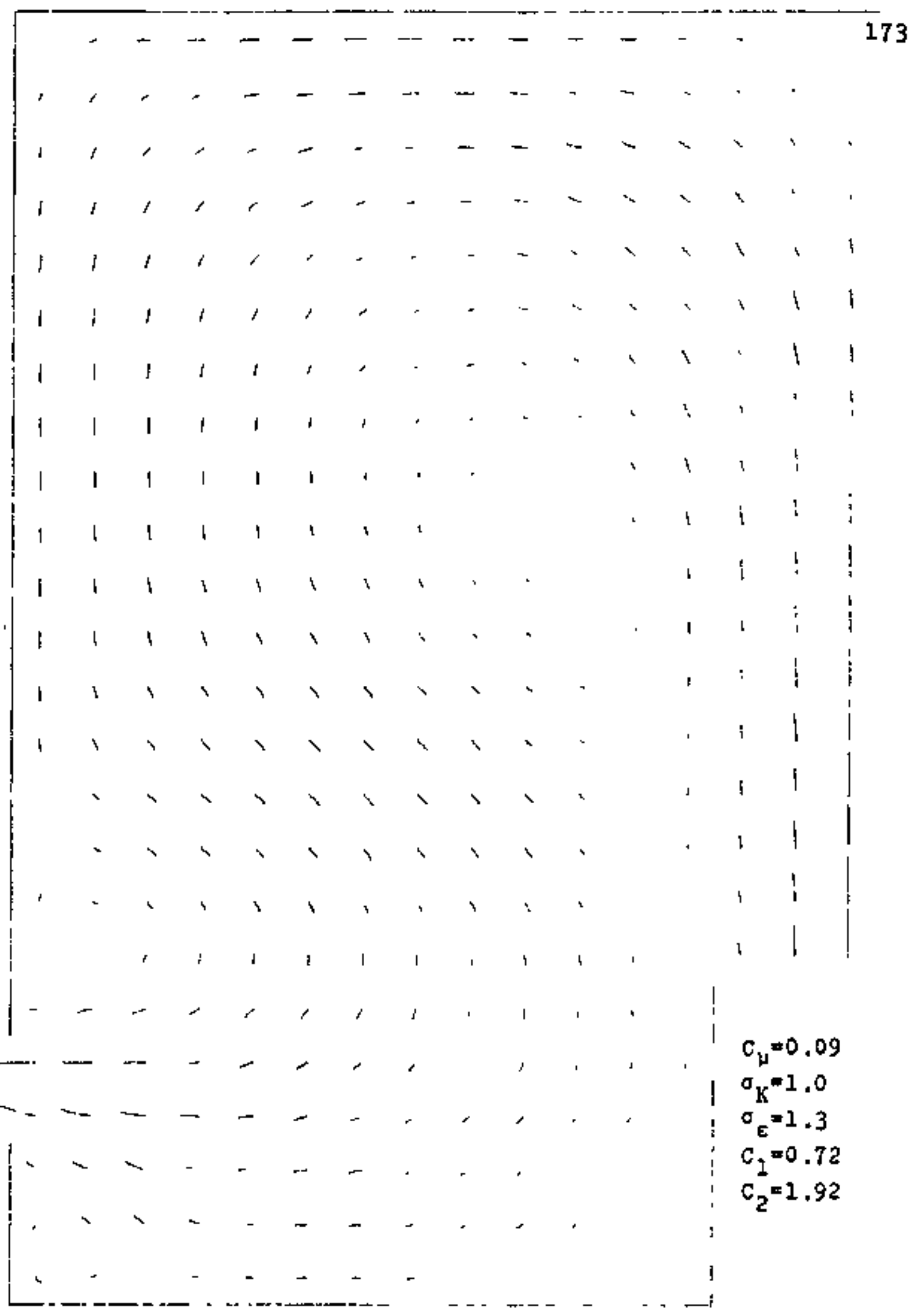

F1. I.15 TEACH-T Frediction w1th $c_{1}=0.72$, FFTF Geometry, Re=70000, Normal Inlet Veloc1ty Distribution 


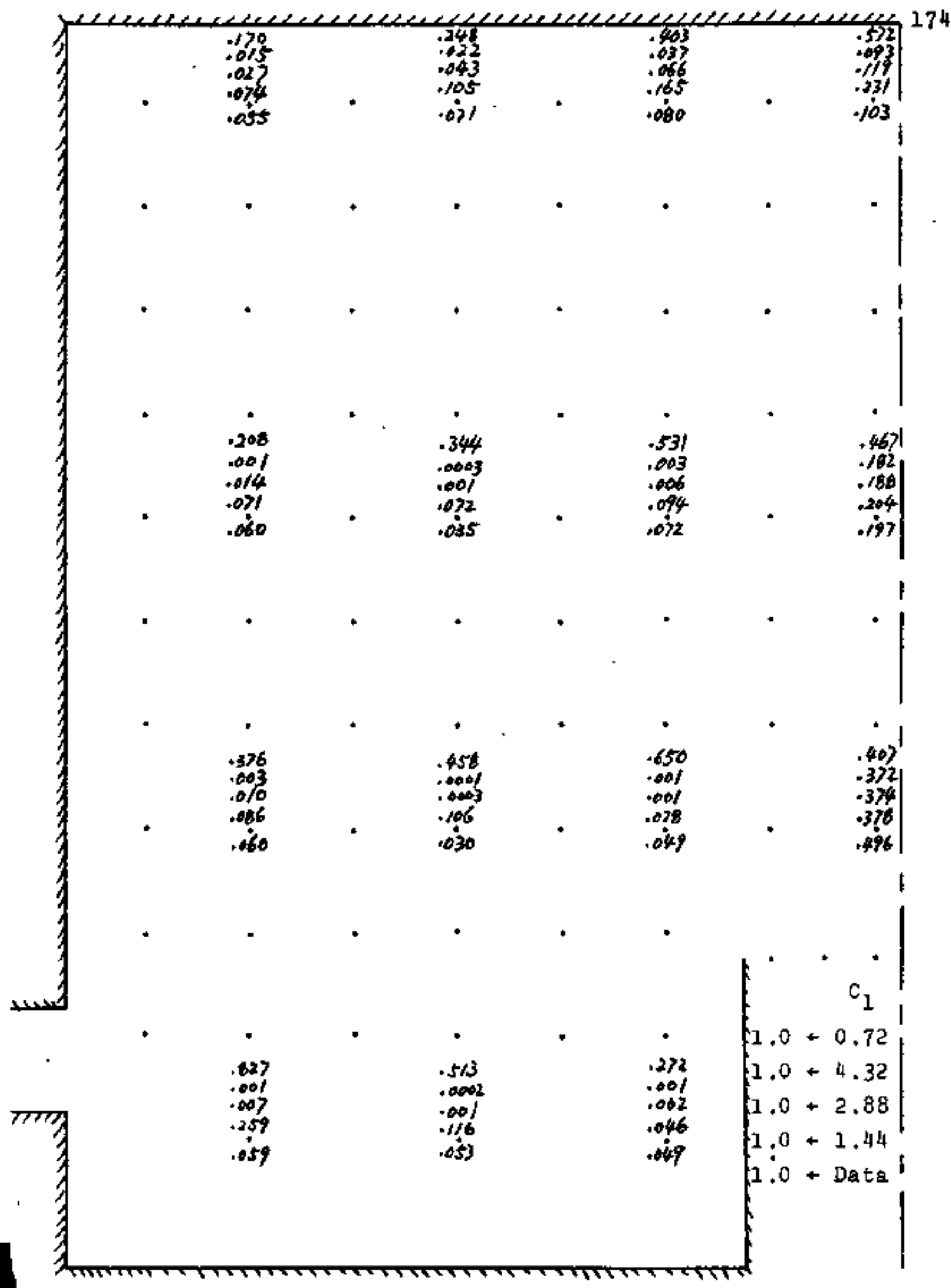

F1g. I.16 Compared Chlcualted and Measured Turbulent Kinetfc Energy Plelds, FFTF Geometry, Re=70000, Normal Inlet Velocity Distribution 


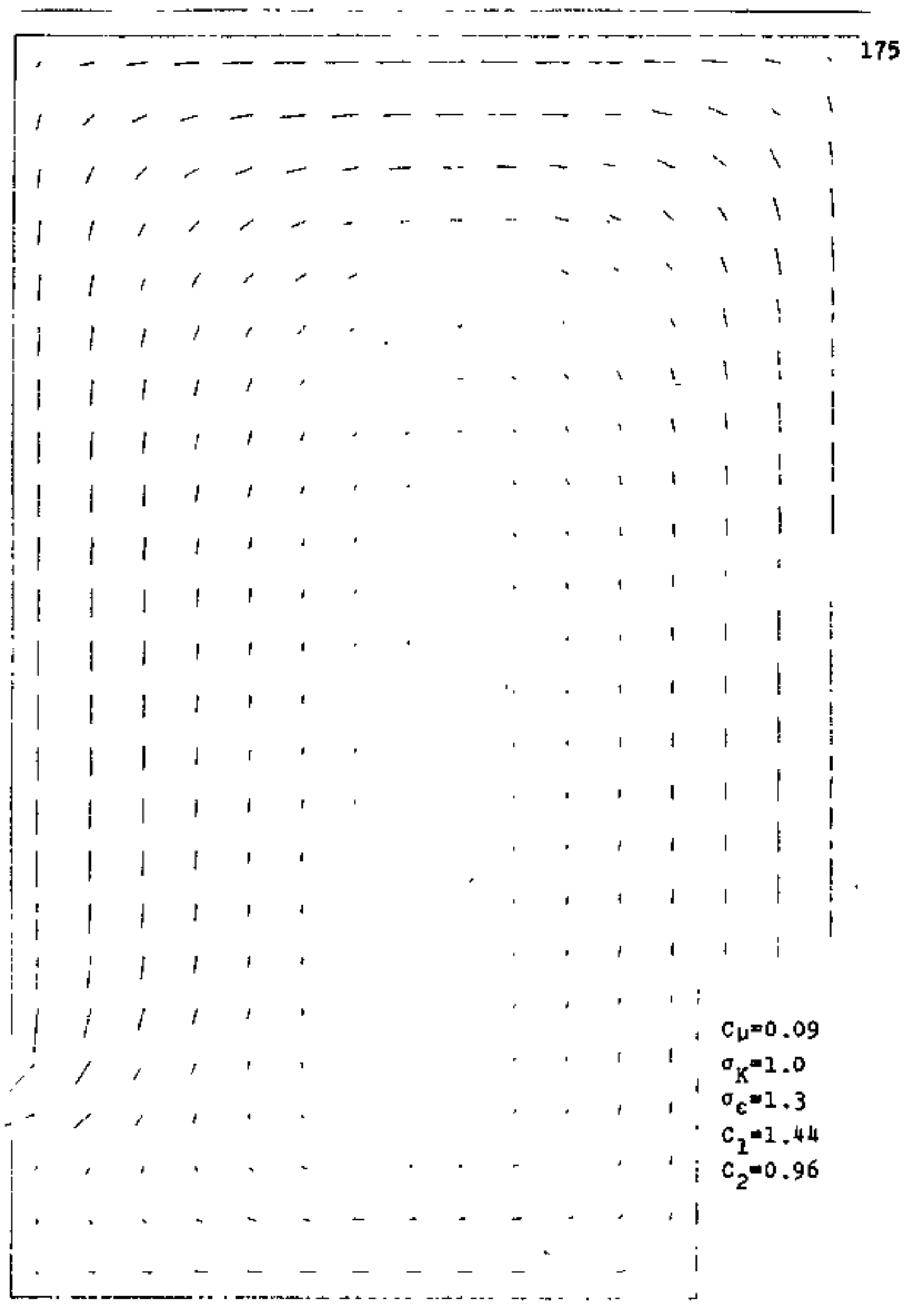




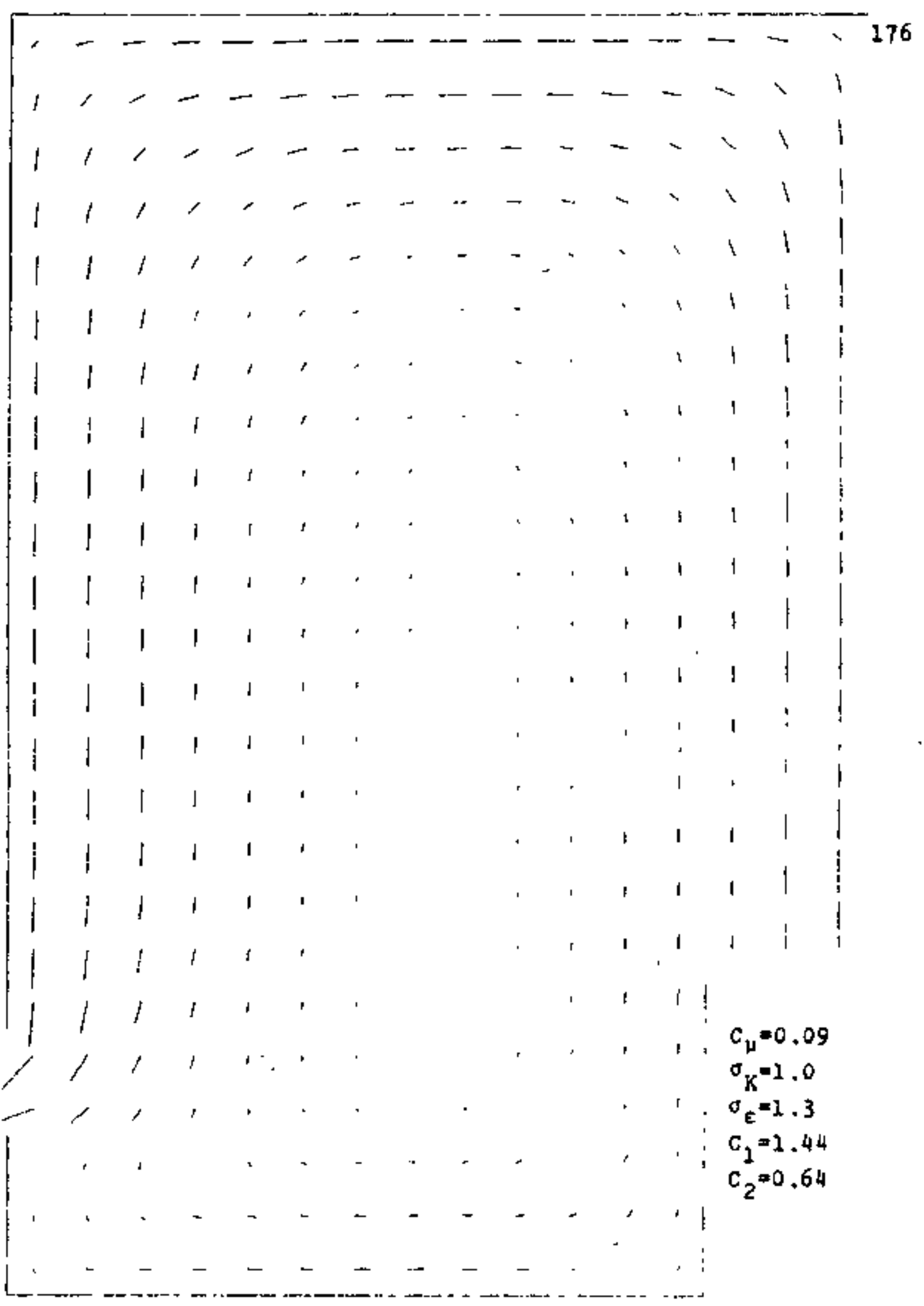

Fig. I.18 TEACH-T Prediction with $\mathrm{C}_{2}=0.64$, FFTF Geometry, Re=70000, Normal Inlet Velocity Distribution 


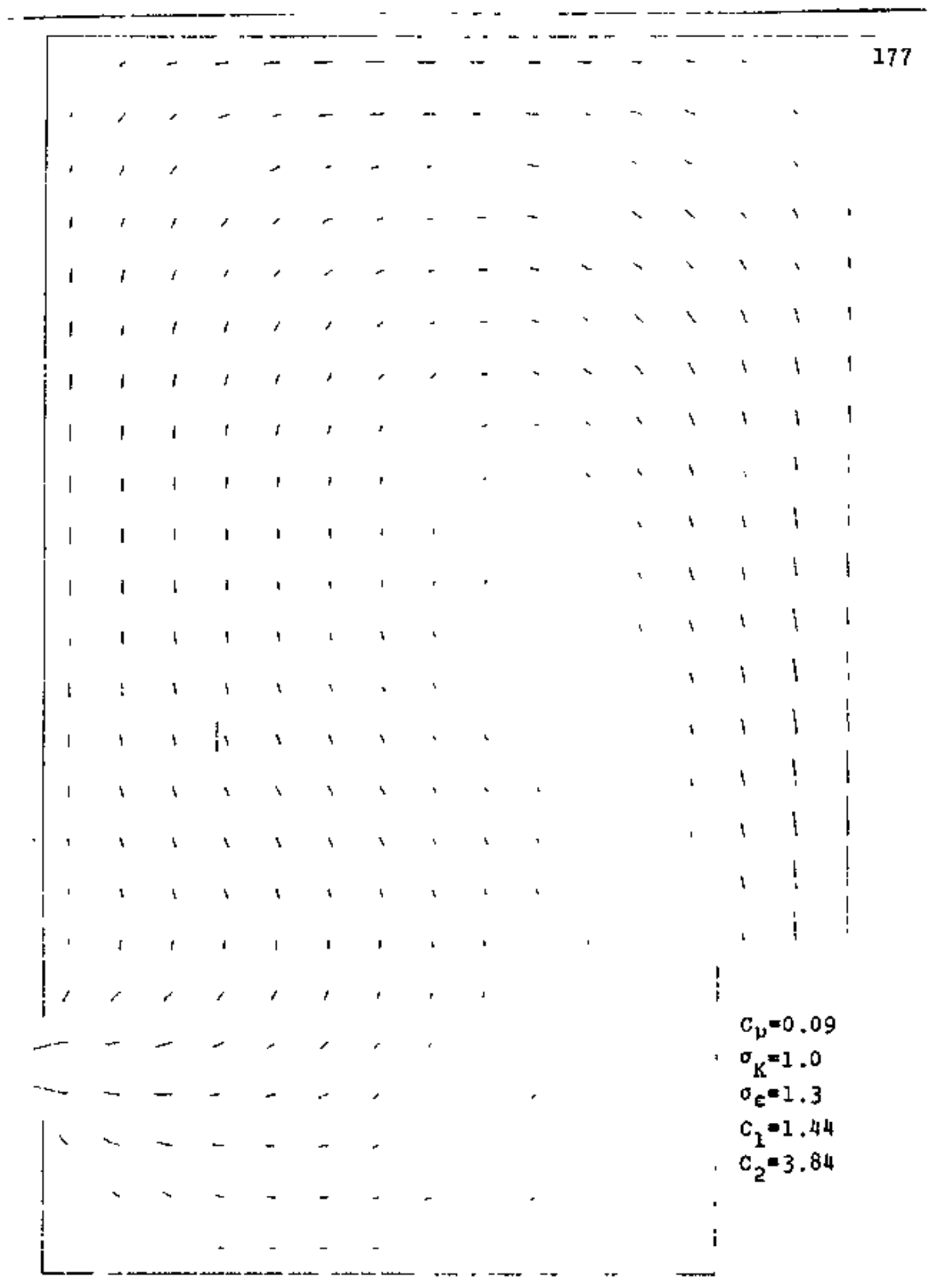

Fig. I.19 TEACH-T prediction with $\mathrm{C}_{2}=3.84$, FFTF Geometry, Rem 70000, Normal Inlet Velocity D1stribution 


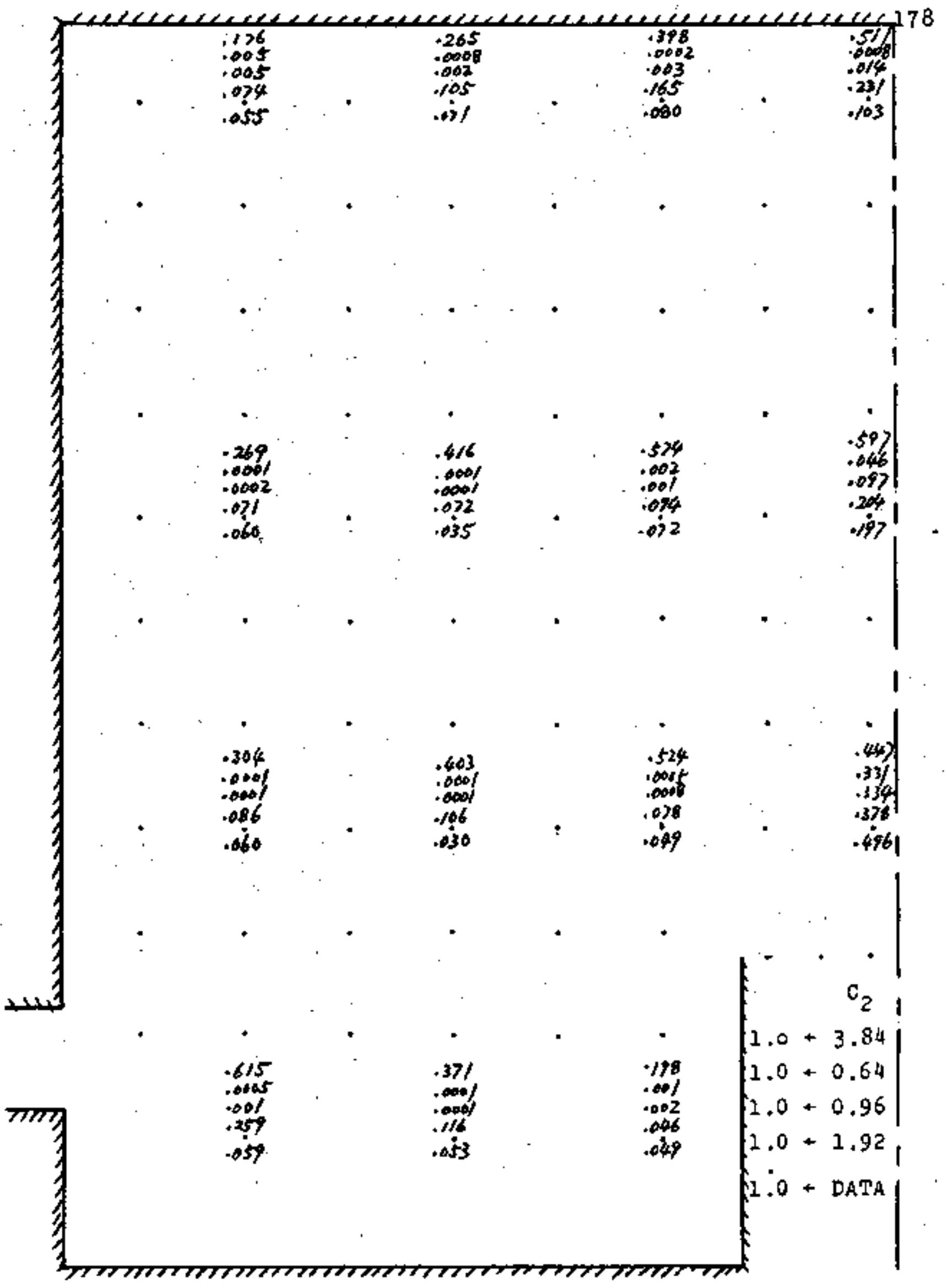

P1G. I.20 Compared Calculated and Measured Turbulent Kinetic Energy F1elds, FFrF Geometry, Re=70000, Normal Inlet Velocity Distribution 


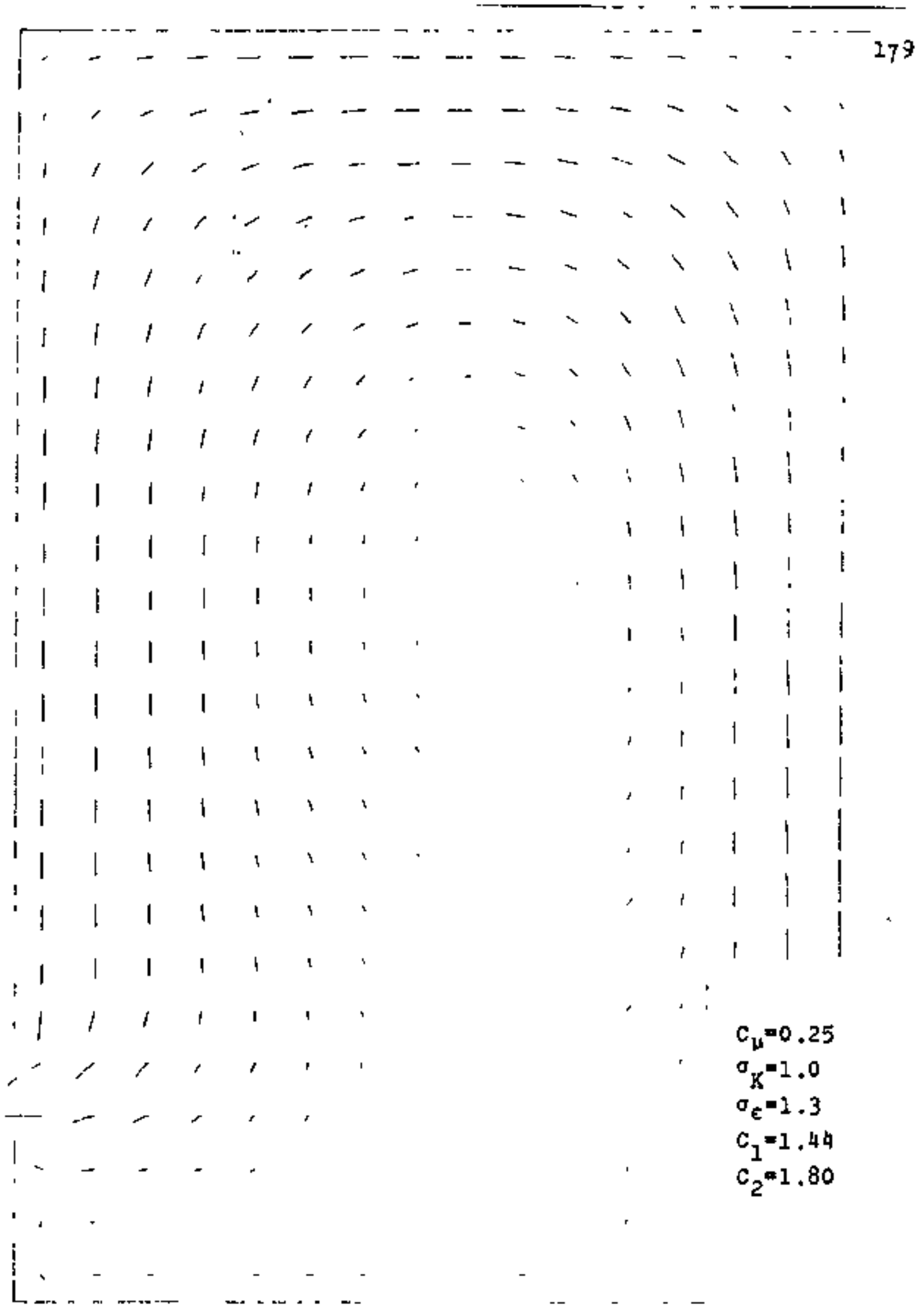

Fig. I.21 TEACH-T prediction with $\mathrm{C}_{\mu}=0.25, \mathrm{C}_{2}=1.80$, Velocity Distribution 


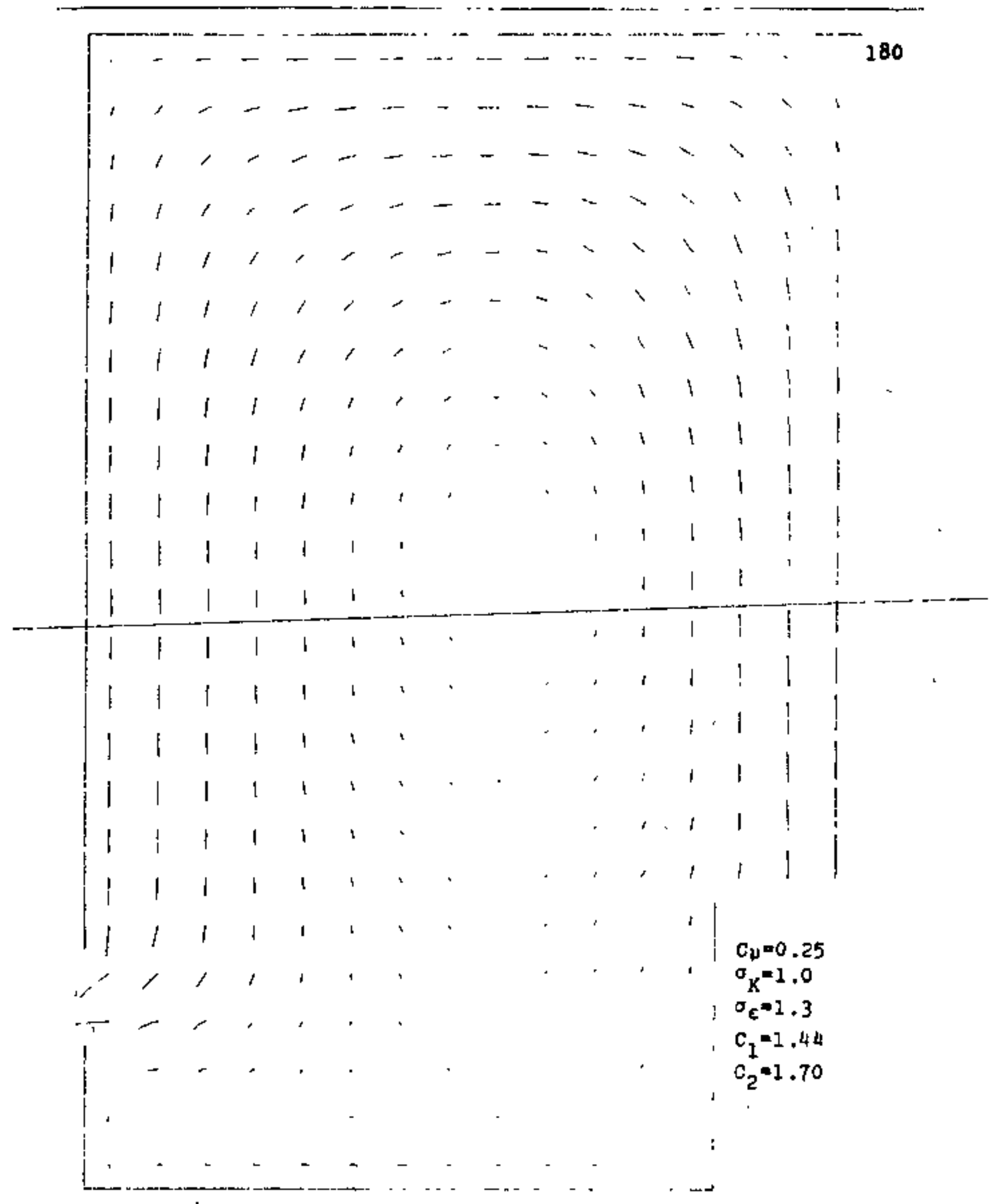

F18. I.22 TEACH-T Frediction with $C_{4}-0.25, C_{2}=1.70$, Distribution 


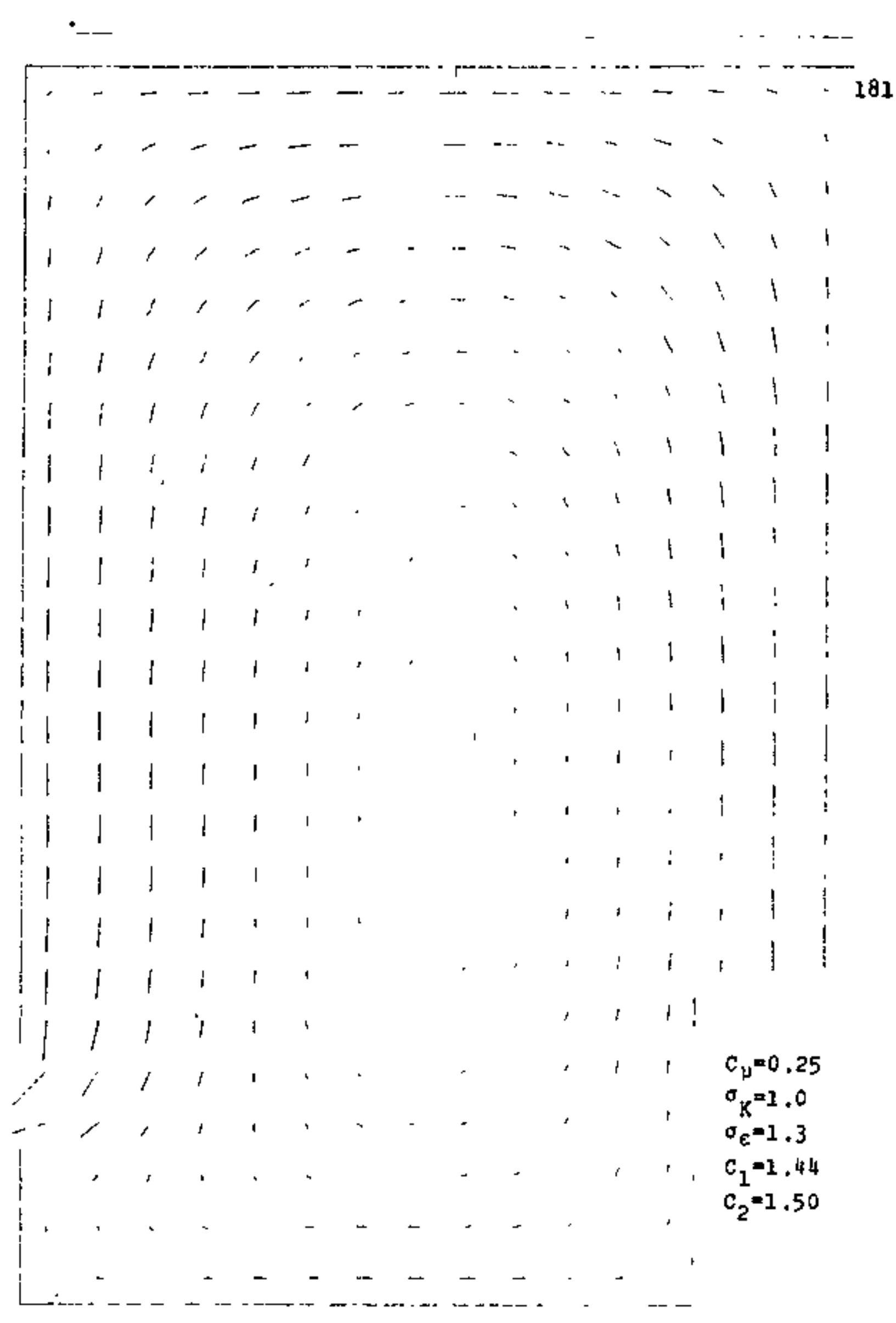

F1g. I.23 TEACH-T Prediction with $G_{1}=0.25, C_{2}=1.50$, FPTP Geometry, Re=70000, Normal Inlet Velocity D1stribution 


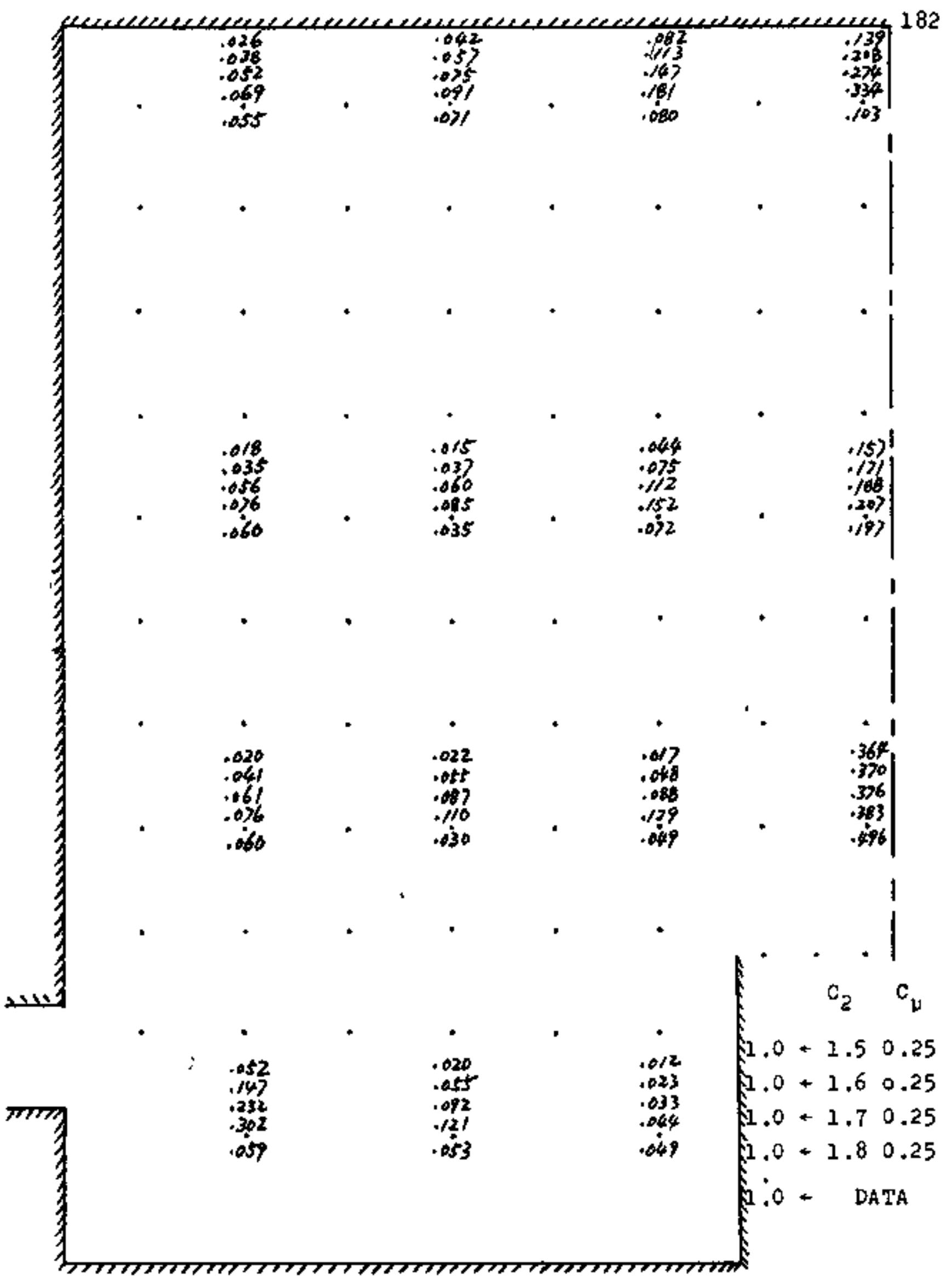

Fis. I.24 Compared Calculated and Measured Turbilent Kinet1c Energy Fielda, PFTF Geometry, Re=70000, Norma ? Inlet velocity Distribution 


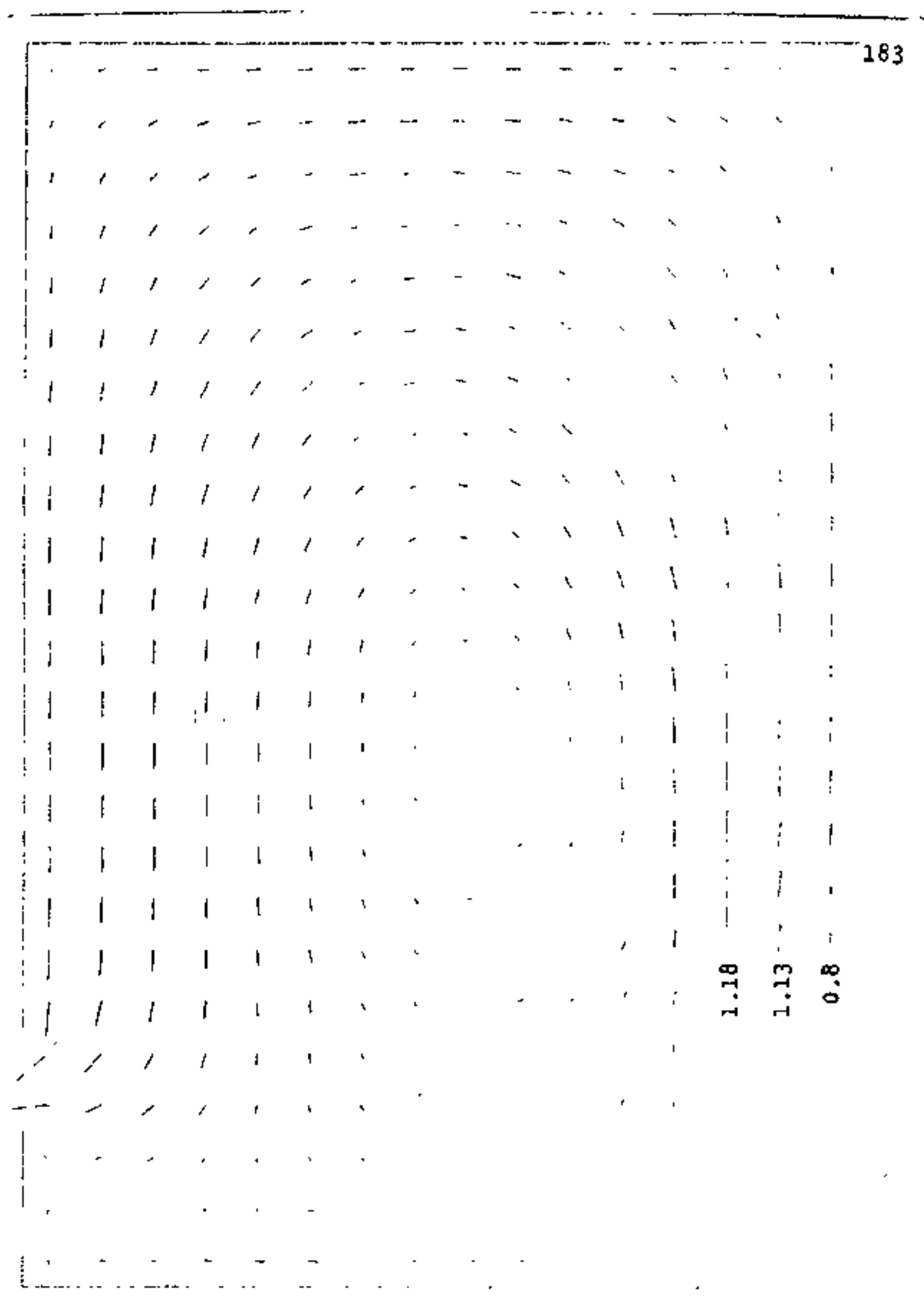

F15. I.25 TEACH-T Predict1on with Inlet Turbulent Energy D1saipet1 on Rates, $0.8,1.13$, and 1.18 , FFTF Geomotry, Re=70,000, Distorted Inlet Velocity D1stribution 


$$
\begin{aligned}
& \begin{array}{ll}
1 & 1 \\
i & 1
\end{array} \\
& \text { - } 11
\end{aligned}
$$

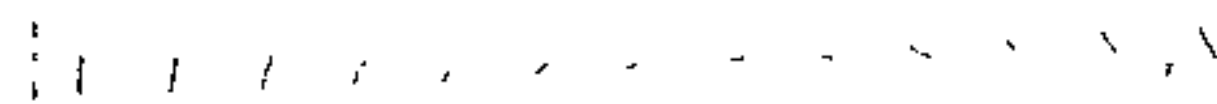

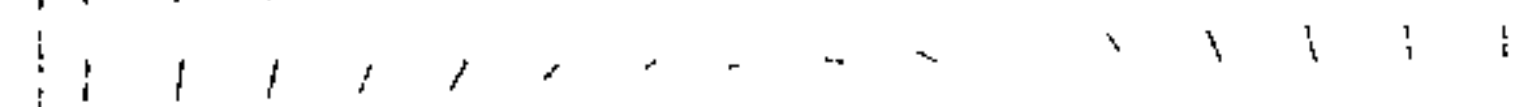

$$
\begin{aligned}
& 1+1,1+1 \\
& =11111 \\
& \begin{array}{lllllll}
i & i & i & 1 & 1
\end{array}
\end{aligned}
$$

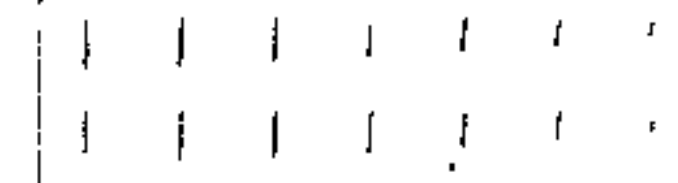

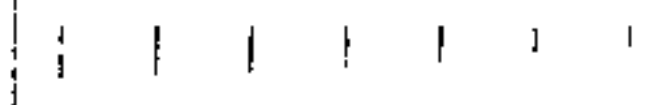

$$
\begin{aligned}
& \text { i } i \quad i \quad 1 \quad i \quad i \quad 1 \\
& \begin{array}{llllllll}
1 & 1 & 1 & 1 & 1 & 1 & 1 & 1
\end{array} \\
& \begin{array}{lllllllllll}
1 & 1 & 1 & 1 & 1 & 1 & 1 & 1 & 1 & 1 & 1
\end{array} \\
& \begin{array}{llllll}
i & 1 & 1 & 1 & 1 & 1 \\
1 & 1 & 1 & 1 & 1 & 1
\end{array} \\
& \begin{array}{lllll}
1 & 1 & 1 & 1 \\
-\infty & 1 & 1 & 1
\end{array}
\end{aligned}
$$

F1g. I.26 TEACH-T Prediction w1th Inlet Turbulent Energy Disa1pation Retes, $0.8,1.25$, and 1.7 , FFTF Geometry, Re=70,000, D1atorted Inlet Velocity Dfatribution 


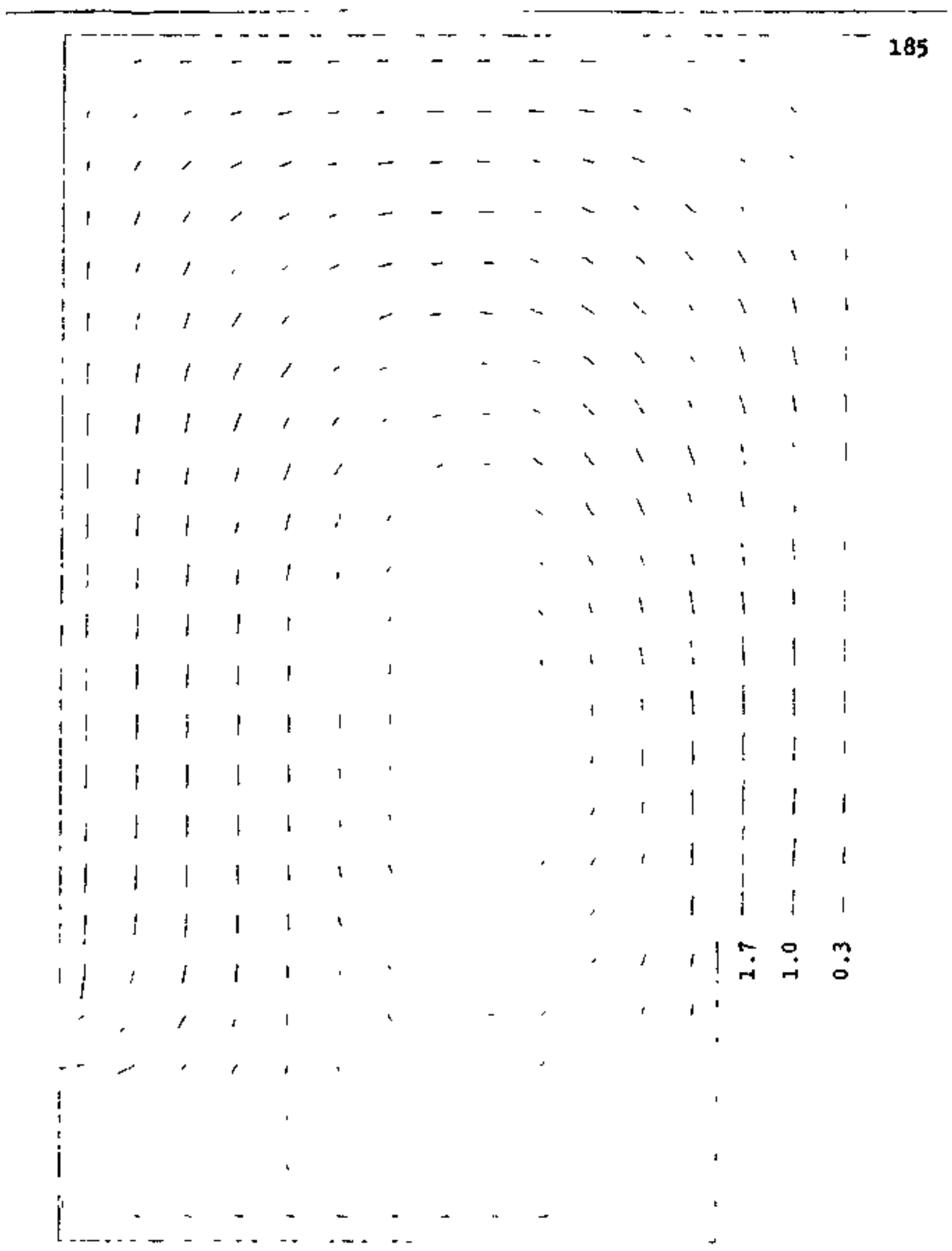

F1g. I.27 TEACH-T Pred1etion w1 th Inlet Turbulent Energy D1Bsipation Rates, $0.3,1.0$, and 1.7 , FPTF Geometry, Re=70,000, Distorted Inlet Velocity Di tribution 


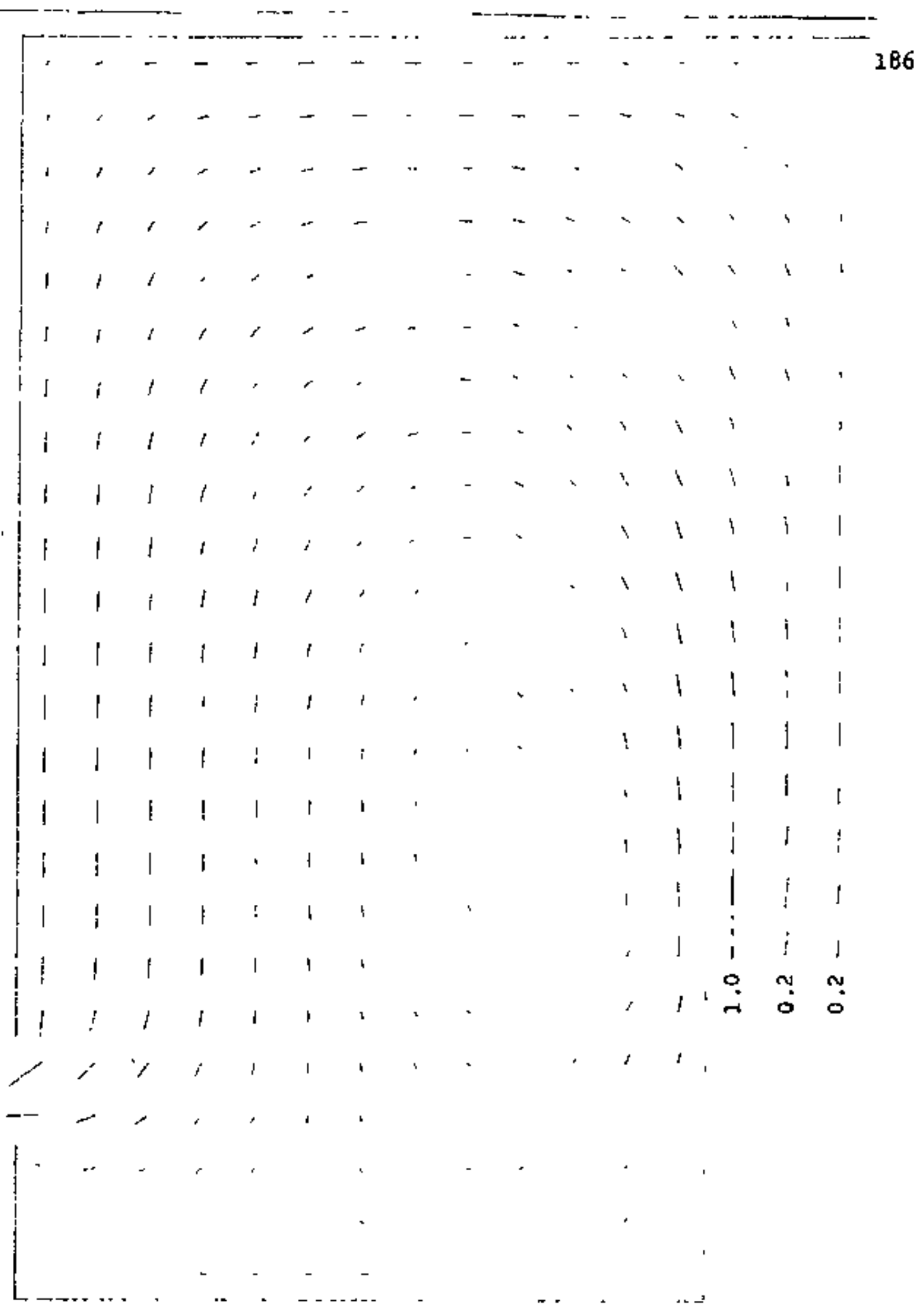

F1g. I.28 TEACH-T Prediction with Inlet Turbulent Energy Dlesipation Ratea, $0.2,0.2$, and 1.0 , FFTF Geometry, Re=70,000, Distorted Inlet Velocity Distribution 


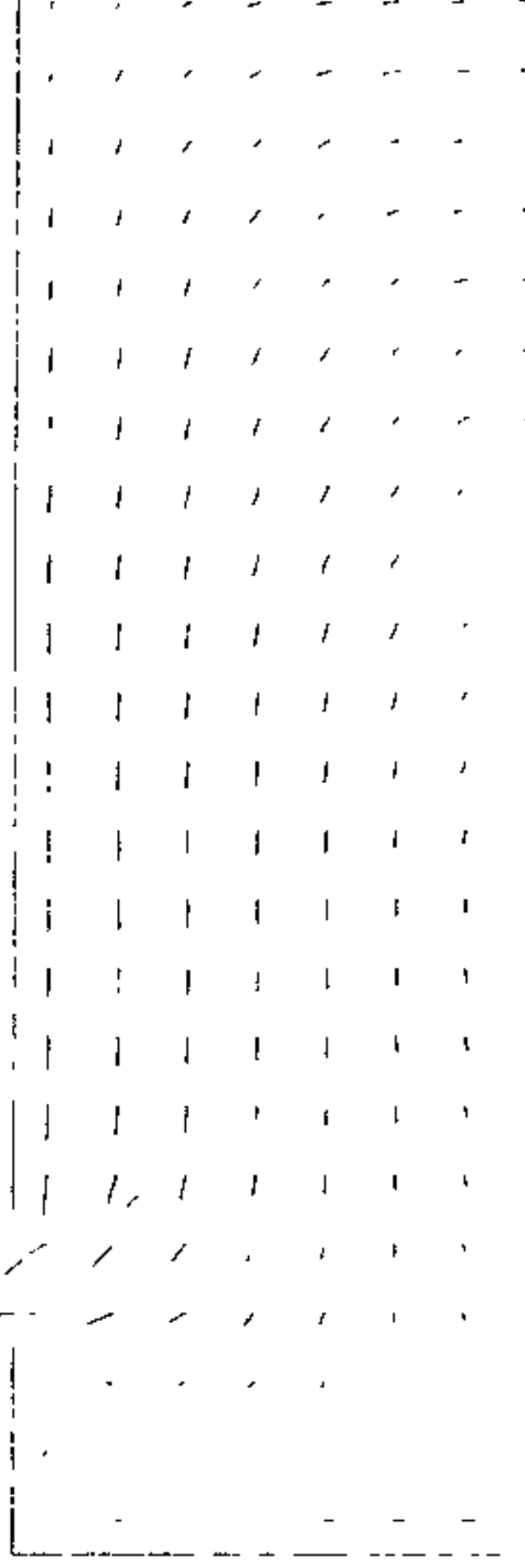

F18. I.30 TEACH-T Prediction w1th Inlet Turbulent Energy D1satpation Rates, $0.3,0.5$, and 0.7 , FPTF Geometry, Re=70,000, D1storted Inlet veloc1ty Diatrioution 


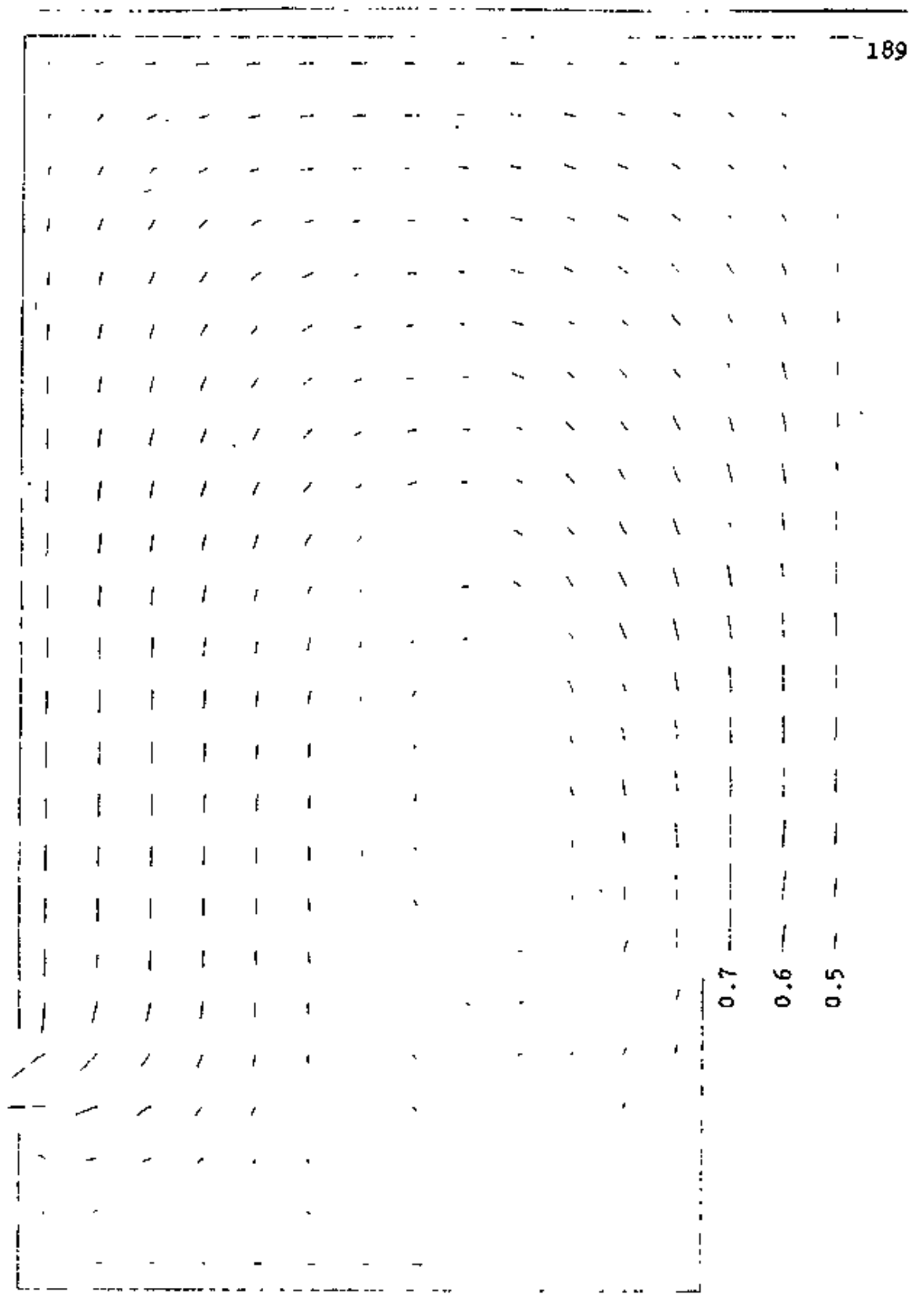

Fig. I.31 TEACH-T Predietion w1th Inlet Turbulent Energy Diastpation Rates, $0.5,0.6$, and 0.7 , PFTF deometry, Re $=70,000$, D1storted Inlet veloc1ty D1stribution 


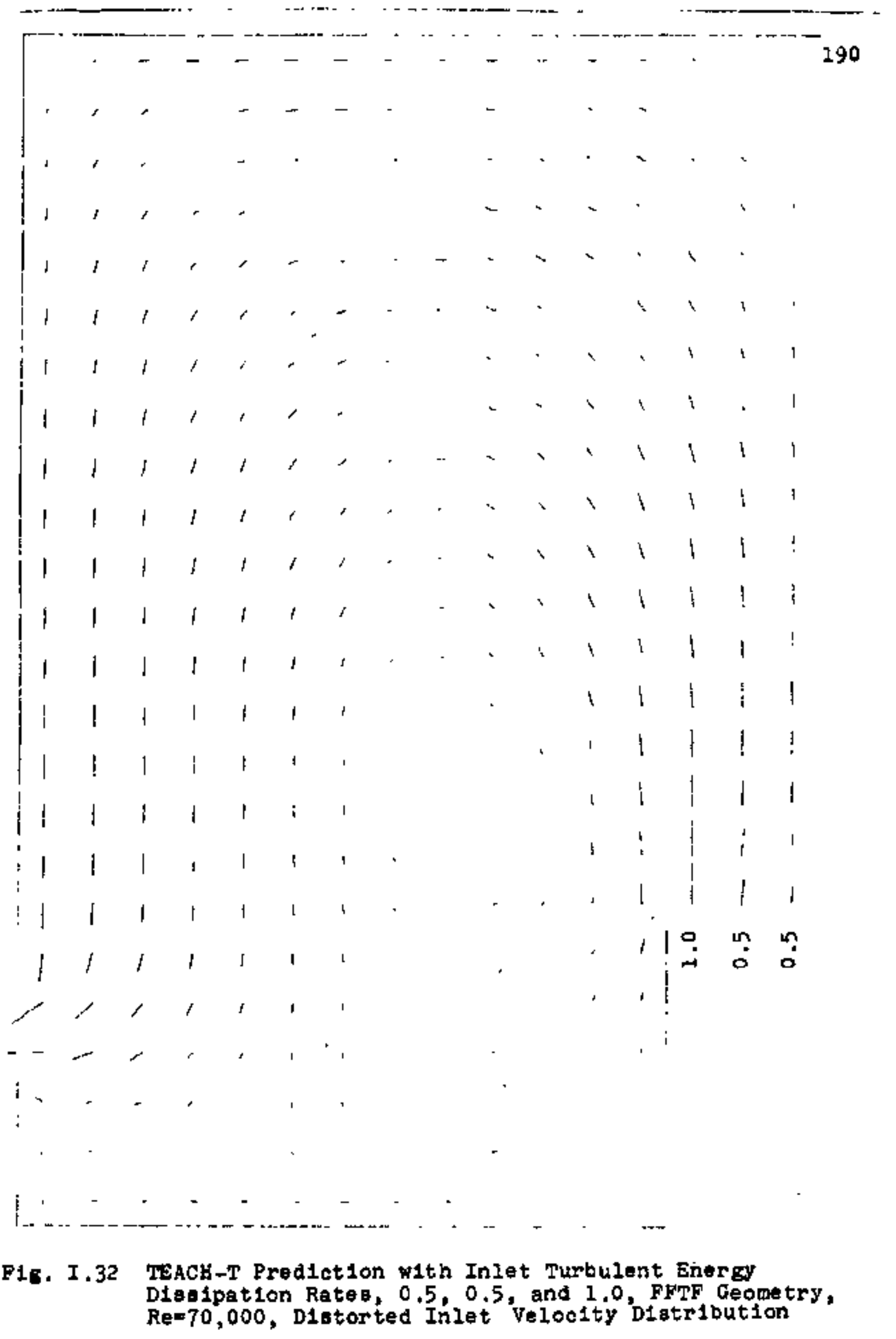




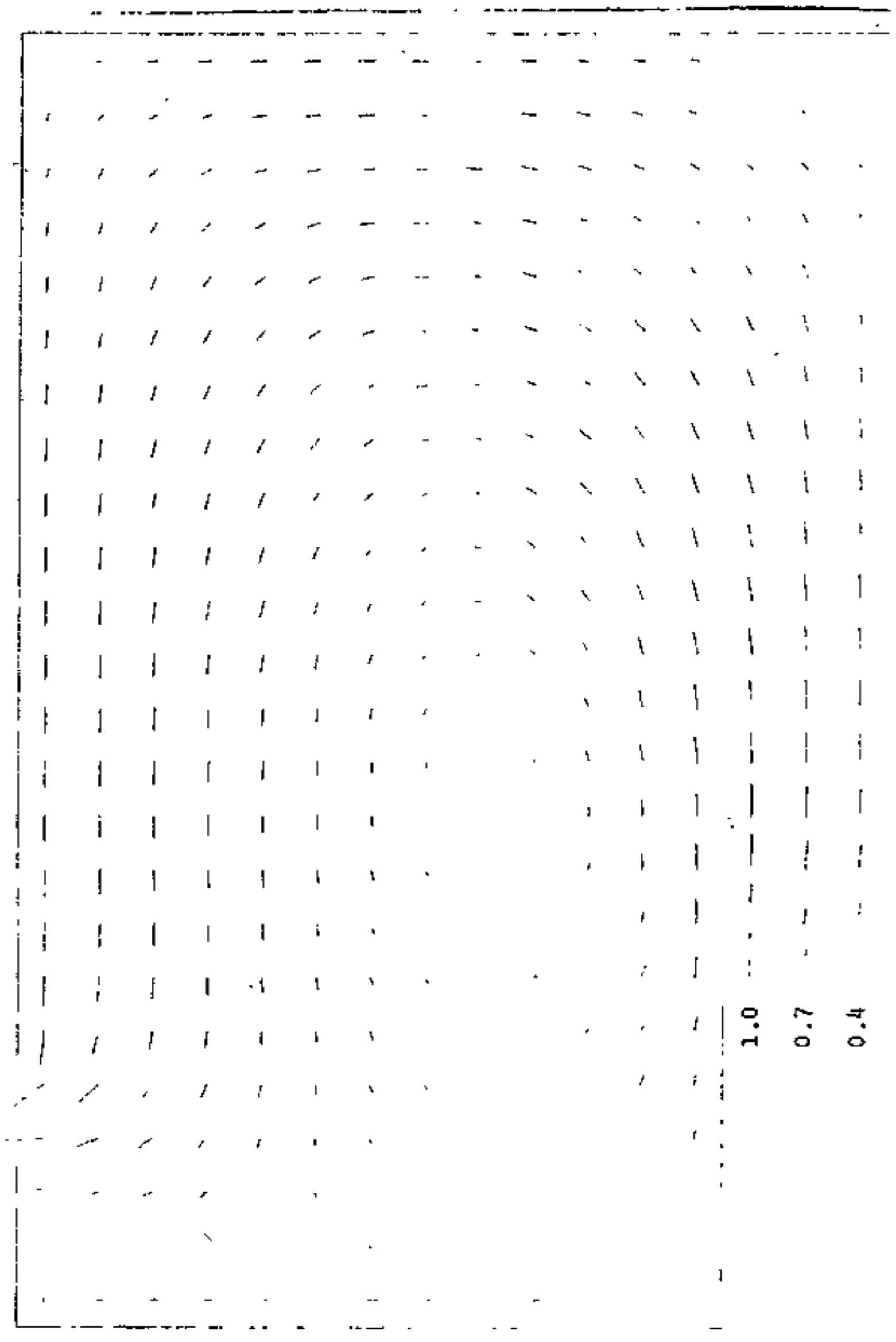

F18. I.33 TEACH-T Prediction w1th Inlet Turbulent Energy D1ssipation Rates, $0.4,0.7$, and 1.0, FFTF Geometry, Re=70,000, D1storted Inlet velocity D1stribution 


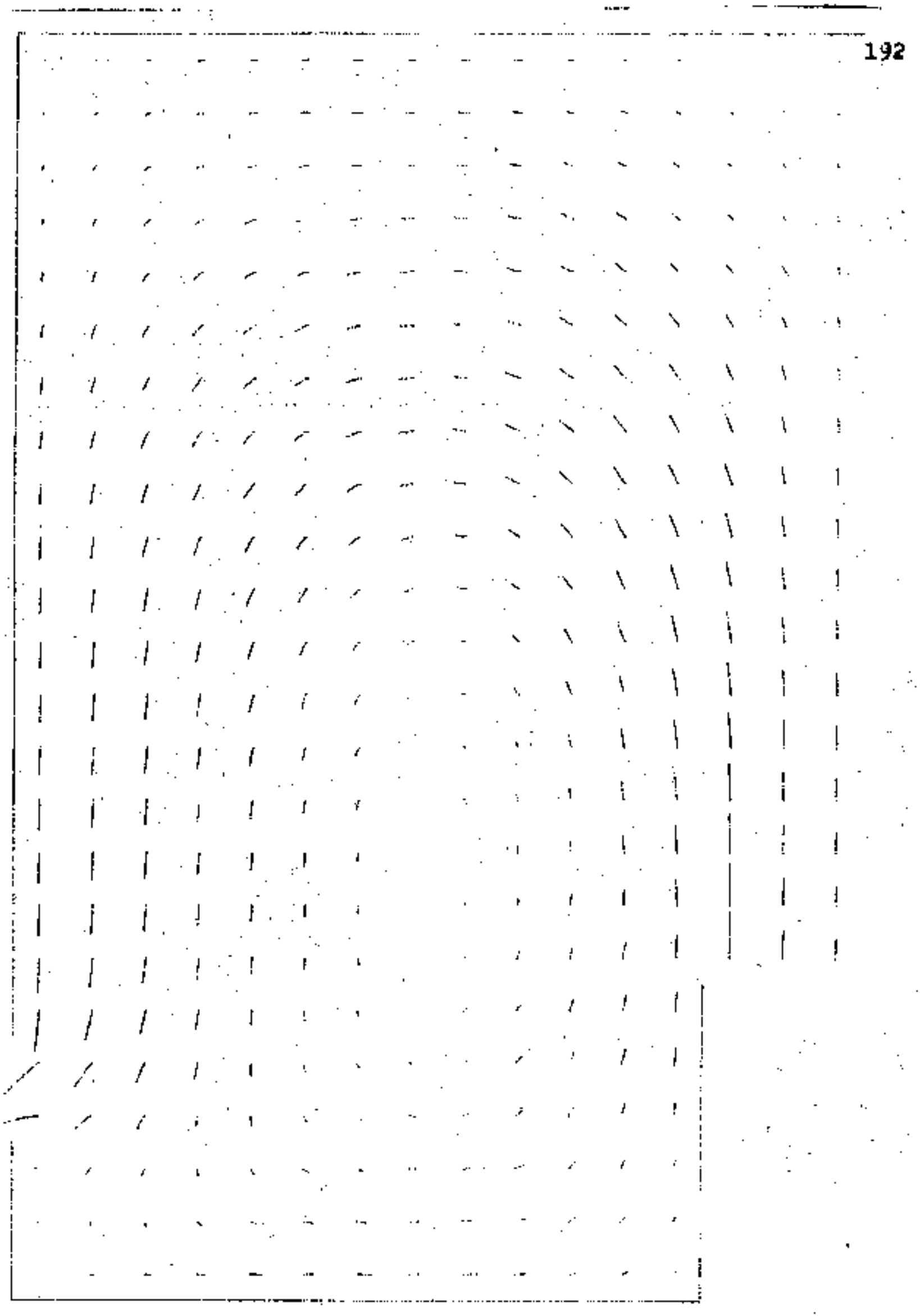

F18. I.34 TEACH T Prodiction w1th $\sigma_{K}=0.1$, FFTF Geometry, Re=70,000, D1storted Inlet veloc1ty D1atribution 


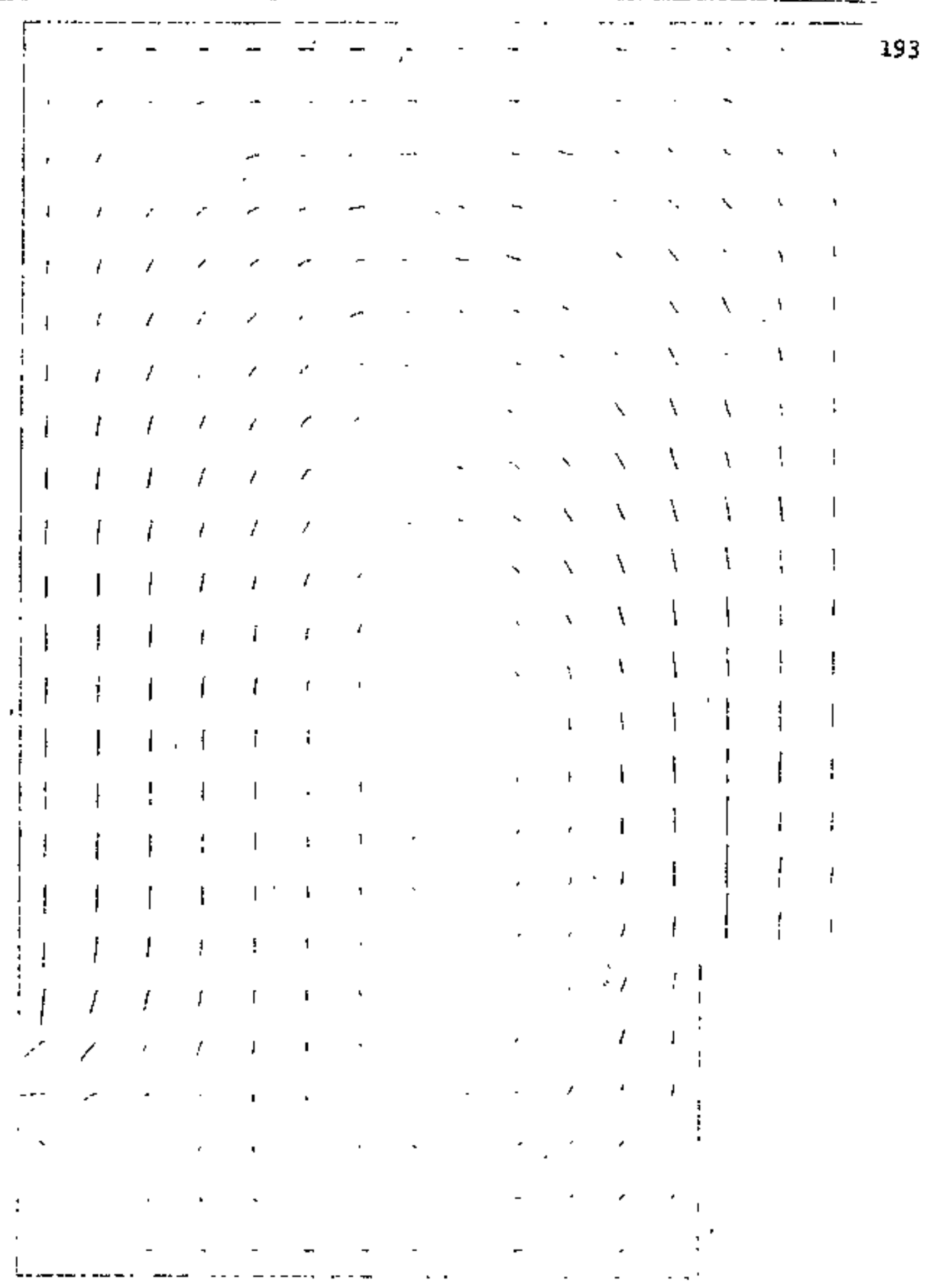

Fig. 1.35 TEACH-T Prediction with $\sigma_{\mathrm{K}}=0.5$, FFTF Goometry, Re $=70,000$, Distorted Inlet Velocity D1stribution 


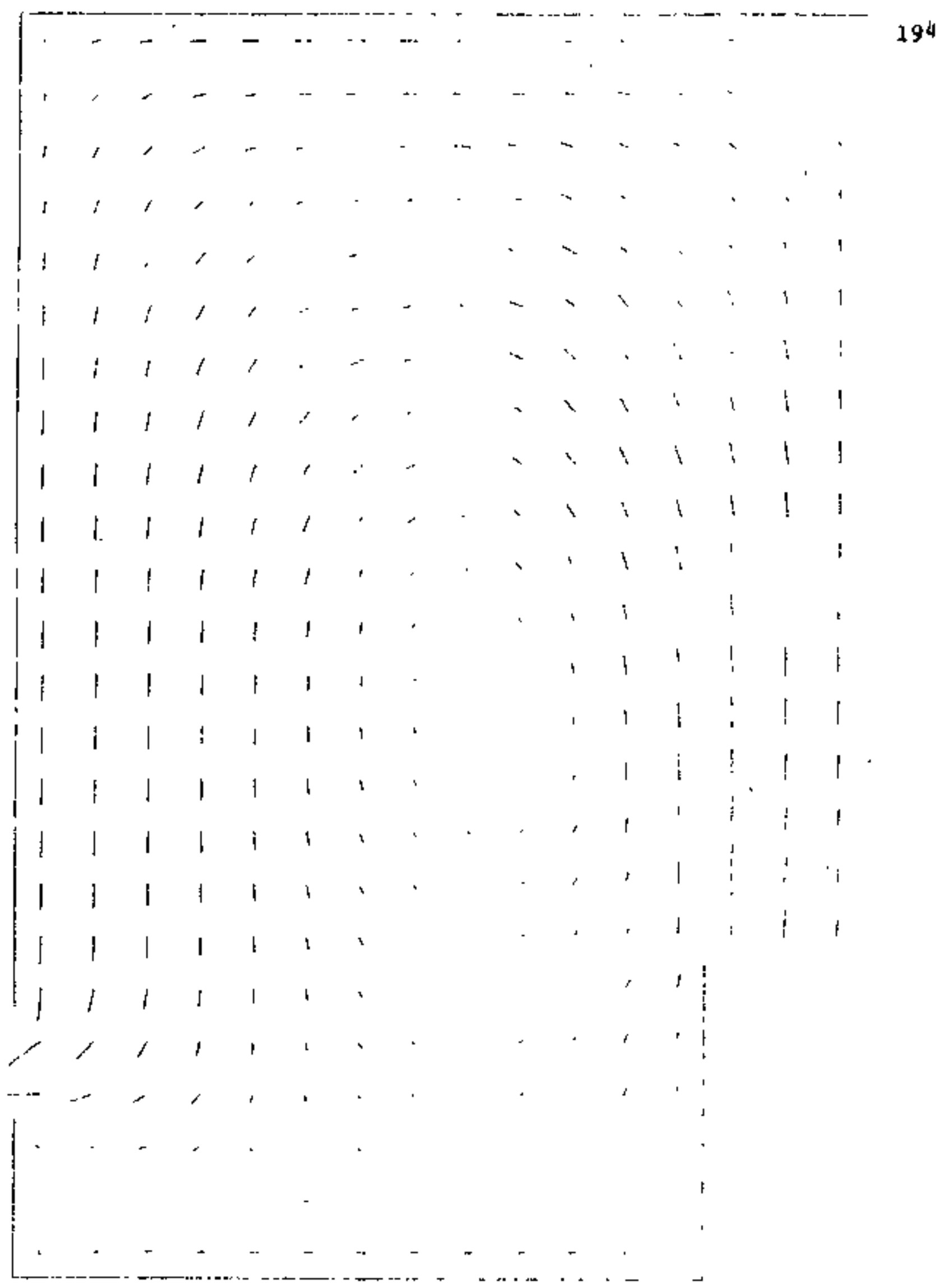

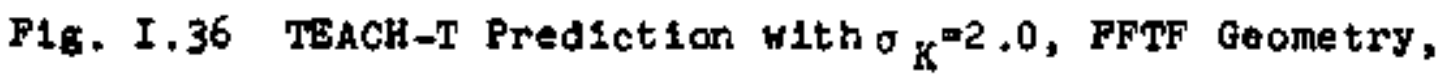
Re $=70,000$, D1storted Inlet Veloc1ty D1stribution 


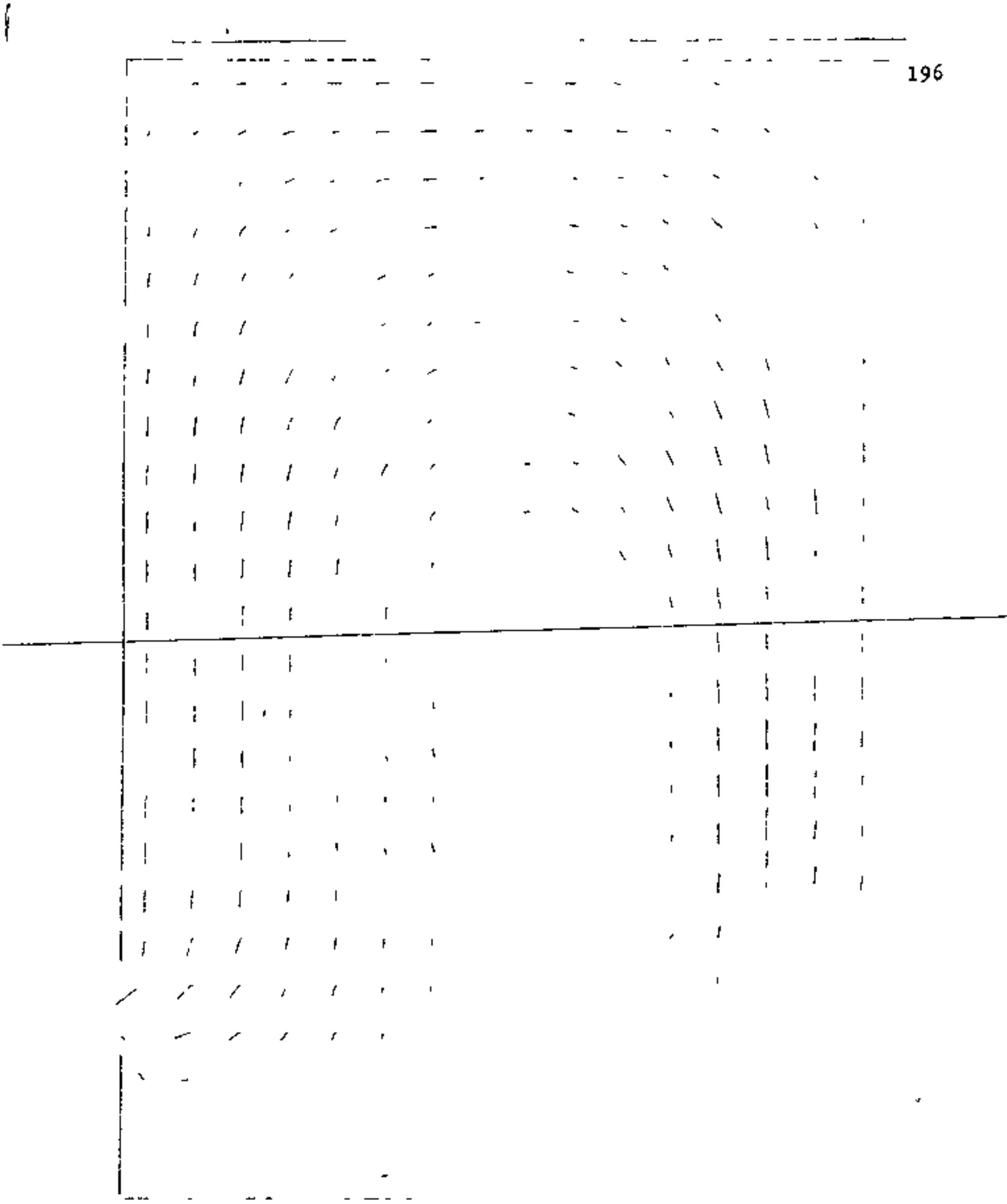

F1g. 1.39 TEACH-T Prodiction with $o_{\varepsilon}: 6$, FFTF Geometry, Re $=70,000$, Distorted Inlet Velocity Distribution 


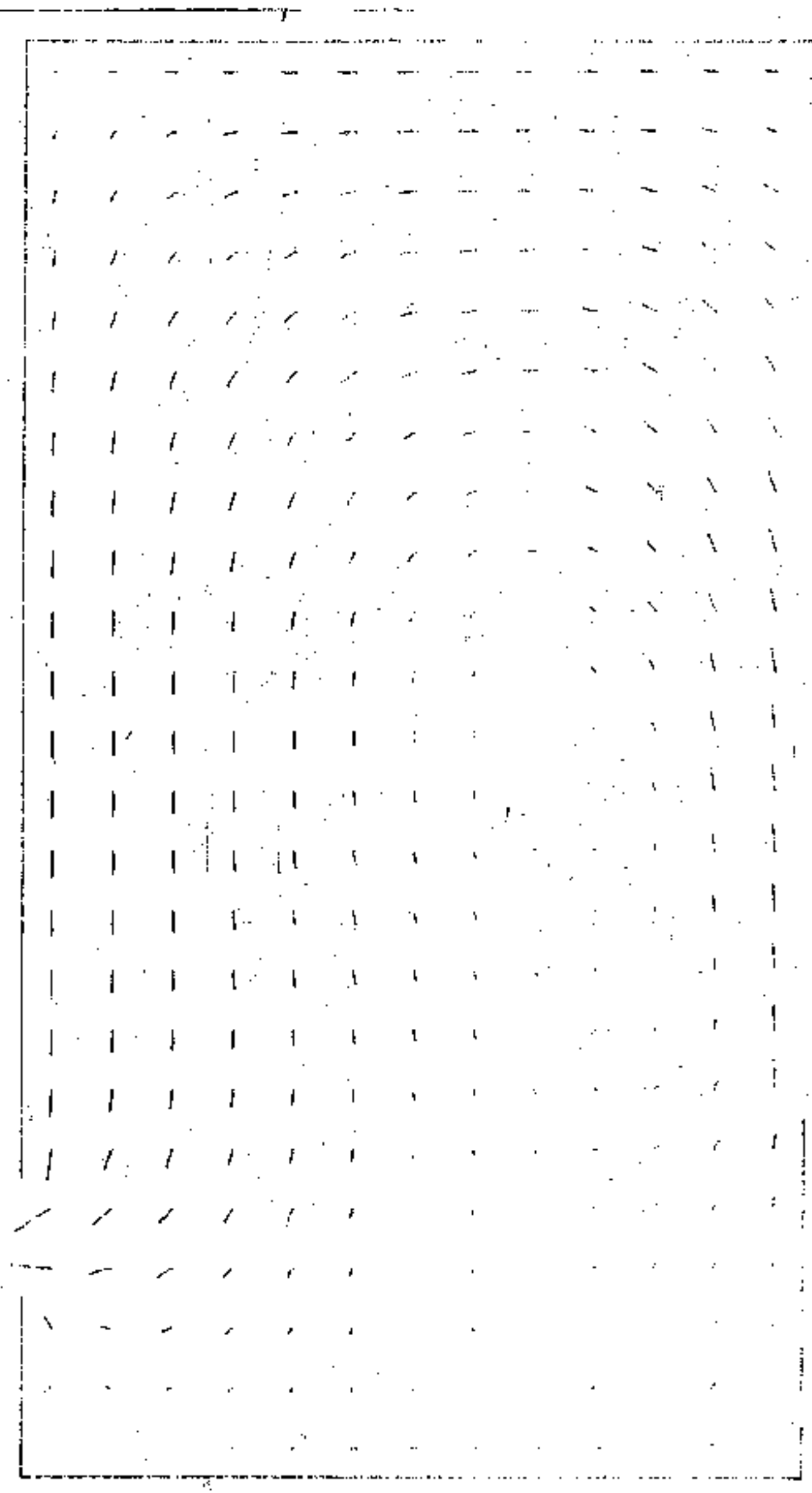

518. I.39 TEACH-T Prediction with $\sigma_{\varepsilon}=3.9$, FFTF GEometry, $R \theta=70,000$, D1storted Inlet Velocity Distribution 


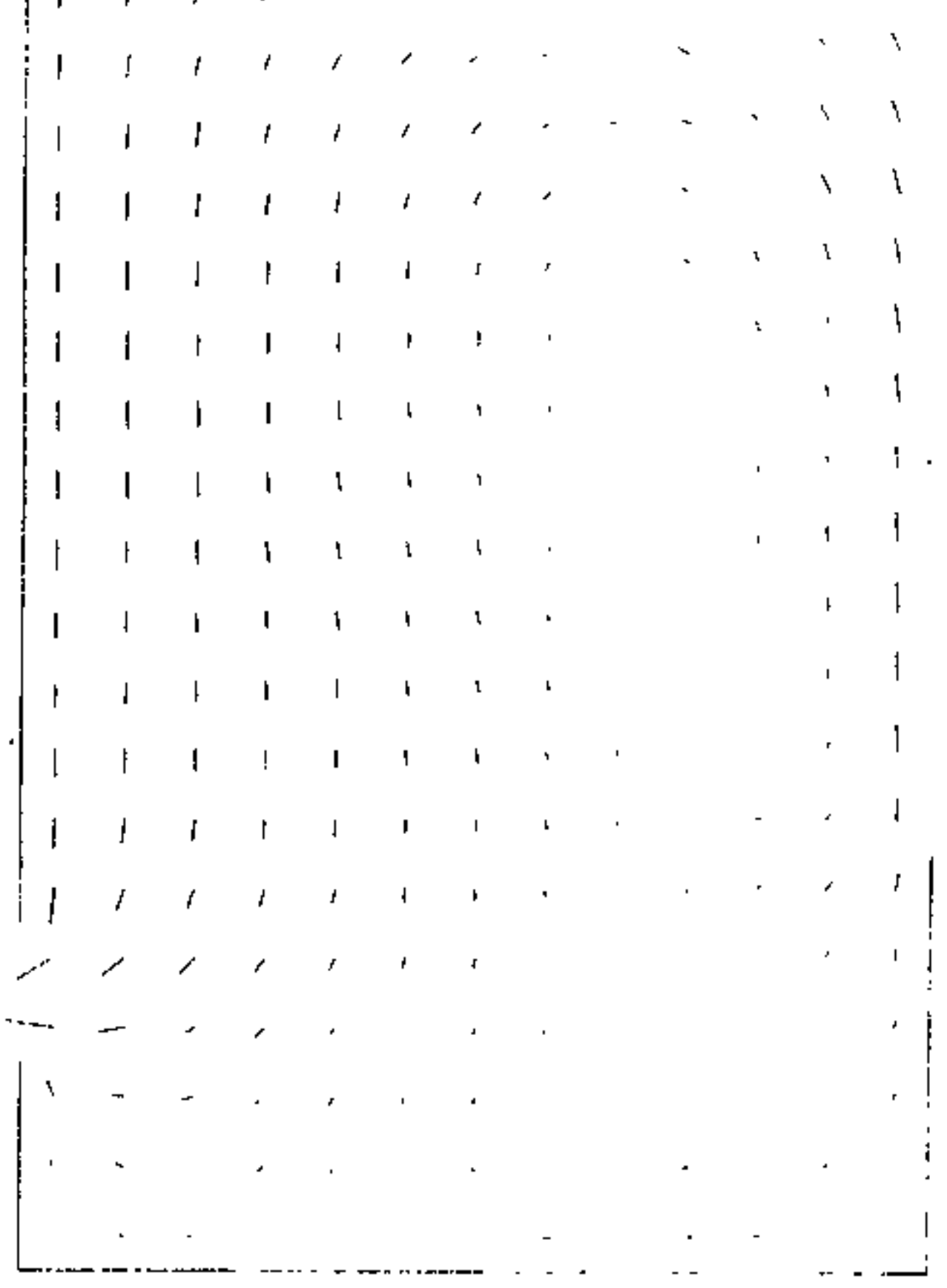

F1g. I.40 JEACH-T Prediction w1th $\sigma_{\varepsilon}$ w3.0, PFTF Oeometry, Re=70,000, Distorted Inlet Velocity Distribution 


\section{BIOGMAPHICAL NNSE}

The author was born and raised in Taiwan, Republic of ChIna, He recelved his Bachelor's degree in Nuclear EngineerIng froth the Nationa? Tsing-Hia Univerity in June 1971. After one year of miltary service in the Chinese Air Force, he came to the Unfted States and entered the Nuclear Engineering Department at M.I,T, where he received h1s Master's degree In February 1975.

The author is a memter of Sigma $X 1$, the American Nuclear Society, the American Spclety of Necharical Englneers, and the Amer1can Soc1ety of Englneering Iducation.

The author is married to the former E-Hua Chou. The author's publications include:

1. Chen, Y.B., K. ID, N.E. Todreas, "Velocity Pleasurement In Edge Channels of W1re-Wrapped LMFBR Fuel Assemblies, "t Trans, Amer. Nuc1. Soc., 19, 458, 1974.

2. Chen, Y.B., Y.W. Golay, "Valddation of Turbulence Modeis for LMFBR Outlet Plenum Flows," ASME/AIChE National Heat Irangres Confererce, Salt Lake C1ty, Utah, 1977. 